\title{
Chrysalis: A Metamorphosis of African Vernacular Architecture Traditionally Inspired Strategies for Community Building
}

\section{Alykhan A. Neky}

B.Arch.Sci., Ryerson University, 2014

A thesis project presented to Ryerson University in partial fulfilment of the requirements for the degree of Master of Architecture in the Program of Architecture

Toronto, Ontario, Canada, 2018

(c) Alykhan A. Neky 2018 


\section{Author's Declaration}

I hereby declare that I am the sole author of this thesis. This is a true copy of the thesis, including any required final revisions, as accepted by my examiners.

I authorize Ryerson University to lend this thesis to other institutions or individuals for the purpose of scholarly research.

I further authorize Ryerson University to reproduce this thesis by photocopying or by other means, in total or in part, at the request of other institutions or individuals for the purpose of scholarly research.

I understand that my thesis may be made electronically available to the public. 
Chrysalis: An African Vernacular Architecture Metamorphosis

Alykhan A. Neky

Master of Architecture, 2018

Architecture Program, Ryerson University

\section{Abstract}

Contemporary architecture in Africa is increasingly dominated by building methods and styles transplanted from the industrialized West, undermining the continuity of African vernacular architecture.

Often poorly grafted to local site conditions, these transplanted building models frequently struggle to support community identities. This thesis argues that this is largely due to inappropriately designed shared spaces and through construction methods that disregard the collective agency of users.

In response, this thesis employs 'Chrysalis': a perceptual lens for reinterpreting vernacular building strategies to demonstrate how collectively built shared spaces can better foster communal cultural expression in contemporary African architecture.

This thesis argues that culturally embedded communal space can advance collective identity, promote safety, and encourage social interaction. It also explores how user-participatory construction methods can empower communities by cultivating self-reliance.

Transformed though 'Chrysalis', a rich history of building traditions is reimagined in the design of a cultural center for a Kenyan Maasai community. 


\section{Acknowledgements}

A special thank you to my supervisor Professor George Thomas Kapelos for his guidance, support, and mentorship throughout the development of this thesis. I am particularly grateful for his intensive engagement with my writing and his thought-provoking constructive criticism. I have been able to learn from his own deep experiences with architectural research and scholarly writing. During the earlier months of my M.Arch, as I was working for Professor Kapelos as a graduate assistant, I was tremendously inspired by the creativity that he brought to his classroom. This experience had a profound impact on me and set a high bar to for me to aspire toward as I worked to frame my own research in a way that could also inspire others.

I wish to thank Dr. John Cirka for his intensive support on the design work completed in this thesis. From the formal composition of the entire cultural center to the proportions of a single Mazeras stone for the building's column cladding, I am grateful for the countless hours that we spent discussing this wide range of design ideas.

I am very grateful to my committee members, Dr. June Komisar and Professor Masha Etkind, both of whom were instrumental to the development of this thesis in sometimes very different ways. Professor Komisar's incisive questions, many of which were highly pragmatic in nature, helped harmonize the design components of this thesis with the larger theoretical ideas being investigated. I will always remember Professor Etkind's mentorship and encouragement throughout my time spent at Ryerson University and in particular the optimism that she instilled in me. Beyond both of my committee member's interests in vernacular architecture, I am indebted to their kindness and selfless desire to teach others.

I am indebted to Dr. Shafique Virani whose mentorship over many years has transformed my own capabilities and aspirations. His own extraordinarily high standards of academic research and dissemination set the highest of benchmarks to aspire toward. I am grateful for his mentorship and detailed feedback throughout the thesis years. Dr. Virani has the rare ability to inspire the boldest of ambitions in people and I am grateful that I was fortunate enough to benefit in this way from him.

I also wish to thank Professor Kendra Smith, Professor Paul Floerke, and Professor Jennifer McArthur for their support during my research. I am indebted to Leo Roytman for his tireless efforts to resolve the many software challenges over the last several years. I am also grateful for the kindness and constructive criticism of Calvin Fung and Shiloh Lazar, two friends from the M.Arch program who have also closely supported me.

I am indebted to Raymond Moriyama for the award of the RAIC Moriyama scholarship, which allowed me to share my work with the Canadian architectural community. The mentorship that he has provided me in recent months has greatly inspired me.

I wish to also thank the Trolltech Foundation for their generous contribution toward the construction and design development of Netii Apa: Maasai Cultural Center. A special thank you to Nelson Ole Reiyia and Eric Young for their contributions to my research through the many conversations that have occurred around the project's development.

Lastly, my sincere gratitude to the Purko Maasai community near Sekenani for welcoming me and sharing their rich traditions, concerns, and future aspirations with me. 
Dedication

For Arif and Nilofer Neky

\&

For Laila Nathani 
Table of Contents

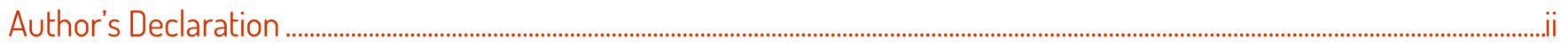

Abstract ....................................................................................................................................................................................iii

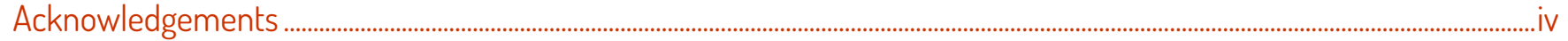

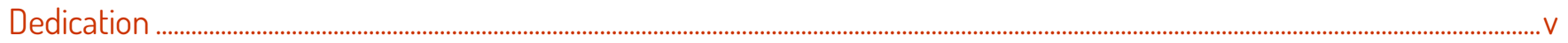

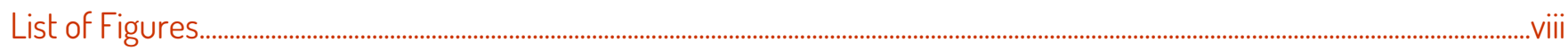

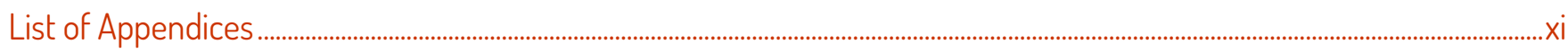

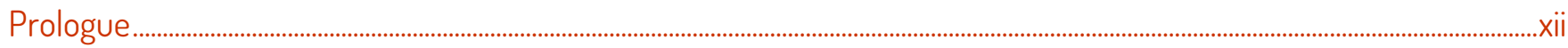

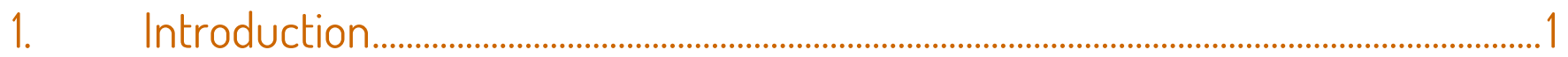

1.1 Surmounting a Colonial Legacy....................................................................................................................................................1

1.2 A Polarization of Architecture? Transplanted vs. Traditional ..................................................................................

1.3 Chrysalis: A Metamorphosis of African Vernacular Architecture ........................................................................19

1.4 Thesis Structure............................................................................................................................................................................22

1.5 Chapter 1 Endnotes......................................................................................................................................................................24

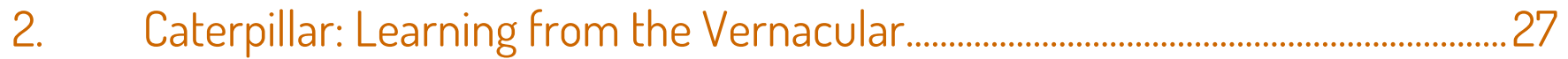

2.1 Embracing New Knowledge.......................................................................................................................................................27

2.2 Africa on the Precipice of Rapid Transformation.....................................................................................................28

2.3 Critical Vernacular Architecture Scholarship..............................................................................................................30

2.4 Defining Vernacular ...........................................................................................................................................................32

2.5 Prominent African Neo-Vernacular Architects.....................................................................................................34

2.6 Research Methodology...............................................................................................................................................36

2.7 Research Questions...............................................................................................................................................................37

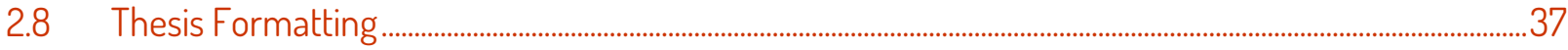

2.9 Chapter 2 Endnotes ...............................................................................................................................................................

3. Chrysalis: Culturally Embedded Communal Space...............................................39

3.1 Vernacular African Boma Spaces ...........................................................................................................................................39

3.2 The Threshold Space: An Introduction............................................................................................................................42

3.3 The Threshold Space: Experienced Transition ........................................................................................................42

3.4 Four Design Strategies for Culturally Embedded Communal Space................................................................48

3.5 Summary of Threshold Space Case Studies ..................................................................................................................56 
3.6 Threshold Space Taxonomy ................................................................................................................................................60

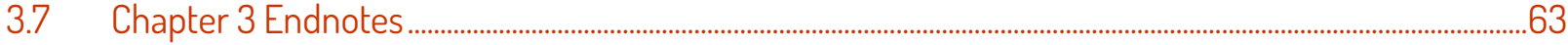

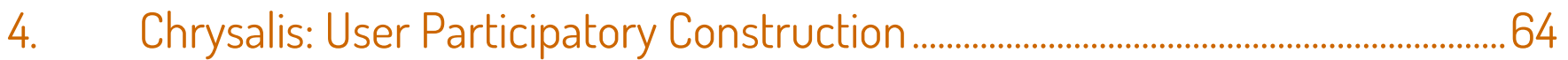

4.1 Vernacular: User Agency.............................................................................................................................................................64

4.2 Participatory Construction in Contemporary Practice............................................................................................66

4.3 0-Sampurumpuru: Butterfly House ..................................................................................................................................69

4.4 Chapter 4 Endnotes .............................................................................................................................................................................79

5. Butterfly: Netii Apa: Maasai Cultural Center ...........................................................80

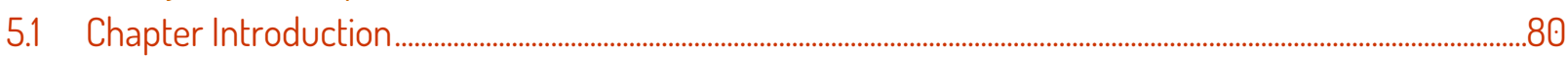

5.2 The Maasai Peoples of East Africa.......................................................................................................................................... 80

5.3 Netii Apa Cultural Center ..................................................................................................................................................90

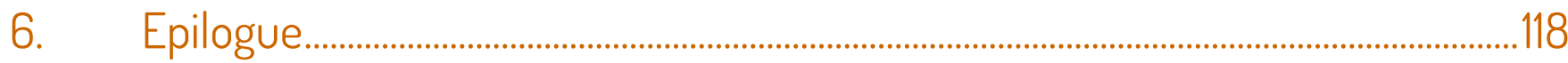

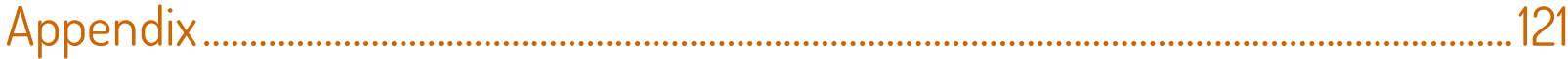

Appendix 1 - Case Study Profiles ......................................................................................................................................................................121

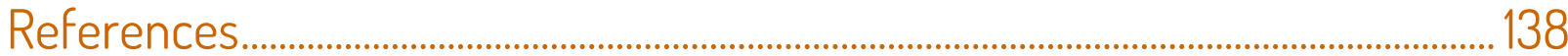

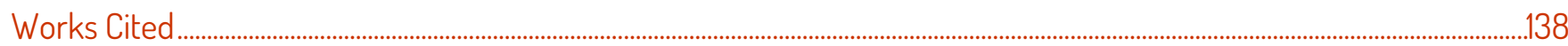

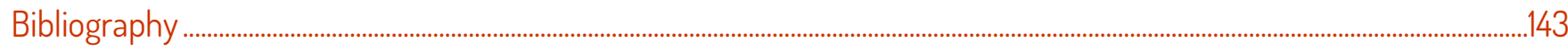




\section{List of Figures}

1.1 - The Berlin Conference - Image retrieved from "http://www.dw.com/en/130-years-ago-carving-up-africa-inberlin/a-18278894".....

1.2 - Westgate Shopping Mall - Image retrieved from http://www.baa-architects.com/retail/westgate.html ................4

1.3 - I\&M Tower - Image retrieved from http://www.skyscrapercity.com/showthread. php?t=515152\&page=266 .........4

1.4 - Jabavu Village Ltd - Image retrieved from http://nairobiwire.com/2016/10/hilton-hotel-to-open-africas-tallest-

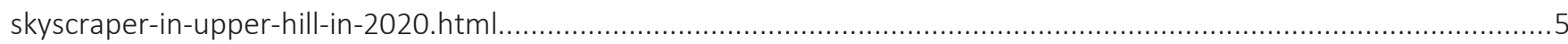

1.5 - Kibera Slum Upgrading Project - Image retrieved from

"https://theinsidescoops.wordpress.com/2013/01/07/kenyans-in-poverty-series-episode-1-kibera/" .........................5

1.6 - Concrete Masonry Unit (CMU) Wall - Image Retrieved from http://www.mikepearsonconstruction.com/wp-

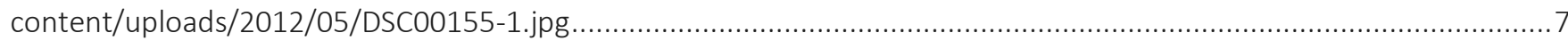

1.7 - Pruitt Igoe Housing Scheme - Image retrieved from "http://www.pruitt-igoe.com/urban-history/".......................9

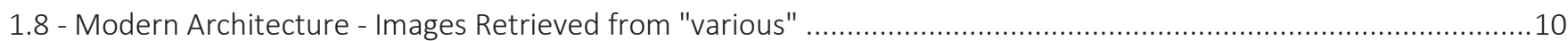

1.9 - The African Experiment: Sketch by Maxwell Fry and Jane Drew - Image retrived from "Tropical Modernism: Fry

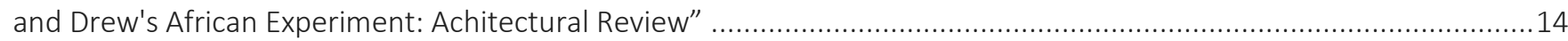

1.10 - Kenyatta International Conference Center - Image Retrieved from

https://upload.wikimedia.org/wikipedia/commons/3/33/Lascar_Kenyatta_International_Conference_Center_\%284522

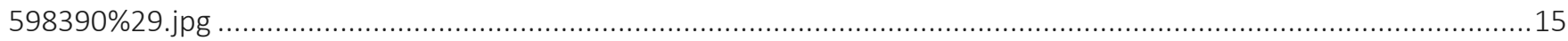

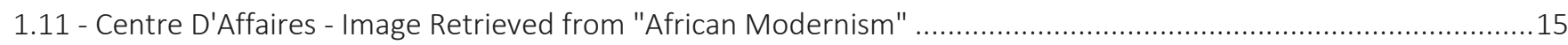

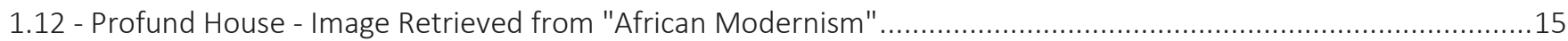

1.13 - 100 Shilling Note - Image Retrieved from "http://www.ra2d.com/images/worldsmoney/Kenyan-Shilling-KES-

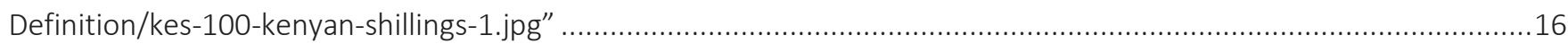

1.14 - Janus: Roman God of Transitions - Image retrieved from "http://gnosticwarrior.com/january-god-janus.html"..21

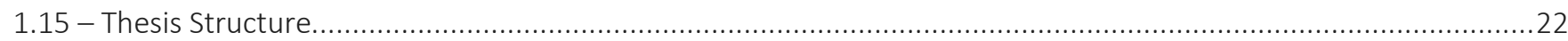

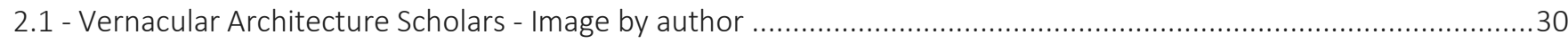

2.2 - Four Parameters of Vernacular Architecture - Image by Author.......................................................................33

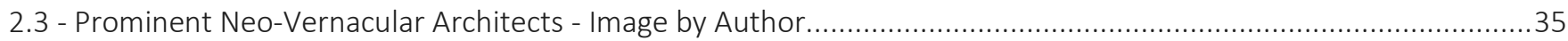

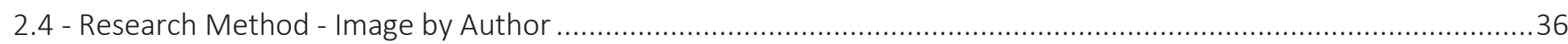

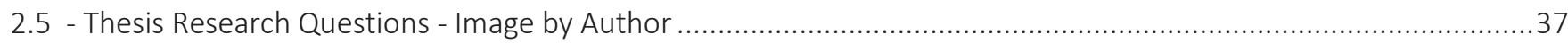

3.1 - Denyer's Floorplans of African Vernacular Buildings - Image Retrieved from "African Traditional Architecture Susan Denyer".....

3.2 - Parthenon in Rome - Image Retrieved from

"https://upload.wikimedia.org/wikipedia/commons/d/da/The_Parthenon_in_Athens.jpg".....

3.3 - Parthenon in Rome Floorplan - Image retrieved from

"https://classconnection.s3.amazonaws.com/836/flashcards/1200836/jpg/2-145E1C781213D34971F.jpg" ...............43

3.4 - Roman Pantheon - Image Retrieved from "Threshold Spaces - Till Boettger" ....................................................44

3.5 - Gothic Portal - Image Retrieved from "Threshold Spaces - Till Boettger" ..........................................................45

3.6 - Japanese House Image Retrieved from "Threshold Spaces - Till Boettger" .........................................................46 
3.7 - Inuit Igloo - Image Retrieved from "Handmade Houses \& Other Buildings - John May"

3.8 - Maasai Homestead - Image Retrieved from

"https://ih1.redbubble.net/image.11040938.9258/flat,1000x1000,075,f.u49.jpg"..... 50

3.9 -Maasai Enkang Floorplan - Image Retrived from "http://www.johntyman.com/africa/a348.jpg"........................51

3.10 - Mama Sarah Obama Nursery School by Francis Kere - Images retrieved from "Design Proposal by Kere

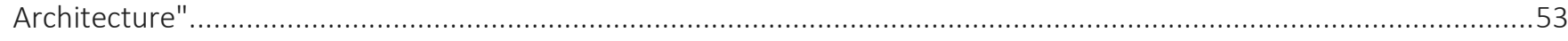

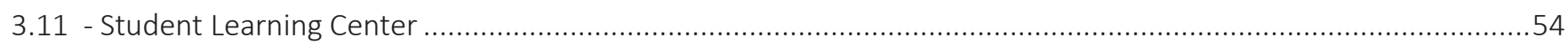

3.12 - Zulu Indlu - Image Retrieved from “Handmade Houses \& Other Buildings - John May" ..................................55

3.13 - Summary of Threshold Space Case Studies - Image by author ..............................................................56

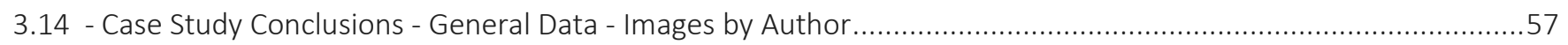

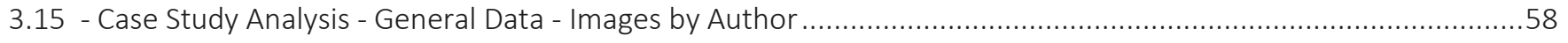

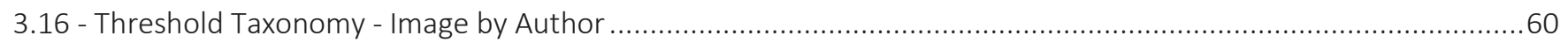

3.17 - Threshold Taxonomy Models - Image by Author ................................................................................61

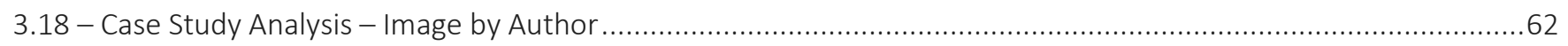

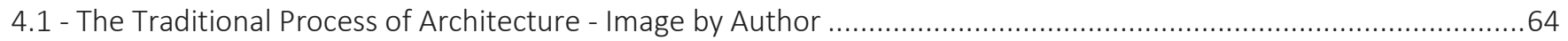

4.2 - Gando Primary School by Francis Kere - Image retrieved from "AKDN.org" ..................................................66

4.3 - Case Study Analysis - Participatory Construction - Figure by Author ........................................................67

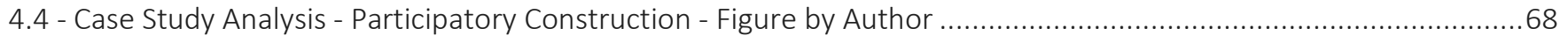

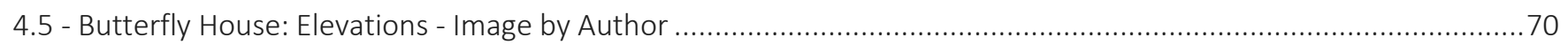

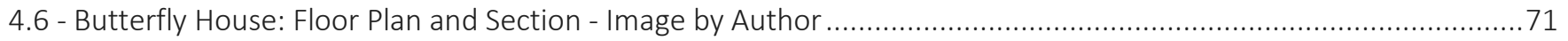

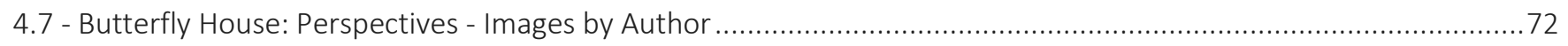

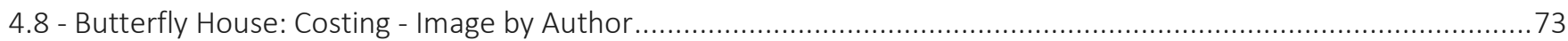

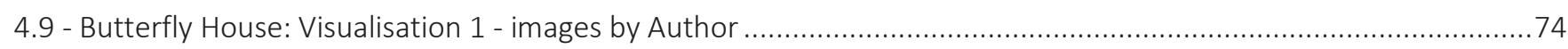

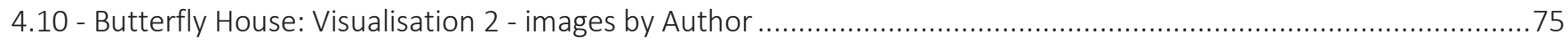

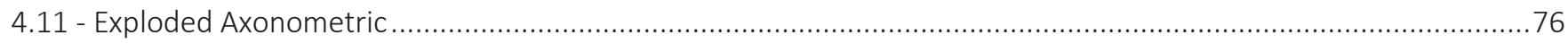

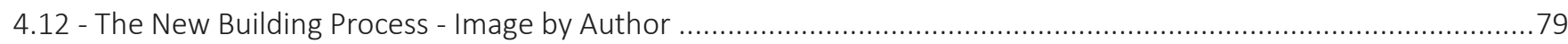

5.1 - Maasai with Cattle - Image retrieved from "http://maasaimedia.com/2014/11/why-all-cattle-are-a-gift-from-godto-the-maasai/".

5.2 - Plan of Maasai Enkang or Homestead - Image retrieved from "Transformation of Maasai Art and Architecture Robert Rukwaro".

5.3 - Maasai Mothers House - Enkaji Entasat - Image retrieved from "Transformation of Maasai Art and Architecture Robert Rukwaro"

5.4 - Maasai Fathers House - Enkaji Orripie - Image retrieved from "Transformation of Maasai Art and Architecture -

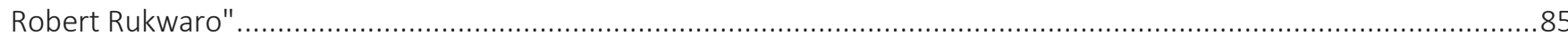

5.5 - Elderly Boy and Girls House - Enkaji oo Nkera and Kitchen structure, Orng'oboor - Image retrieved from

"Transformation of Maasai Art and Architecture - Robert Rukwaro"

5.6 - Section and Wall Section of Maasai House - Image retrieved from "Transformation of Maasai Art and Architecture

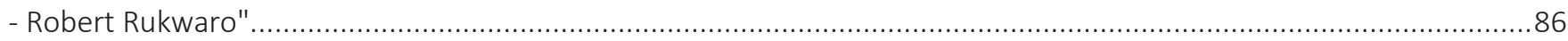

5.7 - A Maasai checks his phone - image retrieved from "http://www.oxfamblogs.org/eastafrica/?p=3615" ...............88 
5.8 - Maasai Lady Transports a Solar Panel - Image retrieved from "http://www.trueactivist.com/wp-

content/uploads/2015/09/maasai.jpg".

5.9 - Maasai Lady Installs a Solar Panel on her House - Image retrieved from "http://assets.inhabitat.com/wp-

content/blogs.dir/1/files/2015/06/Maasai-Green-Energy-Africa-solar-lead.jpg" ...................................................89

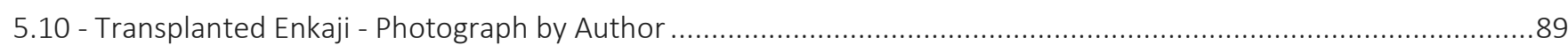

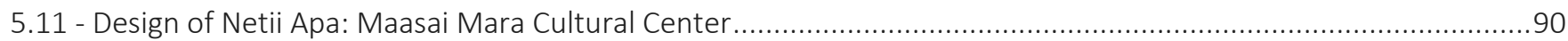

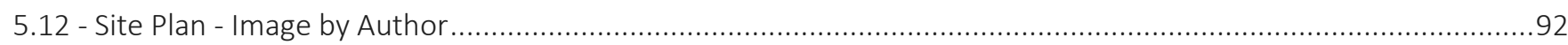

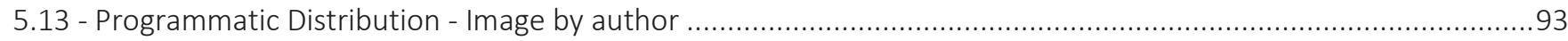

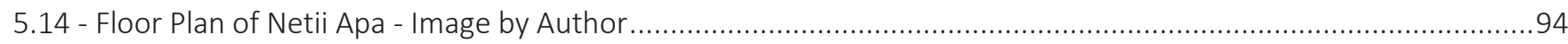

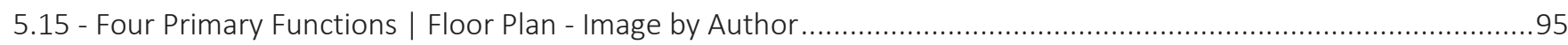

5.16 - Central Boma Communal Space | Floor Plan - Image by Author..................................................................

5.17 - Aerial Perspective of the Cultural Center - Image by Author ..........................................................................97

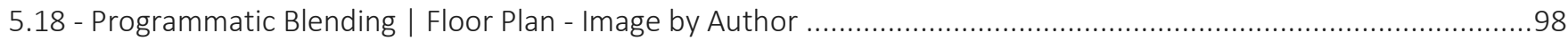

5.19 - Aerial Perspective of Center-Periphery Connection - Image by Author ........................................................99

5.20 - Conference Center to Boma Communal Space Connection - Image by Author ..............................................100

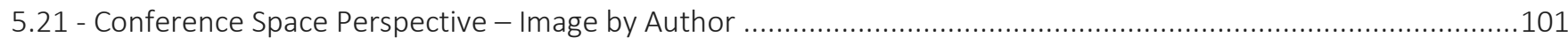

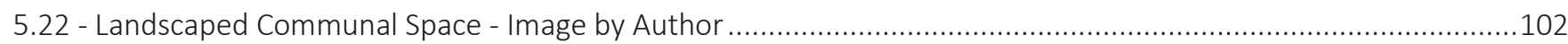

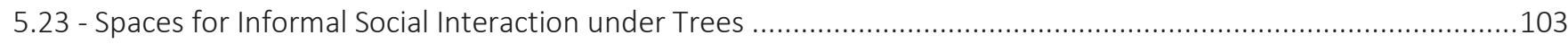

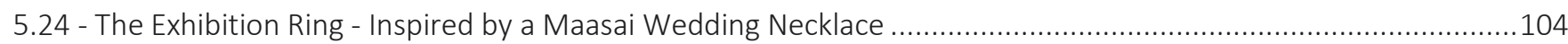

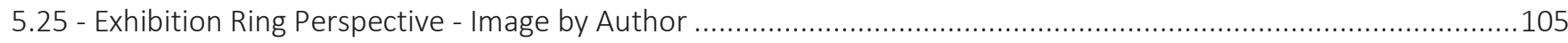

5.26 - Formal Seating for the Performance Space - Image by Author ...............................................................106

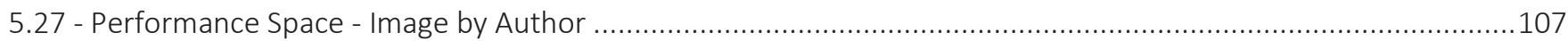

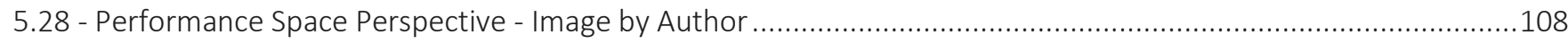

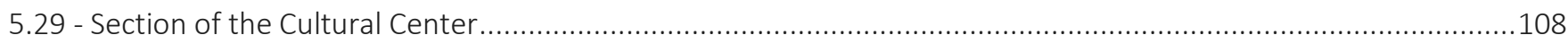

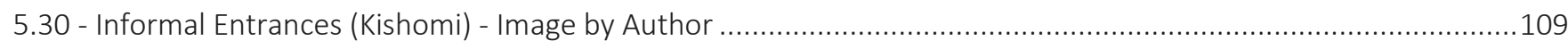

5.31 - Informal Entrance (Kishomi) Perspective - Image by Author..........................................................................110

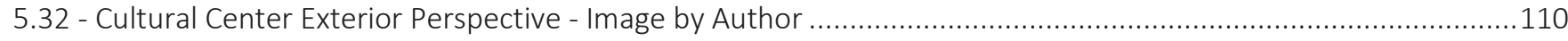

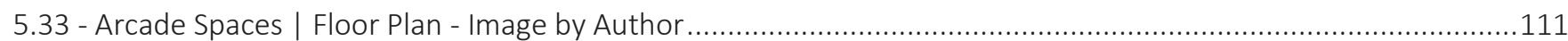

5.34- Arcade Space After Entrance Block Perspective - Image by Author .............................................................112

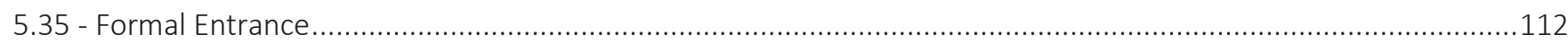

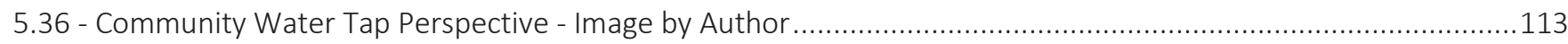

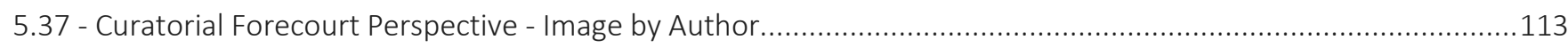

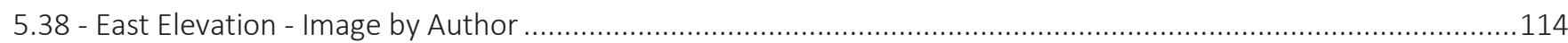

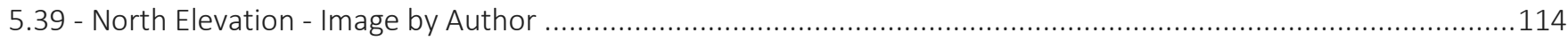

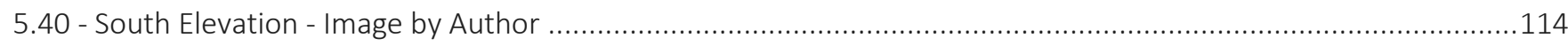

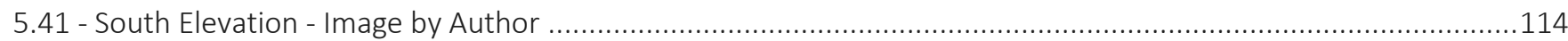

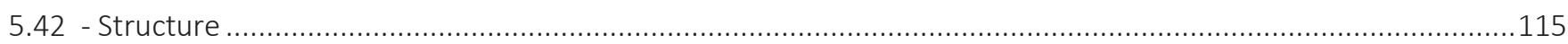

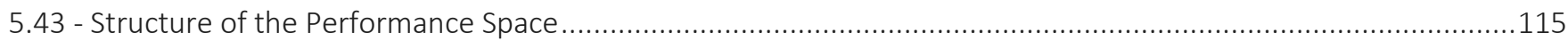


List of Appendices

Appendix 1 - Case Study Profiles ....... 


\section{Prologue}

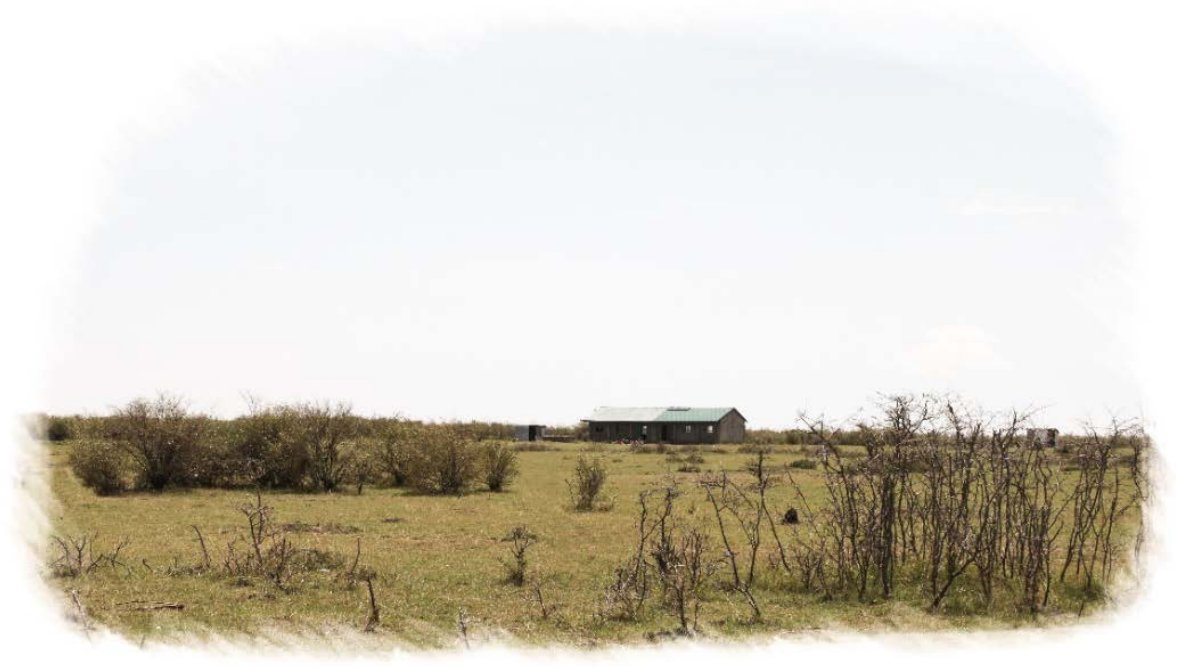

When I was a child, my father accepted a leadership role with the Aga Khan Foundation (AKF). ${ }^{1}$ Over the years, our family regularly learned through dinner table conversations about my father's ideas regarding holistic and sustainable social development, often predicated on the "teach a man how to fish" philosophy. ${ }^{2}$ This helped me develop a sensitivity to some of the world's most disadvantaged. To my dismay, I learned that architectural concerns did not play a major role in these endeavors. However, I was convinced that architecture could be an effective tool to foster community self-reliance and serve social development in a more foundational way.

In 2014, before commencing my M.Arch. degree at Ryerson University in Toronto, I returned home to Kenya. Through the lens of my undergraduate education, I noticed a general polarization between "local contextuallysensitive buildings" and other newer "transplanted" building models from the industrialized West, which were often poorly grafted to site. When I later began formulating my research interests for this M.Arch. thesis, I observed that this polarization was particularly stark between traditional Kenyan buildings and much of the country's contemporary architecture. Over time, I increasingly felt that the contemporary transplants were either too strongly driven by economies of mass industrial production or were discrete stamps of corporate authorship. In general, these crude transplants were completely unlike the deep collective expressions of culture that the traditional buildings had been, despite the latter being increasingly perceived as backwards by many users.

I was later shocked to observe a particularly extreme manifestation of this architectural juxtaposition in Maasai Mara in Kenya. In 2015, during my graduate studies, I travelled from village to village in Narok County and was horrified at the brutality with which the new transplanted buildings turned their backs on the magnificent Maasai culture. So many of these grey building forms lay cold and lifeless, despite being surrounded by the rhythmic pulse of the magnificent savannah. I noticed how many Maasai families were increasingly abandoning their traditional homes, and under the guise of modernity, becoming slaves to these alien structures. The uncomfortable existence of such a transplant in Maasai Mara may be seen in the illustration above.

Roused by what I had seen in the Mara (as it is commonly called), I decided that this thesis would locate itself in the discourse of vernacular architecture, and would explore the role of the trained architect in the creation of contemporary buildings that serve as expressions of collective culture and value systems. This thesis therefore 
reimagines both collective building methods as well as culturally embedded uses of communal space found in African vernacular architecture for the present day. These reinterpreted ideas are then used to guide the design of a rural cultural center for the Purko Maasai ${ }^{3}$ community that I had first visited in 2015.

I later led a grant application process to seek funding for the construction of this cultural center and in 2016, our team was thrilled to receive a generous contribution of USD $\$ 120,000$ from Norway's Trolltech Foundation. It is therefore my ambition to realize this project in Kenya in collaboration with local expertise and the Purko Maasai community. I hope that the cultural center will serve as a contemporary built representation of the community's aspirations for the future, which, unlike many of the architectural transplants, is conceived on a solid foundation of Maasai traditions. I am confident that this idea of "innovation inspired by tradition," which has guided my thesis work, can reintroduce a sense of cultural pride and collective ownership over the center's architecture, a notion that has been slowly evaporating with the upsurge of imported transplants.

As I have outlined in the acknowledgments, this thesis has benefited tremendously from the mentorship of several professors as well as the selfless support of close friends and family. For this and much more, I am indebted to them. Over the last two years, I have also developed several friendships in the Maasai community which have played a significant role in my own education and have been instrumental to the cultural center's design process.

I believe that architecture can be a true expression of the core values that unite a community. I look up to Carlo Scarpa for his intimate collaboration with local artisans, Francis Kere for his ability to lead a community, and Michael Murphy for using architecture to initiate deep social transformation. I have also been immensely inspired by the Aga Khan Award for Architecture, ${ }^{4}$ whose mandate deeply resonates with the ambitions of my own work.

I hope that this thesis will be my first step towards bridging the architectural divide between the denigrated vernacularand the globalized transplants in the developing world, a passion that I believe is shaped by a moral responsibility to ease the growing social divide between the marginalized and the elite.

- Alykhan A. Neky

Prologue Endnotes

${ }^{1}$ According to the organization's website, "The Aga Khan Foundation (AKF) has been implementing innovative, community-driven solutions to development challenges for more than 50 years. It focusses on a small number of specific development problems by forming intellectual and financial partnerships with organizations sharing its objectives. With a small staff, a host of cooperating agencies and thousands of volunteers, the Foundation reaches out to vulnerable populations, irrespective of their race, religion, ethnicity or gender." Further information available at "Aga Khan Foundation," Aga Khan Development Network (AKDN), http://www.akdn.org/our-agencies/aga-khan-foundation-0.

2 The origin of this well-known adage is often contested, but probably first appeared in "Thackeray Anne Isabella Ritchie, Mrs. Dymond (London: Smith, Elder, \& Co., 1885), 342.

3 The Purko clan is one of many sub-tribes within the larger Maasai collective.

${ }^{4}$ More information on the Award is available at: "Aga Khan Award for Architecture," Aga Khan Development Network (AKDN), http://www.akdn.org/architecture. 


\section{Introduction}

\subsection{Surmounting a Colonial Legacy}

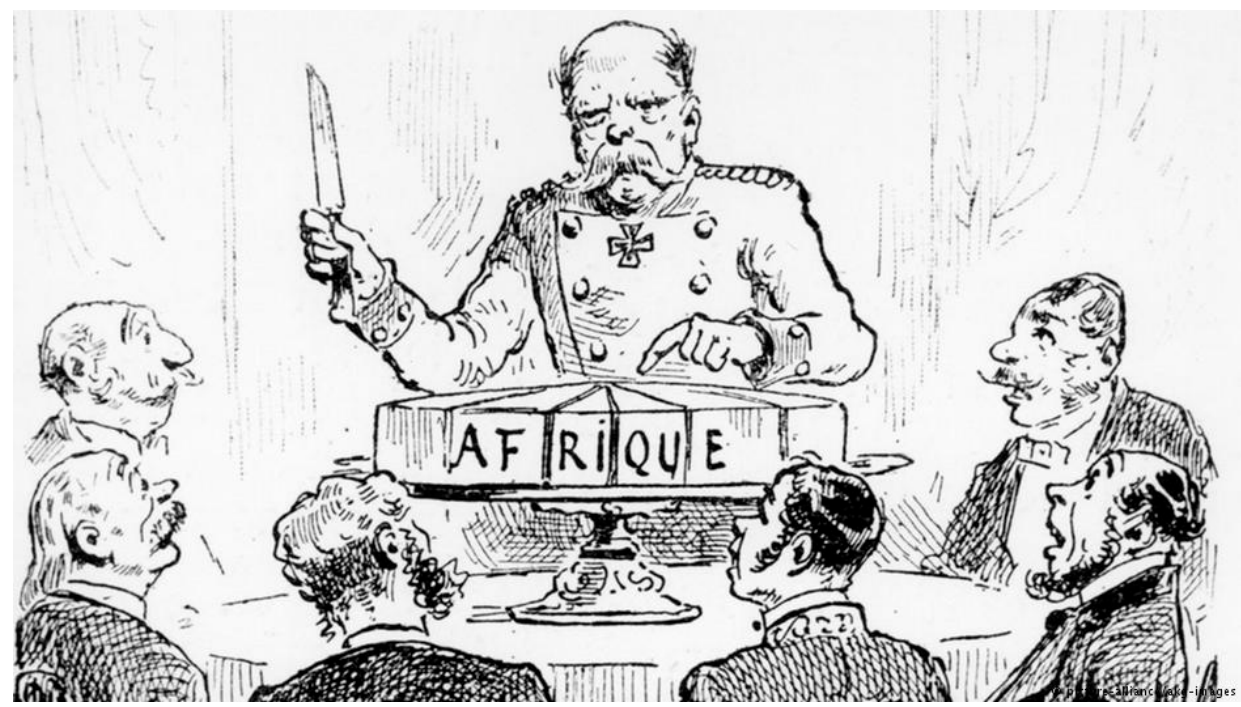

1.1 - The Berlin Conference - Image retrieved from "http://www.dw.com/en/130-years-ago-carvingup-africa-in-berlin/a-18278894"

\subsubsection{The Berlin Conference}

Attached to the wall was an enormous map of Africa. It was five meters tall. It illustrated the "dark continent" with natural geographic features. There were several rivers, some lakes, but only a few names of places. A gathering of 13 European state representatives eyed the recondite map and proceeded to carve out disparate tracts of land for their respective administrations. These colonial powers understood but little about the vast continent of Africa. In fact many parts of the land were completely "undiscovered" at this time. ${ }^{5}$

"Lines of longitude and latitude, rivers and mountain ranges were pressed into service as borders separating the colonies. Or one simply placed a ruler on the map and drew a straight line" 6

- Hilke Fischer

Journalist of African Studies, Political Science and Ethnology

This was the scene at the Berlin Conference of 1884 as described by journalist Hilke Fischer. At this conference, territorial borders were arbitrarily drawn, marking the inception of what was known as "The Scramble for Africa." Over the next several decades, European powers would usher in the era of Africa's colonization and leave a legacy that would forever mould Africa's future development. ${ }^{7}$

\subsubsection{Things Fall Apart}

"Turning and turning in the widening gyre

The falcon cannot hear the falconer;

Things fall apart; the center cannot hold;

Mere anarchy is loosed upon the world."8 
This quotation from William Butler Yeat's poem, The Second Coming, inspired the name of and prefaces the famous novel Things Fall Apart, written by the Nigerian author Chinua Achebe in 1958, a time when Africa witnessed a wave of independence movements sweeping across the continent. It forecasts the devastating experiences of the story's protagonist, Okonkwo, a Nigerian Igbo tribesman who encounters Christian missionaries in his village for the first time. "The center cannot hold" refers to the ensuing breakdown of the Igbo tribal system and community structure, as well as the anarchy that traumatized Okonkwo's world. The novel paints an impassioned picture that illustrates the cultural subversion experienced by many Africans during and even after the colonial era; a phenomenon that was frequently traumatic, symbolized through Okonkwo's suicide at the end of the novel.

Things Fall Apart was a seminal modern novel that offered a new voice to represent indigenous Africans at a time when colonial powers began to withdraw from their conquered lands.

\subsubsection{After Colonialism: Reclaiming African Identity}

From the outset of colonialism marked by the Berlin Conference of 1884, until the African independence movements of the mid-1900s when Achebe's novel was written, the heyday of colonial activity left a complex legacy. It propagated the image of a "superior" European culture that shaped African life in everything from the continent's languages to the architecture of city buildings. Joining Achebe's novel, a variety of other efforts were made to give voice to the "conquered," seeking to discern a modern African identity at the dawn of decolonization.

"The day will come when history will speak... Africa will write its own history... it will be a history of glory and dignity" 9

- Patrice Lumumba

Congolese Independence Leader and First Democratically Elected Prime Minister of Congo

This attempted "cultural reconstruction" was often guided by independence leaders such as Congo's Patrice Lumumba who, as seen in the excerpt from his will cited above, called for Africans to champion their own future using traditional knowledge from the past. Nelson Mandela (d. 2013) championed the anti-apartheid movement in South Africa during this era, and was one of many African anti-colonial activists, who counted among their numbers, Kenya's Jomo Kenyatta (d. 1978), Ghana's Kwame Nkrumah (d. 1972), and Tanzania's Julius Nyerere (d. 1999). Politicians were not alone in this endeavour. In the field of literature, Kenyan author Ngũgĩ wa Thiong'o discussed linguistic subjugation in his book, Decolonizing the Mind, where he called for locally authored literature to speak through indigenous African languages. ${ }^{10}$ In academia, African religions are now increasingly studied "in their own terms, rather than as mere paganisms or heresies." ${ }^{11}$ These examples testify to cross-disciplinary efforts to rebalance the cultural forces at play, illustrating the importance of independent African thinking, leadership, cultural expression and development in the post-colonial era.

Deeply intertwined in this web of cultural reconstruction ambitions have been those of architects. Architects undertook numerous efforts of varying efficacy to rebuild African architectural identity in the post-colonial era, notably through the paradoxical African Modernist Architecture movement of the 1950's and 1960's, which is described later in this chapter. Today, a variety of contemporary architectural styles exist across the continent. However, in sharp contrast to the spirit embodied in Lumumba's afore-cited aspiration, as well as the other efforts 
of post-colonial African leaders, the vast majority of contemporary African buildings do not intimately engage with pre-colonial building traditions. Though the continent represents about $20.4 \%$ of the world's land area, has 58 countries that span diverse geographical regions, and is home to about 3000 different ethnic groups and 2000 languages, ${ }^{12}$ a generalization may be made that today's contemporary African architecture expresses only a relatively narrow slice of Africa's diverse cultural histories, a trend that was initially predicated on the colonial agenda's definition of modernity. If contemporary African building activity continues to generally propagate this truncated version of history, it will only further reinforce the irrelevance of the pre-colonial African heritage.

In the spirit of Lumumba's aspiration, this underrepresented built heritage must therefore "speak" today. In addition to this dire need for indigenous cultural expression, a reinterpretation of pre-colonial building practices might also yield beneficial solutions for current architectural practice today, an idea that has certainly proven true in a few specific cases. This thesis investigates precisely these notions. The work locates itself on the crest of a rising wave of traditionally-inspired, yet forward looking architectural propositions for Africa, in response to the formidable challenge of "transplanted architecture".

\subsubsection{Structure of Chapter 1}

This chapter is the first of five chapters in this thesis and it serves to introduce the purpose of this work. It is organized as follows. Section 1.2 below establishes the central problem that has motivated the writing of this thesis; the general stylistic polarization in Africa between Western transplanted architecture and traditional buildings. To understand this polarization in detail, this section first explores the dangers of transplanted architecture, then identifies the architectural stereotypes that have historically motivated the adoption of Western forms in Africa, and finally it culminates with the theoretical undercurrent of the thesis problem: navigating between the forces of tradition and modernity in African architecture. Section 1.3 introduces the central thesis argument. It asserts that a reinterpretation of collective building methods and culturally embedded communal space found in traditional African buildings can provide a more contextually-informed contemporary architecture, thereby reconciling these aforementioned forces of tradition and modernity. This section will also introduce the primary design investigation for this thesis; a cultural center for a Maasai community in Kenya. It seeks to illustrate the theoretical argument of the thesis through architectural design. Lastly Section 1.4 provides the reader with a roadmap for the rest of the chapters in the thesis. As a result of my almost 20 years of personal experience in Kenya, as well as my investigation of the Maasai cultural center's site, this thesis will often refer to examples in the Kenyan context to support the theoretical arguments being made, many of which have broad applicability across the continent and to a certain extent, even the developing world at large.

\subsection{A Polarization of Architecture? Transplanted vs. Traditional}

\subsubsection{Transplanted vs. Traditional: An Introduction}

In many developing countries today, there exists a common narrative used to describe a supposed conflict of general architectural design styles: localized building traditions clashing with the proliferation of contemporary architecture that is predicated on Western industrialization processes. This narrative typically engenders a range of responses that rest between two poles. At one extreme, some feel that Western models of architecture are almost exclusively synonymous with the idea of progress, placing glossy images of modernity within the reach of citybuilders. ${ }^{13}$ At the other extreme, others perceive contemporary Western architecture as alien, vile and invasive, 
slamming shut the book that tells the long and glorious story of a cultural tradition. ${ }^{14}$ Both sides of this argument often present compelling rationales to justify how new buildings should be built. However, just as invisible winds shape sand dunes in a desert, an often overlooked web of forces govern the relationships between the creation of contemporary and traditional architecture. Such is often the case of those which have shaped battles between tradition and modernity in recent decades of African architecture. However, before a dive into these essential histories, a broad overview of building in the African context today must be presented, introducing these supposedly antithetical architectural design approaches: the "transplanted" and the "traditional."

\subsubsection{Africa's Transplanted Architecture: The Basics}

Today, as many African nations develop, contemporary models of architecture and urbanity are increasingly adopted from the industrialized world, frequently challenging traditional ways of building. ${ }^{15}$ Many of these imported practices are rarely reimagined to reflect the contextual specificities of culture, climate, local resource availability, or in some instances, social disparity. ${ }^{16}{ }^{17}$ Described by Architectural Review magazine as "a global pandemic of generic buildings" 18 , a universal breed of architecture with controversial contextual sensitivity is undeniably on the rise in Africa. ${ }^{19}$ These buildings can therefore be described as "transplanted", closely reflecting the architectural homogeneity seen in many modern city centers across the globe.

What then, does transplanted architecture look like? The following four images depict contemporary buildings located in the city of Nairobi in Kenya. Westgate Shopping Mall in figure 1.2-a, which gained international attention for the 2013 terrorist attack, is a structure that echoes the North American "big box store" building typology. I\&M tower from Figure 1.2-b and the Jabavu Village proposal from 1.2-c are textbook examples of the skyscraper building typology that is found in abundance in the industrialized West, right down to the non-structural glass curtain walls that dictate their exterior architectural expression. Lastly, in the background of figure 1.2-d are a series of conventional concrete-frame apartments that were built as a part of the Kenya Slum Upgrading Project (KENSUP) launched by the Kenya Ministry of Housing in collaboration with United Nations Habitat (UN-Habitat). As a transplant that has adversely impacted just one of many slum communities across the continent, this housing project will be looked at more closely in the next section.

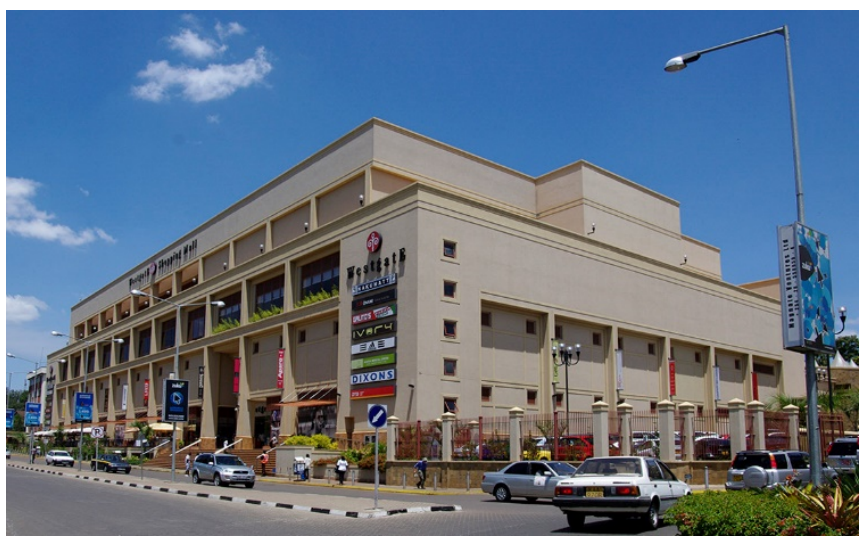

1.2 - Westgate Shopping Mall - Image retrieved from http://www.baa-architects.com/retail/westgate.htm/

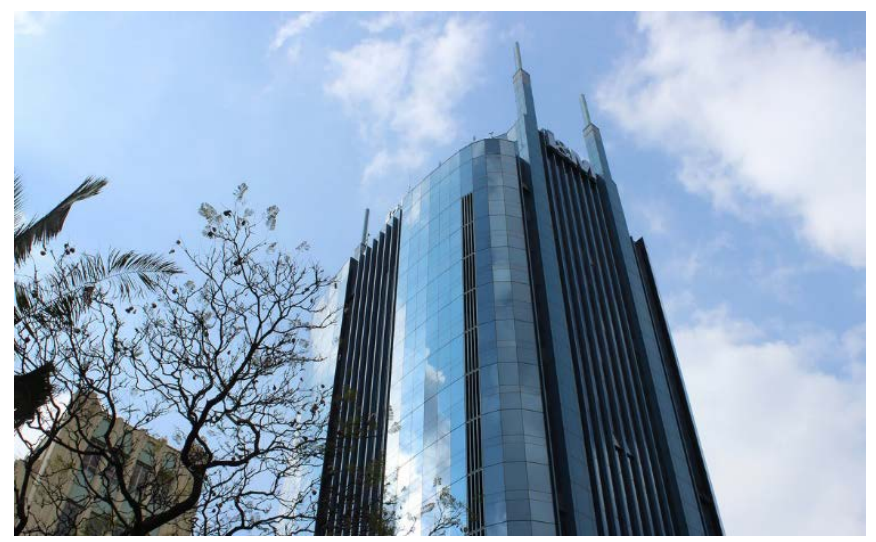

1.3 - I\&M Tower - Image retrieved from http://www.skyscrapercity.com/showthread.php?t=515152\&page=2 66 


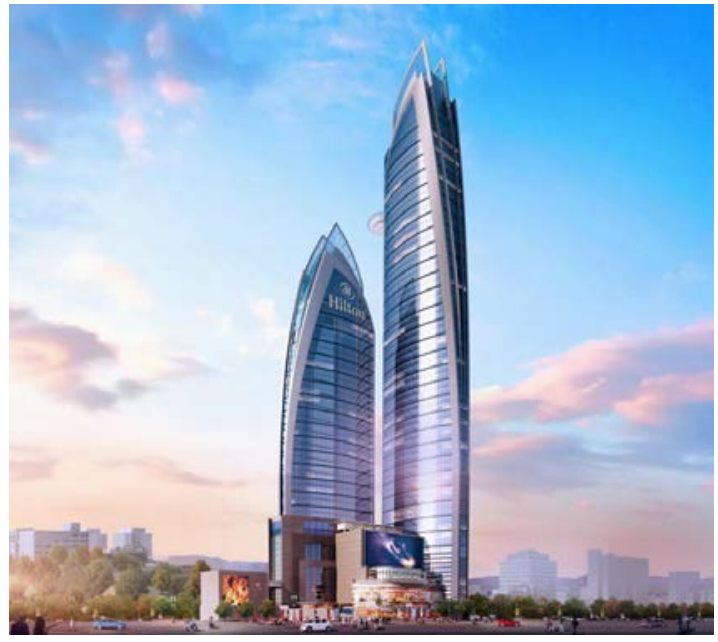

1.4 - Jabavu Village Ltd - Image retrieved from http://nairobiwire.com/2016/10/hilton-hotel-to-openafricas-tallest-skyscraper-in-upper-hill-in-2020.htm/

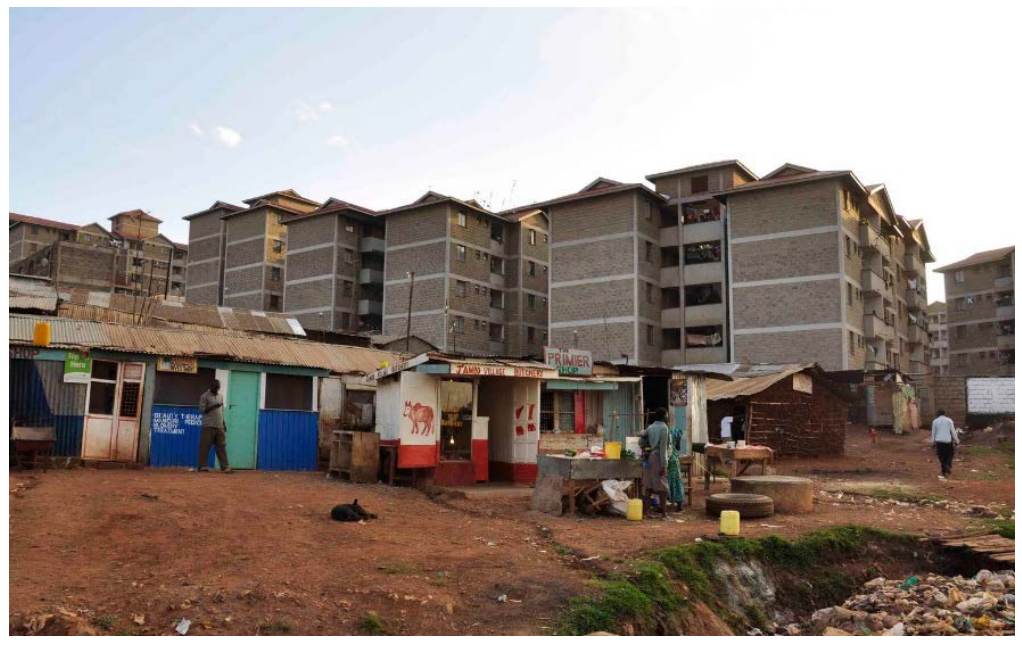

1.5 - Kibera Slum Upgrading Project - Image retrieved from "https://theinsidescoops.wordpress.com/2013/01/07/kenyans-in-poverty-seriesepisode-1-kibera/"

Though these are only a selection of projects from a single country, Kenya, this universal style of building represents much of current architectural practice across the continent. While exceptions certainly exist, they are few and far in between, constituting a very narrow portion of professional building development. Today, architects, let alone laypeople, may find it difficult to identify their global location simply by observing the surrounding contemporary buildings in an African city center. Whether this architecture is referred to as "universal" or "placeless", this dire loss of regionally distinct buildings in a globalised world is certainly not a new concern of contemporary architects and city builders. For Africa, this plethora of homogenous architecture is a reality that falls short of the cultural reconstruction visions championed during the post-colonial era.

\subsubsection{Africa's Transplanted Architecture: A Proliferation of Callous Architecture}

Why is broad homogeneity in architectural styles harmful? Transplanted architecture is arguably "callous". This universal style of the transplants frequently manifests itself through poorly designed buildings in Africa by lacking a deep sensitivity to local culture, climate, resource availability, and social disparity. This is paradoxical, considering the immense importance that is theoretically placed on site-responsiveness in most of contemporary architectural practice. For example, in 2017, the Pritzker Architecture Prize, often referred to as architecture's Nobel Prize, was awarded to RCR architects in large part for their strong, regionally sensitive approaches to design. ${ }^{20}$

In De Architectura, considered to be the first text on architectural theory, Roman Architect Vitruvius writes:

"Granting that countries differ from one another and that they are of various orientations according to the inclinations of the sky, the various people born here and there have natural differences ... Therefore, we should not hesitate to make our houses suitable in plan to the peculiarities of nations and peoples, because in nature herself we have a readily available and ingenious guide" 21 
Popularly known as the "first architect", Vitruvius often described architecture as a reflection of nature. It is evident that he espoused regional specificity in his architecture as a result of what he saw in the natural world. Undeniably, a variety of viewpoints exist within the discourse regarding regional architectural specificity, however, as a seminal architectural text, De Architectura represents an early professional voice calling for the site-responsiveness of buildings and the Pritzker Prize testifies to the centrality of this notion in the contemporary global architectural community. Today, it is also considered standard best practice for an architect to engage in a comprehensive site analysis to inform an appropriate building design response.

Despite this, there are countless examples where African transplanted buildings fail to be sensitive to critical contextual forces. Here, I discuss the apartments built under the Kenya Slums Upgrading Programme (KENSUP) from figure 1.2-d as a typical example, characteristic of this notion. The project has attracted frequent criticism because of the apartments' universal aesthetic, their inability to sustain the vital social networks that otherwise flourish within the adjacent Kibera informal settlements (shown in the foreground of the image) ${ }^{22}$, and their high expense.

Journalist Abby Higgins' interview of Kibera resident Mildred Lunani illustrates some of these challenges. Higgins writes:

"At the pace KENSUP is going, it's hard to believe that the planned upgrade of the entire slum will ever be complete. But it's harder still to imagine that Kibera residents like Mildred will ever feel at home in the monochrome, concrete stacks of The Promised Land." 23

Nicknamed The Promised Land, KENSUP's Kibera slums housing scheme is appropriately described as "monochromatic" by Higgins. It is difficult to discern from the appearance of these KENSUP buildings where in the world they are located or which people live in them. For its residents, this vagueness of architectural identity certainly impedes the sense of pride and ownership that is desired for low-income homes. ${ }^{24}$ This example of transplanted architecture might be described as culturally insensitive in its outward aesthetic expression, but more importantly it fails to sustain, let alone enhance, the lifeblood of civic vitality found in the informal settlements that it replaced. With poorly designed spaces for communal gathering, the KENSUP plan is in many ways antithetical to the vibrant social life and community networks found in the slums. Moreover, this KENSUP plan is expensive. The housing scheme uses the increasingly ubiquitous concrete masonry unit (CMU) construction system that is common across East Africa but that is often ill-suited for these locales. Professor Aimee Buccellato writes:

"modern" materials, such as Concrete Masonry Units (CMUs), are considered by Tanzanians to be a sign of higher social rank and financial standing in comparison to traditional, local materials, mud and timber, despite the near impracticability of the material-CMU's - in the tropical sub-Saharan climate and distance from manufacturers. "25

- Aimee Buccellato 


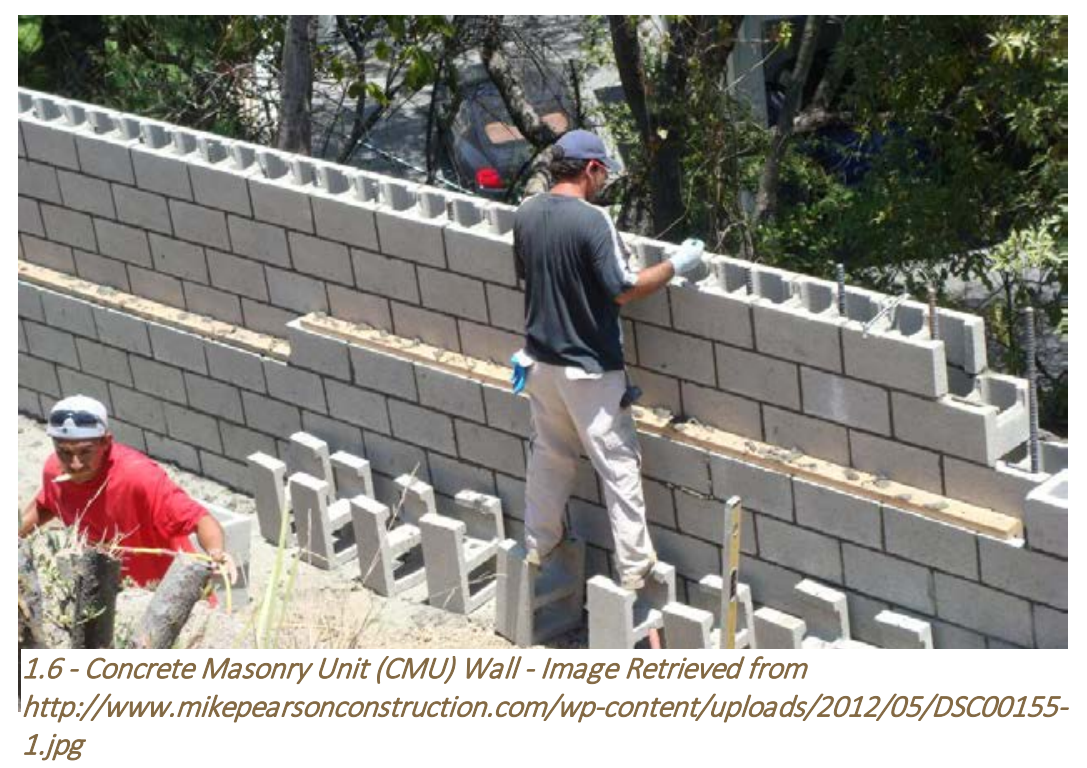

While Buccellato's article refers to a specific case from Tanzania, this adoption of alien ways of building is characteristic of building trends in many parts of the continent. There is no doubt that the high durability of CMU's might make them an attractive material choice for many projects. However, CMU's have a relatively high cost, poor thermal performance against prolonged unwavering temperature spans, and a low value-to-weight ratio which often results in relatively high transportation costs when compared to locally obtained materials such as earth. These ideas might provoke question as to the long-term feasibility of CMU's, particularly when they are so uncreatively amassed in the stacked "living boxes" of this KENSUP design. One might ask, is it really financially, culturally, or environmentally sustainable to build KENSUP's expensive concrete structures for the 250,000 slum denizens of Africa's largest informal settlement? What about the 2.5 million inhabitants of informal settlements in Nairobi ${ }^{26}$ or the 5.3 million slum dwellers that Kenya will see by 2020 ? $^{27}$ It comes as no shock that Lunani would find it difficult to call this concrete monolith "home". In fact, since 2003, many new residents of The Promised Land have opted to relocate back to the decrepit shantytown instead of living in KENSUP's new goliath concrete structures. Lunani's interview continues, identifying a number of policy and administrative failures that make the housing scheme quite unsuccessful. ${ }^{28}$ Transplanted architecture's considerable disregard for site specificities is discernable in this example, and like an unsuccessful organ transplant, provokes a strong possibility of rejection if it is poorly integrated. Kibera is but one example that showcases the dangers of contextually-insensitive transplanted architecture in Africa.

Illustrated in part by this KENSUP example, Africa's transplanted architecture exhibits a trend of general deficiencies. A disregard for passive heating and cooling architectural design strategies is regularly apparent, notably in the commercial high-rise typology that requires artificial cooling technologies to keep the spaces behind the hermetically-sealed curtain wall facades comfortable for its occupants (see figures 1.2-b and 1.2-c). ${ }^{29}$ Moreover, rarely do contemporary transplants express local culture. Common attempts to achieve appropriate cultural expression are often relegated to parroting indigenous architectural forms for new functions, ${ }^{30}$ the surface 
application of locally recognizable cladding materials, and applied stereotypical imagery of Africa's tribes and wildlife (seen later in the façade of the building shown in figure 1.2-e). Furthermore, as seen in the KENSUP project, transplanted architecture is often built using tectonic systems and materials that are almost exclusively predicated on industrial manufacturing processes. In some contexts, this can make buildings quite costly, beyond the financial reach of 389 million Africans living on a daily income of less than $\$ 1.90 .{ }^{31}$ These shortcomings are unfortunately much too common in contemporary building activity, making the "callous" transplants increasing ubiquity across the continent a dangerous inhibitor for overall sustainable development.

\subsubsection{Architectural Stereotypes: Popular Perceptions of Modernity}

From the examples presented, it is clear that sheer pragmatism is only intermittently used as a yardstick for "good" architecture. Buccellato also writes:

"The result Western ideas of urbanity and building typology are seen as superior to traditional African forms and building culture even when incompatible with the environmental and cultural context." 32

- Aimee Buccellato

Assistant Professor of Architecture at the University of Notre Dame

Both of Buccellato's aforementioned comments draw attention to how popular perceptions of progress and modernity are critical in driving building design and construction, sometimes challenging the notion of sitesensitivity as an integral design impetus. Modernity's close association with adopted Western building techniques contributes to the embrace of CMU's in Tanzania, despite the pragmatic disadvantages of their use in some contexts. Certainly KENSUP's housing plans were perceived by many as a forward-thinking solution to Nairobi's many informal settlements, and understandably so. As a building material, the durable concrete masonry units (CMU's) may connote "permanence", "stability" and even "security" when compared to the transient corrugatedmetal slum shanties.

Buccellato's assertion highlights what is sometimes an abyss between architecture "perceived" as forward-looking and architecture that is pragmatically progressive, born from contextual specificity. To better understand this chasm, a historical understanding of the Architectural Modernism movement in Africa is imperative, as it was critical in propagating many of these architectural stereotypes of modernity within general populations, increasing the adoption of transplanted forms in Africa today. 


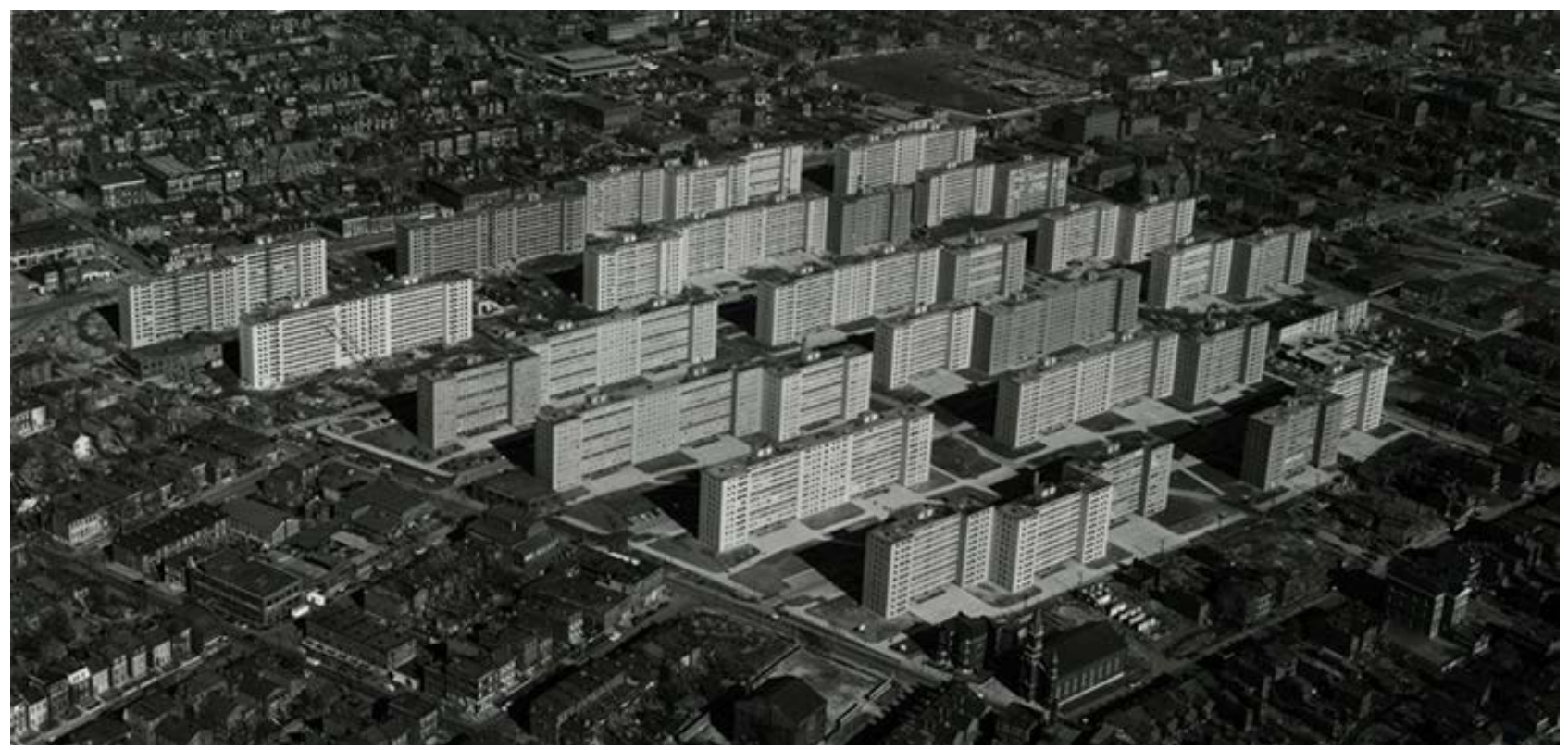

1.7- Pruitt Igoe Housing Scheme - Image retrieved from "http://www.pruitt-igoe.com/urban-history/"

As a relatively fruitless social housing scheme, the KENSUP transplant brings to mind the well-known narrative of Pruitt-Igoe, Missouri's infamous St. Louis housing scheme that was designed in the Modernist Architectural style. Built in the mid-1950's, this subsidized housing complex quickly deteriorated into an urban slum within four years, and to the architect's shock, the complex needed to be demolished less than 20 years after its opening. Designed by Minoru Yamasaki, the demolition of Pruitt-Igoe was popularly regarded as the ultimate debacle of the Modernist Architecture movement. This general style of architecture had elicited popular perceptions of architecture that were particularly lofty, as after World War II, Modernist Architecture in North America and Europe was seen as a powerful vehicle to realize utopian social values following the years of war, destruction, and chaos. A brief introduction to the Modernist style must first be highlighted to understand how architecture, generally viewed as socially-charged and futuristic, perpetuated the widespread appetite for Western building forms in the African postcolonial context.

Frequently devoid of architectural ornamentation, Modern Architecture is a loose term to describe the many visions over the last century that sought to conceive of an architectural style that could "reconcile an idealized vision of society with forces of the Industrial Revolution". ${ }^{33}$ It developed over the decades through the works and legacies of well-known architects such as Otto Wagner (d. 1918), Louis Sullivan (d. 1924), Adolf Loos (d. 1933), Frank Lloyd Wright (d. 1959), Eero Saarinen (d. 1961), Le Corbusier (d. 1965), Ludwig Mies van der Rohe (d. 1969), Louis Khan (d. 1974), Kenzō Tange (d. 2005), Oscar Niemeyer (d. 2012), and significant others. Many of their works and a few others are chronologically illustrated in the collage in figure $1.2-\mathrm{g}$, with an emphasis on the Western context. ${ }^{34}$ 


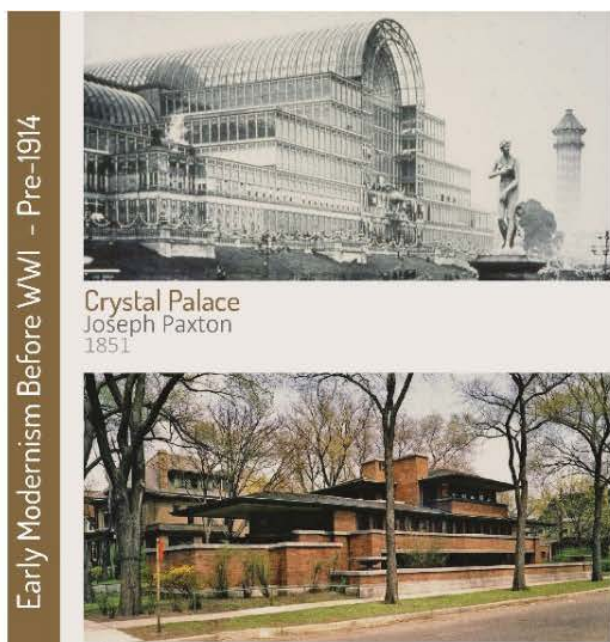

The Robie House

Frank Lloyd Wright

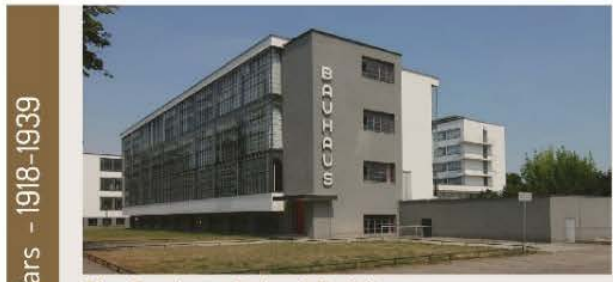

The Bauhaus School Building

Walter Gropius

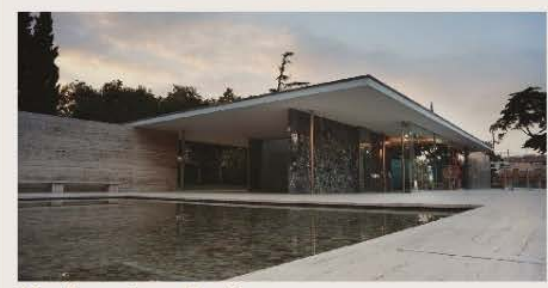

The Barcelona Pavilion Ludwig Mies van der Roh

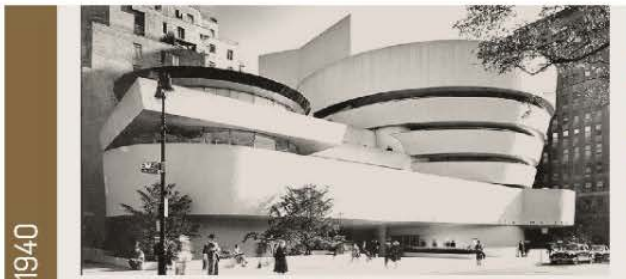

Solomon Guggenheim Museum Frank Lloyd Wright

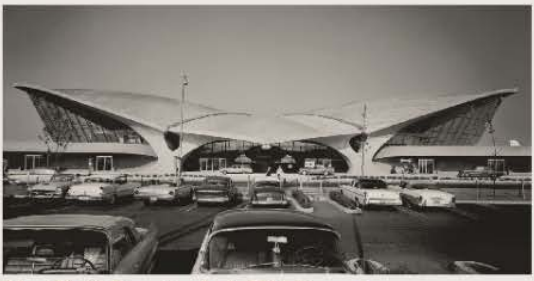

The TWA Terminal at JFK Airport

Eero Saarinen

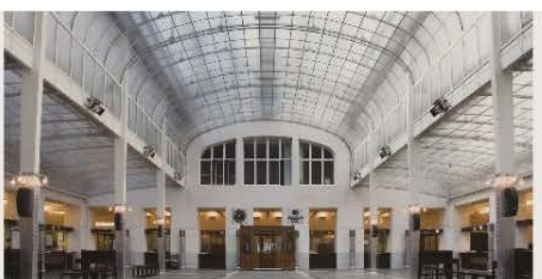

Austrian Postal Savings Bank

Otto Wagner

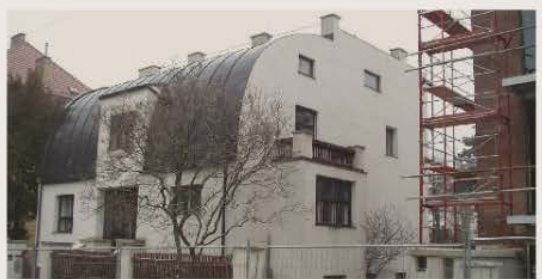

The Steiner House

Adolf Loos

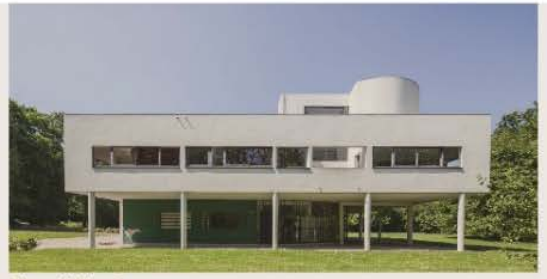

The Villa Savoye

Le Corbusie

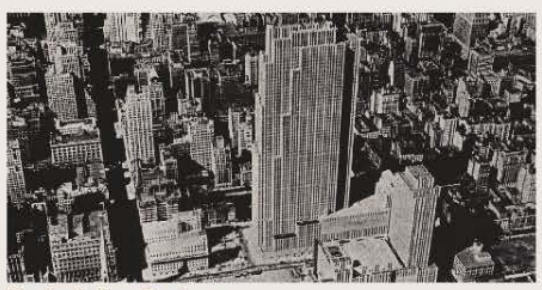

Rockefeller Center

Raymond Hood

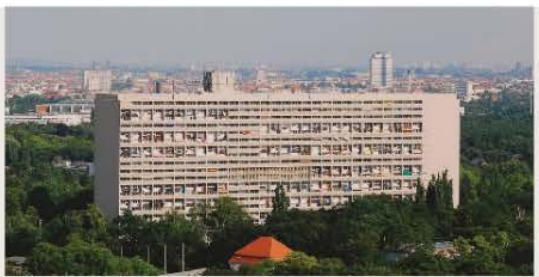

Austrian Postal Savings Bank Le Corbusie

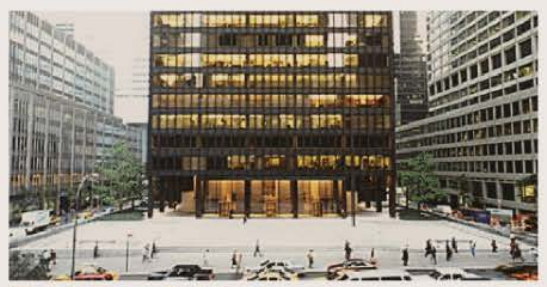

The Seagram Building

Ludwig Mies van der Rohe

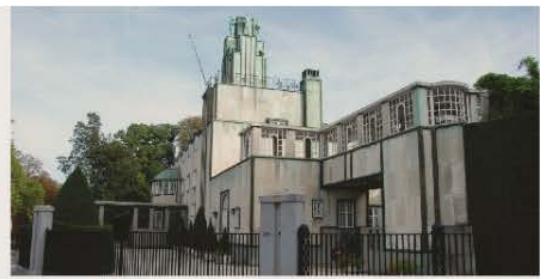

Stoclet Palace

Josef Hoffmann

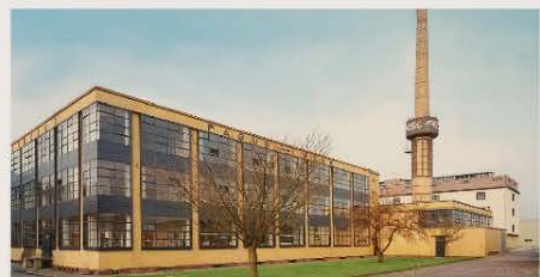

The Fagus Factory

Walter Gropius and Adolf Meyer

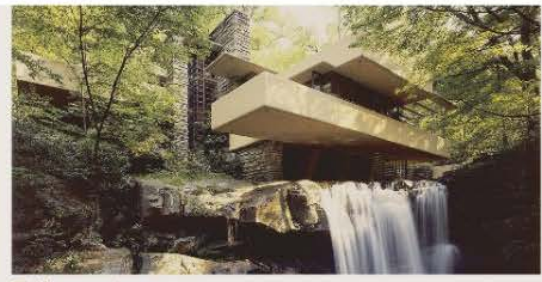

Fallingwater

Frank loyd Wright

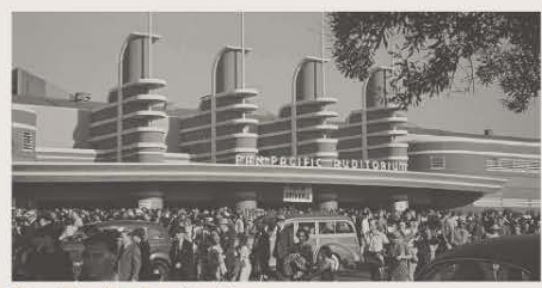

Pan Pacific Auditorium

Wurdeman \& Becket

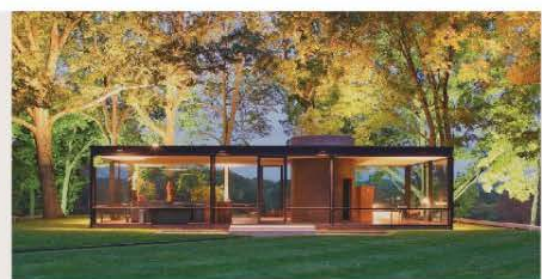

The Glass House

Philip Johnson

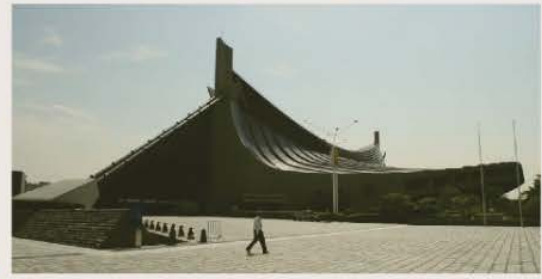

Yoyogi National Gymnasium

Tange 
William JR Curtis, one of the leading academic voices on twentieth century architecture, describes the Modernist architectural style as:

"... an invention of the late nineteenth and early twentieth centuries... conceived in reaction to the supposed chaos and eclecticism of the various earlier nineteenth-century revivals of historical forms. Basic to the ideal of a modern architecture was the notion that each age in the past had possessed its own authentic style, expressive of the true tenor of the epoch. According to the same outlook, a break supposed to have occurred somewhere around the middle of the eighteenth century, when the Renaissance tradition had faltered, leaving a vacuum into which had flowed numerous 'inauthentic' adaptations and recombinations of past forms.

The task then, was to rediscover the true path of architecture, to unearth forms suited to the needs and aspirations of modern industrial societies and to create images capable of embodying the ideals of a supposedly distinct 'modern age'. ${ }^{35}$

- William J.R. Curtis

Architectural Historian and author of Modern Architecture since 1900

As Curtis writes, more than simply a general style in which to create buildings, Modernist architecture was commonly viewed as an instrument to realize idealized aspirations for society by harnessing the new tectonic possibilities effectuated by industrial processes. At this time, the image of progress was intimately linked with Modernist Architecture through two of the style's most crucial characteristics: a general attitude of disdain toward specific cultural traditions and a conscious effort for the style to be universally relevant across geographies.

Predicated on creating a style appropriate for the then new construction technologies of steel, concrete, and glass, Modernist architecture commonly rejected cultural referencing in its expression, thereby liberating architecture from the "shackles" of history. Instead, it more commonly expressed though material detail-design techniques how these new construction materials and technologies could be fabricated and assembled. With straight lines and clean surfaces, Modernist Architecture is often described as rational and minimal. One might say that the style commonly sought to express "technological sophistication". Secondly, the Modernist Architecture label refers to architectural approaches that frequently sought to be distinctly global or universal. In 1925, Walter Gropius, considered one of the founders of the International Style of Architecture, which later grew into the Architectural Modernism movement, wrote that there should be "A uniformity of the character of modern buildings across natural borders" ${ }^{36}$ Recognizing the increasingly interconnected nature of the world at the time, Modernist architecture sought to stay relevant by being international. These two principles helped to create a general style of architecture that was deemed to be progressive and "appropriate for the modern age," 37 to use the words of Curtis.

Though Modernist Architecture, particularly in its earlier days of the International Style, is sometimes described as the "one-size-fits-all" approach to building design and has indeed challenged regional approaches to design, ${ }^{38}$ it would be incorrect to see the style as an ideological monolith. Since 1925, the general movement of Modern Architecture was comprised of diverse sub-categorizations that were adopted almost globally over several decades to serve a variety of purposes "from mass housing to the glorification of capitalist institutions, from rarefied villas to spaces of sacred meaning". ${ }^{39}$ Nevertheless, the general movement has been one of the most important forces of the architectural discourse worldwide over the $20^{\text {th }}$ century. Over the last hundred years, "the future" was built in 
the cutting edge, technologically sophisticated, Modern architectural style, intimately linking it with images of modernity and progress.

Understandably, the demolition of the Pruitt-Igoe housing scheme might then give the appearance that Modern architecture had failed to transform the St. Louis ghetto communities and achieve the bright and stable future that the style had once promised. It pricked the inflated bubble of utopian ideals that were popularly attached to building design and construction, causing the architectural Historian, Charles Jenks, to famously state that the demolition of the Pruitt-Igoe housing complex represented the "death of Modern Architecture". ${ }^{40}$ However, authors such as Katherine Bristol have debunked the myth that Pruitt-Igoe was the failure of an architectural style, instead demonstrating how the breakdown of this housing scheme can be attributed primarily to institutional and

policy deficiencies, fiscal instability, and egregious maintenance shortcomings. ${ }^{41}$ However, despite Bristol's 1991 publication, many architects that studied the profession between 1930's and 1970's might sympathize with Jenks' sentiment, as the popular narrative around Modern architectures capacity to actualize social utopias had conceivably come to a close. The romanticised notion of Modernist architecture as a vehicle to realize social ideals demonstrates the importance of popularly conceived stereotypes of modernity, particularly when they help to fuel drastic changes in the built environment. As suggested th the outset of the sections on "Architectural Stereotypes", sheer pragmatism is rarely used as the sole impetus in the creation of architecture. Architecture is not neutral, nor is it silent. Architecture can in fact help define the notion of modernity for a society.

The acme of Modernist architecture also occurred when African states began to gain independence from colonial administrations. Both of these narratives did indeed collide. Just as Modernist Architecture is recognized for its widespread utility in post-war North America and Europe, it is known less in the West that Architectural Modernism widely took root in Africa's post-colonial era. The socially-charged nature and technological sophistication of Architectural Modernism made it the style of choice for new African cities. Eager to shake off their colonial histories, the newly independent countries could use Modernist Architecture as vehicle to signal their entry into the international community as progressive, contemporary states. In retrospect, as a style that was founded in the industrialized nations of the world, Architectural Modernism in Africa also played a large role in conflating the notions of modern and Western, a stereotype that continues to fuel the adoption of transplanted forms today.

\subsubsection{Architectural Stereotypes: The Hegemony of African Modernist Architecture}

The outset of this chapter referenced the many African independence movements of the 1950's and 1960's, a process that was highly complex and frequently fraught with violence. More recently, many scholars, such as Romon Grosfoguel, have argued that Africa's post-colonial era was less of a romantic narrative of nations achieving sovereignty than it was a process by which a new era of neo-colonialism began to thrive. ${ }^{42}$ For example, from the 1950's and 1960's onwards, many African states such as Senegal or Niger were still dependent on their colonial administrations, financially or otherwise. West African states in particular, such as Chad, the Central African Republic, Senegal, Mali, and Côte d'Ivoire still feared the presence of foreign military power within their borders. This was also a time when many of the first African independence administrations evolved into authoritarian regimes. In subsequent decades, the International Monetary Fund (IMF) and World Bank, furthering a capitalist agenda, established many imperious Structural Adjustment Plans (SAPS's) by giving out large loans to African leaders. For many African states, the decolonization process was far from simple and the authenticity of their status 
of "sovereignty" is certainly questionable. These ideas are outlined in the book, African Modernism, edited by Manuel Herz. ${ }^{43}$ Likewise, the genuine decolonization of Western approaches to architecture in Africa is equivocal, evidenced by a minimal role of indigenous architectural creativity in this neo-colonial era. After colonial powers had formally left the continent, was the new African Modernist Architecture authentically African? Perhaps it was seen by many indigenous populations to be transplanted, just like the earlier architecture from the colonial age.

The relationship between the notion of modernity and African Modernist Architecture can be seen in a single image, Figure 1.2-h. It is an illustration from a 1953 Architectural Review article entitled "The African Experiment" that showcased the built work of architects Maxwell Fry (d. 1987) and Jane Drew (d. 1996) in West Africa. ${ }^{44}$ The former is credited with launching Tropical Modernism in West Africa, a substyle of the larger Modernist movement that was thought to be appropriate for many African countries. ${ }^{45}$ The illustration from the article portrays a young African girl about to attend school in the Modernist building that is shown in the background. This illustration, incidentally, later informed Fry's design for the Nigerian University of Ibadan. ${ }^{46}$ Dwarfed by the concrete building and with a slightly titled head, the girl appears apprehensive, as if this is her first day of school in the new structure. Standing in the dark shadows, the girl is possibly overcome with a feeling of trepidation. This is certainly understandable, perhaps because the huge school symbolises the many Western educational institutions established by colonial administrations across many African nations. Perhaps it is because the large rectilinear concrete school is built in the "strange" Modernist Architectural style, certainly a peculiar structure in relation to the traditional home that the girl might live in. One can empathize with the girl's apparent meekness or nervousness, particularly when recalling the title of Achebe's novel, Things Fall Apart vis-à-vis the reaction that Okonkwo had in response to the cultural erosion that impacted his tribe. The juxtaposition of the concrete school with the African girl in the image represents many complex themes of the African Modernism movement in a microcosm, most notably the interlinking of the notion of "progress" with the burgeoning Modernist building development that began to command African soil in the post-colonial era. The rise of African Modernism is highly paradoxical, and with the limited engagement of local practitioners, it can be argued that it was oftentimes a transplanted style of architecture in itself. 


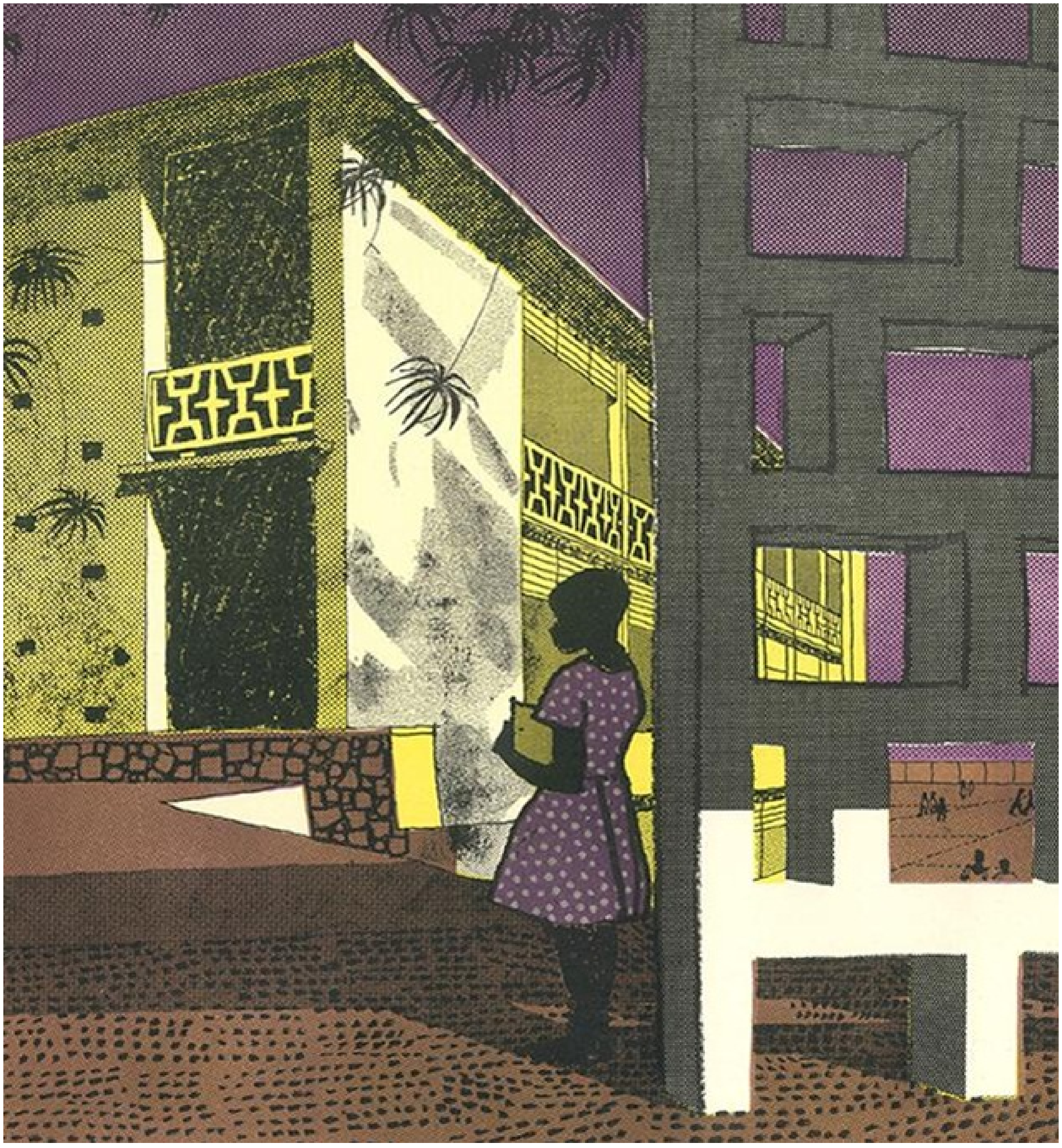

1.9 - The African Experiment: Sketch by Maxwell Fry and Jane Drew - Image retrived from "Tropical Modernism: Fry and Drew's African Experiment: Achitectural Review" 
Some notable examples of African Modernist buildings include Nairobi's Kenyatta International Conference Centre (KICC) designed by Karl Henrik Nøstvik (d. 1992) from 1966-1973, Dakar's Centre D’Affaires designed by Henri Chomette (d. 1995) with Roland Depret (presumed by Herz) from 1977-1981, and Lusaka's Profund House designed by Architrave Ltd. by W.G. Jabs and P.C. Bartman in 1974. ${ }^{47}$ These are pictured below in figures 1.2-i, 1.2-j, and 1.2k. These buildings represent Modernism's growing attractiveness at this time in Africa.

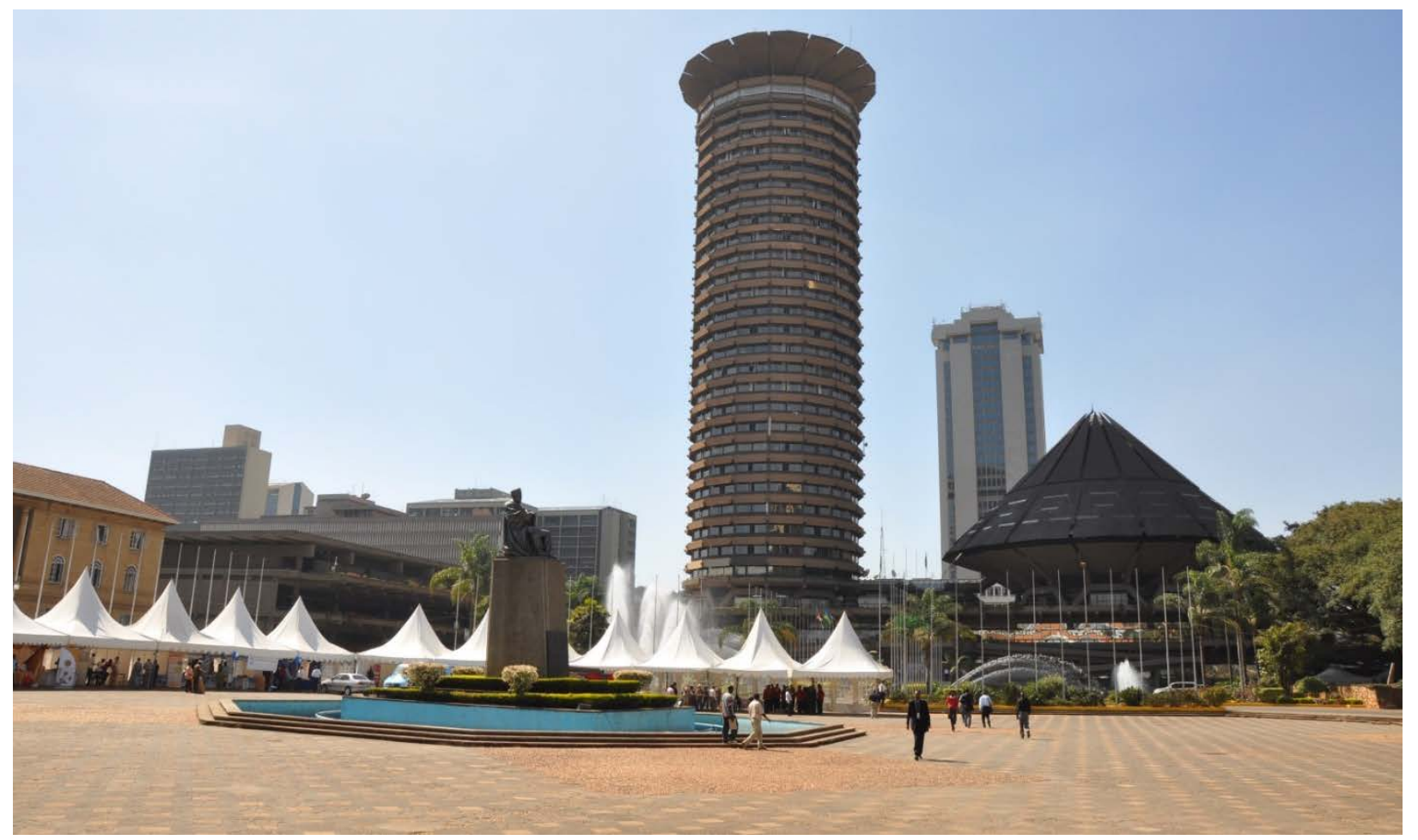

1.10 - Kenyatta International Conference Center - Image Retrieved from

https://upload.wikimedia.org/wikipedia/commons/3/33/Lascar_Kenyatta_International_Conference_Center_\%284522598390\%29. jpg
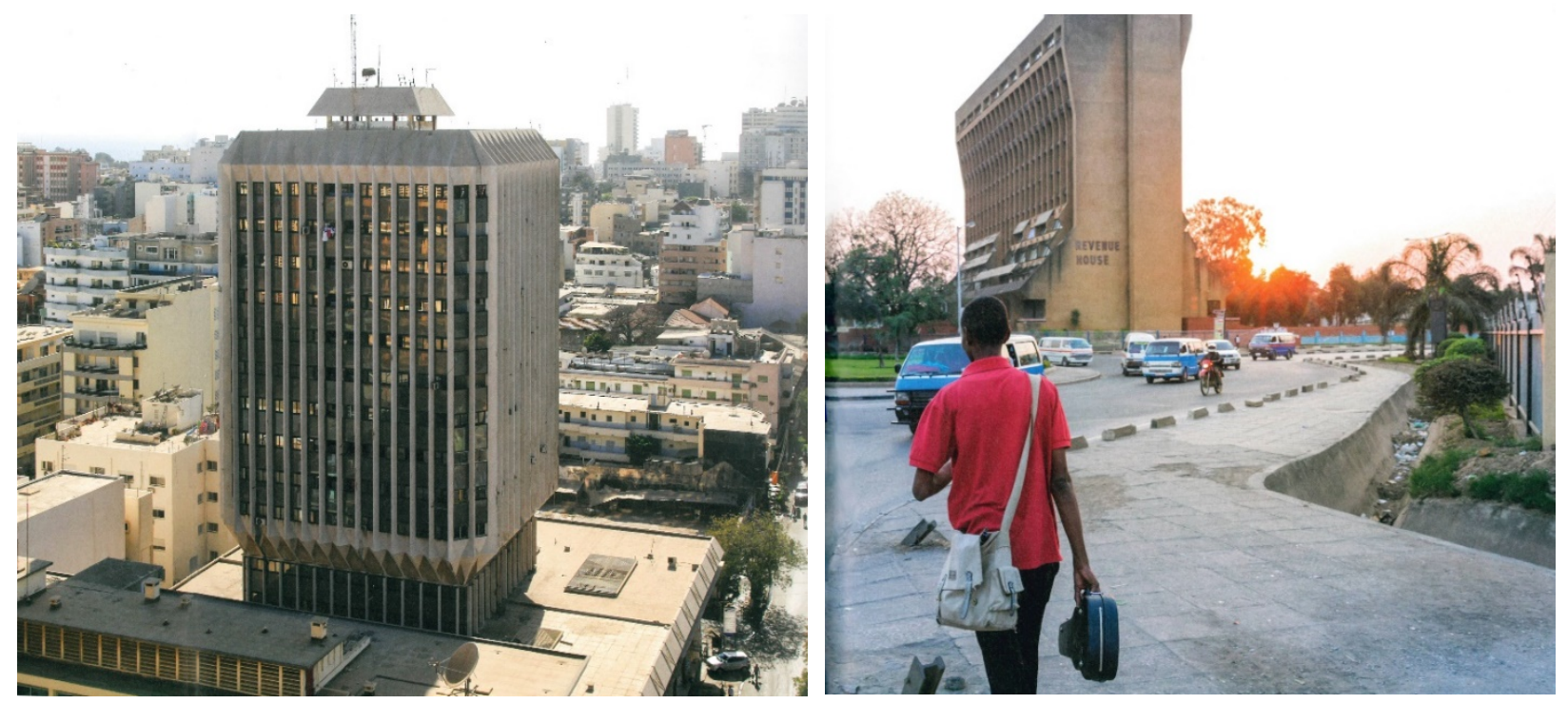

1.11 - Centre D'Affaires - Image Retrieved from "African Modernism"

1.12 - Profund House - Image Retrieved from "African Modernism" 
The impact of Architectural Modernism on African nations was immense but also highly paradoxical. The Modern architectural style, predicated on Gropius' notions of "universal applicability", was an apparently contradictory choice for African nations operating in an era of cultural reconstruction who wished to assert unique national and cultural identities. ${ }^{48}$ As an interface between "the world" and Kenya, the Kenyatta International Conference Centre (KICC) on the one hand, is an example of a building in which the Modernist style's universal aesthetic might have been perceived as appropriate in order to assert the country's new post-colonial engagement with the international community. After all, the building had to be seen as new and forward-looking by the outside world, and was even considered for the World Bank's 1973 annual meeting venue. ${ }^{49}$ However, on the other hand, choosing the international modernist aesthetic might also be seen a contradictory, speaking little of Kenyan tradition and therefore hindering the building's ability to represent a unique national identity on the global front. Despite this paradox, KICC today is today popularly seen as distinctly "Kenyan" to the extent that it is pictured on the local currency (figure 1.2-I). A closer look at the building's amphitheatre illustrates just how significant the building's "architecture" was in contributing to the building's iconic status.

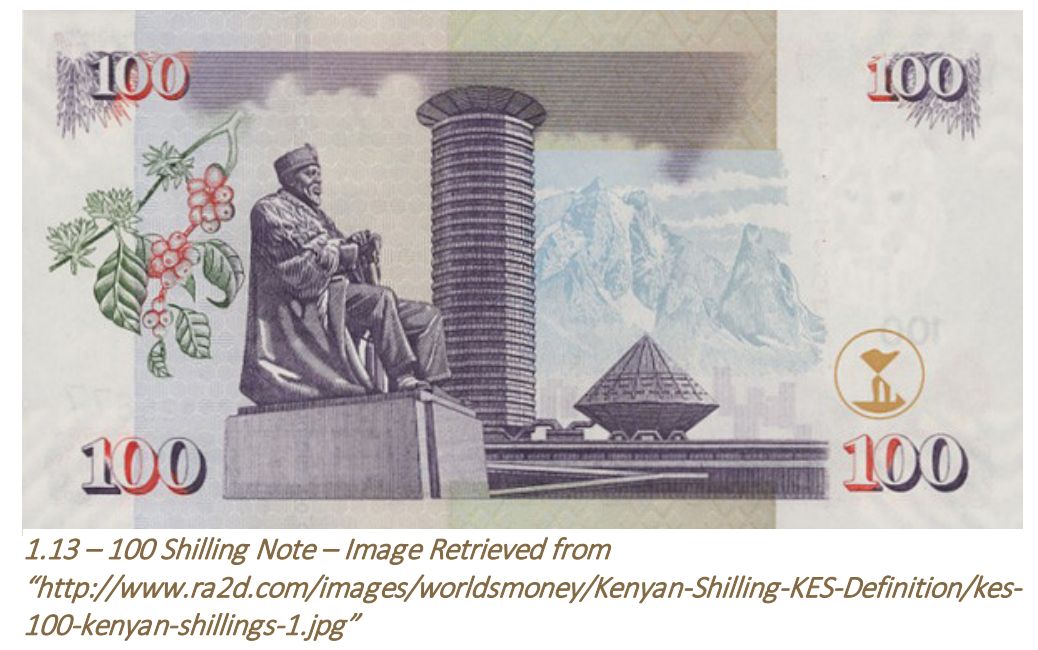

Like many transplants in Africa today, the amphitheatre of KICC (the conical structure pictured on the right of both figures 1.2-e and 1.2-1) is an example of an appropriation of the traditional form, that of a generic African hut, for a new function. As outlined before, this is one common strategy in which contemporary African architecture claims to pay tribute to heritage. While this particular gesture is perhaps a polite salute to a traditional Kenyan building form (albeit a generic one), it can be argued that this sculptural mimicry is a rather limited reference of Kenyan architectural traditions. The KICC's construction processes, materials and even the architect himself are more ideologically relatable to the aforementioned logic of Architectural Modernism and the International Style. ${ }^{50}$ The influence of Kenyan building heritage on the other parts of the building is even more obscure than this example of the amphitheatre. Moreover, the Norwegian architect, Nøstvik, brought to Kenya as part of a Norwegian aid package, had never previously designed a building in Kenya. Tom Anyamba, Professor of Architecture at the University of Nairobi, states that there are elements of KICC which are of Norwegian influence. ${ }^{51}$

Pictured on the 100-shilling note in the pocket of every Kenyan, it can be argued that the KICC's iconic identity was achieved less through its architectural design and more by its initial political role as the headquarters for Kenya's 
first independent government, the Kenya African National Union (KANU), as well as its programmatic function as an "international" building. Today it remains one of the continent's most famous conference centers.

As outlined by Herz, post-colonial Modernist buildings were rarely designed by local practitioners but instead, almost exclusively by little-known foreigners such as Henri Pottier (d. 2000), Roger Tallibert (d. unknown), Henri Chomette (d. 1995) and others. Primarily of Scandinavian, French and English origin, almost all undertook their architectural training outside of Africa, most commonly at London's Architectural Association (AA). ${ }^{52}$ For example, Ola Uduku writes about the strong ties between the AA and the Tropical Architecture movement in West Africa. ${ }^{53}$ African Modernism was less of a then-contemporary grassroots-led approach to building design than it was the export of Architectural Modernism from the West into Africa, also seen through Fry's immense influence there. As illustrated in the example of KICC, the limited engagement of local African designers reinforced the notion of a "topdown" building development approach employed by the many foreign architects. It can therefore be argued that African post-colonial Modernist architecture in many ways catalyzed existing building stereotypes by deepening the close associations of modernity and progress with foreign architects and Western styles, undermining the utility of traditional building methods.

\subsubsection{A Recoil from Traditional African Ways of Building}

Modern Architecture may have been perceived differently by African citizens than the leadership of the many new "independent" administrations. Author V.S. Naipaul expresses a commoner's perspective in his novel, A Bend in the River, whose story is set in an unnamed imaginary African state during this independence era.

We watched and wondered while the buildings were run up. And then we began to understand that what the President was attempting was so stupendous in his own eyes that even he would not have wanted to proclaim it. He was creating modern Africa. He was creating a miracle that would astound the rest of the world. He was by-passing real Africa, the difficult Africa of bush and villages, and creating something that would match anything that existed in other countries. ... Under the rule of our new President the miracle had occurred: Africans had become modern men who built in concrete and glass and sat in cushioned chairs covered in imitation velvet. ${ }^{54}$

\section{V.S. Naipaul}

Nobel Prize winning writer

One can imagine the reactions of local peoples between the 1950's and 1970's, who looked toward a liberated "African" future with confidence, but saw these ideals manifested, once again, through the building of Western cities. Naipaul even hints directly at Modernist architecture by referencing the new materials of glass and concrete that it readily used. While leaders of the newly independent African nations were seeking to make their presence known on the international front, the novel describes the new buildings as disingenuous, not accurately representing "real Africa", nor the "difficult Africa of bush and villages". ${ }^{55}$ The satirical lines might speak to a body of Africans who were not willing to abruptly let go of traditional ways of living. Like the protagonist of Naipaul's book, perhaps they too saw the new buildings as alien, disregarding true African traditions. Though many independence leaders of African states championed African modernism, one can imagine a feeling of dismay by many commoners as they watched traditional ways of building disappear. V.S. Naipaul's observations illustrate the primary argument that Professor Buccellato expressed in her "Exploring Vernacular East African Architecture": 
"Another, perhaps more established trend in African development is the elevation of non-African architecture above vernacular tradition. Formal architectural expression in Africa has long been influenced by European architecture much in the same way Africans were compelled to adopt European languages, governing systems, and aspects of European culture during colonization. African cities existed and thrived before colonial rule, but not in the way that Europeans defined cities." 56

- Aimee Buccellato

Assistant Professor of Architecture at the University of Notre Dame

Architectural Modernism's mandate to jettison historical tradition meant that indigenous African ways of building, already subverted by the colonial regimes, were only further reinforced as "backward" when the popularity of Modernism grew with city builders. William Curtis writes,

"Even if there had been architects keen on interpreting national traditions, they would have had difficulty finding relevant local precedent for such functions"

- William J.R. Curtis

Architectural Historian and author of Modern Architecture since 1900

Traditional buildings that supported functions similar to those of new developments may have been scarce, however, many contemporary African architects such as Diébédo Francis Kéré and Hassan Fathy have successfully set pioneering precedents where traditional ways of building have been completely reimagined to support entirely new functions. In Kéré's case, this was done without local precedent in the town of Gando. The architectural biases perpetuated by Modernism in the post-colonial era must be recognized to explain some of the reasons why local traditional buildings were infrequently investigated by the vanguard of the formal architectural community. In the context of the widespread affinity for forward-looking Modernist Architecture by city builders, were traditional African buildings even deemed worthy of the title of "architectural precedent"? Certainly, by virtue of their architectural approaches, Kéré and Fathy would hesitate to cite Curtis' statement as a sufficient reason for the evasion of African indigenous ways of building by the formal architectural community. Commonly perceived to be an inviable source of knowledge, traditional building consequently remained in a relative state of creative stasis in relationship to professional community. It is important to note that other than a few exceptions such as the Tropical Architecture School in Nigeria and the University of Kumasi Architecture School in Ghana, ${ }^{57}$ the minimal presence of formal architecture schools in the continent could be another reason for infrequent investigations in local methods.

Whether it is Fry's illustration showing the juxtaposition of his Modern building with the African schoolgirl or the astonished reaction of Naipaul's story protagonist, a tension between modernity and tradition is indeed evident in the architecture of the post-colonial era, one that, in general, was arguably not well balanced in African Modernist architecture. Though there are wonderful exceptions, as a general movement, the style spoke too dominantly of a new "universal future" that was perhaps not inspired enough by a "local past". Modernism may therefore not have been an optimal building style for nations seeking to solidify their distinctive national identities. For the want of competing on the international front, African Architectural Modernism instead helped to solidify a one-sided definition of what it meant to be "modern" in the $20^{\text {th }}$ century. As a result, through the post-colonial era, the notion of "Western" continued to become generally synonymous with "progress"; ergo, the notion of "traditional" or "African" became associated with "backwardness", despite the fact that the "Western", like the transplanted forms 
today, often resulted in buildings that were poorly integrated into local context. ${ }^{58}$ What was once described by Walter Gropius as "a uniformity of character" 59 for Modern architecture might also be seen in many parts of Africa today as simply "transplanted"; too dominantly inspired by audacious technological prowess with a tendency to forget the regional nuances of climate, culture, social stratification, and other forces that are distinctly "local". Biases and architectural stereotypes throughout the post-colonial era significantly contributed to a polarization of architecture between "transplanted" and the "traditional".

\subsubsection{Architectural Stereotypes: The Three Generations of Transplants}

Just as the post-colonial era can be viewed as neo-colonial reshuffling of foreign power systems over African states, the Modernist style gained a certain hegemonic control over African building activity, not dissimilar from the way earlier colonial architecture manifested mighty European imperial power through built form. The difference at this time was that imported styles of architecture were often willfully selected by new African leaders instead of being imported by European colonialists.

Perhaps the first mass influx of transplanted architecture from the West can be attributed to Africa's colonization. Likewise, African Modernism can be seen as part of a second wave of cultural transmission from the West; a transplanted architecture of the neo-colonial era that paved the way for the third "evolutionary state" of transplanted architecture, that of the present day.

Today, this legacy is unmistakeable. When examining the evolution of African architecture over the last century, it is often difficult to draw deep relationships between the contemporary transplanted and pre-colonial buildings, namely when analyzing their design and construction processes, as well as their resulting architectural expressions. Modernity today is still strongly defined by the West, contributing to the widespread adoption of transplanted forms, illustrated by the four recent projects in Nairobi in section 1.2.2. Consequently, local prestige associated with African traditional buildings continues to trickle away. Regrettably, in general, indigenous building tradition continues to play a nugatory role in the mass of contemporary building development.

\subsection{Chrysalis: A Metamorphosis of African Vernacular Architecture}

\subsubsection{Harmonizing Tradition and Modernity: Inspired by the Vernacular}

As recognized by Buccellato and others ${ }^{60}$, the historical subversion of local culture during colonialism has powerfully shaped the evolution of contemporary African architecture. Moreover, current architectural practices in Africa deviate from the cultural reconstruction envisioned by the African independence leaders. Thiong'o once passionately advocated for a return to indigenous knowledge in order to protect indigenous cultural identity, evidenced by his strong desire to write and publish in his traditional tribal language of Gĩkũyũ. ${ }^{61}$ Is a parallel exploration into Africa's diverse building traditions necessary to combat today's "global pandemic of generic buildings"? ${ }^{62}$ As demonstrated by this introduction, the crudeness of the manner in which much of contemporary African architecture responds to contextual specificities demands an affirmative answer to this question. Recalling Patrice Lumumba's will, cited at the beginning of this chapter, "The day will come when history will speak... Africa will write its own history" ${ }^{63}$. If history is truly allowed to speak, perhaps universalized building transplants shouldn't be the archetype of common practice in $21^{\text {st }}$ century contemporary African architecture. In the spirit of Lumumba's sentiment, it can be stated that these transplants do not tell the story of Africa because they are not properly authored by Africa. Perhaps a new architectural narrative needs to be told in an African vernacular. 
Amy Buccellato's previously cited "Exploring Vernacular East African Architecture" concludes the debut of the problem of Africa's transplanted architecture in this chapter and introduces "vernacular architecture", the local building traditions of the commoner that have historically existed outside the realm of professional architecture practice and that serve as the specific theoretical architectural discourse that informs this thesis investigation. As will further be described in Chapter 2, vernacular architectural principles have long played a peripheral role in professional practice despite numerous theoretical vernacular architecture contributions to the discourse in recent decades. Due to the rapid building development that the continent will see in the near future, like Thiong'o's return to traditional language, an appropriate look at the diversity and utter regional specificity of African vernacular architecture is necessary to inspire new contextually-sensitive building approaches. However, for fear of being driven by idealism and nostalgia, a return to historical tradition can be a precarious path for an architect to walk. Even award winning architects such as Egypt's Hassan Fathy have been criticised for a supposed glorification of the past, despite the immense impact of his Vernacular-inspired mud Architecture in Egypt ${ }^{64}$. It is therefore imperative to differentiate between "tradition" and "traditionalism" as described in Pelikan's The Vindication of Tradition:

"Tradition is the living faith of the dead, traditionalism is the dead faith of the living. And, I suppose I should add, it is traditionalism that gives tradition such a bad name."65

- Jaroslav Pelikan

Professor of the history and theology of Christianity at Yale University

More recently, a variety of Vernacular-inspired contemporary buildings have begun to stimulate interesting conversations within the international architectural community. Many architects such as Diébédo Francis Kéré and Kunlé Adeyemi who effectively navigate between vernacular tradition and modernity in the African context have also been recognized by the Aga Khan Award for Architecture, in large part for their locally-sensitive, traditioninspired, forward-looking buildings. Conceived in the late 1970s, the Aga Khan Award for Architecture was founded to identify exceptional examples of building solutions in Muslim societies. The following extract from a 1989 speech by the Award's founder might be seen as an architectural elaboration of Pelikan's sentiment.

"Firmly anchored in the present, the best architectural efforts are those that dare to innovate, to start from what we have, and actively invent the future in practical, empowering terms, thereby creating a heritage for the future. Invariably, such efforts do not copy the past, or import solutions developed for other problems and other cultures. What the Muslim world needs today, I suggest, is more of those innovative architects that can navigate between the twin dangers of slavishly copying the architecture of the past and of foolishly ignoring its rich legacy. It needs those who can thoroughly internalise the collective wisdom of bygone generations, the eternal Message and ethic with which we live, and then reinforce them in the language of tomorrow."66

- His Highness the Aga Khan

Chairman and founder of both the Aga Khan Development Network (AKDN) and the Aga Khan Award for Architecture (AKAA) 
The sentiment expressed by His Highness the Aga Khan with regard to the context of the Muslim world then guides the theoretical framework of this thesis in the African context: unlike many transplants seen across Africa, notions of tradition and modernity must harmoniously co-exist in contemporary architectural solutions. The Aga Khan's speech brings to mind Janus, the Roman god of transitions, beginnings, and ends, seen in figure 1.3-a. As the twoheaded god who has one visage looking towards the future and the other towards the past, Janus is an appropriate symbol for an architect's requisite dual-vision emphasized by the Aga Khan.

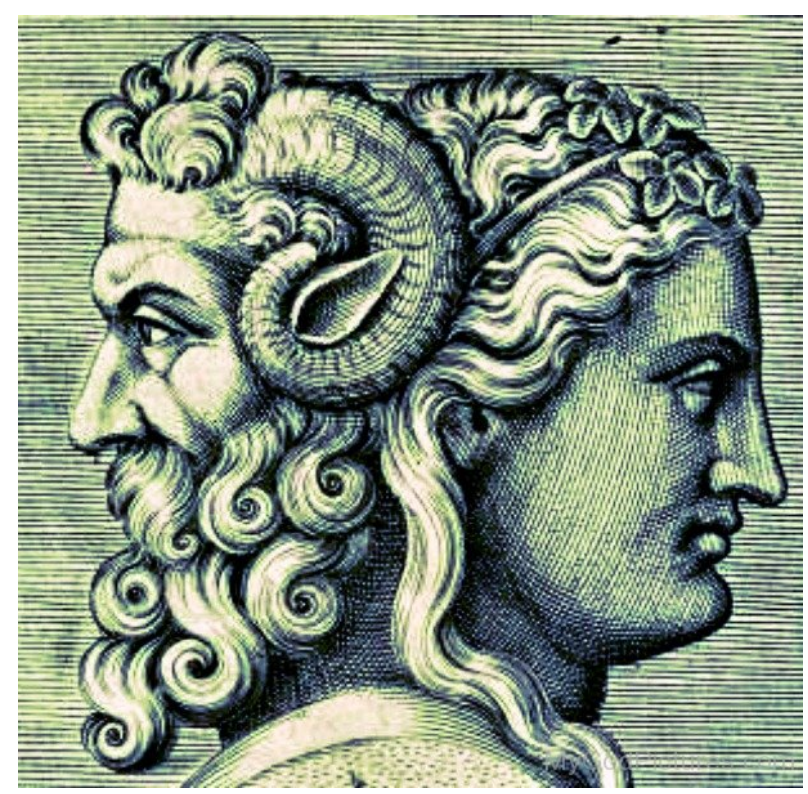

1.14 - Janus: Roman God of Transitions - Image retrieved from "http://gnosticwarrior.com/january-god-janus.html"

Contemporary transplanted architecture in Africa rarely speaks of the rich legacies of African building traditions. On the other hand, parroting traditional buildings of the past will yield an anachronistic architecture with an impaired ability to meet the needs of the present. Just as a butterfly bears little resemblance to a caterpillar, the future doesn't have to imitate or "look like" the past, but it can be deeply informed by it. However, between the two lies the rarely noticed transition point where the past and future intersect, the "chrysalis".

In response to increasing polarization between vernacular buildings and contemporary transplanted architecture in the African context, this thesis employs "Chrysalis" as a conceptual symbol to reinterpret African vernacular building traditions for the present day context. Building traditions of collective construction and culturally embedded communal space that are frequently seen in many examples of African vernacular architecture are analyzed and reimagined in the following chapters, to determine how collectively built shared spaces can foster a contemporary community architectural expression.

Entitled Chrysalis, this thesis specifically explores the architecture of a Maasai community in southwestern Kenya as a case study, where new transplanted buildings are "callous" toward local contextual variables, placing them at extreme odds with Maasai vernacular architecture. 
By harmonizing the rich Maasai tradition with best practices of the formal architectural discourse, this thesis reconciles the polarized themes of tradition and modernity in the design of a Maasai cultural center, thereby demonstrating how a vernacular-inspired, contextually sensitized architectural response can act as a development catalyst for other rural African communities. Through this Chrysalis, a metamorphosis of African vernacular architecture begins.

\subsection{Thesis Structure}

Harnessing this theme of metamorphosis, this thesis draws inspiration from the lifecycle of a butterfly for its overarching organization and is divided into three conceptual stages as illustrated in the following diagram. This organisation is used in the formation of the thesis argument and is subsequently used to organize the five key chapters of this book as follows.

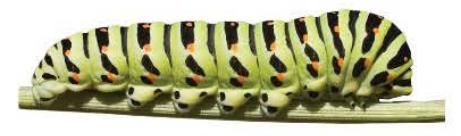

Vernacular Building Heritage

Time

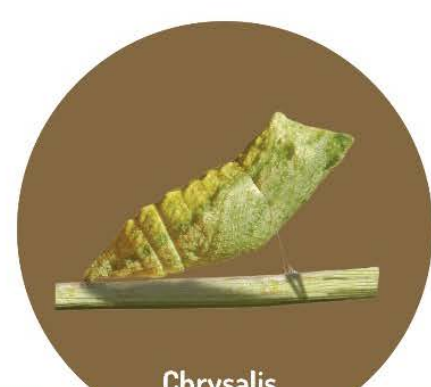

Chrysalis

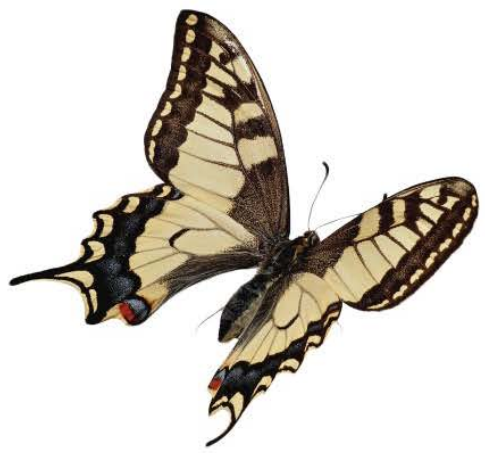

Contemporary Architecture Strategies

\subsection{5 - Thesis Structure}

\subsubsection{Stage 1 - Caterpillar}

Chapter 2 - Caterpillar - Learning from the Vernacular will begin by analyzing the texts of notable vernacular academics to understand the evolution of the discourse and its key messages, namely how they might be relevant to contemporary practice in Africa. This section is titled Caterpillar to illustrate the potential that vernacular building has to transform into new, currently relevant, architectural language.

\subsubsection{Stage 2 - Chrysalis}

Chapters 3 and 4, are titled, Chrysalis: Culturally-Embedded Boma (Compound) Space, and Chrysalis: User Participatory Construction, respectively. These chapters constitute the main areas of research for this thesis. They analyze the common presence of these ideas in vernacular architecture as well as some additional examples in contemporary architecture. These "Chrysalis" chapters act as a theoretical nexus where the ideas identified from the vernacular building heritage are melded with best practices of the formal discourse and then reimaged into architectural strategies for contemporary practice in Africa. 


\subsubsection{Stage 3 - Butterfly}

Chapter 5 is entitled Butterfly: Netii Apa: Maasai Cultural Center. In this chapter, the reinterpreted ideas from the vernacular heritage are applied in the cultural center's design for a Maasai community located in Maasai Mara in southwestern Kenya. This design project seeks to illustrate how and why these notions should be considered by contemporary architects thereby easing the polarization between the "backwards" vernacular and the increasingly ubiquitous 'transplanted' models of architecture described in this introduction.

\subsubsection{Chrysalis: An African Vernacular Architecture Metamorphosis}

The lifecycle of the butterfly then offers a multifaceted symbol of 'transformation' where Chrysalis becomes the locus of creativity, the nexus where past tradition and the innovation necessary for the future intersect. 


\subsection{Chapter 1 Endnotes}

${ }^{5}$ Hilke Fischer, "130 Years Ago: Carving up Africa in Berlin," Deutsche Welle, http://www.dw.com/en/130-years-agocarving-up-africa-in-berlin/a-18278894.

${ }^{6}$ Ibid.

7 Ibid.

8 The quotation is an excerpt of William Butler Yeats' 1919 poem entitled The Second Coming which prefaces Achebe's book Things Fall Apart, Chinua Achebe and Uche Okeke, Things Fall Apart (London: Heinemann Educational Books Ltd, 1985), v.

9 Patrice Lumumba; the Truth About a Monstrous Crime of the Colonialists, Patrice Lumumba's Will (Moscow: Foreign Languages Publishing House, 1961), 231.

${ }^{10}$ Oliver Lovesey, Approaches to Teaching the Works of NgũGĩ Wa Thiong'o, Approaches to Teaching World Literature, (New York: Modern Language Association of America, 2012), 11.

11 John D. Hargreaves, "Cultural Decolonisation: Unesco and Africa," History Today 36

no. 3 (1986), http://www.historytoday.com/john-d-hargreaves/cultural-decolonisation-unesco-africa.

12 "African Holocaust," African Code, http://www.africanholocaust.net/peopleofafrica.htm.

13 The following publications speak to the close association of Western building models with modernity. Aimee Buccellato and Megan Reineccius, "Exploring Vernacular East African Architecture: Lessons for the Modern World" (paper presented at the Subtropical Cities 2013: Braving A New World: Design Interventions for Changing Climates, Florida, United States of America, 2013), 56. Robert Wambugu Rukwaro and Sylvester J. M. Maina, Transformation of Maasai Art and Architecture (Nairobi: ARTS Press, 2006), 148.

${ }^{14}$ The following publications speak to perception of western architecture as "disingenuous" to African tradition, Jean-Paul Bourdier and T. Minh-Ha Trinh, Vernacular Architecture of West Africa: A World in Dwelling (Abingdon, Oxon England;

New York: Routledge, 2011), 7. Fathy's viewpoint may be described as a more traditional one on this spectrum. He writes, referring to traditional Egyptian architecture, "It was like a vision of architecture before the Fall: before money, industry, greed, and snobbery had severed architecture from its true roots in nature." Hassan Fathy, Architecture for the Poor: An Experiment in Rural Egypt (Chicago, USA: University of Chicago Press, 1973), 7.

${ }^{15}$ Buccellato and Reineccius, "Exploring Vernacular East African Architecture: Lessons for the Modern World". 16 Ibid.

17 William J. R. Curtis, Modern Architecture since 1900, 3rd ed. (London: Phaidon Press Limited, 1996), $567-68$.

18 "'Notopia Is Less a Warning Than a Prophecy of Doom'," The Architectural Review (2016).

19 Buccellato and Reineccius, "Exploring Vernacular East African Architecture: Lessons for the Modern World", 57.

20 This is evidenced by the jury citation as follows: "All their works have a strong sense of place and are powerfully connected to the surrounding landscape. This connection comes from understanding - history, the natural topography, customs and cultures, among other things - and observing and experiencing light, shade, colors and the seasons. The siting of buildings, the choice of materials and the geometries used are always intended to highlight the natural conditions and pull them into the building." "The Pritzker Architecture Prize," The Hyatt Foundation, http://www.pritzkerprize.com/2017/jury-citation.

${ }^{21}$ Pollio Vitruvius and Thomas Gordon Smith, Vitruvius on Architecture (New York: The Monacelli Press, 2003), $185-86$.

22 The apartments are located in the Soweto East neighborhood of Kibera slums in Nairobi, Kenya.

${ }^{23}$ Abby Higgins, 2013, https://www.one.org/international/blog/why-residents-of-kibera-slum-are-rejecting-new-housingplans/.

24 "The affirmation of the concept of identity is today a principle of fundamental importance for steering innovative policies of urban development, geared towards the quality of living conditions" Cesare Sposito, "Identity, Flexibility and Sustainability for the New Social Housing," Techne : Journal of Technology for Architecture and Environment (2012).

${ }^{25}$ Buccellato and Reineccius, "Exploring Vernacular East African Architecture: Lessons for the Modern World", 57.

${ }^{26}$ The population of Kibera slums is disputed depending on what areas are included within Kibera's territory. Population statistics have been retrieved from what the author has considered to be the most reliable source "'Population and 
Health Dynamics In Nairobi's Informal Settlements ", in Report of the Nairobi Cross-sectional Slums Survey(NCSS) (Nairobi: African Population and Health Research Center (APHRC), 2014), xvii."

${ }^{27}$ Raakel Syrjänen and UN-HABITAT KENSUP Team, "Un-Habitat and the Kenya Slum Upgrading Programme: Strategy Document," ed. Tom Osanjo (2008).

28 Journalist Abby Higgins continues to paraphrase comments made my Kibera resident Mildred Lulani from an interview:

"While she doesn't miss the housing, she does miss that part of life in Kibera. She's lived in her new housing for three years and doesn't know any of her neighbors. High crime rates, the lack of sanitation and the poor housing are a constant struggle for Kibera residents. But Lunani's experience points to the intangible value of the community in the slum. The social networks, the business, the employment opportunities and the low cost of living attracts new residents, despite the harsh circumstances" Beyond any architectural design shortcomings, this second quote speaks to the nature of the poorly run housing scheme. Both the previous in-text excerpt as well as the latter quote have been retrieved from "Higgins."

${ }^{29}$ Njeri writes on contemporary buildings in Nairobi, "These buildings are characterised with their extensive use of glass on their facades, the sealing off of the building from its surroundings creating an artificial environment within the building which is mechanically controlled and fully air-conditioned to archive thermal comfort requiring additional energy to operate them, examples include Lonrho Africa, I\&M building ... , view park towers ... among others. The higher energy consumption leads to higher emissions of carbon dioxide to the atmosphere contributing directly towards global warming and climate change." Mwangi Mercy Njeri, "Transformation of Nairobi Post-Independence Architecture: Climate Responsive Architecture" (University of Nairobi, 2002), xiv-5.

${ }^{30}$ An example of this notion will be provided in section 1.2.6 using the Kenyatta International Conference Center

${ }^{31}$ According to the World Bank, half of all people living below the poverty line live in sub-Saharan Africa ""Poverty," World Bank, http://www.worldbank.org/en/topic/poverty/overview."

${ }^{32}$ Buccellato and Reineccius, "Exploring Vernacular East African Architecture: Lessons for the Modern World", 57.

${ }^{33}$ Curtis, Modern Architecture since 1900, 7.

${ }^{34}$ This collage has been created using, Ibid.

35 Ibid., 11.

${ }^{36}$ Walter Gropius, Internationale Architektur, trans. Kenneth W. Kaiser, BauhausbüCher, L (München,: A. Langen, 1925).

${ }^{37}$ Curtis, Modern Architecture since 1900, 11.

${ }^{38}$ The well-known Critical Regionalism movement is an example of a regionalist reaction to universality that is frequently attributed to Architectural Modernism

${ }^{39}$ Curtis, Modern Architecture since 1900, 13.

${ }^{40}$ Katherine G. Bristol, "The Pruitt-Igoe Myth," Journal of Architectural Education 44, no. 3 (1991): 163.

${ }^{41} \mathrm{lbid}$.

${ }^{42}$ Ramon Grosfoguel, "The Epistemic Decolonial Turn " Cultural Studies 21, no. 2 (2007).

${ }^{43}$ Manuel Herz et al., African Modernism: The Architecture of Independence: Ghana, Senegal, CôTe D'ivoire, Kenya, Zambia (Zurich, Switzerland: Park Books, 2015).

${ }^{44}$ Information retrieved from a recent Architectural Review article that recalled Fry's Drew's work in West Africa and also sourced a second Architectural Review article on the architects work from 1953. The illustration with the girl is by Gordon Cullen from the new 2014 article. It is as follows "lain Jackson, "Tropical Modernism: Fry and Drew's African Experiment," Architectural Review (2014), https://www.architectural-review.com/rethink/tropical-modernism-fry-anddrews-african-experiment/8665223.article?search=https\%3a\%2f\%2fwww.architectural-

review.com\%2fsearcharticles\%3fqsearch\%3d1\%26keywords\%3dTropical+Modernism\%3a+Fry+and+Drew\%27s+African+E xperiment."

${ }^{45}$ Uduku writes "Thus when the architect Maxwell Fry, who had already spent part of his national service in the Gold Coast, was unable to secure employment in the United Kingdom he was suggested that he should consider working in the colonies. His initial appointment in Ghana as the planning advisor to the colonial office in Accra, can be seen as a key starting point of the era of tropical architecture in West Africa." Ola Uduko, "Modernist Architecture and 'the Tropical' in West Africa: The T Ropical Architecture Movement in West Africa, 1948-1970," Habitat International 30 (2006): 398.

${ }^{46}$ Jackson, "Tropical Modernism: Fry and Drew's African Experiment."

${ }^{47}$ Herz et al., African Modernism: The Architecture of Independence: Ghana, Senegal, CôTe D'ivoire, Kenya, Zambia.

${ }^{48} \mathrm{lbid}$.

49 Ibid., 432.

${ }^{50}$ Two sources were consulted on KICC which both cited Kard \$1enrik Nøstvik as the architect. They also refer to a local architect named Henry David Mutiso, the head architect of the Ministry of Public Works who was initially tasked with 
proposing the design for KICC but which was rejected by President Jomo Kenyatta. Though Mutiso recommended Nøstvik to design of the existing KICC building, it is unclear whether Mutiso also worked collaboratively with Nøstvikn on this second proposal. Both sources consulted are as follows: Ibid., Yuko Iwatani and Evelyne Wanjiku, A Brief Tour of the Buildings of Nairobi, 1st ed. (Nairobi, Kenya: Yuko Iwatani, United Nations Office Nairobi (UNON), 2010$), 19$.

51 It appears that KICC was Nøstvik's first building in Kenya.

52 Herz et al., African Modernism: The Architecture of Independence: Ghana, Senegal, CôTe D'ivoire, Kenya, Zambia, 11; Udo Kultermann, New Architecture in Africa (London: Thames and Hudson, 1963).

Kultermann, New Architecture in Africa, 8.

${ }^{53}$ Uduku describes the close affiliation between the AA and the Tropical Modernism [the label for modernist architecture movement in Africa] movement. He describes the role of the AA as follows: "The Architectural Association (AA) by virtue of its location in central London and its international connections, had students and tutors who were at the forefront of the [Tropical Modernism] movement." Uduko also states that, "Many of the AA students at the time also found themselves billeted to tropical regions as research officers or part of the engineering corps as part of their time spent after graduation on national service". Uduko, "Modernist Architecture and 'the Tropical' in West Africa: The T Ropical Architecture Movement in West Africa, 1948-1970," 398.

54 V. S. Naipaul, A Bend in the River, 1st ed. (New York: Knopf Inc., 1979), 78.

55 Ibid.

56 Buccellato and Reineccius, "Exploring Vernacular East African Architecture: Lessons for the Modern World", 56.

57 Uduko, "Modernist Architecture and 'the Tropical' in West Africa: The T Ropical Architecture Movement in West Africa, 1948-1970," 400.

${ }^{58}$ Curtis, Modern Architecture since 1900, 567-68.

${ }^{59}$ Gropius, Internationale Architektur.

60 See bibliography for the work of Robert Rukwaro.

61 "I believe that my writing in Gĩkũyũ language, a Kenyan language, an African language, is part and parcel of the antiimperialist struggles of Kenyan and African peoples... I want (Kenyans) to transcend colonial alienation... We African writers are bound by our calling to do for our languages what Spencer, Milton and Shakespeare did for English; what Pushkin and Tolstoy did for Russian; indeed what all writers in world history have done for their languages by meeting the challenge of creating a literature in them, which process later opens the languages for philosophy, science, technology and all other areas of human creative endeavors. "Retrieved from Ngũgi wa Thiong'o, Decolonising the Mind: The Politics of Language in African Literature (London, Portsmouth, N.H.: J. Currey; Heinemann, 1986), text, 28.

62 "'Notopia Is Less a Warning Than a Prophecy of Doom'."

63 Patrice Lumumba; the Truth About a Monstrous Crime of the Colonialists, 231.

${ }^{64}$ Curtis, Modern Architecture since 1900, 569.

65 Jaroslav Pelikan, The Vindication of Tradition, The 1983 Jefferson Lecture in the Humanities (New Haven: Yale University Press, 1984), 65.

${ }^{66}$ His Highness the Aga Khan, "Aga Khan Award for Architecture Ceremony, Cairo," Aga Khan Foundation. 


\section{Caterpillar: Learning from the Vernacular \\ "maybe you are searching among the branches for what only appears in the roots"67}

- Jalāl ad-Dīn Muhammad Rūmī,

13th-century Persian Poet, Jurist and Theologian

\subsection{Embracing New Knowledge}

Like the roots of a tree hidden beneath the surface of the ground, the discourse of vernacular architecture is a body of knowledge that has been historically been shrouded from the formal realm of professional architecture. Just as discussed in Chapter I, vernacular architecture and traditional architecture have often been deemed "old", or "backwards", and even sometimes unworthy of architectural study. Even less investigation has been undertaken of subset of traditional architecture which grapples with the African context.

Seminal texts such as A History of Architecture by Spiro Kostof and a World History of Architecture by Michael Fazio reflect how sparse knowledge on African architecture is. Fazio describes the African architecture section of his influential book;

"... a recognition that what follows is unfortunately brief, given that the African continent includes several dozen countries with widely varying climatic conditions, vegetation, and building materials, and that many of them have a radically different cultures. ${ }^{168}$

"Where [Africa's] architecture has been closely studied, the work is most often been done by anthropologists and not architectural historians and so is probably most familiar to the public through the pages of such publications as National Geographic Magazine, and while African art became extremely influential in Europe and America in the early twentieth century, African architecture has not achieved such prominence..." 69

- Michael Fazio

Emeritus Professor of Architecture at Mississippi State University

As illustrated by Fazio, this vacuum of knowledge that has historically been present in the architectural discourse is perhaps reflective, if not contributive to the rare utilization of local building traditions in contemporary African architecture. Intellectual voids such as those within Fazio's history text are examples of the limitation of resources on traditional buildings for architects practicing in the African context. Today, the spread of transplanted forms across the continent stands a poor chance of being remedied if sufficient knowledge on alternative, traditionallyinspired approaches of building is relatively difficult to obtain.

As Chapter 1 described, the negative perception of vernacular forms is a formidable hurdle to cross, but nonetheless, an absolutely necessary task. These biases are also exacerbated by more antiquated definitions of the role of the architect; that of the architecture professional as a singular master-builder and all powerful polymath. This romanticised image of the architect's role prohibit the discourse from learning from ways of building that draw upon the "collective wisdom of bygone generations" ${ }^{70}$ This image can sometimes undermine ideas of collaboration, cross-disciplinary intellectual exchange and especially collective building. The latter idea has historically been off the radar of mainstream discourse and ongoing efforts to embrace them must be bolstered. Consequently, the discourse may in turn continue to uncover a newfound capability to shape how the future of African architecture and urbanity will unfold. This is a particularly critical notion for the diverse continent of over 1 billion people that 
will battle an array of social challenges in tandem with some of the highest rates of urbanization between now and 2050. ${ }^{71}$ Academic scholarship in this area may therefore combat the negative biases around traditional architecture by facilitating the creation of vernacular-inspired contemporary forms which could serve as tangible built examples that redefine these architectural stereotypes to the broader public. In addition to historical and artefactual research approaches to traditional structures, built architectonic investigations may bring the building knowledge of the past to life today.

Only until relatively recently, towards the later decades of the $20^{\text {th }}$ century, have efforts to repair this this intellectual void been attempted. Many of these efforts are commendable. In particular, the lifetime efforts of the scholar Paul Oliver are worthy of our highest appreciation. However, as seen in the traditional architecture of the Maasai peoples which this thesis investigates as a case study, there are many vernacular knowledge gaps that still await study.

\subsubsection{Structure of Chapter 2}

Having been acquainted with the intellectual gaps that have historically existed on this topic of African traditional architecture, the remainder of this chapter will establish a foundation in vernacular architecture for the reader.

Section 2.2 will first reassert the need to investigate African vernacular and traditional buildings by providing an overview of some of the continents general developmental challenges. Section 2.3 will then proceed into a literature review of the most critical vernacular architecture scholarship that has influenced this thesis. Section 2.4 outlines the terminology and definitions of vernacular architecture, those that have been used in vernacular architecture scholarship as well as how they have informed a definition for this thesis. For both the experienced architect as well as the layperson, the definitions covered in this section constitute the theoretical heart of this chapter. In addition to Kere and Fathy who were introduced in Chapter 1, a few influential vernacular-inspired contemporary architects will be introduced in Section 2.5, many who have been particularly inspirational for this thesis. Lastly, section 2.6 , section 2.7 and section 2.8 respectively outline the research methodology for this thesis, its primary research questions, as well as the formatting of this document.

\subsection{Africa on the Precipice of Rapid Transformation}

In general, Africa is faced with several critical developmental challenges including high rates of urbanization, large population growth, and array of social obstacles. Joan Clos, under-secretary general of the United Nations writes the following:

"The overarching challenge for Africa in the decades to come is massive population growth in a context of widespread poverty that, in combination, generate complex and interrelated threats to the human habitat." 72

This is a sentiment shared by Aimee Buccellato in her aforementioned article Exploring Vernacular East African Architecture;

"Predictably, rapid urbanization as a result of globalization has created a host of new development challenges for Africans, including pressures on the environment, existing infrastructure and urban 


\section{building stock and a shortage of both time and adequate building materials to construct new}

housing and services." 73

Aimee Buccellato

Assistant Professor of Architecture at the University of Notre Dame

These quotations highlight the challenges that lie ahead of Africa's forthcoming development. The current trend of transplanted forms, which are largely contextually callous, is certainly not appropriate when considering the difficult developmental challenges ahead. The architecture for Africa's near future should be financially and environmentally sustainable, culturally appropriate, and sensitive to the public domain. More importantly these notions need to manifest themselves in common practice instead of only in sporadic projects, which is certainly a large challenge. The widespread poverty across sub-Saharan Africa also suggests that the often contextually insensitive transplanted breed of buildings can give way to a new paradigm of architecture. This next section will take a closer look at population growth, one of the most powerful developmental forces that the continent has already begun experiencing.

\subsubsection{Population Growth}

"Africa has the highest rate of population growth among major areas, growing at a pace of 2.55 per cent annually in 2010-2015. Consequently, of the additional 2.4 billion people projected to be added to the global population between 2015 and 2050, 1.3 billion will be added in Africa," more than half of the projected global population growth. ${ }^{74}$

"Regardless of the uncertainty surrounding future trends in fertility in Africa, the large number of young people currently on the continent who will reach adulthood in the coming years and have children of their own, ensures that the region will play a central role in shaping the size and distribution of the world's population over the coming decades." 75

- $\quad$ - United Nation World Urbanization Prospects

Just as the 'baby boomer' generation transformed culture, societies, and economies in post-war North America and Europe, the anticipated population boom in Africa will be a great transformational force for the continent in the near future. Though Africa is certain to face many of its own unique challenges, lessons may be extrapolated from historical architectural responses to the demographical, cultural and economic forces of the post-World War II era. In the context of these challenges, this thesis provides a way forward. This thesis recognizes how vernacular forms are so specifically culturally and environmentally intertwined, and in particular, the manner in which contextual forces that have been synthesized over time to make the vernacular forms so regionally distinct and appropriate. 


\subsection{Critical Vernacular Architecture Scholarship}

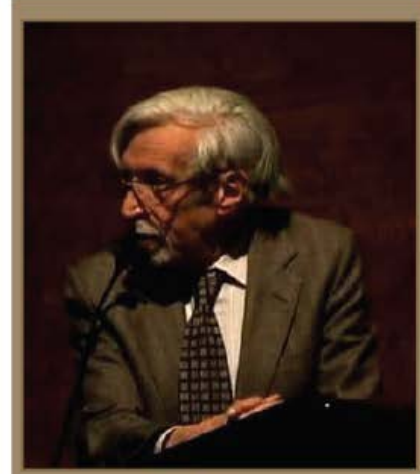

Paul Oliver

Vernacular Architecture

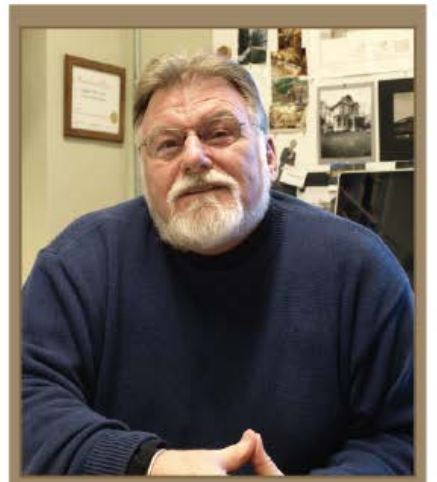

Dr. Kingston Heath

Contemporary Vernacular

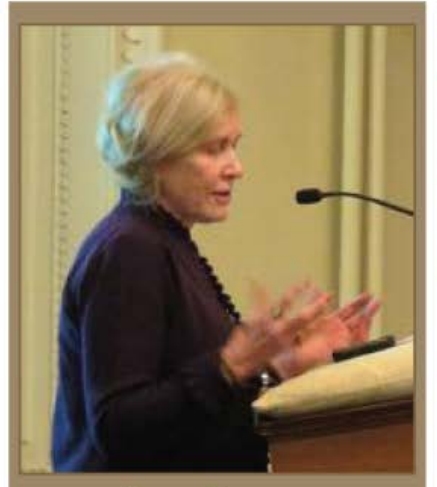

Susan Denyer African Vernacular Architecture

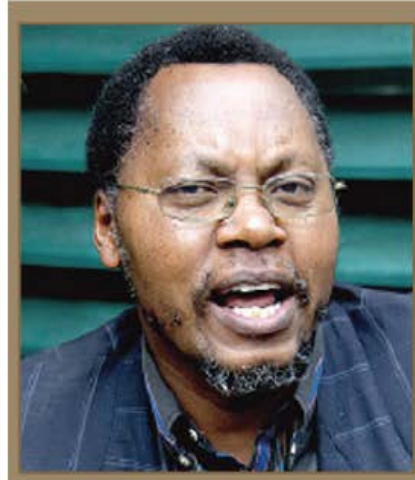

Dr. Robert Rukwaro Maasai Vernacular Architecture

\section{1 - Vernacular Architecture Scholars - Image by author}

The above vignette portrays four scholars in the field of vernacular architecture of particular interest. In this diagram, each author's photograph represents one of four general categorizations of vernacular research for this thesis, which will be explored as follows.

\subsubsection{Vernacular Architecture: The Buildings}

In the diagram, Paul Oliver's photograph represents the foundation of vernacular scholarship. His efforts were pioneering in that they brought vernacular architecture into the general architectural discourse for one of the first times. Prior to the 1990's vernacular architecture scholarship was relatively sparse. However, one of the first works was Bernard Rudofsky's Architecture without Architects ${ }^{76}$ which was published by the Museum of Modern Art in New York a few decades before Oliver began his work on the subject. Oliver's masterpiece was completed through a three part encyclopedia on vernacular architecture which asserted the vacuum of knowledge in the field in the 1990's. ${ }^{77}$ This encyclopedia was published in 1997, however the work began almost a decade in advance. His work is primary descriptive, documenting the vernacular structures through a variety of lenses from external environment, culture, symbolism, typologies, geographical location and much more. His photograph in the above diagram also represents the range of work that follows this descriptive, analytical approach of documenting vernacular forms.

Other sources that follow suit are as follows. The 2007 Atlas of Vernacular Architecture of the World ${ }^{78}$ also by Paul Oliver which draws relationships between vernacular architecture with their geographical positioning. Also in 2007 the book Traditional Buildings: A Global Survey of Structural Forms and Cultural Functions ${ }^{79}$ by Allen G. Noble also applies similar lenses as Oliver's to explore traditional dwellings. In 2010, John May published Handmade Houses and other Buildings: The World of Vernacular Architecture. ${ }^{80}$ This source also documents a range of vernacular buildings from across the world, providing a short summary of each building as well as orthographic and three dimensional drawings of each structure. The book also concludes with slum dwellings and informal settlements which are described as a "contemporary vernacular". May's source can best be described a handbook, providing a brief summary to a wide range of buildings. Lastly, also written by Allen G. Noble is the 2014 book entitled Vernacular Buildings: A Global Survey ${ }^{81}$ like his aforementioned work, provides a wide overview of vernacular 
buildings with a particular emphasis on the materials employed by these structures as well as their construction techniques. Thus concludes the section of works that are generally descriptive in nature. These sources provide a solid foundation on the vernacular buildings themselves. While many of the above sources include many theoretical discussions, at the heart of this general categorization is the buildings themselves as physical objects, and the complex forces that shape their making.

\subsubsection{Vernacular Architecture: Theory and Contemporary Practice}

The second categorization of scholarly vernacular works, represented in the diagram through Kingston Heath, perhaps has a more ambiguous definition. However this category might be described as a summation of theoretical works on the subject, combined with a few select texts that seek to abstract ideas present in the vernacular buildings for their application in contemporary practice. These sources differ from the previous categorization as the vernacular structures themselves do not play a central role in the literature as physical objects.

The first text within this categorization is that of Vicky Richardson entitled New Vernacular Architecture, published in 2001. ${ }^{82}$ This source describes contemporary approaches to vernacular design. The text begins by probing the notion of vernacular architecture as a supposed oxymoron, reflecting the notion of architecture created without architects and how that might be in contrast with the pre-meditated nature of an architecture operating in contemporary practice. Oliver also has published a more theoretical text entitled Built to Meet Needs: Cultural Issues in Vernacular Architecture. ${ }^{83}$ In this 2006 work, Oliver tackles the more theoretical notions surrounding vernacular architecture including transmission, tradition, culture, conservation and their application in the twentyfirst century. In 2006, Lindsay Asquith and Marcel Vellinga, the former who worked with Oliver on his encyclopaedias, published Vernacular Architecture in the Twenty-First Century. ${ }^{84}$ This work presents a series of essays by authors or practitioners in the field which tackle major theoretical issues in the application of vernacular architectural principles to modern day practice. Lastly Kingston Heath published Vernacular Architecture and Regional Design: Cultural Process and Environmental Response ${ }^{85}$ in 2009 where he draws relationships between vernacular traditions and contemporary regional design.

\subsubsection{African Vernacular Architecture}

This categorization unites the sources of vernacular architecture that are embedded in the African context. A particularly well-known source in this category is Hassan Fathy's, Architecture for the Poor republished in $1973^{86}$. This text was originally published in 1969 under the name, A Tale of Two Villages. The source describes in detail "Fathy's plan for building the village of New Gourna from mud bricks employing such traditional Egyptian architectural designs as enclosed courtyards and domed and vaulted roofing." This work is of paramount importance to the field, as Fathy was a pioneering practitioner in that he advocated for traditional building through his built works at a time when Architectural Modernism was nearly ubiquitous. Indigenous African Architecture ${ }^{87}$ by Rene Gardi is a 1973 pictorial guide to traditional buildings in West Africa. The work might be comparable to that of Denyer's thematically but with a special emphasis on West Africa. The work focuses on various cultural groups, types of vernacular forms and building materials. The 1997 publication by Nnamdi Elleh tackles a history of African

architecture and is not limited to the vernacular. Entitled African Architecture: Evolution and Transformation, ${ }^{88}$ this source is organized by global geographies and presents a comprehensive overview of African Architecture of the past. Susan Denyer's 1978 African Traditional Architecture ${ }^{89}$ might be likened to the early work of Oliver as well as 
those of May and Noble in that it is centered around the buildings themselves and less dominated by theoretical discussions. Denyer covers African vernacular styles, decoration, building materials, process, typology in both rural and urban contexts. Her work is particularly influential to this thesis. Vernacular Architecture of West Africa: A World in Dwelling ${ }^{90}$ is a fairly recent publication by Jean-Paul Bourdier and Trih T. Minh-ha. The 2011 book focuses on West African vernacular architecture and straddles the extremes of theoretical essays and more pragmatic analyses of buildings, the latter organized by cultural group.

\subsubsection{Maasai Vernacular Architecture}

This categorization brings together two sources that focus on the vernacular forms of the Maasai indigenous peoples of which this thesis investigates in detail. The book African Traditional Architecture ${ }^{91}$ by Kaj Blegvad Andersen is a survey of vernacular forms across the country of Kenya. Published in 1977, this source is of particular interest as it discusses the vernacular forms of the various tribes of Kenya including the Maasai. Lastly of central importance was the work of Dr. Robert Rukwaro and Sylvester Maina entitled Transformation of Maasai Art and

Architecture. ${ }^{92}$ Published in 2006, this work is an in-depth analysis of Maasai vernacular architecture with significant discussion around new Maasai architectural forms brought about by the forces of industrialization and westernization.

\subsection{Defining Vernacular}

The definition of vernacular architecture varies slightly from scholar to scholar and has acquired new meaning over time. This section will first begin by exploring the etymology of the term. A discussion will follow of the definition's key parameters as discussed by notable experts in the field, helping to finally inform a comprehensive definition that will be used in this thesis.

\subsubsection{Etymology of Vernacular}

The word vernacular is a word of Etruscan origin, derived from the Latin vernaculus which means "domestic, native, indigenous; pertaining to home-born slaves". "verna" means "home-born slave, native,". The word vernacular is usually used in English within the context of linguistics. As a noun it means "native speech or language of a place," and originates from $1706 .{ }^{93}$

\subsubsection{Vernacular in the Context of Architecture}

Just like "vernacular" refers to the "native" language of a place, vernacular architecture can be said to refer to the "native", home-born architecture of a place. This is the definition championed by vernacular scholar, Kingston Heath. This definition draws a strong connection between the architecture itself and the physical locale within which it is built. Therefore, the term vernacular architecture in the architectural discourse most often refers to traditional buildings which are regionally distinctive.

However, this notion may have been more relevant in the past when information can be seen as having closer association with physical locales. Newer works on the subject, notably of Nezar Al-Sayyed, recognize that information is less place-based today. He argues that the definition needs to change to respond to our Information Age. From his perspective, the increasing digitization of information can in a sense weaken the role of a singular physical locale on the on the building knowledge. This evidenced by the manner in which building knowledge, which was traditionally place-based and "stored" with the makers of vernacular buildings, is now increasingly available to 
scholars globally. However, one could argue that this knowledge exists in theoretical form until it is embodied in a tangible building. As many examples of vernacular architecture are highly regionally responsive, the utility of vernacular knowledge is then applicable to only very select contexts, continuing the paramount role of the locality on the particular building knowledge, namely because they are the sites where the ideas may be most appropriate.

To illustrate this notion, this thesis focuses on the vernacular architecture of the Maasai and recognizes that though information on Maasai construction techniques is today available across the globe, it obviously finds its particular utility in Maasai contexts today. Certainly Maasai living in the southwestern plains of Kenya have a certain pragmatic know-how of how to apply the knowledge of traditional construction techniques even though this knowledge is theoretically universally accessible. Furthermore, the specific use of building materials, such as earth, that are employed in the Maasai tradition must be of some architectural value in the specific locale as they are still readily used by Maasai. Therefore vernacular architecture at its essence retains a certain intimacy with the specificity of geographical location. However, the increasingly interconnected nature of communication opens up possibilities for a cross pollination of ideas, and vernacular building knowledge that has traditionally been created in a specific locale may find new utility in other locales across the globe. This is later evidenced by the introduction of bamboo construction techniques to the thesis design site in Kenya which have been drawn from the vernacular bamboo building traditions in Asia. From this perspective, the architect's role is then to synthesize this knowledge and determine new relationships between vernacular knowledge and their appropriate application in specific contexts.

\subsubsection{A Definition of Vernacular Architecture for Chrysalis}

Bernard Rudofsky's broad description of vernacular architecture as "architecture without architects" will be accepted as the departure point for the definition for this thesis. ${ }^{94}$ However, as illustrated below, after a survey of scholarly texts in the field, four primary points have been selected to comprise the term "vernacular architecture" for this thesis.

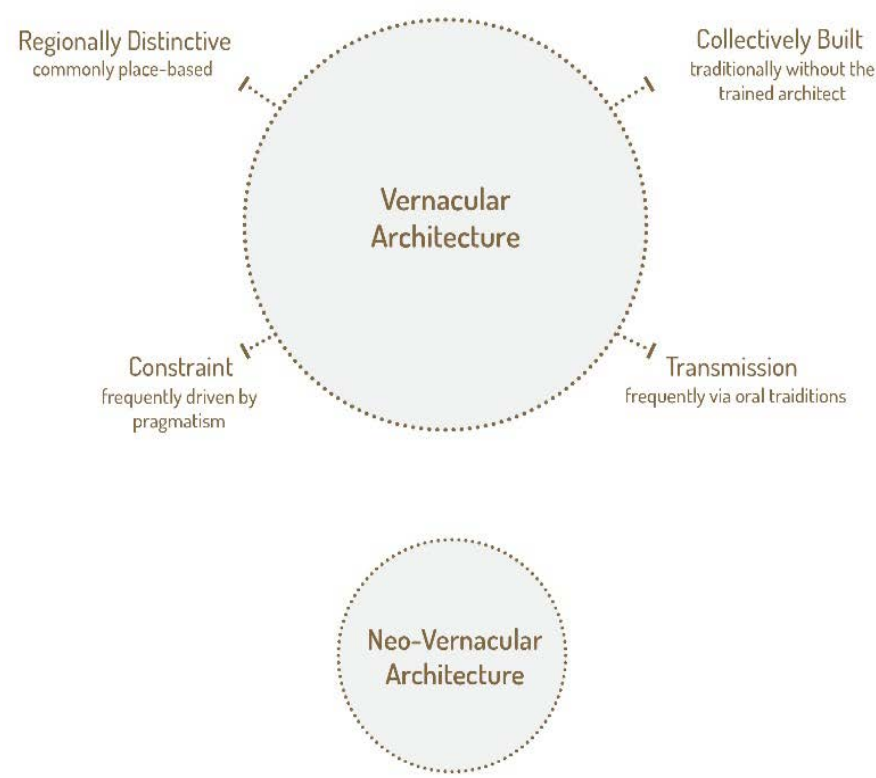

2.2 - Four Parameters of Vernacular Architecture - Image by Author 
Firstly, vernacular architecture is commonly regionally distinctive. As has already been described, it is commonly place-based, responding to site specificities of culture, environment, local materials and more. Secondly, it often collectively built by users and not with formally trained architects. Thirdly, vernacular architecture is often born from "constraint", driven by economies of efficient resource utility. This design is therefore pragmatic and derived though a "needs only" basis, using both materials that are readily available and efficient assembly techniques. Architecture of this nature is usually not superfluous. Lastly, construction knowledge is usually transferred from builder to builder through the act of making the building. Oral traditions are the medium in which the generation, storage, and transmission of these ideas exist. These four legs on which the definition of vernacular architecture stands can be understood as interrelated perceptual lenses, each playing varying roles from context to context.

Lastly, the above diagram identifies the term "neo-vernacular" which is advanced by the scholar Suha Ozkan to refer to contemporary interpretive approaches of vernacular architecture. This idea is of particular importance to this thesis as the term vernacular architecture has been defined in part as "buildings that are not produced by formally trained architects". Therefore, many contemporary architects who choose to study vernacular buildings to inform their contemporary projects can be labelled as neo-vernacular (the alternative being stylistic mimicry). This is the attitude toward the vernacular embraced by this thesis. Chrysalis seeks to reinterpret critical notions from the African vernacular for the present day without the stylistic mimicry or imitation.

\subsection{Prominent African Neo-Vernacular Architects}

\subsubsection{Hassan Fathy}

"He who finds a new path is a pathfinder, even if the trail has to be found again by others; and he who walks far ahead of his contemporaries is a leader, even though centuries pass before he is recognized as such."

The previous quotation by Ibn Khaldun is appropriate to introduce Hassan Fathy and his work. As a practitioner, Fathy was extremely influential in the field of vernacular architecture. His aforementioned book describes his work with mud-brick architecture in great detail. He is of particular importance particularly because of the time period within which he operated. He was well known for advancing vernacular techniques at a time when the International Style and Architectural Modernism were ubiquitous languages for architecture. Wakil describes this in the following:

"There has been, throughout history, a constant and inevitable change and development of architectural forms; but there has also been a continuity in this process. Change sanctioned by tradition has never destroy the unity of traditional architecture, but the notion of unremitting progress which has been so dominantly prevailing in the last thirty or years, has not only succeeded in destroying the unity and integrity of traditional ways of building, it has imposed the exact parody of unity, that is to say, regimented uniformity. This unmitigated 'progress' has resulted in an almost uniform adoption of the 'International Style', with global monotony and dressed up in varying degrees of 'local and 'ethnic' cosmetics" 95 . 
Fueled by a shortage of modern building materials at the time in Egypt, Fathy rebelled against the status quo by demonstrating that vernacular could still be a valid form of construction. His efforts have earned him the unofficial title of Egypt's most reputable architect since ancient times as well as the Aga Khan Award for Architecture: Chairman's Award. His work is described by Egyptian Architect Abdel Wahed El-Wakil in James Steele's monograph as follows:

"To the Western world, Hassan Fathy has always spoken the language of communal architecture, the language of anonymous community builders whose ideas and practical knowledge he has constantly recognized as a genuine and yet untapped source of inspiration for industrial man trapped in his chaotic surroundings; a source that should help us to free ourselves from our narrow world of official and commercial architecture ${ }^{1196}$

- Abdel Wahed El Wakil

Egyptian Architect

\subsubsection{Contemporary Architects Inspired by Vernacular Traditions}

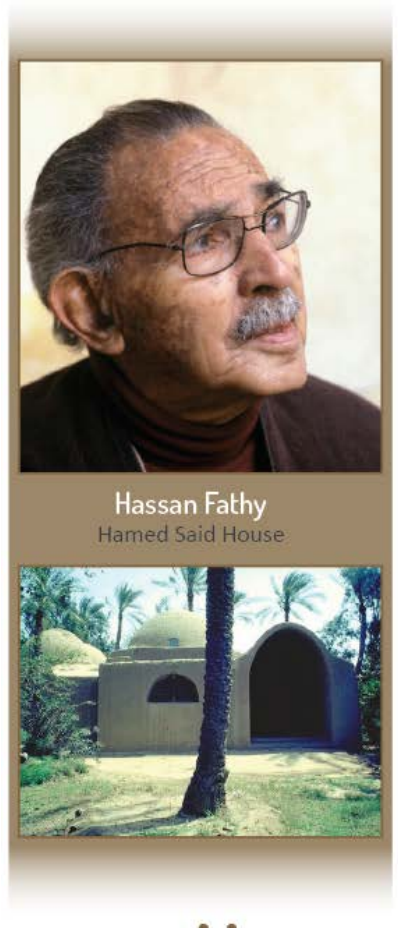

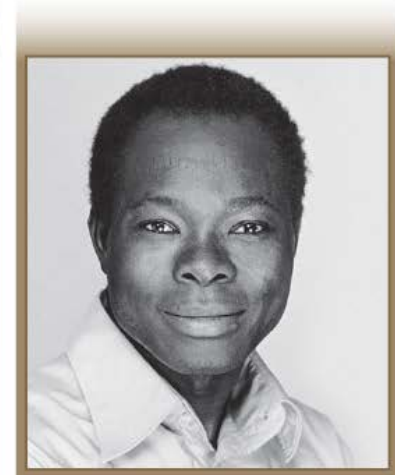

Francis Kere
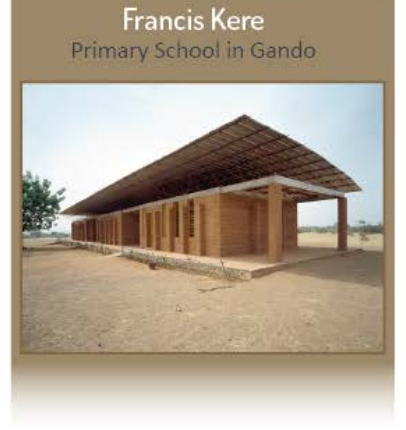
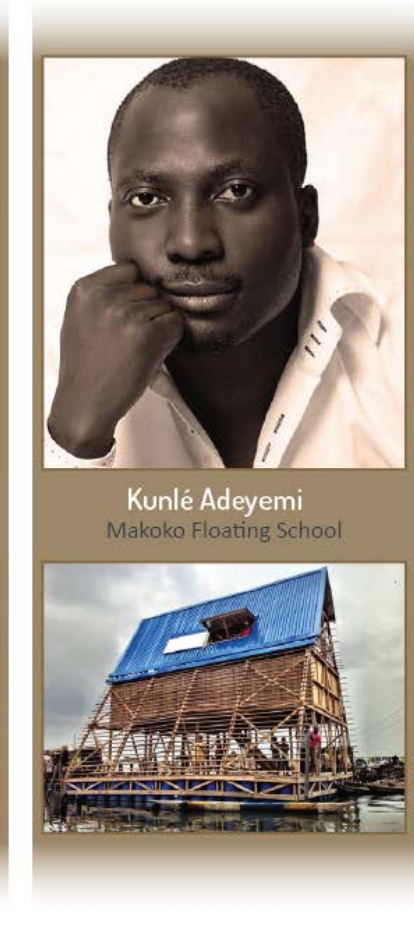

Kunlé Adeyemi Makoko Floating School

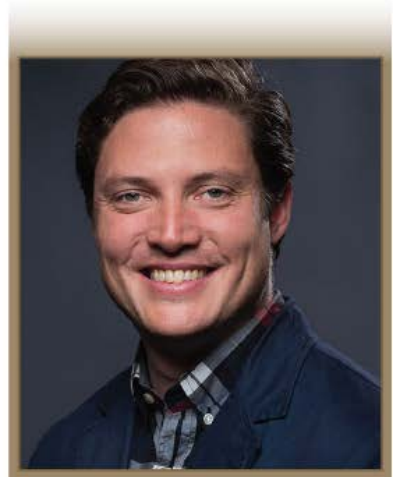

Michael Murphy

Butaro Hospital

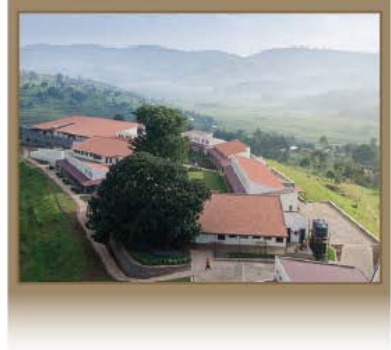

\section{3 - Prominent Neo-Vernacular Architects - Image by Author}

The consolidation of vernacular architecture into a formal discourse is a relatively recent phenomenon, beginning in last decades of the $20^{\text {th }}$ century. Therefore it is important to highlight other pioneering practitioners who have recognized the importance of reinterpreting ideas from traditional architecture for tangible application, particularly in Africa. The following practitioners operate within a similar ethos as Fathy, years after his Egyptian mud brick buildings were created. Nigerian-born architect Kunle Adeyemi, the founder of NLE Architecture, was the focus of international attention for his Makoko Floating School. This project was recently recreated at the 2017 Venice Biennale and a third version is under intensive design development. David Adajye is a Ghanian-British architect who primary works in the Western World. He has however published on the field of African Architecture. Of paramount 
importance is Francis Kere who, as this thesis demonstrates, might be solely responsible for creating a neovernacular archetype commencing with his Gando Primary school in Burkina Faso. Awarded the Aga Khan Award for Architecture, Kere has risen to international prominence and almost all of his work can be described vernacularinspired despite the formal differences in appearance between his projects and the traditional buildings in Burkina Faso.

\subsection{Research Methodology}

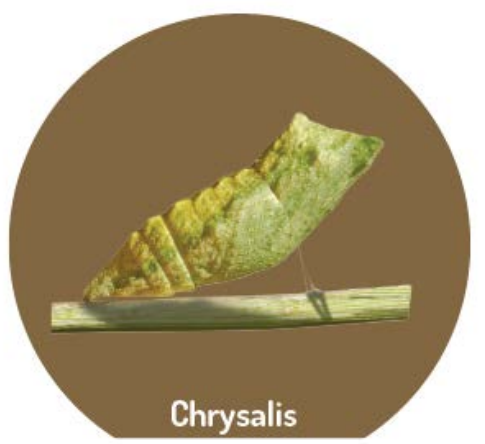

Logical Argumentation (Historical, Anthropological, Architectural)

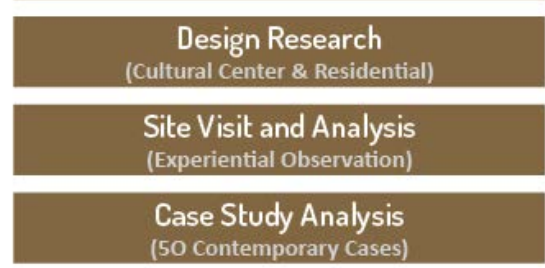

\section{4 - Research Method - Image by Author}

The method for the research carried out in this thesis has been informed by Architectural Research Methods by David Wang and Linda N. Groat. ${ }^{97}$ The terms used in the image above are defined extensively in the text by Wang and Groat. This thesis seeks to apply a cross-disciplinary lens to the research as illustrated by the following strategies; experiential observation through interviews and first-hand experience, case studies and combined strategies, historical research, artefactual research and lastly logical argumentation. This cross-disciplinary approach is advocated by many vernacular scholars in particular.

"The study of vernacular architecture demands in interdisciplinary approach. This makes it exciting, but wonder if it's in here and drawbacks is that it is inevitable that things will be said with which specialists in individual disciplines will take issue."

\section{- Susan Denyer}

Author of African Traditional Architecture

Denyer, the author of African Traditional Architecture, strongly recommends an interdisciplinary approach for the study of vernacular architecture as seen in the quotation below. This is perhaps due to the complexity of forces that shape the production of buildings. As vernacular buildings are intimately linked with culture, an anthropological lens 
can be of particular importance when studying vernacular architecture. This has been an important consideration in this thesis work and will be expanded upon in Chapter 5 when the Maasai indigenous Peoples are introduced by drawing up the works of Robert Rukwaro ${ }^{98}$ and Valeer Neckbrouck ${ }^{99}$.

\subsection{Research Questions}

This thesis's interpretive attitude toward the vernacular manifests itself through two primary research questions, as depicted in the illustration below. Firstly, how can culturally embedded space advance collective social identity, ensure safety, and promote social interaction? Secondly, how can user-participatory construction methods empower communities by cultivating self-reliance? These are the two lenses used to investigate the vernacular in this thesis.
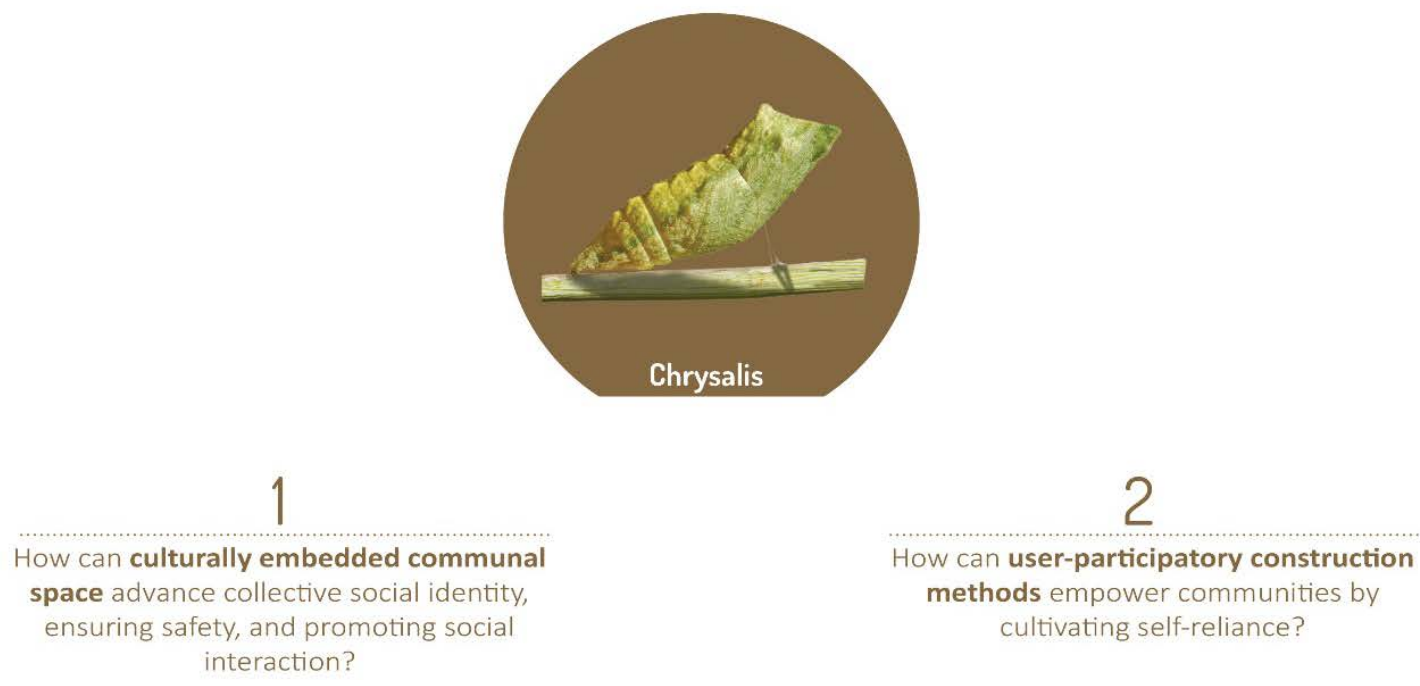

2.5 - Thesis Research Questions - Image by Author

\subsection{Thesis Formatting}

This formatting for this thesis follows "Documentation Style I" of the $16^{\text {th }}$ edition of the Chicago Manual of Style. Documentation Style I uses a system of footnotes or endnotes, the latter will be used describe referenced material at the end of each chapter, as seen in the next and final section of this chapter.

\subsection{Chapter 2 Endnotes}

67 "Jalaluddin Rumi," Good Reads, http://www.goodreads.com/quotes/616306-maybe-you-are-searching-among-thebranches-for-what-only.

${ }^{68}$ Michael W. Fazio, Lawrence Wodehouse, and Marian Moffett, A World History of Architecture, $3^{\text {rd }}$ ed. (London, United Kingdom: Laurence King Ltd, 2014).

69 Ibid. 
70 Khan, "Aga Khan Award for Architecture Ceremony, Cairo."

71 Population Division United Nations Department of Economic and Social Affairs, "World Urbanization Prospects: The 2014 Revision, Highlights," (United Nations, 2014).

72 "World Urbanization Prospects: The 2014 Revision," (United Nations, 2015).

73 Buccellato and Reineccius, "Exploring Vernacular East African Architecture: Lessons for the Modern World".

74 United Nations Department of Economic and Social Affairs, "World Urbanization Prospects: The 2014 Revision."

75 Ibid.

${ }^{76}$ Bernard Rudofsky, Architecture without Architects: A Short Introduction to Non-Pedigreed Architecture (USA: Museum of Modern Art: New York, 1964).

77 Paul Oliver, Encyclopedia of Vernacular Architecture of the World (New York: Cambridge University Press, 1997).

78 Marcel Vellinga, Paul Oliver, and Alexander Bridge, "Atlas of Vernacular Architecture of the World," (Abingdon, Oxon ; New York: Routledge,, 2007).

${ }^{79}$ Allen G. Noble, Traditional Buildings: A Global Survey of Structural Forms and Cultural Functions, International Library of Human Geography ; (London; New York: I. B. Tauris, 2007).

80 John May, Handmade Houses \& Other Buildings: The World of Vernacular Architecture (High Holborn, London: Thames \& Hudson, 2010).

${ }^{81}$ Allen G. Noble, Vernacular Buildings: A Global Survey (London: I.B.Tauris, 2014).

82 Vicky Richardson, New Vernacular Architecture (London: Laurence King Publishing, 2001).

83 Paul Oliver, Built to Meet Needs: Cultural Issues in Vernacular Architecture, 1st ed. (London: Architectural Press, 2006).

${ }^{84}$ Lindsay Asquith and Marcel Vellinga, Vernacular Architecture in the Twenty-First Century: Theory, Education and Practice (London; New York: Taylor \& Francis, 2006).

85 Kingston Wm. Heath, Vernacular Architecture and Regional Design: Cultural Process and Environmental Response, 1st ed. (Oxford ; Burlington, Mass.: Architectural Press/Elsevier, 2009).

${ }^{86}$ Fathy, Architecture for the Poor: An Experiment in Rural Egypt.

87 René Gardi, Indigenous African Architecture (New York,: Van Nostrand Reinhold, 1974).

88 Nnamdi Elleh, African Architecture: Evolution and Transformation (New York: McGraw-Hill, 1997).

${ }^{89}$ Susan Denyer and Peter McClure, African Traditional Architecture: An Historical and Geographical Perspective (New York, USA: Africana Publishing Company, 1978).

90 Bourdier and Trinh, Vernacular Architecture of West Africa: A World in Dwelling.

${ }^{91}$ Kaj Blegvad Andersen, African Traditional Architecture: A Study of the Housing and Settlement Patterns of Rural Kenya (Nairobi ; New York: Oxford University Press, 1977).

92 Rukwaro and Maina, Transformation of Maasai Art and Architecture.

93 Douglas Harper, "Etymonline," http://www.etymonline.com/index.php.

94 Rudofsky, Architecture without Architects: A Short Introduction to Non-Pedigreed Architecture.

95 Abdel Wahed El Wakil and James Steele, Hassan Fathy, Architectural Monographs (London, New York: Academy Editions, St. Martin's Press, 1988), 8.

96 Ibid., 7.

${ }^{97}$ Linda N. Groat and David Wang, Architectural Research Methods (New York: John Wiley \& Sons, Inc., 2002).

98 Rukwaro and Maina, Transformation of Maasai Art and Architecture.

${ }^{99}$ Valeer Neckebrouck, Resistant Peoples: The Case of the Pastoral Maasai of East Africa, ed. Arij A. Roest Crollius, Inculturation (Rome: Centre "Cultures and Religions", Pontifical Gregorian University, 1993). 


\section{Chrysalis: Culturally Embedded Communal Space}

\subsection{Vernacular African Boma Spaces}

The surveys of African vernacular buildings by in the works of Susan Denyer, Paul Oliver, Labelle Prussin and others demonstrate the diversity of building forms across the continent as well as the multitude of social, cultural and environmental forces that shape these buildings. Susan Denyer comments on the distribution of vernacular building styles across Africa:

"Many theories put forward are highly simplistic and rely on the idea that styles can be 'explained' simply by Portuguese or Islamic influence, for example. The diversity of styles illustrated in this book should show that although certain generic characteristics have emerged, most styles were very specific to local conditions. It seems much more satisfactory to think of individual styles as a complex interweaving of many different ideas. .. . A conceptual model to explain this would be a process rather like the assortment of genes and chromosomes which underlies the mechanisms of biological interaction."100

The comparison that Denyer makes between vernacular buildings and biological genetic codes speaks to the wonderful variety of buildings that has emerged over the continent, born from the specificities of context. This is indeed not dissimilar to biological evolution as described by Darwin. Denyer isn't the first vernacular architecture specialist to draw these comparisons. Despite regional and cultural differences in African vernacular architecture and the utter specificity of the forces that shape their production, one can't help but notice a common capacity for these buildings to support complex dynamic family structures and community activities through the use of partially sheltered outdoor space. The following are a series of floor plans of African vernacular buildings that Susan Denyer has illustrated that showcase the frequent occurrence of this partially sheltered space across the vernacular architecture across a variety of cultures. 

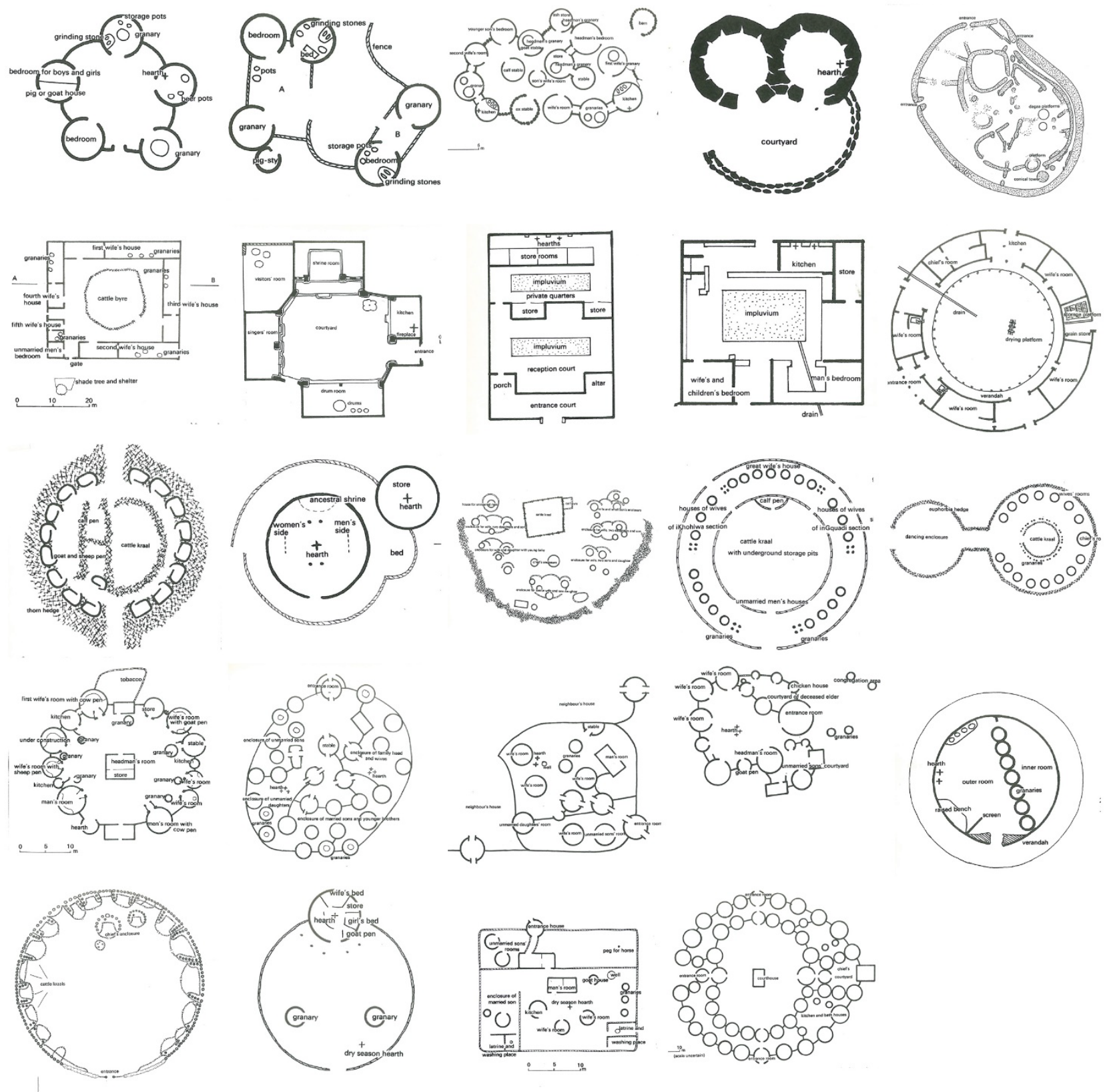

3.1 - Denyer's Floorplans of African Vernacular Buildings - Image Retrieved from "African Traditional Architecture - Susan Denyer" 
These spaces are undoubtedly as diverse as the building forms that surround and create them. They range in form, scale and function. Many authors refer to a group of building forms and their corresponding collection of outdoor spaces as 'compounds'. These 'compound spaces' are most notably found in rural buildings and they often are the focal point of community life. They support a tremendous diversity of uses from social interaction, to ceremonial dance, living spaces for animals, and much more. Susan Denyer writes about the multifaceted uses of these communal spaces.

"The requirements of the family were simple and mainly similar in all agricultural societies: a place for each member to sleep; a place for cooking; places for food storage and somewhere to protect animals at night, such as cattle, goats and chickens; a place to eat and a place to sit and talk in the day and practice craftwork, basket making, spinning and weaving. In most parts of Africa, for a

greater portion of the year, the weather is warm and when it is dry many activities can be performed outside. So it demarcated space was often sufficient for some activities, and this must be considered as much a part of the homestead as the buildings. In parts of Uganda the men prefer to sit at the gate of their compound under shady trees to talk and eat their food. In northern Ghana and northern Nigeria the women like to cook outside in the dry season in an unroofed space, partly surrounded by a low wall for shelter from the winds. The trees, their shade, the cooking stones and their surroundings thus became rooms of the homestead." 101

- Susan Denyer

Author of African Traditional Architecture

These outdoor spaces may be overlooked when studying these vernacular buildings because of the absence of obvious 'built enclosure'. Instead they are the 'negative' spaces in between the buildings. They are comprised of landscape elements such as trees, fences, shrubs, outdoor furniture and more and lend themselves well to a variety of uses. However, as Denyer mentions, these spaces must be considered as much a part of the homestead as the buildings themselves. Abdel Wahed El Wakil, one of Egypt's most well-established architects refers to a similar notion in his introduction to James Steele's monograph entitled Hassan Fathy.

"The anonymous builders draw no line between architecture and landscaping. With them, landscaping is not 'commissioned' as an afterthought. Neither is sculpture. The three are inseperable." 102

- Abdel Wahed El Wakil

Egyptian Architect

Many African vernacular buildings demonstrate a holistic conception of building, landscape and culture, highlighting to need to examine these outdoor spaces with due assiduity. These sentiments highlight the importance of considering these spaces in their specific cultural contexts. The function of these spaces and how they are created require further investigation as well as a term and definition that might allow architects to better advance their utility in contemporary architecture.

The wide range of spatial layouts and functions of these spaces make it difficult to explicitly define them. Every culture may use them differently, the underlying architectural strategies utilized to create these spaces vary, and the importance of the space to the overall building or homestead also differs in functional or symbolic significance from case to case. 
In order to better analyze them and explore their interstitial nature as intermediary communal spaces, the notion "threshold space" will be used as a perceptual lens into their study. Threshold space will be used to describe the habitable medium between the complete enclosure of indoors and the opposite extreme of the outdoors. The term threshold refers to the intermediary spatial character of this space, and will uncover their relevance to contemporary practice.

\subsection{The Threshold Space: An Introduction}

Till Boettger, German architect and lecturer at the Department of Design and Interior Design of the BauhausUniversity Weimar argues that threshold spaces are neglected overlooked transition spaces between outside and inside, or between one space and another. ${ }^{103}$

This definition, primarily the former, will borrowed and applied to describe the compound spaces of African vernacular buildings throughout this chapter. A focus on the notion of threshold space stems from an observation that they have historically served as habitable intermediary spaces that support a range of critical socio-cultural activities that bind a community together as well as the fact that they lie somewhere along the spectrum in between complete enclosure, or 'inside', and the untamed wild, or 'outside' in vernacular African architecture.

In his book entitled Threshold Spaces: Transitions in Architecture: Analysis and Design Tools, Boettger describes how threshold spaces can be understood as a volume of space that facilitates experiential transition for a 'sentient' human being as they move between spaces in a building. ${ }^{104} \mathrm{He}$ argues that these spaces thrive on 'spatial ambivalence', interrupting spatial boundaries for a transition from one to another. They can be read as a spatial transition element but also perceived as a barrier. ${ }^{105} \mathrm{He}$ describes this work as "a quest for the essence of a threshold space and its capabilities. The use, interpretation, and design of transitions are clarified and newly defined based on the spatial concept of a threshold space". 106

Much of Boettger's work is centered on how designed threshold spaces affect an occupants experience though space and time. His work is therefore strongly described using a phenomenological lens to architecture. The occupant-centric understanding of threshold spaces that Boettger describes will be borrowed for a brief moment to better understand his definition, after which this chapter will seek to expand this definition in section 3.4 by exploring the notion of threshold space as it pertains to collective culture instead of a single occupant's sensory experience of transition. Four design parameters of the aforementioned 'compound space' are identified and their role in supporting community culture and activities in the context of African vernacular traditions as well as contemporary practice is analyzed.

\subsection{The Threshold Space: Experienced Transition}

Boettger explains the architectural role of the threshold space through a few historical examples. He often uses a series of diagrams to identify the body of the threshold space in these examples which help to provide an understanding of the purpose of the threshold space as well as its aforementioned 'ambivalence'. The next four examples will explain Boettger's definition of the threshold space. Firstly its importance as transitional volume for an occupant's experience will be outlined, followed by a description of how architectural elements are used in a spatial sequence to shape this experience of transition. The last two examples will explore the cultural role of the threshold space as a preparatory spatial element for an occupant in a building. 


\section{Parthenon}

Boettger describes the colonnaded arcade, or peristasi, that encloses the interior of the Parthenon as the threshold space. Its function is to shape the occupants experience as they transition from the outside world into the temple. The threshold space in this case then "link(s) the secular world with that of the gods". ${ }^{107}$ This example illustrates the mediating role of the threshold space between inside and outside and its importance in shaping an occupant's disposition and mood from one realm into the other.

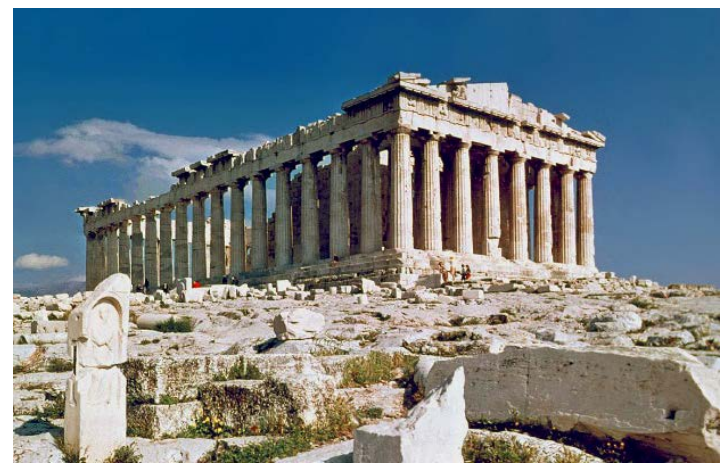

3.2 - Parthenon in Rome - Image Retrieved from "https://upload.wikimedia.org/wikipedia/commons/d/da /The_Parthenon_in_Athens.jpg"

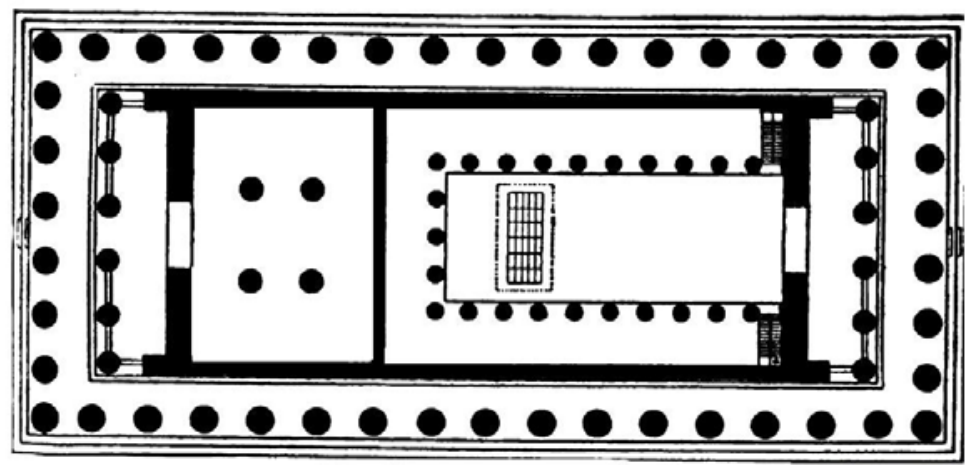

3.3 - Parthenon in Rome Floorplan - Image retrieved from

"https://classconnection.s3.amazonaws.com/836/flashcards/1200836/jpg/2145E1C781213D34971F.jpg"

\section{Pantheon in Rome}

Boettger describes the threshold space of the Panthenon though a deconstruction of the spatial sequence into the building which is best illustrated in the following diagram. First, an occupant arrives at Piazza della Rotonda before the Pantheon where they are introduced to the building façade. They then ascend the stairs and traverse across the portico followed by crossing a second transitional element before finally entering the main circular room. This is the journey between 'outside' and 'inside'. Boetter argues that this spatial sequence 'decelerates' the occupants approach and allows them to become conscious of their transition into the building. ${ }^{108}$ This example expands on the 'mediating role' of the threshold space in the previous example by emphasizing that an architect can shape the experienced transition of an occupant through a designed spatial sequence. In this example we see how the spatial sequence is much more prolonged for the occupant than in the case of the Athens Parthenon. 


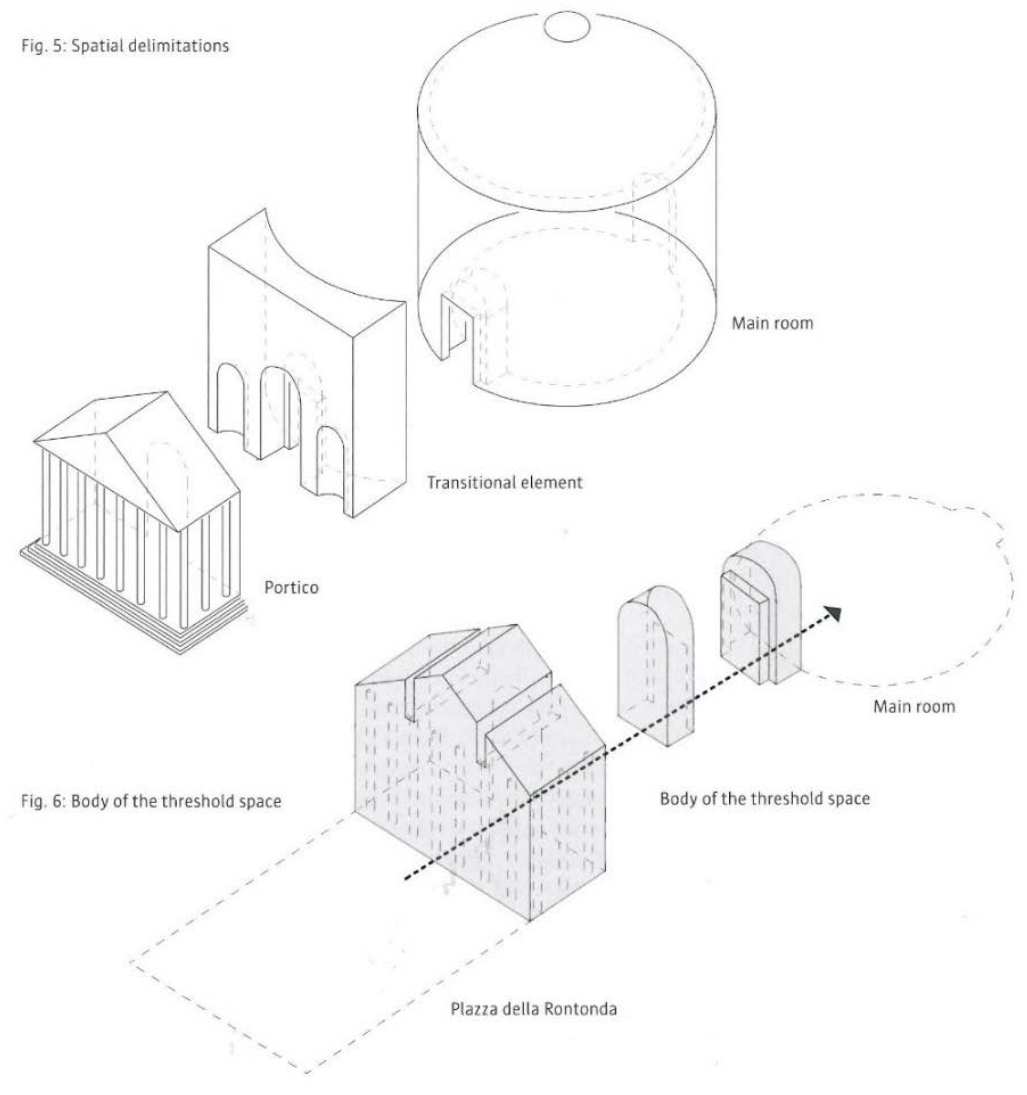

3.4 - Roman Pantheon - Image Retrieved from "Threshold Spaces - Till Boettger"

Gothic Portal

The threshold space in this example is a preparatory spatial element, similar to those seen in the previous two cases, however Boetgger expands on the strong symbolic role that the Gothic entrance has. The stone sculptures at the entrance often portray characters from biblical stories, making an occupant conscious of the divine as they enter the Church. ${ }^{109}$ Threshold spaces can therefore play a strong role in expressing culture upon transition between inside and outside 


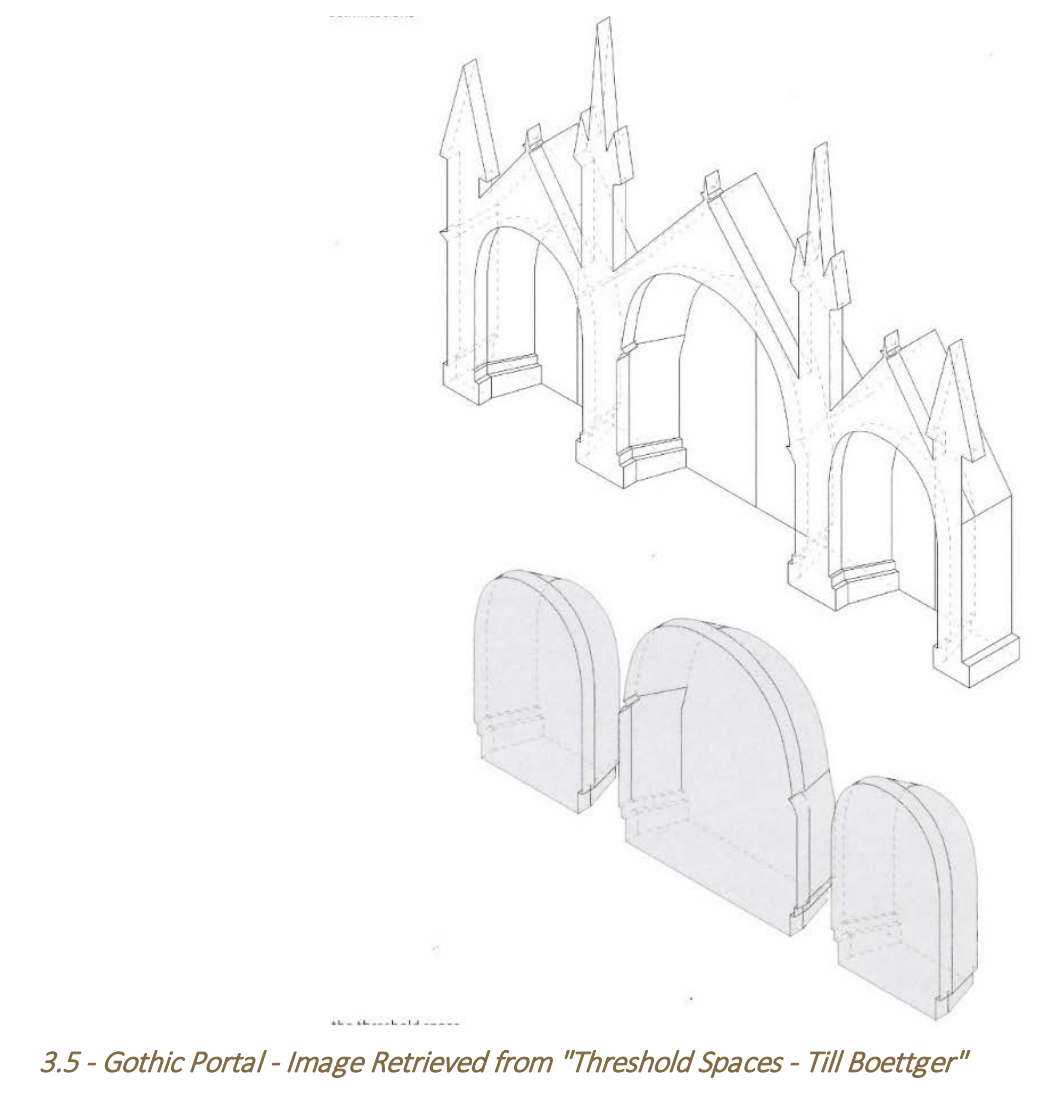

Japanese Houses

Lastly, Boettger discusses the role of transition element in a traditional Japanese house. The Japanese house does not have a separate threshold space but in fact expresses a slightly different concept of transition. Between the extreme outside and extreme inside of the mat room, several gradients of transition are present. Several variations of transition spaces comprise a threshold space. This is particularly ambiguous because the role of the threshold space is deeply integrated with spatial plan of the entire building, making it particularly difficult to demarcate a separate transition space. Nonetheless, the experiential transition is facilitated by a variety of architectural elements, from the first step to ascend into the house, until the sliding screen doors adjacent to the inside mat room. 

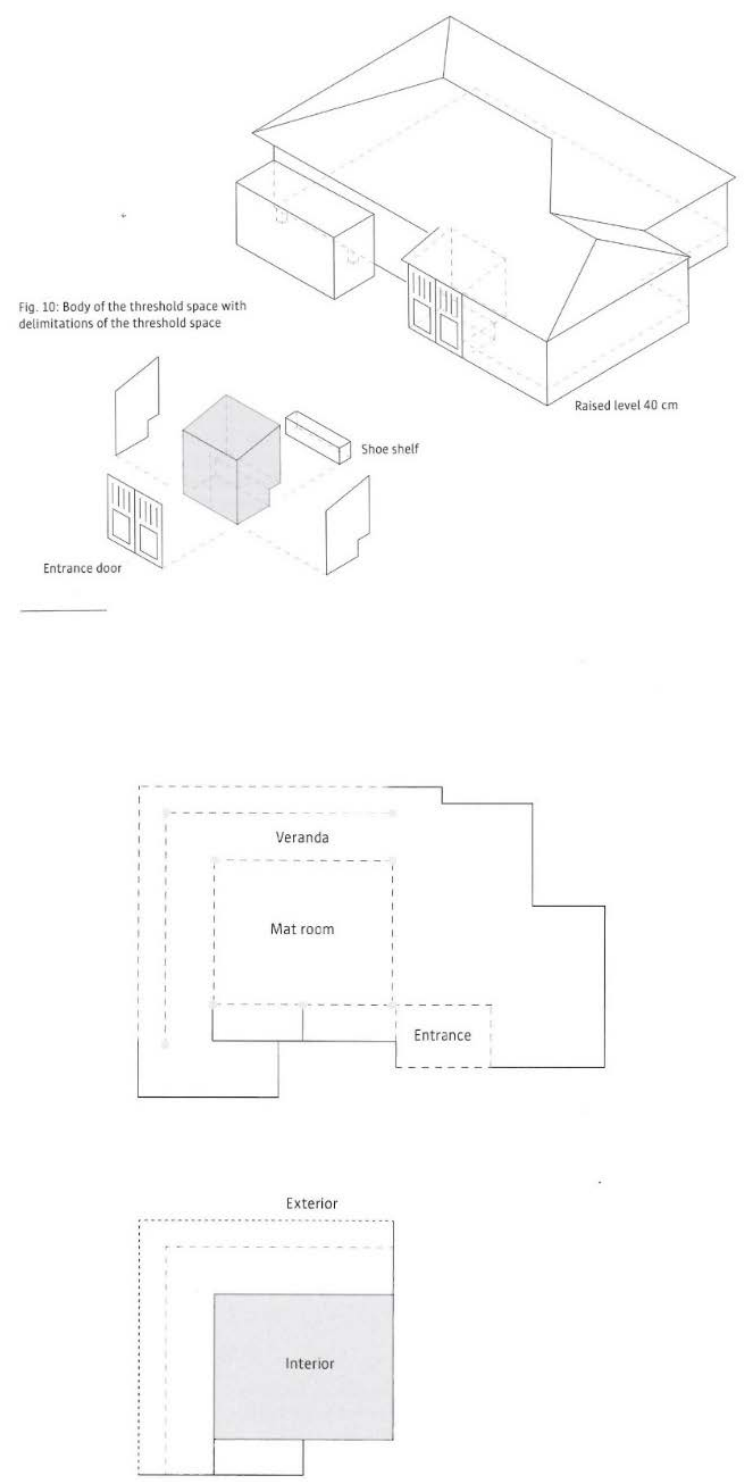

3.6 - Japanese House Image Retrieved from "Threshold Spaces - Till Boettger"

Threshold Space: A New Definition

From these examples we can understand the threshold space as a theoretical construct that describes architectural transition space(s) that shape an occupant's experience between the extremes of outside and inside.

An analysis of both contemporary and vernacular African buildings reveal that well designed African compound spaces are a way to realize permeable relationships between a building's 'inside' and 'outside'. They support a range of socio-cultural community activities, exhibit a partial sense of enclosure and have characteristics of both inside and outside space in varying degrees. The threshold space might be understood as the ambiguous nexus between architecture and landscape design. 
Adopting the term threshold space in this thesis will help make prominent a part of vernacular buildings that can sometimes be overlooked, particularly because it constitutes of primarily 'empty space' in these traditional structures. Despite this tendency, an observation that contemporary African regional architecture also frequently tends to exhibit well designed threshold spaces necessitates the creation of pertinent knowledge so that these spaces can be better designed. While the ideas advanced by this thesis may have universal relevance, the expanded definition of the threshold space will benefit practitioners who wish to seek inspiration from vernacular traditions when operating in rural contexts in the developing world. Threshold spaces are then a way to explore African compound spaces and to determine how their continuity will be useful for contemporary African regional responses.

This work offers a new lens into these transition spaces in addition to the phenomenological one of Boettger. It will explore four new spheres to be considered as four parameters of the 'compound space' that define the role of the threshold space in supporting community culture and activities in the context of African vernacular traditions as well as contemporary practice. In the spirit of vernacular architecture, the emphasis on this new work will be primarily pragmatic and will seek to benefit architecture practitioners working in the developing world. The term threshold space will be used to describe the compound space for the remainder of this thesis and will pertains more to collective culture instead of a single occupant's sensory experience of transition. The four new spheres of the threshold space that will be explored are, the Environmental Buffer Zone, Polyvalent Space, Safety by Surveillance, and lastly, Unity of Disparate Forms. 


\subsection{Four Design Strategies for Culturally Embedded Communal Space}

\section{Environmental Buffer Zone}

Threshold spaces act as buffer zones against the environment. Environment in this thesis will be defined as both climatic forces such as temperature and precipitation as well as the dangers associated with wild animals in certain
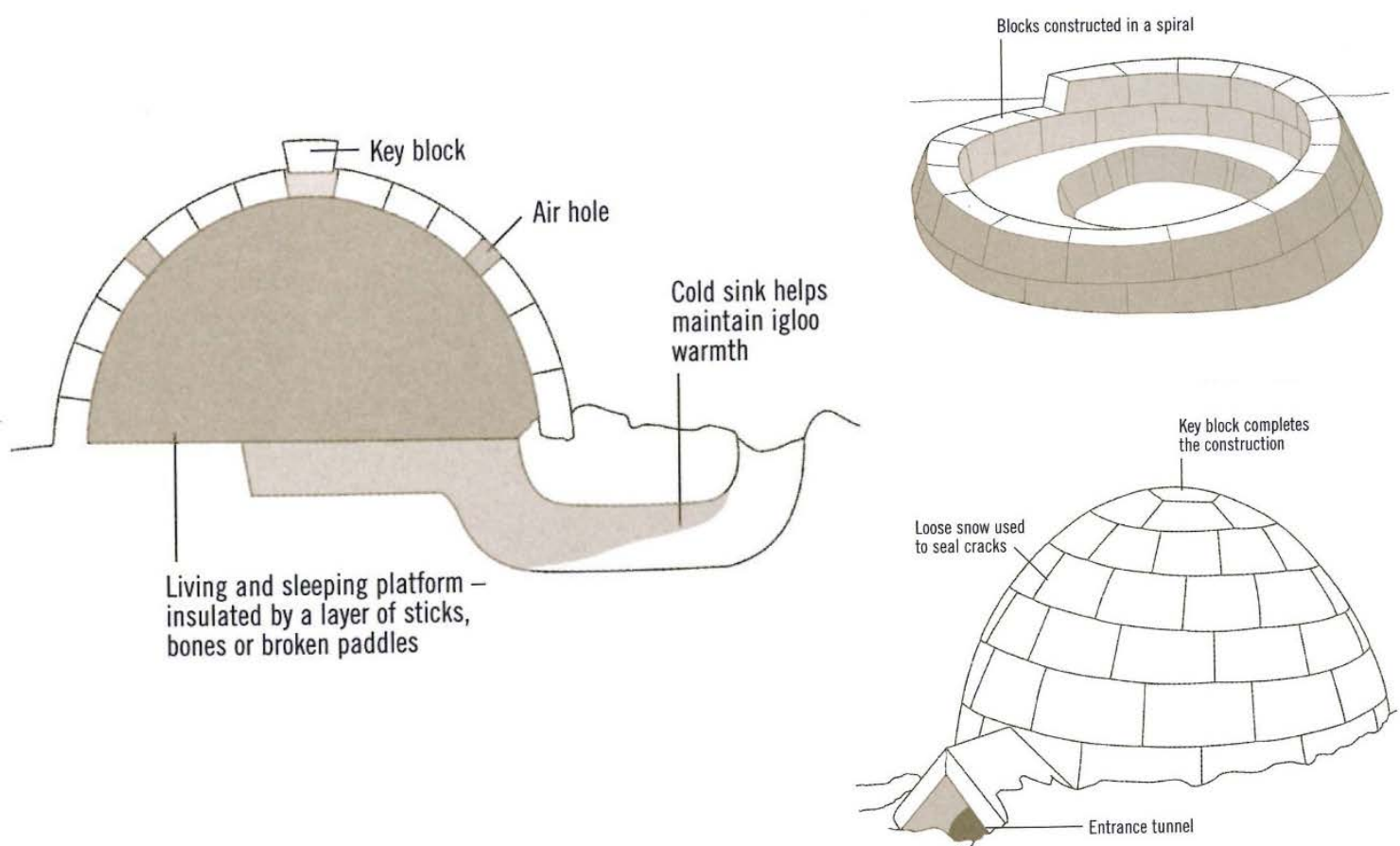

3.7 - Inuit Igloo - Image Retrieved from "Handmade Houses \& Other Buildings - John May"

contexts. In many examples of vernacular architecture, threshold spaces have acted as safety zones or buffers between the building 'inside' and 'outside'.

This example of the Inuit Igloo illustrates how the threshold space, illustrated in the diagram as 'cold sink', acts as a thermal buffer for the building, keeping warm air within the body of the Igloo. The entrance passage is then a threshold space. When examining the exterior of the Igloo, the most prominent formal geometrical elements are the dome of the living quarters and then secondly, the entrance tunnel. The threshold space significantly contributes to the formal or sculptural appearance of this building. In this example, the functional use of the threshold space is expressed formally in the massing of the building, highlighting its importance. Threshold spaces can then significantly determine the outward appearance of buildings, allowing structures to formally express a pragmatism that might be considered aesthetically pleasing.

In many forms of African vernacular architecture, threshold spaces act as environmental buffer zones in a variety of ways that draw people to utilize their protective qualities. Many vernacular building employ elaborate architectural devices to shield against wild animals or even for protection against enemy. An example of the latter would be circular tolou found in the Fujian province of southwest China. However, the protection against environmental forces is certainly a relevant consideration in the conception of architecture today. In vernacular architecture, the desire for protection can encourage collective gathering, making the 'environmental buffer zone' an attractive 
quality of a communal space. For the want of shelter from climatic forces or wild animals, a community comes together in a threshold space.

In the following figure, the Maasai Enkang, the threshold spaces acts as an area of safety to protect the cattle at the center of homestead from wild animals, particularly at night. This is crucial to the lifestyle of the Maasai tribe as even today, many thrive as a unique pastoralist culture within the twenty-first century. The threshold space's utility as a buffer zone from wildlife is evidenced by the thorn hedges that are labeled in the plan.

Polyvalent Space

However, this buffer space in the Maasai Enkang serves the community more ways than simply keeping wild animals out. The central space supports a range of social activities that are paramount to the function of the community. They range from informal social interaction to formal and ceremonial dances.

This illustrates the second design parameter for threshold spaces, the notion of multiple uses or polyvalancy. This term polyvalence has been borrowed from an article by architect Herman Hertzberger who uses the term polyvalence in contrast to multipurpose design. He writes as follows:

"The difference between multipurpose and polyvalence is that in multipurpose the design is deliberately made to suit the different predetermined ends, whereas the notion of polyvalence is where it is not established beforehand how a form or space will act in unspecified situations, in effect providing it with a competence to be able to handle unexpected applications. By looking ahead to these situations and designing the form of buildings and spaces accordingly, armed with

what we know about general human behaviour, polyvalence can be said to provide for the unexpected.

Instead of leaving out as much as possible, polyvalence entails introducing the greatest number of spatial conditions that can play a part in every situation whatever the function, and can simply be put to use on each new occasion"110

- Herman Hertzberger

Dutch Architect and author of Polyvalence

Hertzberger highlights the importance of polyvalent space not having pre-conceived uses which avoids the creation of space that is overly prescribed. A polyvalent space is created with the competence or a robustness to withstand a variety of uses, which may change over time. This notion is particularly evident in the Maasai Enkang, where a polyvalent communal space enables an abundance of uses for the community. This polyvalent quality speaks to the vernacular ethos of constraint outlined in section 2.3 whereby the maximum amount of utility is derived from a created space. 
Thus polyvalency is integral to the threshold spaces in the vernacular African context. Reimagining this notion for contemporary practice is critical, particularly in an age of environmental concern and in contexts where poverty is a formidable social development challenge. Economies of reduced means present in the vernacular are certainly valuable today as a way of creating sensible, efficient buildings. The Maasai Enkang is a prime example of how a threshold space can be layered with multiple, polyvalent, uses. Its responsibility of providing safety from the external natural environment as previously described in under 'environmental buffer zone' also supports the community in a slightly different regard - that of social cohesion.

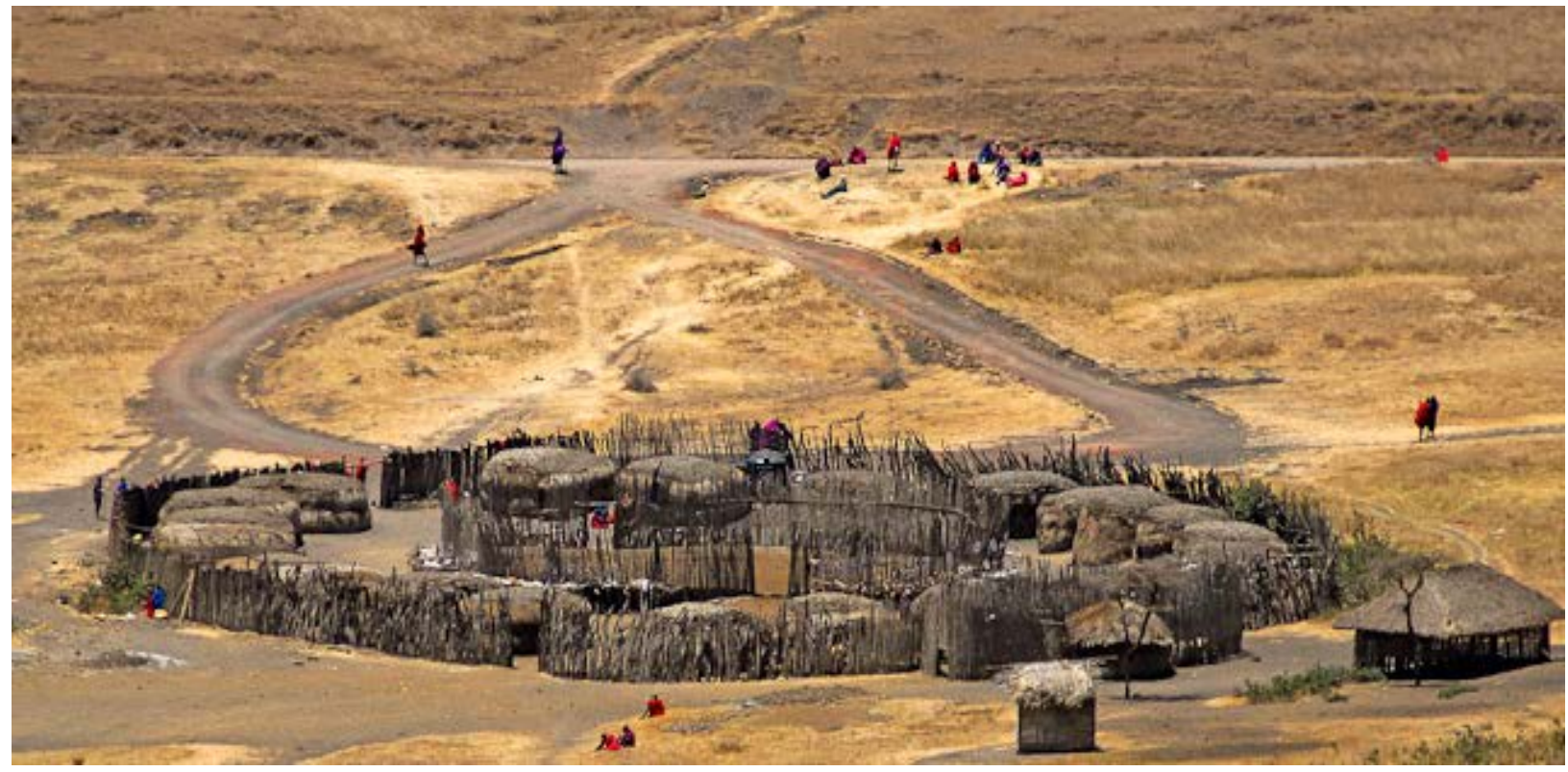

3.8 - Maasai Homestead - Image Retrieved from "https://ih1.redbubble.net/image.11040938.9258/flat,1000x1000,075,f.u49.jpg" 


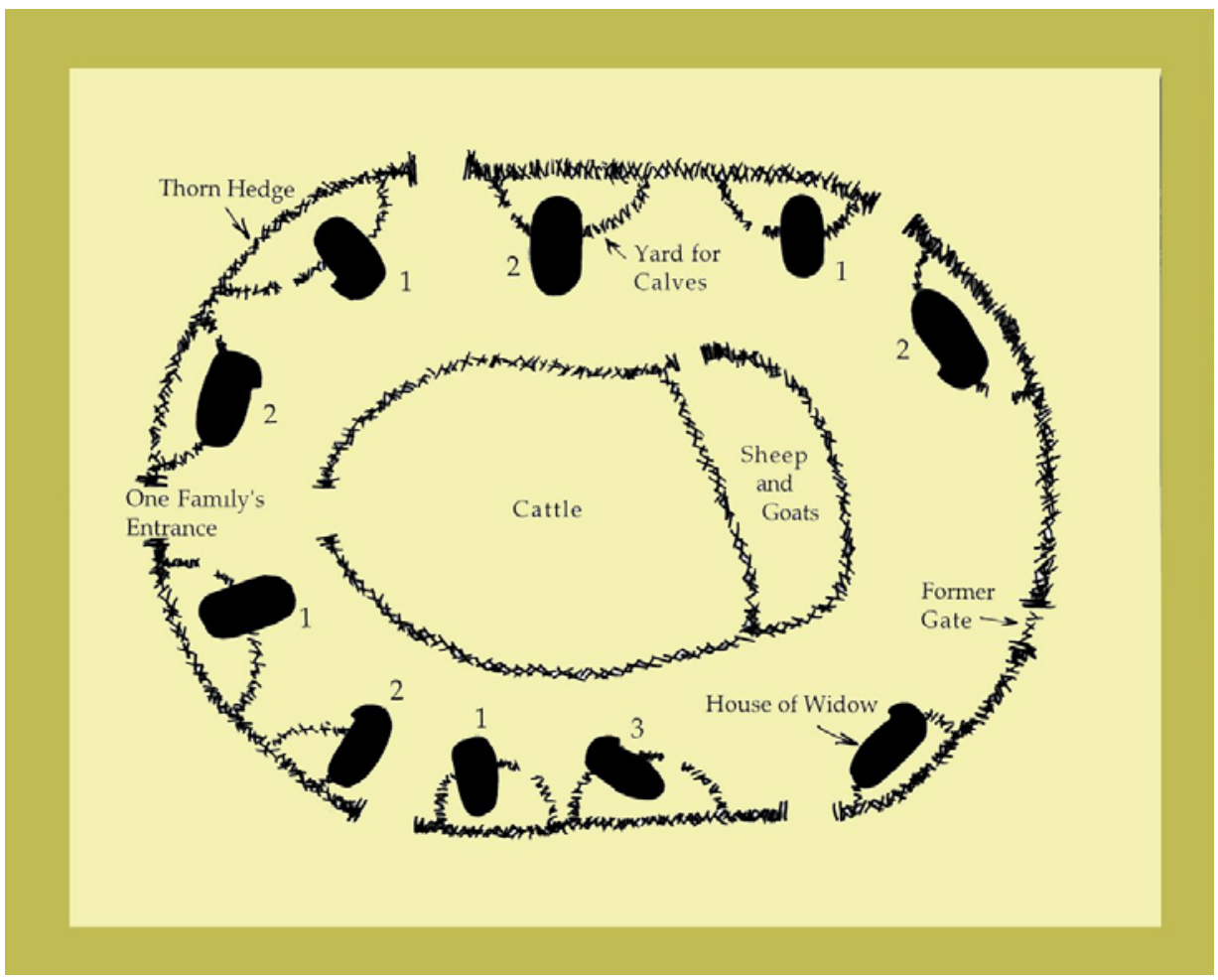

3.9 -Maasai Enkang Floorplan - Image Retrived from "http://www.johntyman.com/africa/a348.jpg"

\section{Safety by Surveillance}

As Maasai typically live communally, based on elaborate kinship ties, the Enkang reflects the communal identity of its denizens by means of a threshold space that conducive to social cohesion. A glimpse at the Enkang's plan and one can see that it is strongly guided by a design principal of 'centrality', with open void space in the middle of the plan and buildings at the perimeter. In addition to supporting cattle living spaces at night, the open center of the plan allows for clear sightlines throughout the building which are conducive to a sense of safety in the homestead. The term "safety by surveillance" is borrowed from Jane Jacob's ideas on informal surveillance and "eyes-on-thestreet" as described in her extremely influential book, The Death and Life of Great American Cities. ${ }^{111}$ The term has been adapted to describe the informal manner in which denizens of a homestead "watch" each other informally thereby creating a feeling of safety.

Jane Jacobs, North American activist renowned for her contributions to urban design theory during the 1960's and 1970's, describes the importance of visual interaction in cities through her term "eyes on the street". In her book, she describes them as the eyes that belong to "the natural proprietors of the street" which contribute to the necessary idea of "safety by surveillance" in cities. ${ }^{112}$ She states that buildings must face the streets and "induce people in buildings along the street to watch the sidewalks" all around the clock. This consideration for 'natural surveillance' is predicated on a healthy visual dynamism at the street and contributes to a private sense of ownership of public property. These ideas are remarkably consistent with the thinking of contemporary city building efforts as evidence by Toronto's Tall Building Guidelines. ${ }^{113}$ Jacobs describes not only the role of "informal surveillance" but she also describes its intimate connection with a strong community ethos. A collective sense of ownership allows citizens to ensure mutual safety and security. An anecdote from Jacob's trip to Upper Broadway in 
New York describes this idea. She recalls a central mall dividing the street where benches oriented towards the street are filled with people that are "watching pedestrians who cross the mall in front of them, watching traffic, watching people on busy sidewalks, watching each other" ${ }^{114}$ She writes the following.

"I had not been there longer than a minute, barely long enough to begin taking in the streets activity of errand goers, children playing and loiterers on the stoops, when my attention was attracted by a woman who opened a window on the third floor of a tenement across the street and vigorously yoo-hooed at me. When I caught on that she wanted my attention and responded, she shouted down, "The bus doesn't run here on Saturdays!"115

- Jane Jacobs

North American Urban Design Activist and Author of The Death and Life of Great American Cities

Jane Jacobs' anecdote highlights the strong relationship between "informal surveillance" and the social interaction appropriate for a community ethos. Eyes oriented towards the street in this case prompted the concern for the wellbeing of another citizen. "Safety by surveillance" here has causally mitigated the anonymity between two people, a common burden to community building found in dense cities. Prefaced by visual interaction, the community ethos in this particular part of Broadway was evident and quite apt for the notions of 'neighborhood' that Jane Jacobs so famously advocated for. Conversely, the opposite can also be seen in another example by Jane Jacobs, also in the city of New York.

Through this lens of safety, her example demonstrates the correlation between a lack of a genuine sense of community and unsafe city streets. She describes the wealthy streets of Park Avenue and upper Fifth Avenue that struggle with a sense of community. Their streets are bare, lacking the animation and energy seen at the Broadway intersection. They also therefore lack a certain 'natural surveillance', as eyes are absent from the street. Jacobs describes how a community actually has to be manufactured to ensure a level of safety. "A network of doormen and super intendents, of delivery boys and nursemaids, a form of hired neighborhood, keeps residential Park Avenue supplied with eyes". This 'hired' community takes their stand at the buildings' street-oriented thresholds to watch the sidewalks. This showcases a reaction to the absent community ethos in these upper neighborhoods, and how the lack of "informal surveillance" was diagnosed as a primary problem.

Informal safety then is an extremely desirable attribute of communal space, one that is commonly found in African vernacular architecture. However, this notion is also present in a contemporary building; the Mama Sarah Obama Children's Institute. The program of the building is starkly different from the Maasai homestead, however, the sense of safety created by an 'open' threshold space is present in both examples. The floor plan of the children's institute is not dissimilar from the Enkang. A perimeter of building forms separate the condition of extreme 'outside' from a central threshold space. This space is emphasized with a sunken courtyard, protected by an airy roof structure. All entrances to the nursery school are accessible via the threshold space. Though this project is unbuilt, one can imagine the vibrancy of the social space as depicted in the top right render. Like the Maasai Enkang, these factors all work together to create a sense of safety for the nursery students, further facilitated by the open windows shown in white in the renders. 
Drawing inspiration from Jane Jacob's Death and life of American Cities, a 'safety by surveillance' is created in the Nursey school by allowing for the informal oversight of students. This primarily created by the spatial arrangement. Of the building
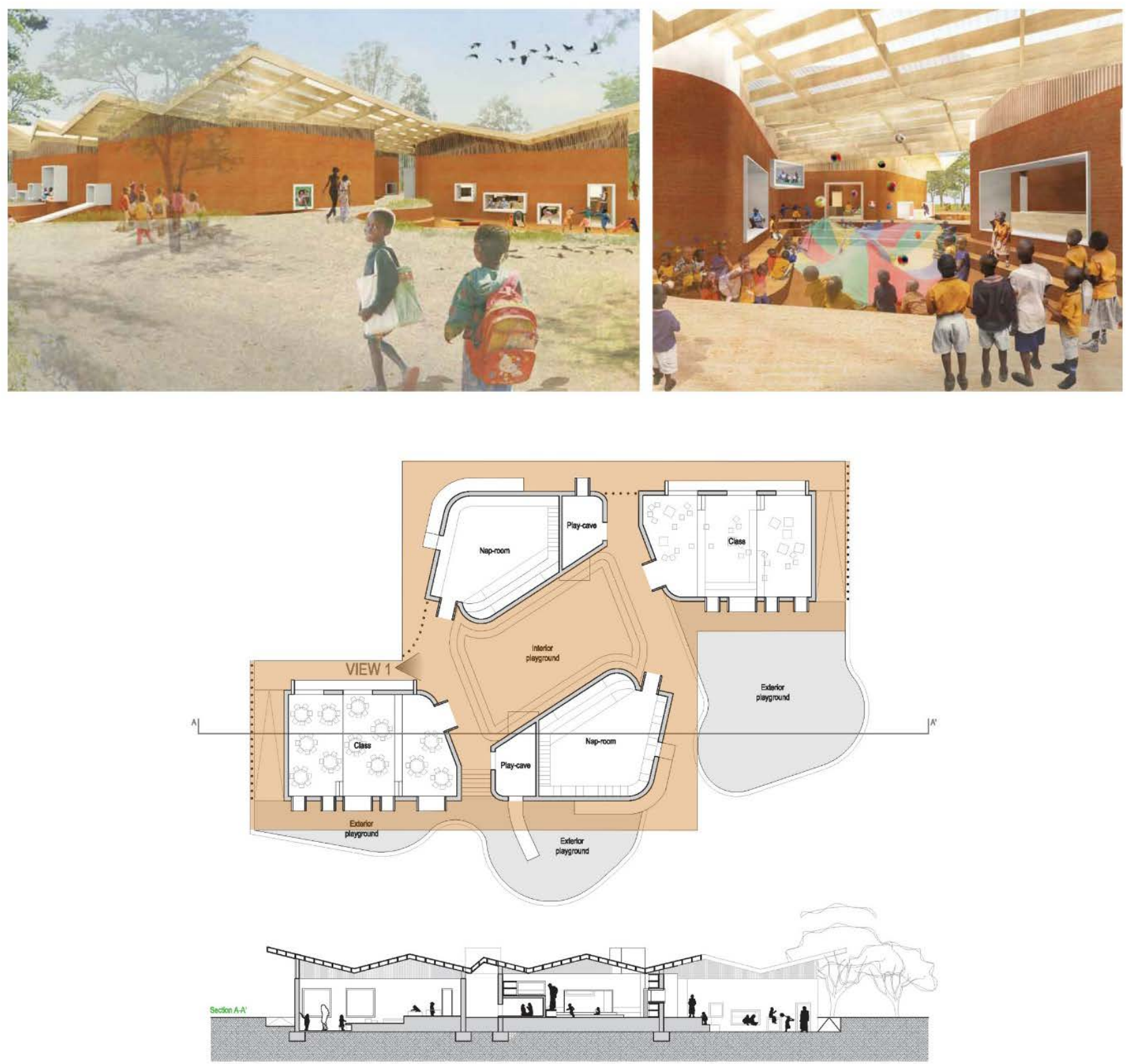

3.10 - Mama Sarah Obama Nursery School by Francis Kere - Images retrieved from "Design Proposal by Kere Architecture" 


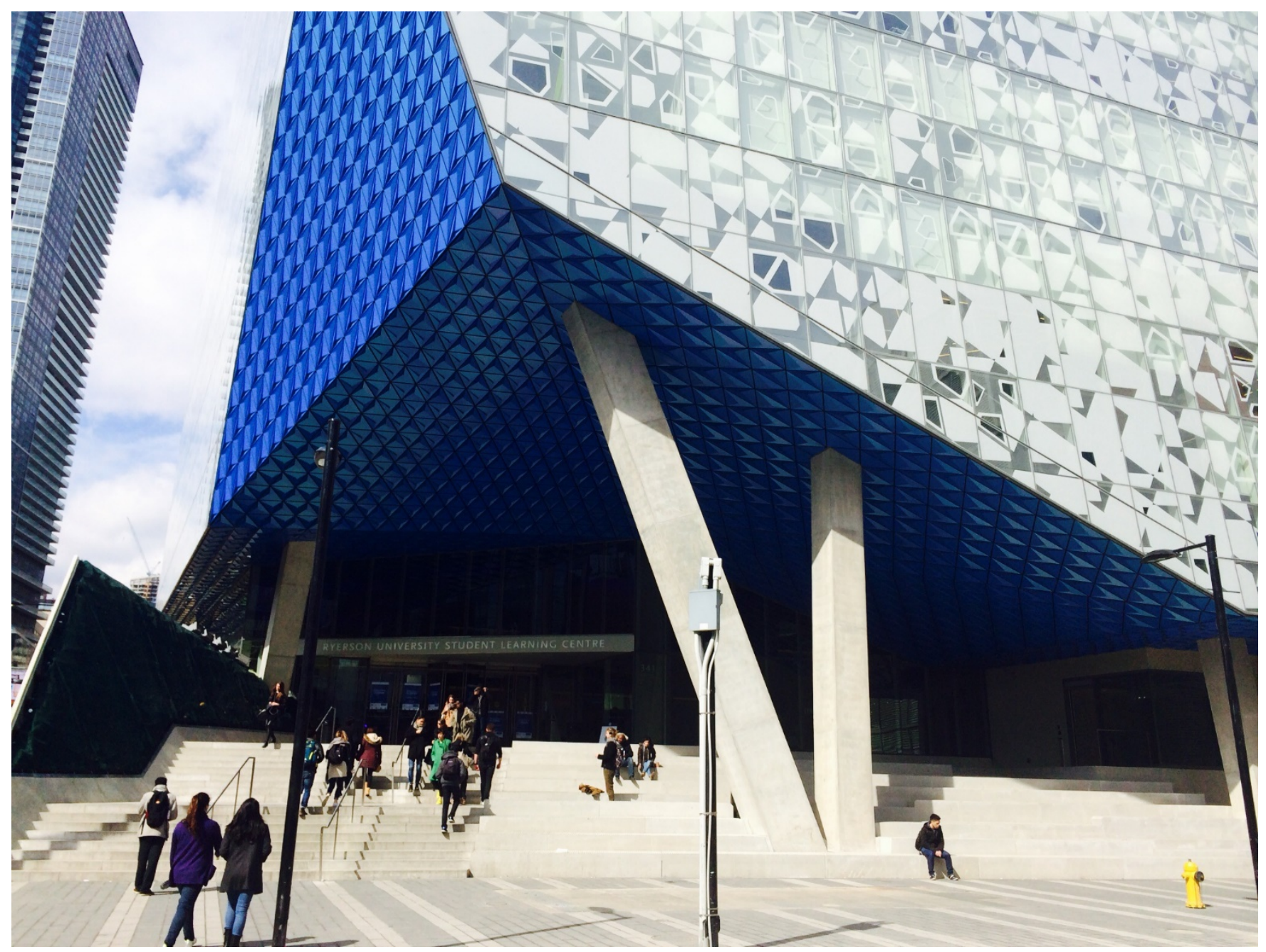

3.11 - Student Learning Center

This notion of 'safety by surveillance' can have great advantages in urban contexts. Eyes on the street as described by Jacobs is particularly evident in the Ryerson University's Student Learning Center. In this example, the open 'mouth' of the building, as an intermediary transition space between 'inside' and 'outside' creates a sense of community for the university by encouraging social cohesion.

The stairs of the building offer a place of rest, sheltered by the overhanging eave of the building. Bounded by two streets, the tiered seating creates a sense of safety though informal surveillance in the immediate vicinity. Even at the darkest hours of the night, the building attracts activity and thus promotes a feeling of safety around the clock, a notion that is not present in many other parts of the City of Toronto. 
Unity of Disparate Forms
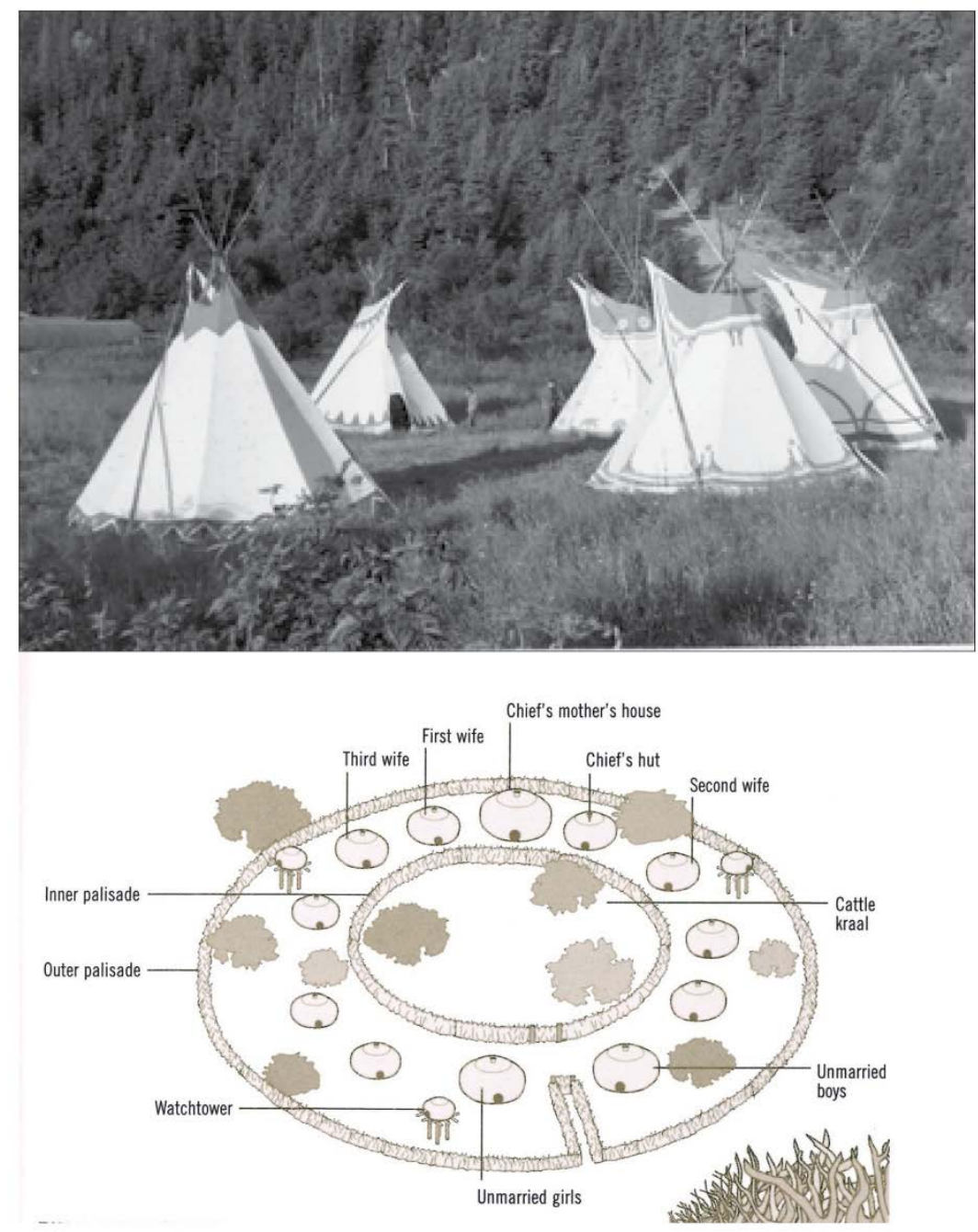

3.12 - Zulu Indlu - Image Retrieved from "Handmade Houses \& Other Buildings - John May"

Threshold spaces can also help to unite disparate buildings into a common habitable entity. Many examples of traditional architecture in the African context exhibit close association of several structures into an aggregate that closely reflects kinship ties of a community or clan. This might be viewed in contrast with building typically found in western cities where in general, singular building entities are erected on single parcels of land. This is common with commercial and high rise residential buildings found in city centers. This contrast is important to notice. In traditional African building, in addition to social structures, this may be a reflection of a more temperate climate year round and therefore less of a need to enclose space. Another possible reason for this might be the contrasting notions of permanency associated with vernacular African architecture and contemporary western buildings. 
The Maasai Enkang is characteristic of the aforementioned generalization of vernacular forms. A large compound space unties several smaller houses or enkaji in a similar way that the Zulu Indlu from the previous figure does. Strategies that describe how to best use communal space to best unite disparate forms would enable the longevity of this traditional practice into contemporary architecture.

\subsection{Summary of Threshold Space Case Studies}

Threshold spaces can be created in a variety of ways and as demonstrated in the previous examples. It is significantly shaped by the formal arrangement of the building. To better understand this, approximately 50 contemporary African buildings were analyzed to determine the primary massing strategies undertaken by architects to create threshold spaces. The following is a selection of floor plans from the case study analysis with the threshold spaces identified in orange.

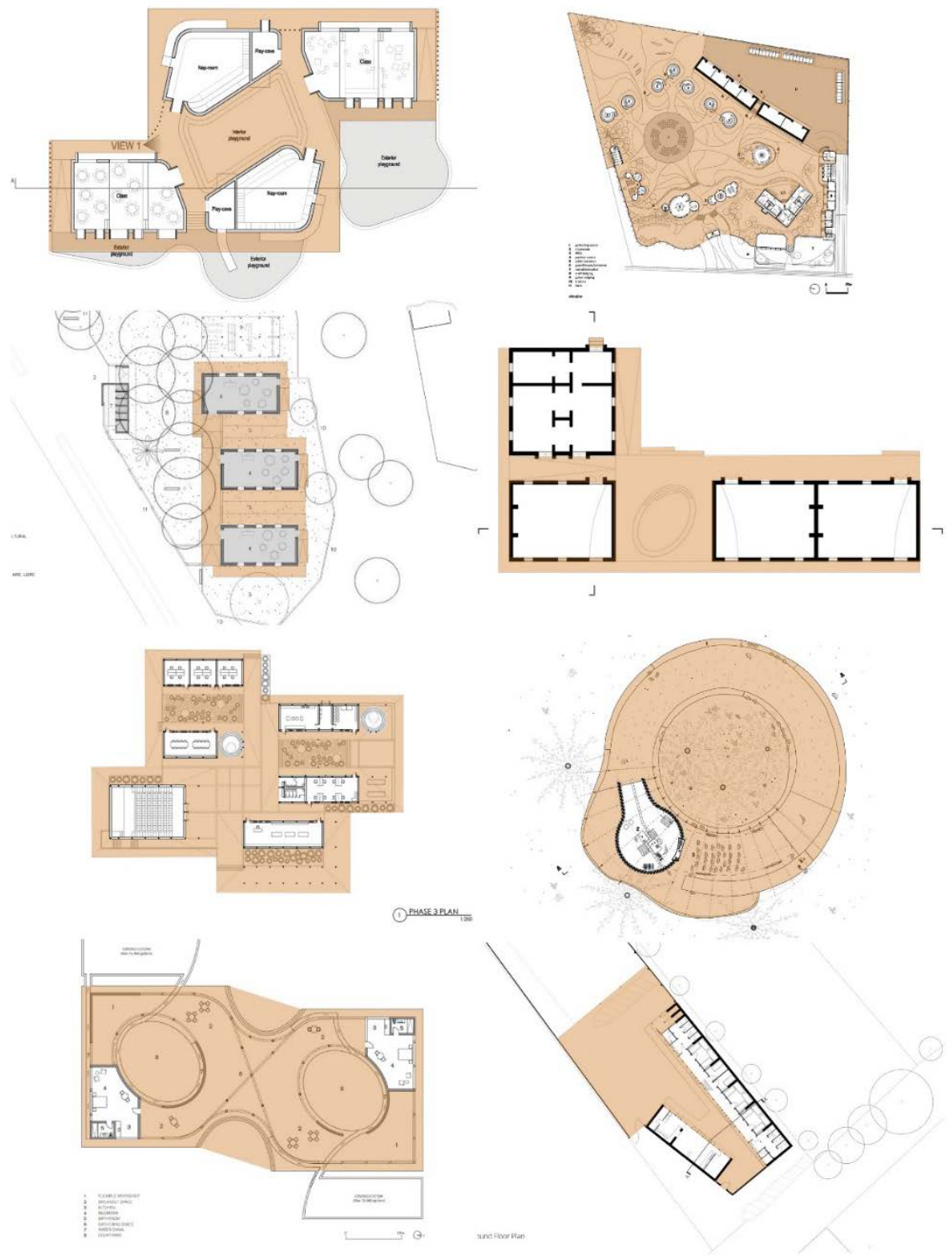

3.13 - Summary of Threshold Space Case Studies - Image by author 
Primary general conclusions to the case study analysis are illustrated in the charts that follow.

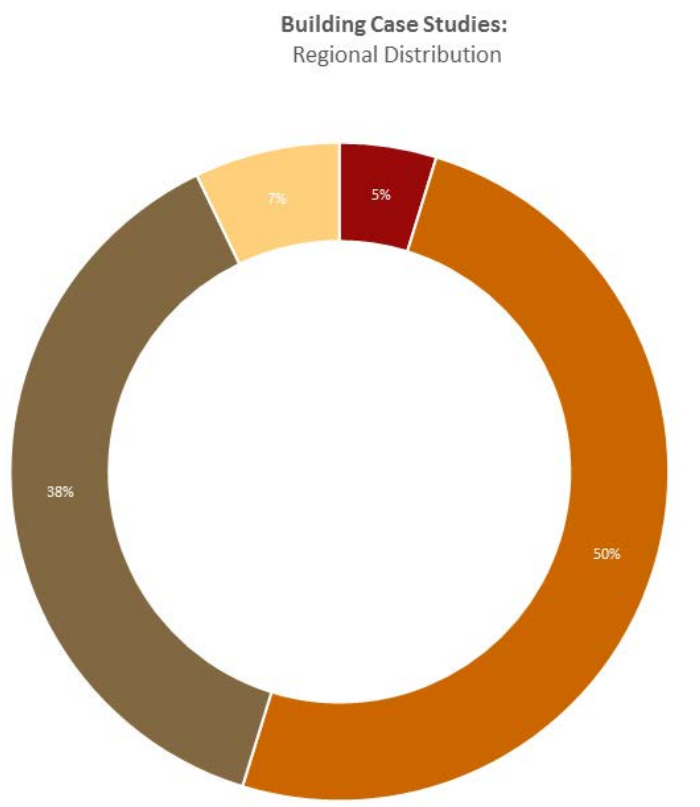

Building Case Studies:

Programmatic Distribution

- Northern Africa

- Western Africa

- Eastern Africa

" Southern Africa

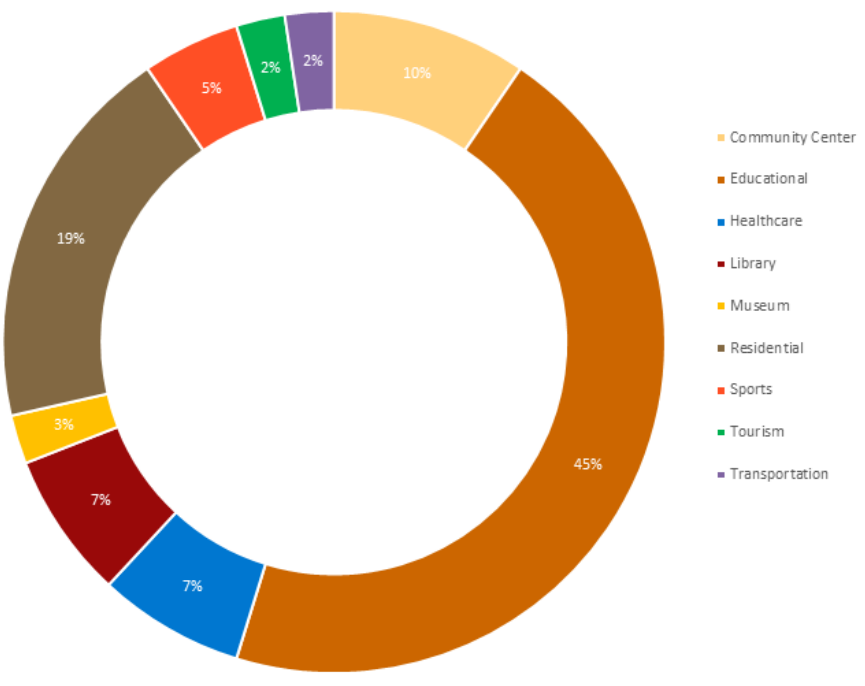

Building Case Studies:

Area Range Distribution

Distribution Across Geographical Contexts
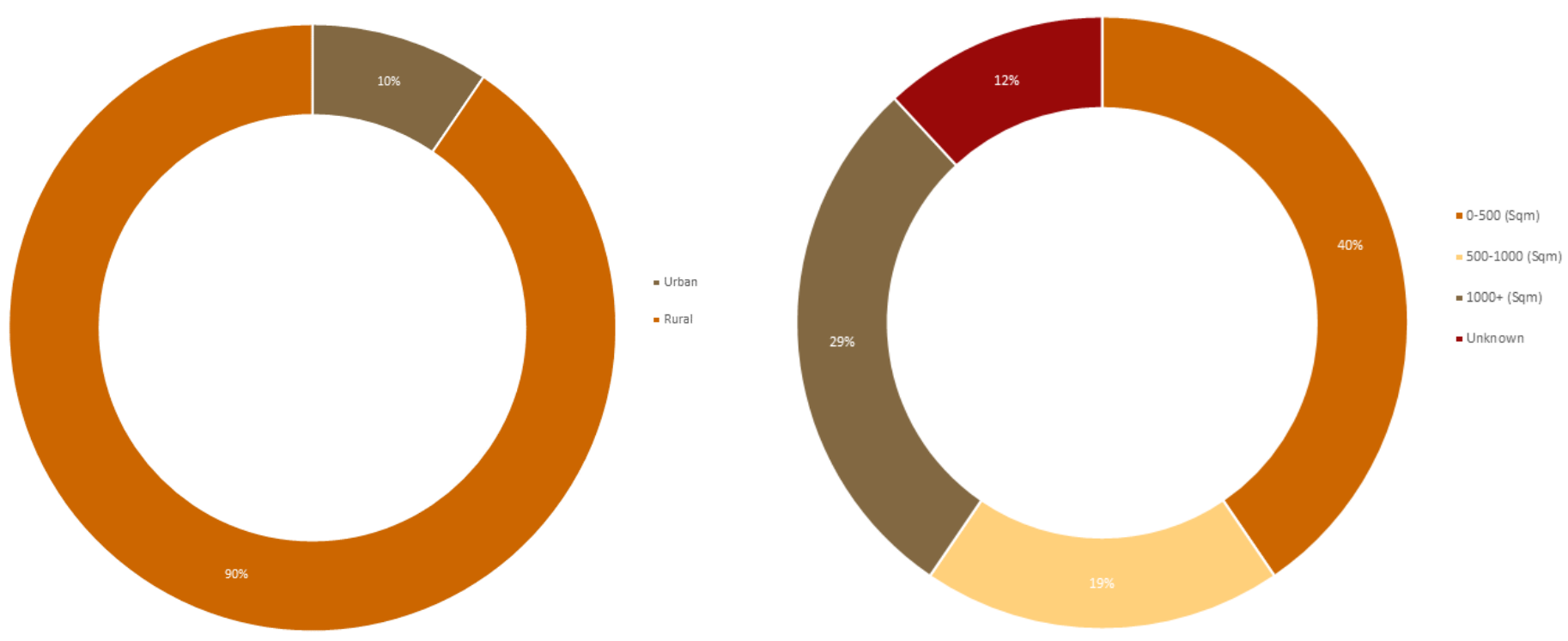

3.14 - Case Study Conclusions - General Data - Images by Author 
Building Case Studies:

Distribution of Cost (KSH per Sqm)

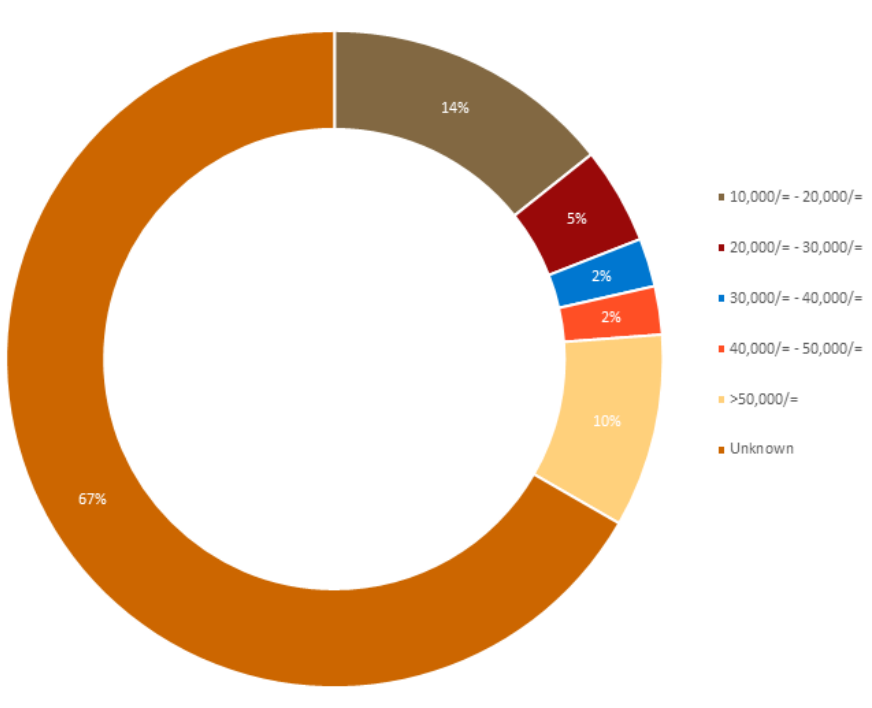

Building Case Studies:

Distribution of Cost (USD per Sqm)

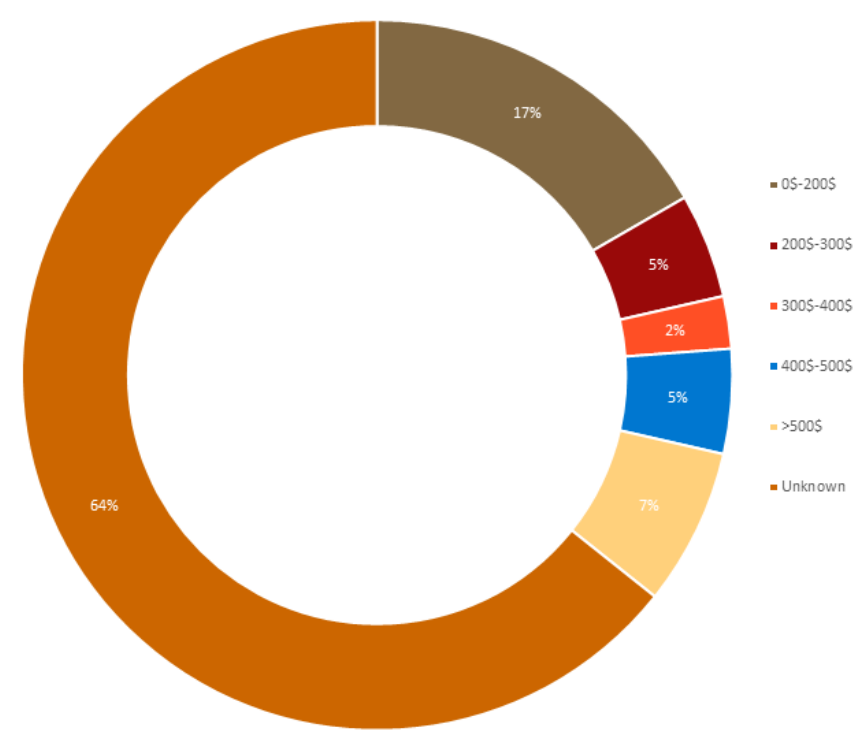

Building Case Studies:

Year Range Distribution

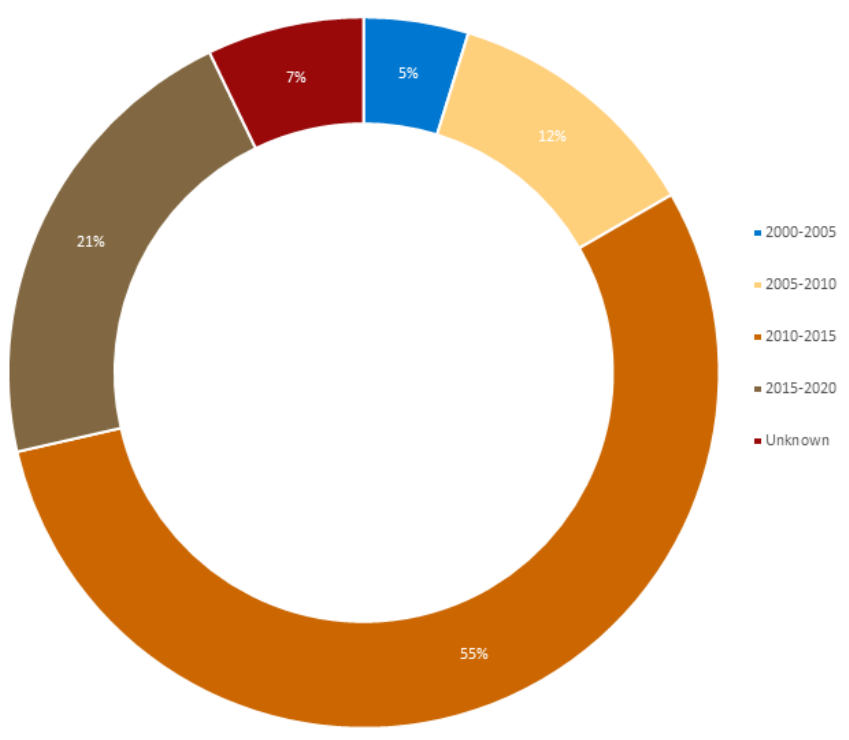

3.15 - Case Study Analysis - General Data - Images by Author 
The previous seven charts summarize a range of general information that was derived from the case study analysis. This information describes the case study projects in general terms. The parameters are as follows: regional distribution, programmatic distribution, distribution across geographical contexts, area range distribution, cost per area distribution (USD and KSH) and finally the project date distribution. These general parameters give an overview of the nature of the buildings that were studied. The next section will explore how these case studies expressed threshold space design elements and the next chapter will describe the role of participatory construction and local labour in the study. The general information is as follows:

From the fifty studies analysed, approximately 50\% of them are located in Western Africa, while Eastern Africa constitutes the second largest region at about 38\%. This data might suggest that both of these regions the highest rate of building activity according to popular publications.

Secondly, from the collection of cases selected, about $45 \%$ of the projects were related to education, and the second highest category was residential. The remaining functions were roughly evenly distributed amongst the following uses: community center, healthcare, library, museum, sports institutions, tourism and transportation. This might suggest that a majority of vernacular inspired buildings are being developed as educational buildings, primarily by non-governmental organizations.

Of the 50 building studied approximately $90 \%$ were found in rural contexts perhaps demonstrating that vernacular inspired architecture finds its relevance outside of the city serving the large rural population across the entire continent. Only $10 \%$ of the buildings that were collected were built in urban contexts.

The sizes of the buildings collected were distributed across four categories. The largest at approximately $40 \%$ was within the smallest range of 0 to $500 \mathrm{~m}^{2}$, the second at $19 \%$ within the range of $500-1000 \mathrm{~m}^{2}$. Lastly, $29 \%$ of the buildings were above the range of $1000 \mathrm{~m}^{2}$. Most of the case studies were therefore relatively small buildings.

The years that these buildings were constructed were organized according to four categories as well as one that was labeled as "unknown". The largest category was within the year range of 2010 to 2015, which constituted about 55\% of the case studies. The second largest category was within the range of 2015 to 2020 . The remaining buildings were rough evenly distributed across the remaining categories. This might suggest that vernacular inspired architecture is increasingly finding relevance, and increasingly drawing international attention due to the possible increase of publication online.

The next two diagrams speak to the distribution of cost of these buildings one of the charts uses US dollars while the other one uses can your showings. The majority of buildings were built within the zero to \$200 per square metre range indicating the relevance of vernacular inspired architecture in poor context. However, a large amount of data was unavailable or would have been a particularly tedious endeavour for the study.

In conclusion, the following generalizations may be articulated to loosely speak to the contemporary vernacularinspired architecture in Africa. These vernacular inspired buildings are most commonly found in rural Eastern and Western Africa and are usually small educational buildings which are primarily construction on a tight budget. 


\subsection{Threshold Space Taxonomy}

When looking at the floor plans, one can see the variety of formal massing strategies present. The Obama Nursey school utilizes a roof to create a sense of enclosure in the threshold space. The Maasai Enkang creates a threshold space through an aggregation of homes. The variety of strategies are represented in the following taxonomy diagram and physical models of each variation have been created to understand and communicate their spatial relationships and the way they support the four threshold design parameters.

The six darker squares that contain drawings are 'ideal types', showing the 'purest' form of a single threshold massing strategy. For example in the third type, forms are arranged in a ring. This shows how buildings can be arranged to create a sense of enclosure by means of the association of the buildings themselves. This is an additive strategy where forms come together to create a distinctive threshold space. Another example is the sixth strategy, a subtractive one, where a courtyard has been created from a form, creating a threshold space to be traversed by an occupant before

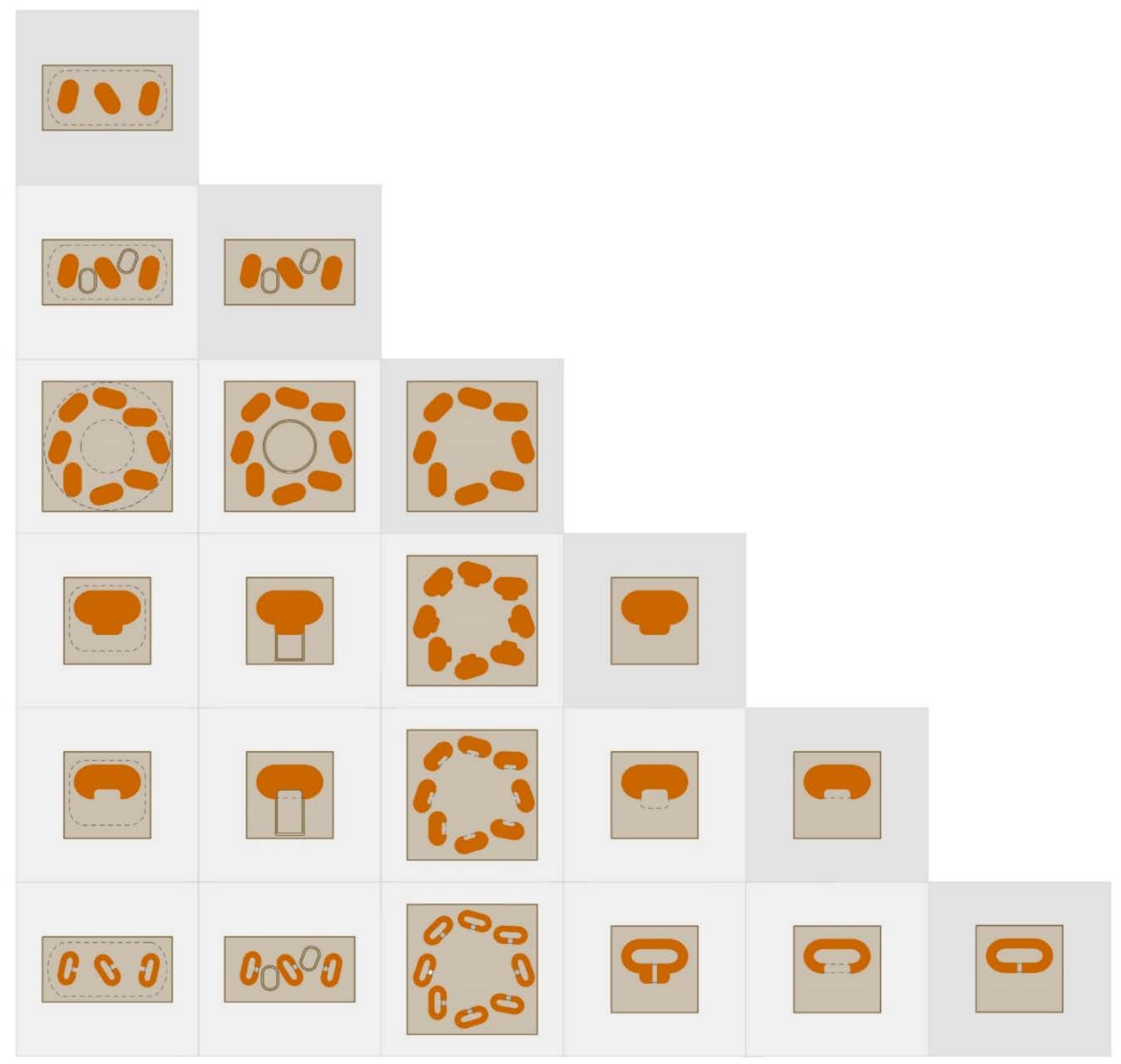


The remaining variations in the diagram represent combinations of strategies. Appendix 1 closely shows how this taxonomy can be used to categorize different case studies according to their threshold massing strategy. The following are a selection of images that depict physical models that were created.
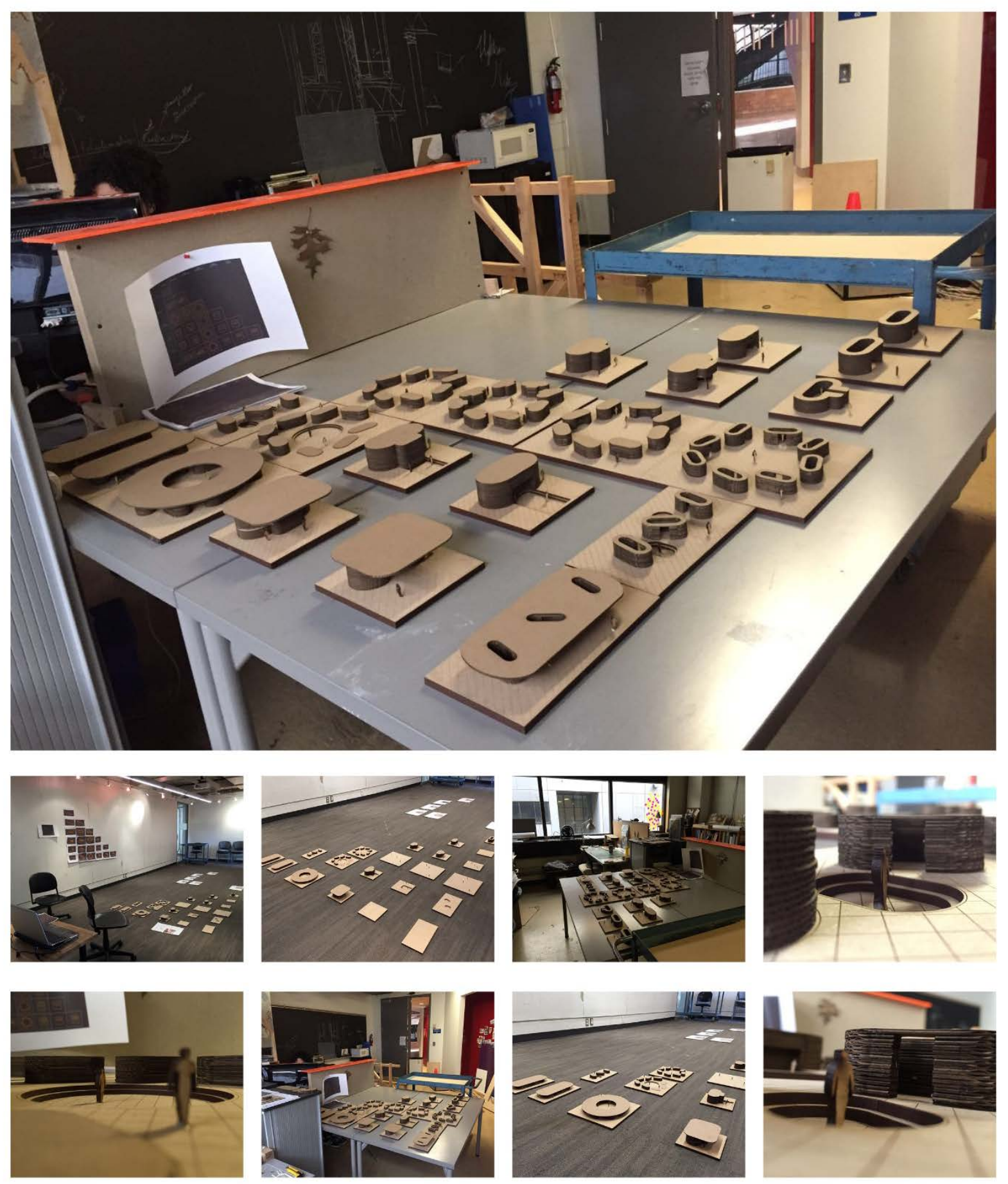

3.17 - Threshold Taxonomy Models - Image by Author 
The following two diagrams summarize information about threshold spaces in the contemporary 50 cases selected.

Building Case Studies: Use of Threshold Space
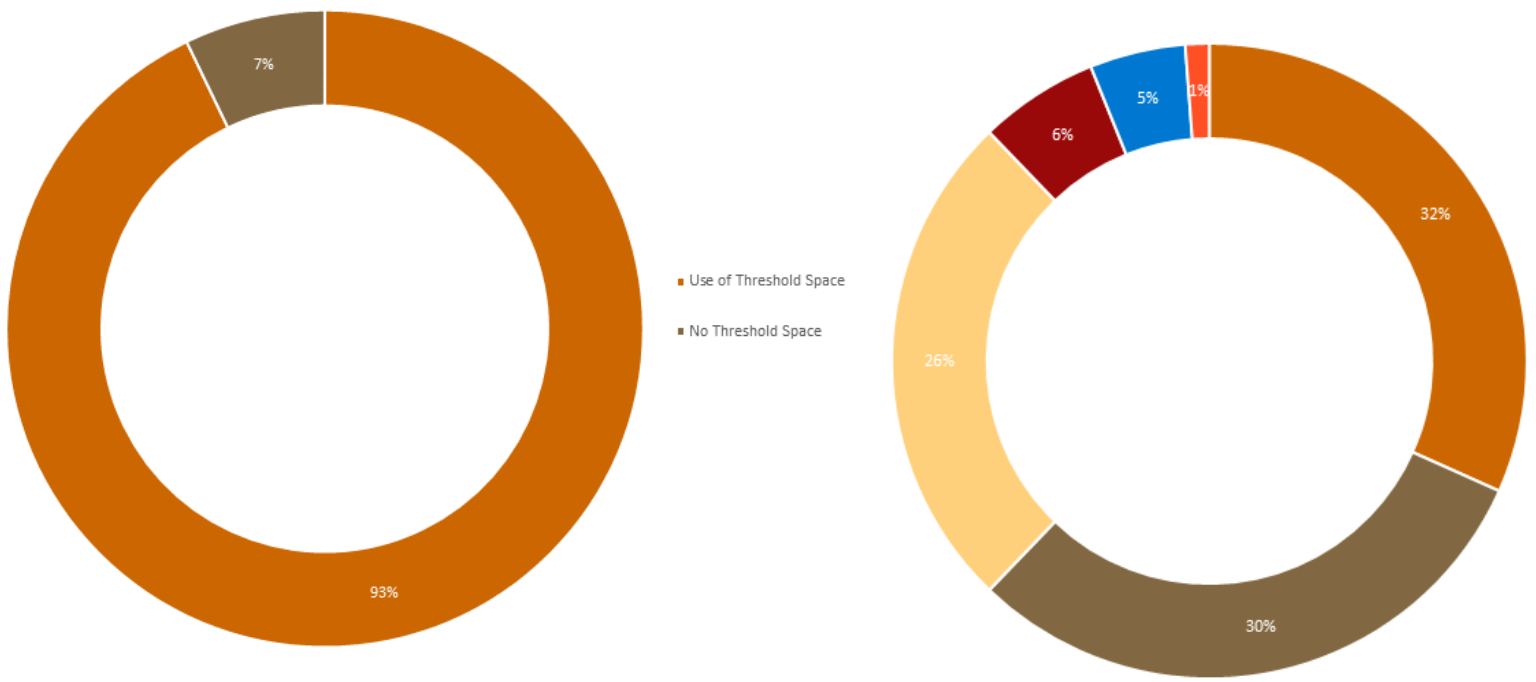

From the buildings studied, an overwhelming majority of them used some kind of threshold space in their design conception. Approximately $93 \%$ of the buildings use a threshold space and only $7 \%$ did not. This might indicate the paramount importance of threshold spaces in the relation of vernacular-inspired forms today.

Secondly of the projects that did use threshold spaces, an analysis was done to determine what kinds of strategies were most prominent to create them, based on the threshold taxonomy diagram that was described earlier. The categories seen in the second diagram represent labels that are not mutually exclusive. For example any single building might have multiple labels attached to it and therefore some buildings may have more labels and others.

As seen in the second chart, the most popular strategies that were used for creating threshold spaces in vernacular inspired architecture were "unifying roof", "unifying ground plane", and "additive: creation of enclosure". The least popular strategy was the "courtyard: subtractive". Other less popular strategies were "subtractive: form perimeter" and "additive: protracted transition". This data might suggest the following. The most effective, or most popular ways to create threshold spaces in vernacular-inspired architecture are to conceive of several buildings and draw relationships between them using roofs and well-designed ground planes. Interestingly, these are the three most prominent strategies that are used in the creation of the Maasai traditional homestead. In the final design chapter, these strategies will manifest themselves in a variety of ways to create a contemporary threshold space that serves as a Maasai communal space at a cultural center. 
100 Denyer and McClure, African Traditional Architecture: An Historical and Geographical Perspective, 160.

101 Ibid., 21.

102 El Wakil and Steele, Hassan Fathy, 7.

103 Till Boettger and Egon Schirmbeck, Threshold Spaces: Transitions in Architecture: Analysis and Design Tools, trans. Helen Labies-Volz (Basel; Boston: Birkhäuser, 2014), 4.

104 Ibid.

105 Ibid., 10.

106 Ibid., 12.

107 Ibid., 22-24.

108 Ibid., 25-26.

109 Ibid., 26-27.

110 Herman Hertzberger, Architecture and Structuralism: The Ordering of Space, trans. John Kirkpatrick, Polyvalence (nai010 publishers, 2014).

111 Jane Jacobs, The Death and Life of Great American Cities, Vintage Books ed. (New York: Vintage Books, 1992).

112 Ibid., 35.

${ }^{113}$ City of Toronto, "Tall Buildings Design Guidelines," ed. Urban Design (Toronto: City of Toronto, 2013).

114 Jacobs, The Death and Life of Great American Cities, 37.

115 Ibid., 38. 


\section{Chrysalis: User Participatory Construction}

\subsection{Vernacular: User Agency}

"Trust in people. Trust in people. It's an extraordinary phenomenon of development that the most powerful force is people changing their own environment. What they need in many cases is the wherewithal to change."

- His Highness the Aga Khan

Chairman and founder of both the Aga Khan Development Network (AKDN) and the Aga Khan Award for Architecture (AKAA)

The above sentiment speaks to a foundational principle of social development today, the utmost importance attached to the notion of people being the masters of their own destinies. Communities living in poverty can themselves be enabled with the tools and processes to change their own future. In general, aid is best provided to a people group in need when it fulfills this principle. Within the traditional context of architecture, this is rarely a principle that translates well and in fact is contributive to the presence of poorly integrated transplanted forms in the context of social and community development (An example to follow in chapter 5 ).

The Contemporary Process of Architecture

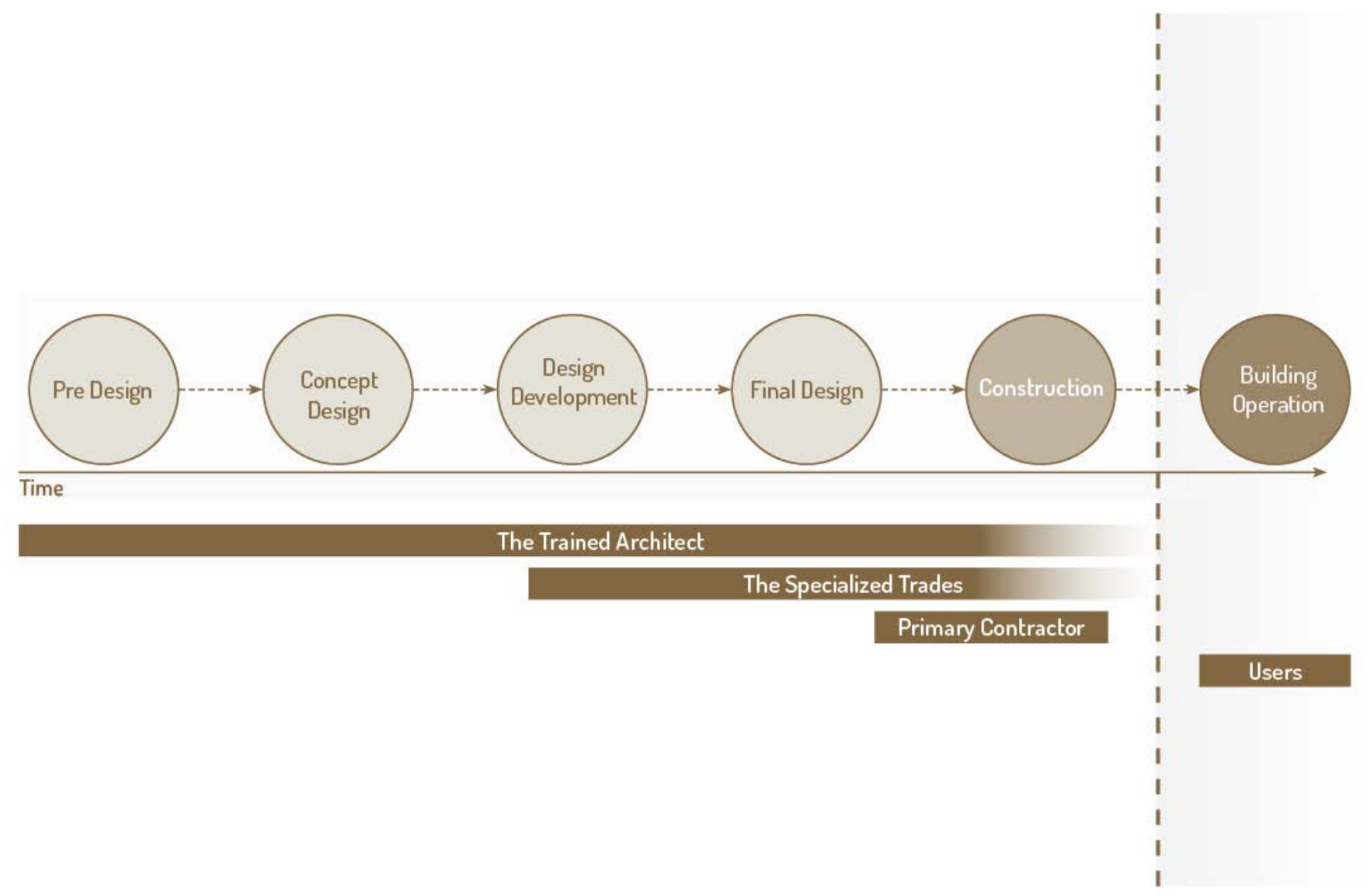

4.1 - The Traditional Process of Architecture - Image by Author 
The traditional building process does not deeply involve users as an active contributors. The users of building, in the contemporary building process, sometimes provide input to the contracted architect as a client at the outset.

However, as the process evolves over several stages, the client or in many cases, the users have little engagement until they take occupancy. This is demonstrated in the above diagram with the dashed line to the right of the page.

This process does not lend itself well to user creativity or in fact, user participation of any kind. While it might be initially unorthodox to imagine a process where the users and architects are more intimately intertwined in the process, when viewed in the context of the social development principle presented at the beginning of the chapter, the contemporary building process is in direct opposition that that notion. Users or clients are treated as static entities that sometimes commence and then finally receive a completed building. This is of course an understandable reality as the construction of buildings requires the extensive training. However, there have been many examples of user participatory design in architecture and even fewer examples of user participatory construction in architecture. The collaboration of architect and user is paramount to these approaches and often the building's tectonic resolution is not predicated on complex technologies so as to enable the involvement of the so-called "unskilled" lay person.

This is a notion that is increasingly taking root in the new African vernacular approaches today, most notably in the work of Francis Kere. However, Hassan Fathy recognized the dangers of building that relied too heavily on complex, expensive technological approaches in the mid 60's in response to the rise of Architectural Modernism in Egypt. He writes in Architecture for the Poor:

"Engineers and architects concerned with the cheap ways of building for the masses had devised all sorts of complicated methods for constructing vaults and domes. Their problem was to keep the components in place until the structure was completed, and the solutions had ranged from odd shaped bricks ... through every variety of scaffolding, to the extreme expedient of blowing up a large balloon in the shape of the required dome and spraying concrete onto that. But my builders needed nothing but an adze and a pair of hands."116

\section{- Hassan Fathy}

Egyptian Architect and author of Architecture for the Poor

Fathy's comment illustrates his innovative building response to the status quo of "high-tech" construction the time. However, his "innovation" was to return to vernacular ways of building, a notion that certainly would be perceived as quite contrary to the meaning of the word. Fathy succeeded in updating traditional building techniques to advance a new generation of vernacular-inspired architecture. His work used to labour of local artisans and frequently discarded the building techniques associated with Architectural modernism. This however meant that he had to use construction processes that in contrast required more intensive labour.

This is a phenomenon that made Francis Kere's 2001 Gando school arguably one of the most influential vernacularinspired contemporary works on the contemporary African architecture stage. The primary school, located in Gando, Burkina Faso and pictured in the following figure, was unique in that it used local community labour in the construction process, a phenomenon which is exceptionally rare in contemporary most building activity in the developed world. In the Aga Khan Award for Architecture Report, Kere writes upon completion of the project about the notion of participatory construction. 
"I shall never forget how the village community threw themselves into the adventure of constructing their own school out of clay and using the most primitive tools with an indescribable eagerness and enthusiasm and with a commitment that they had never shown before. For whole hours, days, weeks and months they used their bare hands to dig out and sieve the clay which was

transported in donkey carts to the building site. And the women of the village would bring the water that was needed for construction, carrying it on their heads sometimes from over a distance of 7 kilometers"117

- Francis Kere

Architect

As a result of the volunteerism seen through the community's efforts to build the school, Kere estimated that the overall cost of the building was about a third of the cost of a similar but more conventional structure. Kere's methods have opened a door to the notion of participatory architectural practices in contemporary African architecture.

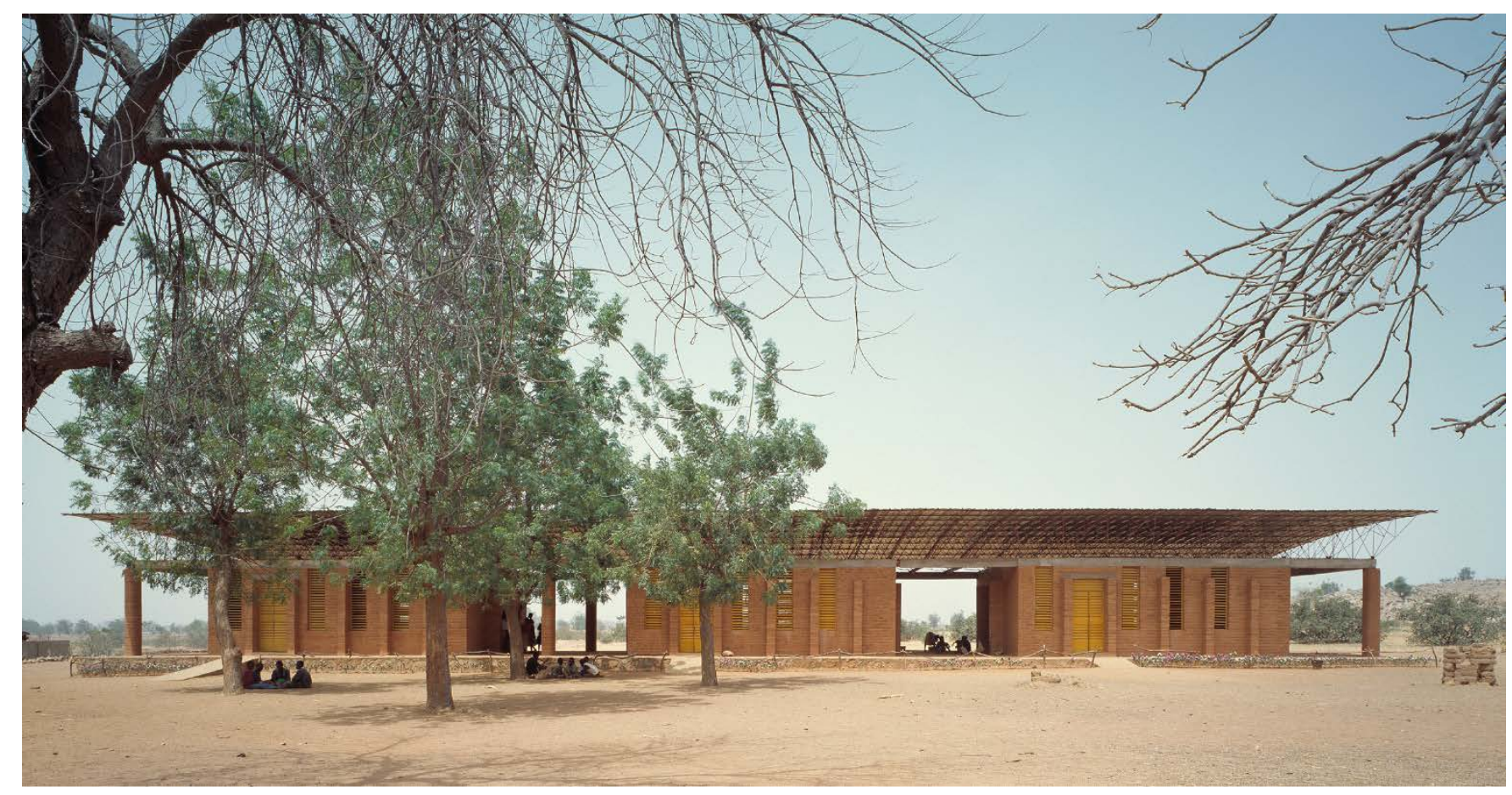

4.2 - Gando Primary School by Francis Kere - Image retrieved from "AKDN.org"

\subsection{Participatory Construction in Contemporary Practice}

Kere's quote highlights the critical relationship between participatory construction and the tectonic conception of a building. It is paramount that buildings be designed in a way that lend themselves well to low tech construction methods for the purpose of harnessing un-skilled labour. While of course there are exceptions, repetitive "lowtech" tasks have proven to be quite well suited for contexts such as Gando. For example the choice of earthen blocks meant that the community could play a role in creating them and perhaps transport, cutting costs significantly. 
Therefore, drawing inspiration from these practices employed in the Gando School, the notion of participatory construction was examined in the aforementioned case study analysis. From the 50 buildings that were studied, data was collected to determine relationships between the tectonic resolution of the building and the inclusion of participatory construction techniques. The following charts summarize the findings.

Building Case Studies: Locally Driven Construction

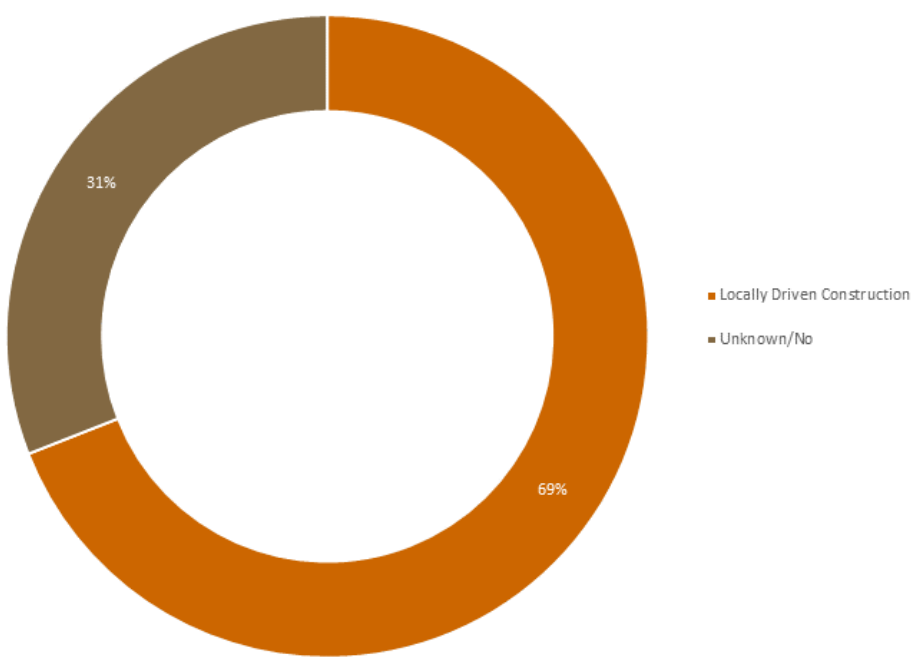

Building Case Studies: Distribution of Roof Cladding Materials

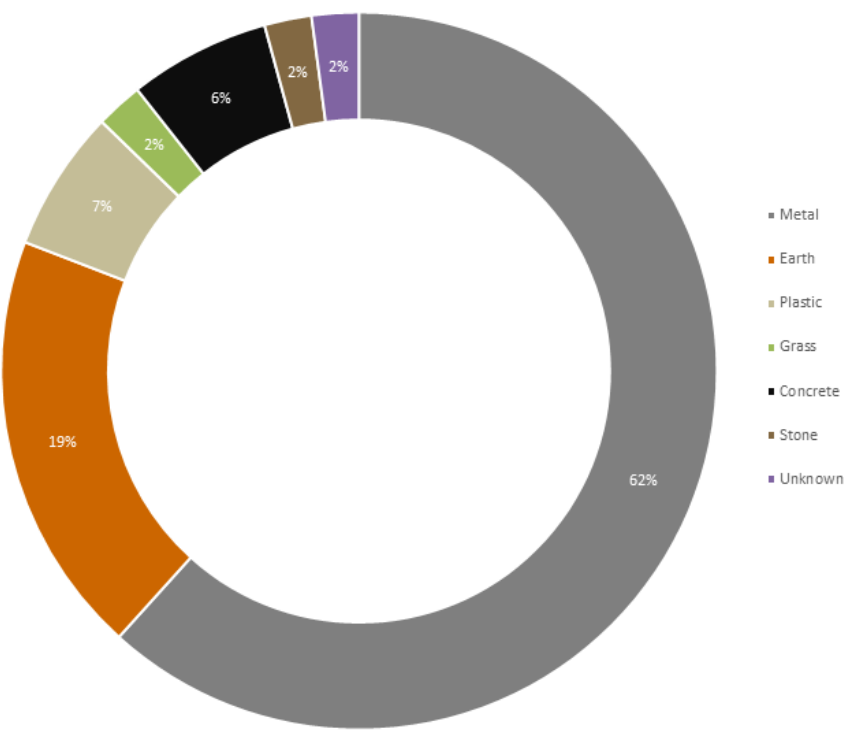

Building Case Studies: Distribution of Roof Structure Materials

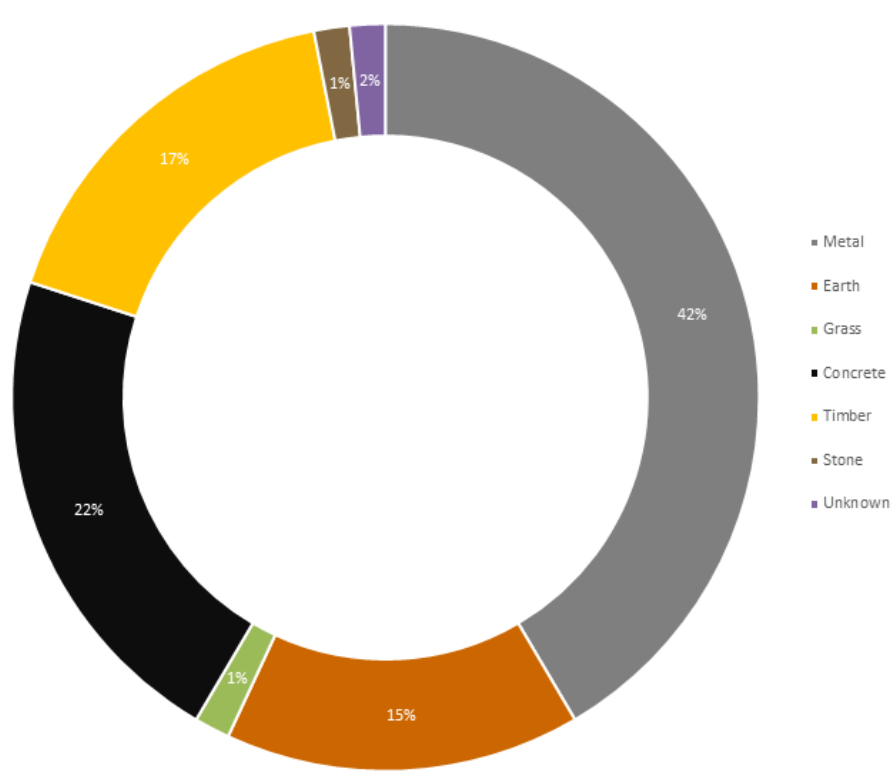



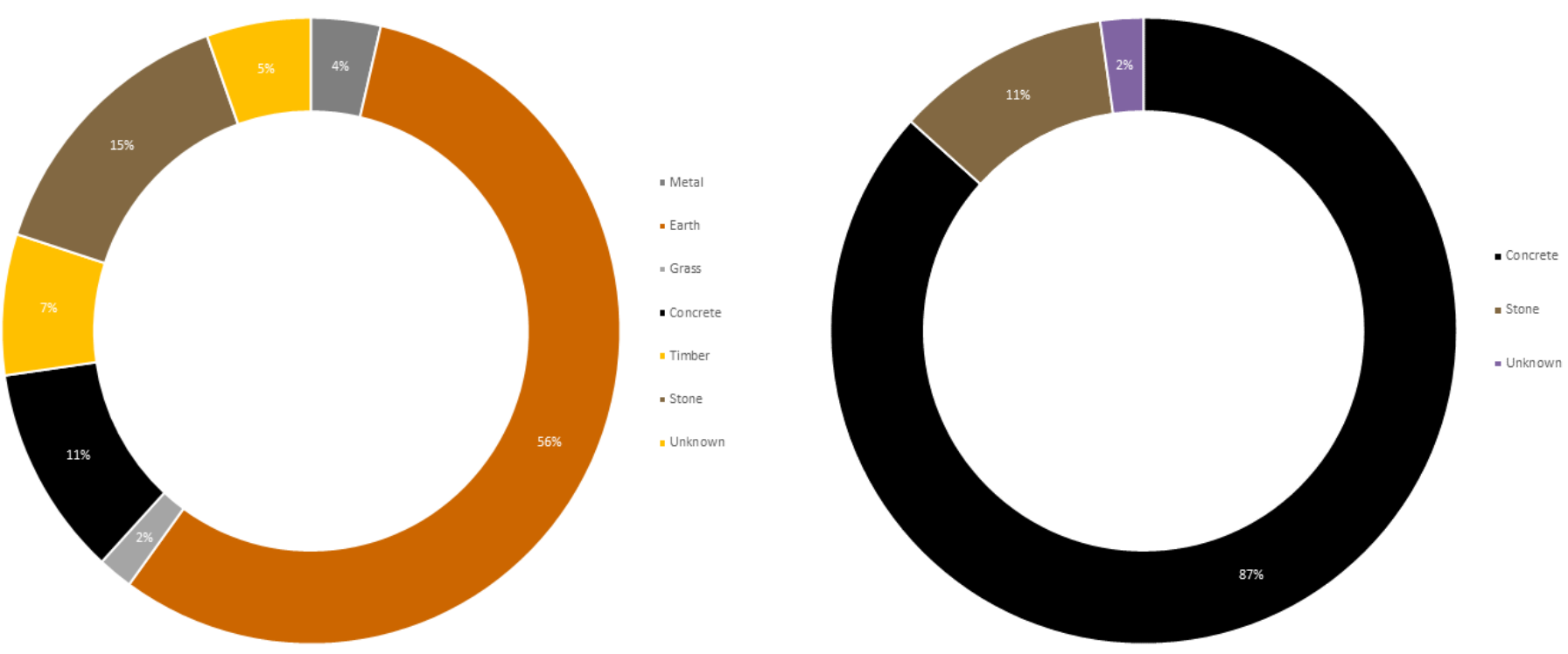

4.4 - Case Study Analysis - Participatory Construction - Figure by Author

50 Case studies were examined to identify the frequency of locally driven construction methods or the presence of participatory construction techniques. It was found that out of selection of buildings, approximately $31 \%$ of them included some method of participatory construction or locally driven construction. These methods were therefore found to not be popular in the processes of the many vernacular-inspired contemporary buildings. This is unlike the previous section in the thesis where an overwhelming majority of the buildings utilized some form of threshold space. As previously mentioned, understanding the link between the materials choices and tectonic resolution with that of participatory construction methods is critical so as to facilitate a participatory process early in the design development. The following analyses therefore analyze the various "material systems" that were employed in the buildings.

The materials employed in buildings were analyzed across four categories; the roof cladding material system, primary structural material system, wall material system, and lastly the foundation material system. These categories were created to draw relationships between the role of the architect and the role of local labour or informal labour in the construction process.

It was found that for the roof cladding material system, the most popular material was metal, almost always seen as in corrugated sheet form. The second most popular of roof cladding material was earth, often times used in the form of a second skin below a primary cladding system. This double skin system was utilized for Kere's Gando school.

The roof structure materials were distributed as follows. Approximately $42 \%$ of the case studies employed metal as the primary material to hold up the roof structure. Timber, concrete, and earth were less but equally popular 
materials for the roof structure, each accounting for about $15 \%$ to $20 \%$ of the case studies. Lastly, rarely were stone and grass used for the roof structure.

For the wall materials. And overwhelming $56 \%$ of case studies utilized earth in the wall material system. The secondary materials that were chosen ranged from concrete, to timber, to stone, and finally metal, each of these ranging from about 4 to $15 \%$ of the total amount.

The last material system that was analyzed was the foundation. The foundation systems employed a narrow range of materials. An overwhelming $87 \%$ of buildings used concrete in the foundation, and secondly stone was also used in approximately $11 \%$ of the buildings. In almost all the buildings was the foundation built in the same way: concrete foundation with stone hard-core infill.

In conclusion, as each building reflects the contextual specificities of environment and available materials, it can be difficult to draw general conclusions about material systems that have been employed, the rationale behind their selection and their relationships to participatory construction and local labor. However, in general, many of the assembly methods utilize low-tech systems. Earth was a very common material, often manufactured on site. When detailed appropriately, earth appears to be a material that lends itself to low tech assembly methods, particularly when it is formed with an earth press on site. The most popular material for roof cladding was corrugated metal.

It is interesting to notice the many authors that have referred to today's informal settlements and shantytowns as the "new vernacular". The rationale frequently provided is that formally trained architects are almost never directly involved in their formulation. Therefore the conception of slums and shantytowns originates from the occupants themselves and their ways of building are transmitted in a similar fashion as the vernacular forms from the past. One of the common materials employed in these contexts is corrugated metal. This is primarily because it is lightweight and therefore easy to transport. It is also relatively cheap, quite durable and easy to assemble. It is therefore interesting to notice the popular presence of corrugated metal in these 50 vernacular-inspired case studies. In addition to earth, corrugated metal might therefore might be considered to be a "vernacular material". These two materials were employed to design a single house for the Maasai community near Sekenani, where the site of the thesis design project: the Maasai cultural center is also located. This project was completed as an experiment to identify how the material choices of metal and earth could be used to develop a low cost building whose construction methods would enable the participation of community members.

\subsection{0-Sampurumpuru: Butterfly House}

Project Analysis

Butterfly House, is a schematic proposal for a low cost housing model for a Maasai community group in Kenya. The project seeks to continue the Maasai vernacular tradition of user agency in the building process while introducing new regionally sensitive building techniques that are inspired by global best practices.

The project utilizes interlocking stabilized soil blocks (ISSB) and locally grown bamboo as its primary materials, thereby minimizing the building's cost and embodied energy. These materials enable the participation of 'unskilled' community members in collaboration with specialized trade workers, allowing the construction process to become a community skills-training opportunity. The refinement of these learned building techniques over subsequent community-led building projects can be studied by architects, challenging their traditional role, as local users are 
invited to learn, build, and innovate in the design process. Butterfly House therefore seeks to be scalable and replicable.

The process of participatory construction might foster a communal sense of ownership over the proposed building techniques, and enable the growth of a small indigenous Maasai artisan labor force. As women are the traditional builders of the vernacular forms, this project can continue and enhance that role within Maasai patriarchal society.
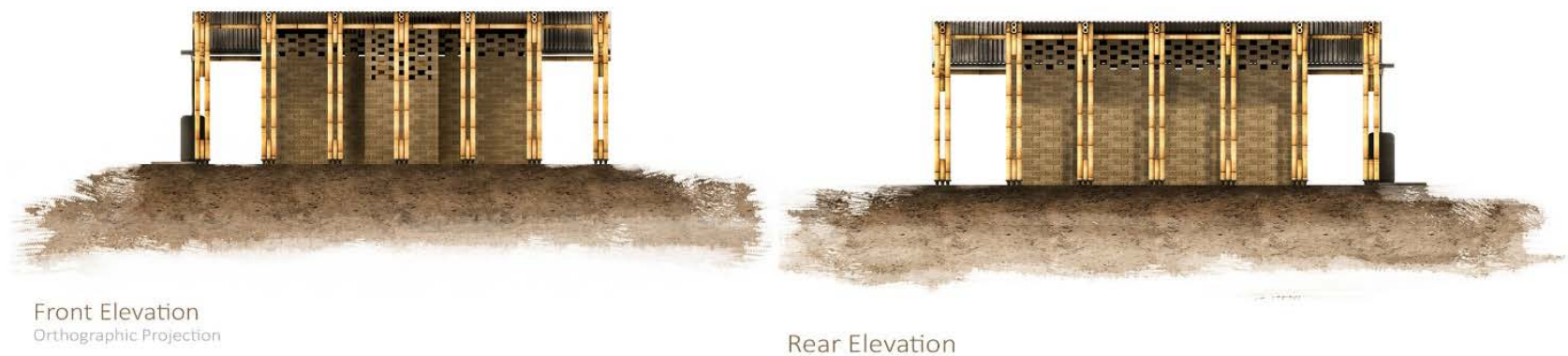

Rear Elevation Orthographic Projection

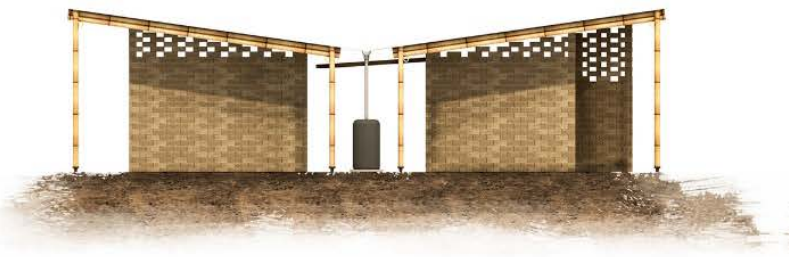

Side Elevation

Orthographic Projection

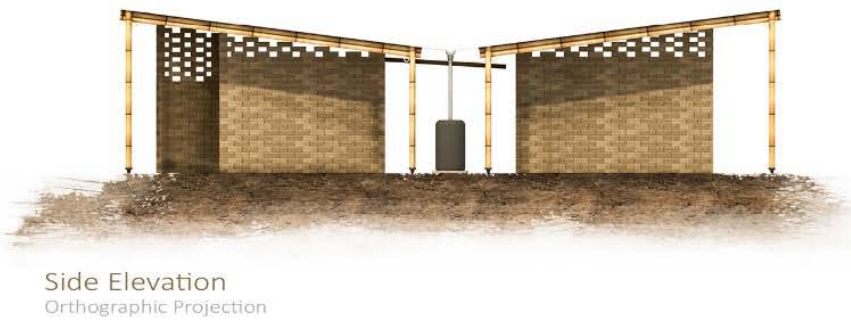

4.5 - Butterfly House: Elevations - Image by Author

The proportions and primary spatial arrangement as seen in the following orthographic drawings are derived from the traditional Maasai Enkaji, or house (extensive discussion of Maasai vernacular architecture is present in Chapter 5). In the plan, a small protrusion houses the hearth which traditionally occupied the center of the plan but however made the interior of Maasai houses quite smoky due to an inappropriate design for the fume exhaust. When viewed in the elevation, this new hearth culminates in perforated brick façade, as seen in the front elevation. This allows smoky air to escape from the house using passive design techniques.

From the elevations, the v-shaped form of the roof becomes apparent, earning the project the name Butterfly House. In the elevations, large roof overhangs are present to encourage informal gathering at the perimeter.

\section{Materials}

The floor plan dimensions begin to hint at the specific nature of the materials that were selected, the odd dimension numbers are based on the module of the standardized stabilised soil bricks that are becoming increasingly popular in the area. These soil blocks are made on site with a block press which require only a YouTube 
video to be watched in order learn how to make them. The blocks are interlocking and therefore can be stacked with significantly less mortar. In fact mortar is used only at the corners for reinforcement. Therefore these stabilised soil blocks enable the participation of a lay person.

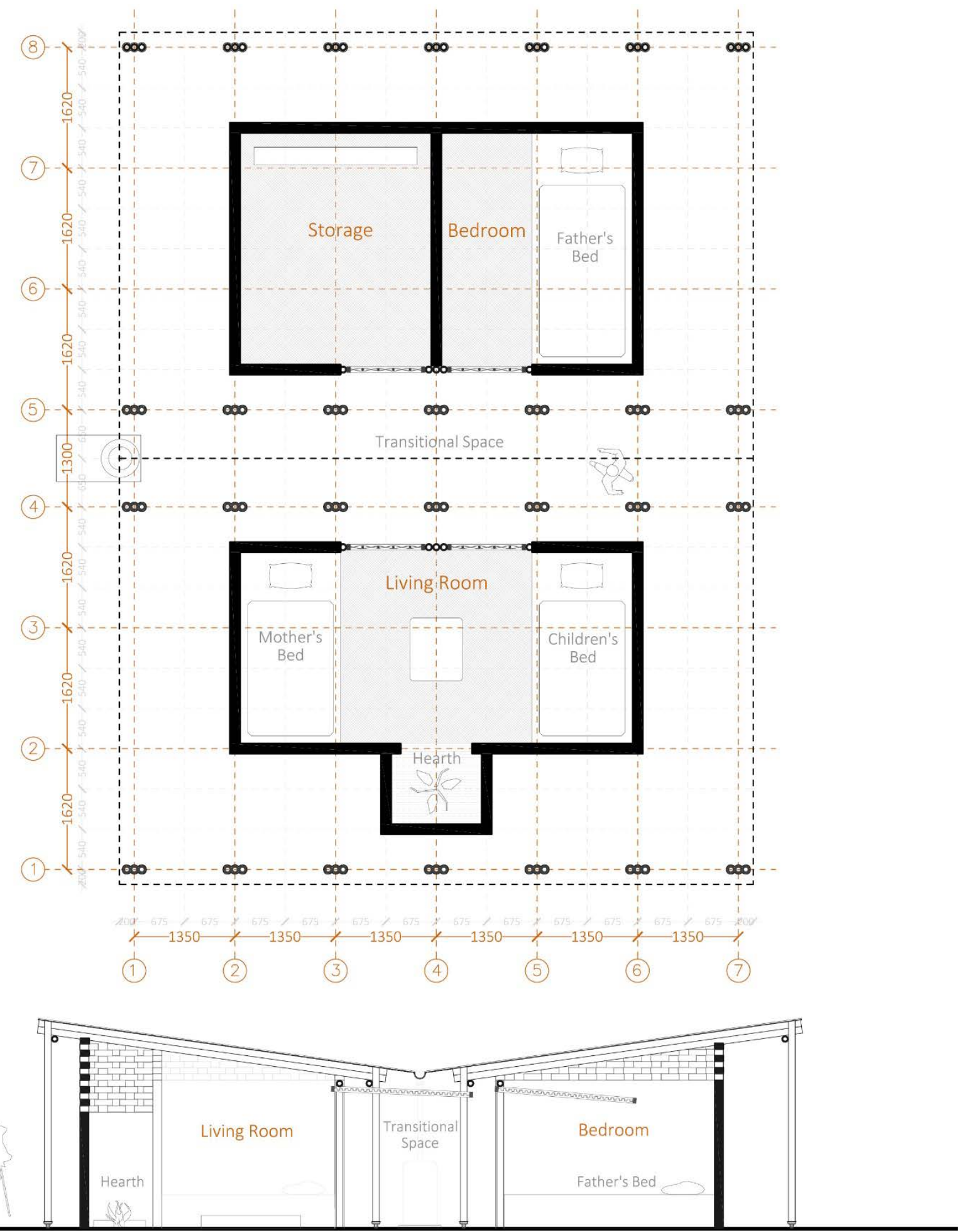

4.6 - Butterfly House: Floor Plan and Section - Image by Author 

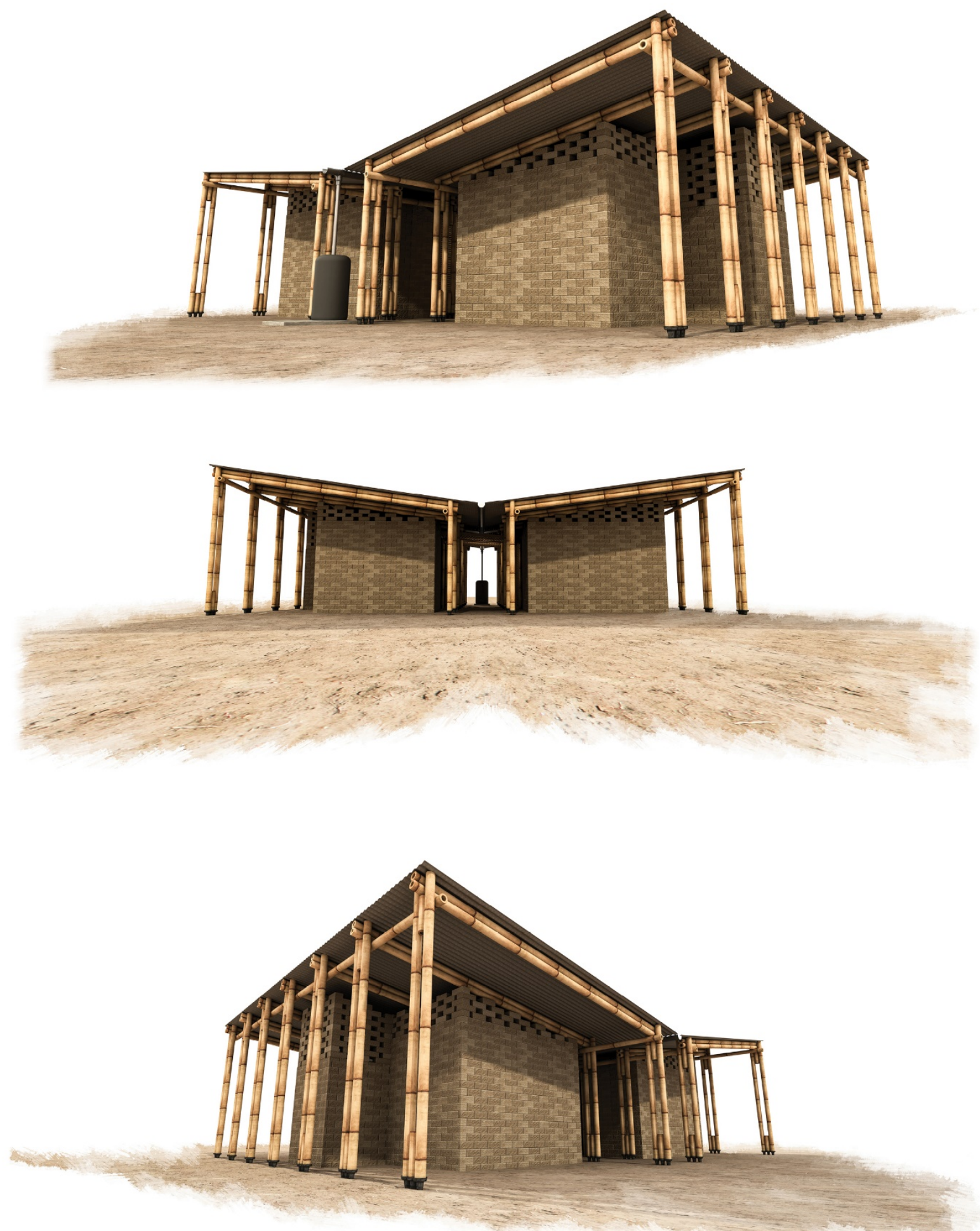
The corrugated roof is supported by golden bamboo columns which are found near a river about 10 kilometers away from the site. Bamboo has a rich history in the vernacular architecture in other parts of Africa but more so in Asia. It was however outlawed for commercial use during a previous presidential administration. As a result, this opportunities surrounding bamboo construction are immense for Maasai Mara. Known as an extremely sustainable material, bamboo grows incredibly quickly and can be used in the structure of buildings as both compression and tension members. With a rich history of being used in vernacular architecture, numerous detailing methods are known that require only rope or twine to bind the members together. The details used for the project were derived from the Bamboo Construction Handbook. ${ }^{118}$

\section{Costing}

As will be described in Chapter 5, a traditional Maasai house costs about 30,000 KSH or about 300 USD. Alternative contemporary proposals in the Maasai context significantly discard the financial status of many community member and so the widespread acceptance of a low cost house is yet to be realized. Costing about 250,000 KSH or about 2500 USD, Butterfly House is within the affordability range of many community members. The pricing below was determined by the author by checking the costs of all the materials at a hardware store in the nearby town of Narok in collaboration with a local tradesman.

\begin{tabular}{|c|c|c|c|c|}
\hline Item & Unit Price (Ksh) & Unit Type & Quantity Required & Total Cost \\
\hline \multicolumn{5}{|l|}{ Structure } \\
\hline Bamboo Poles & 190 & pole & 115 & 21,850 \\
\hline Mild Steel Footing & 300 & custom designed footing & 34 & 10,200 \\
\hline \multicolumn{5}{|l|}{ Chemical Treatment (borax) } \\
\hline \multicolumn{5}{|l|}{ Sisal Rope $\left(0.5^{\prime \prime}\right)$} \\
\hline \multicolumn{5}{|l|}{ Rainwater Harvesting System } \\
\hline Corrugated Steel ( 30 guage, $0.85 \mathrm{~m} \times 3 \mathrm{~m}$ ) & 760 & sheet & 40 & 30,400 \\
\hline PVC Gutter (140mm x 5m) & 1,550 & pipe & 2 & 3,100 \\
\hline PVC Downpipe ( $82 \mathrm{~mm} \times 4 \mathrm{~m})$ & 500 & pipe & 1 & 500 \\
\hline Downpipe Clip & 65 & clip & 1 & 65 \\
\hline Tank (500L) & 6,800 & tank & 1 & 6,800 \\
\hline \multicolumn{5}{|l|}{ Screws } \\
\hline \multicolumn{5}{|l|}{ Door } \\
\hline Bamboo Poles & 190 & pole & 12 & 2,280 \\
\hline Woven Bamboo Door (timber frame) & 2,500 & door & 4 & 10,000 \\
\hline \multicolumn{5}{|l|}{ Interlocking Stabilized Soil Blocks } \\
\hline Block Press Machine & 75,000 & machine & 1 & 75,000 \\
\hline Bricks (including labour, cement, soil) & 15 & brick & 2800 & 42,000 \\
\hline Cement (50 kg) & 750 & bag & 4 & 3,000 \\
\hline Soil & - & & & - \\
\hline Water & - & & & - \\
\hline \multicolumn{5}{|l|}{ Labor } \\
\hline Architects Design & 10,000 & design drawings & 1 & 15,000 \\
\hline Architects Material Research & 15,000 & local material research & 1 & 15,000 \\
\hline Architects Site Supervision & 2,000 & daily site supervision & 5 & 10,000 \\
\hline Laborers & 400 & day & 5 & 2,000 \\
\hline Working Total & & & & 247,195 \\
\hline
\end{tabular}

4.8 - Butterfly House: Costing - Image by Author 

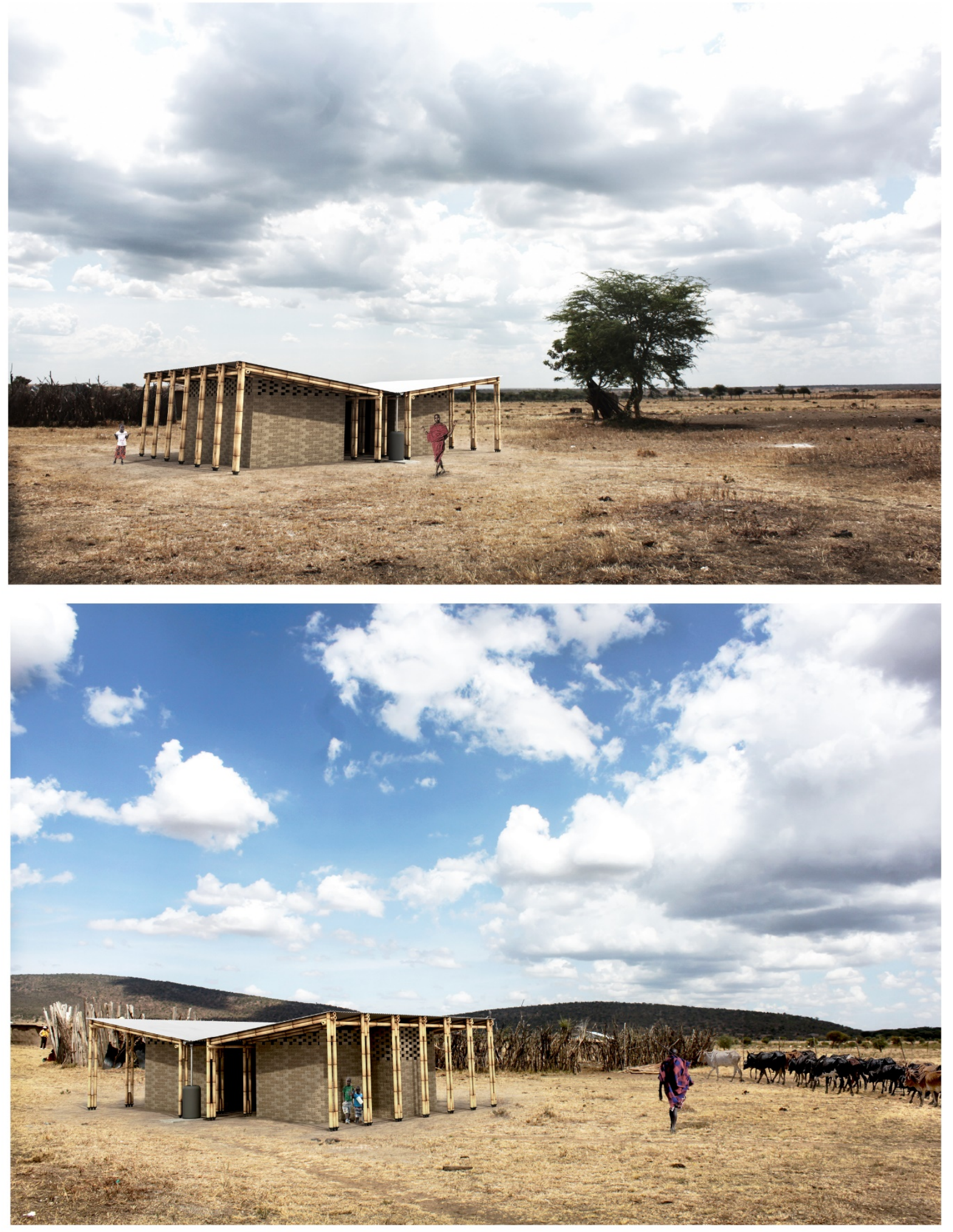

4.9 - Butterfly House: Visualisation 1 - images by Author 

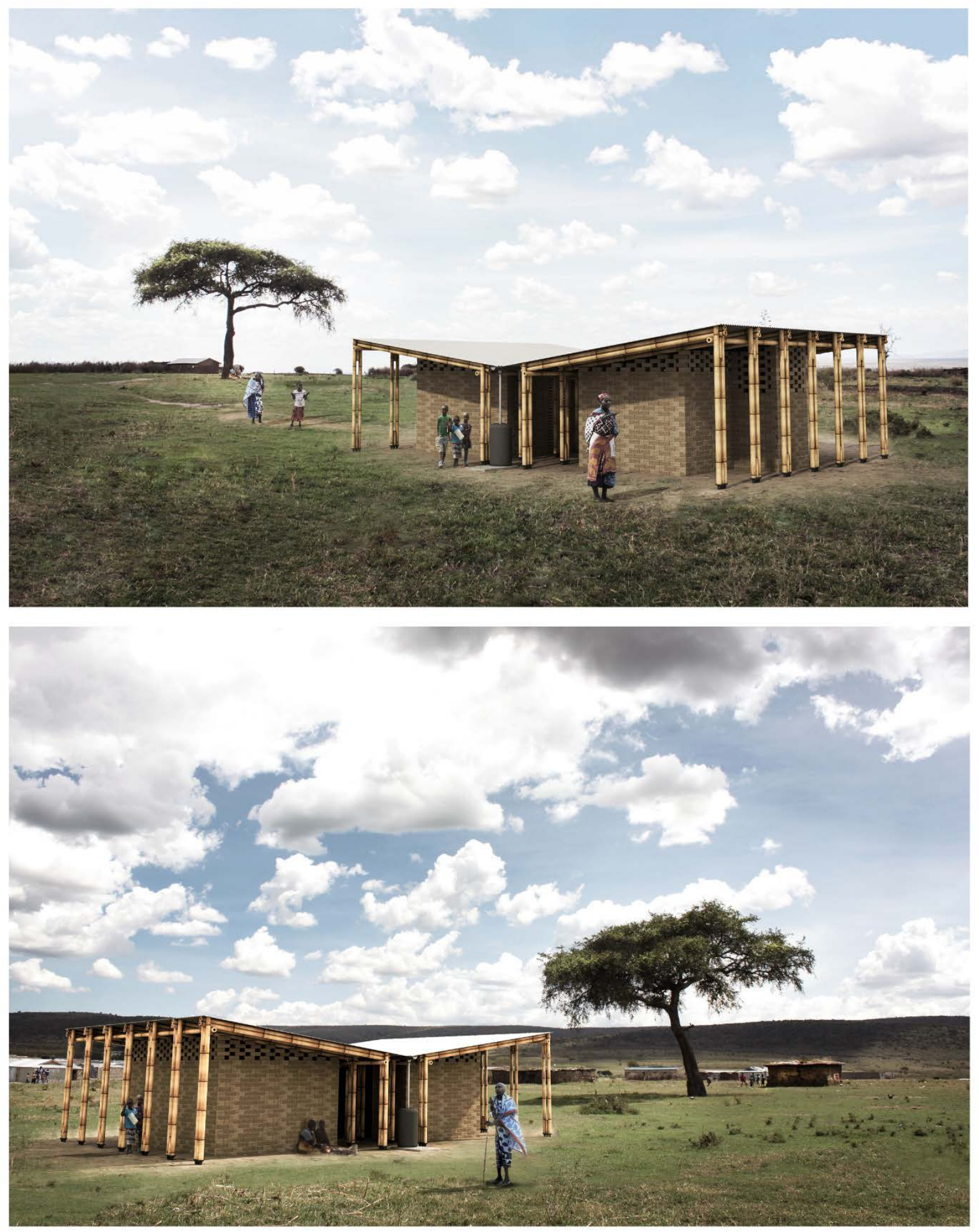

4.10 - Butterfly House: Visualisation 2 - images by Author 
Butterfly Anatomy: Materials and Constructions Systems

Exploded Perspective
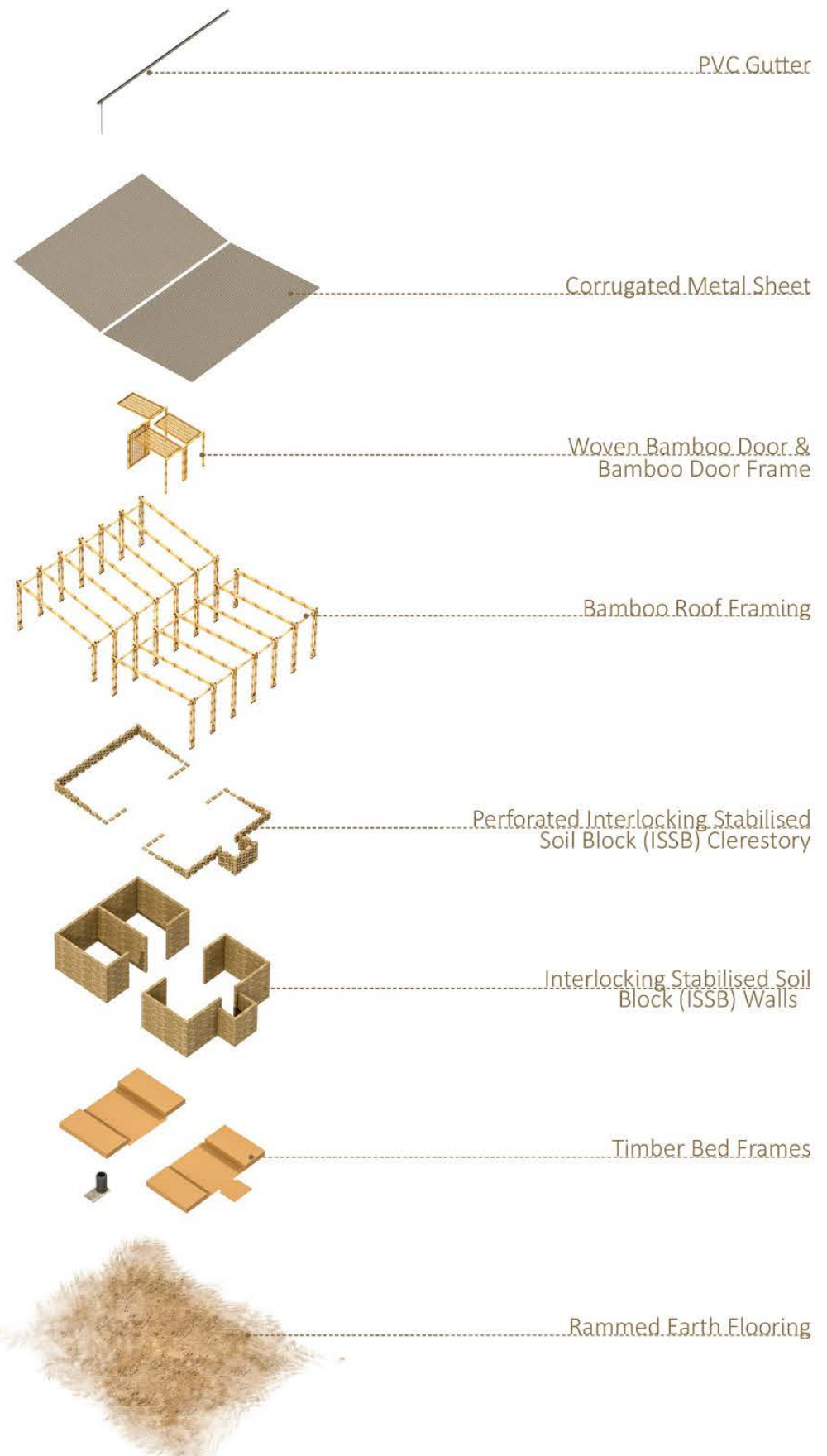

4.11 - Exploded Axonometric 
The previous visualizations show the project rendered in two different contexts to illustrate the user demographic and physical setting.

The materials described in the previous cost analysis are distributed into the following material systems as seen in the exploded axonometric diagram on the previous page. The roof system is comprised of a corrugated metal sheet bound to a bamboo frame which rests on metal footings that are hammered into the ground, eliminating the need for a concrete foundation. The body of the building is comprised of stabilized soil blocks which culminates in a perforated brick wall near the top to enable passive ventilation. The floor uses a rammed earth system.

Many of the systems enable participation on the part of community members in collaboration with more skilled artisans or tradesmen. The completed building is displayed at the bottom of the axonometric drawing.

Transformation of the Maasai Enkaji

Maasai have traditionally been a semi-nomadic people, untethered to any single locale. Just as butterflies freely roam the skies, Maasai would freely roam the beautiful and sometimes dangerous East African savannah. Historical sources state that in the mid 19th century, Maasai were masters of the entire Great Rift Valley!

Today, the Maasai are less like butterflies. Their semi-nomadic lifestyle is no longer possible and consequently their buildings are drastically changing. A sedentary lifestyle is increasingly becoming the status quo as they readily adopt new construction systems and spatial arrangements. These new ways of building often ignore the rich architectural traditions of the Maasai and frequently struggle to reflect their distinct cultural identity.

The butterfly is then an appropriate design departure point for a new Maasai enkaji, or house. The free movement of the butterfly is a subtle reminder of the Maasai semi-nomadic lifestyle of the past. As a creature that undergoes deep transformation in its own life cycle, it is an appropriate symbol for the metamorphosis that the new houses seek to inspire in Maasai Mara.

The following image, inspired by the popular images of Darwinian evolution, showcases the transformation of the typical Maasai house over time. Unlike many of the transplanted forms which are invading the Maasai Mara context, Butterfly House is an evolution of traditional ways of building. For example, the manner in which timber and sticks are assembled in the traditional house is reinterpreted in Butterfly House. While the sensibilities remain the same, the materials change. Traditional houses were made out of mud and grass. After having introduced the new material choices of bamboo and stabilised earth blocks, Butterfly House is likewise made of "mud "and "grass". This gradual evolution of traditional building sensibilities seeks to enable the easy-adaptation into the community, a notion that is predicated on avoiding too much "disruption." 


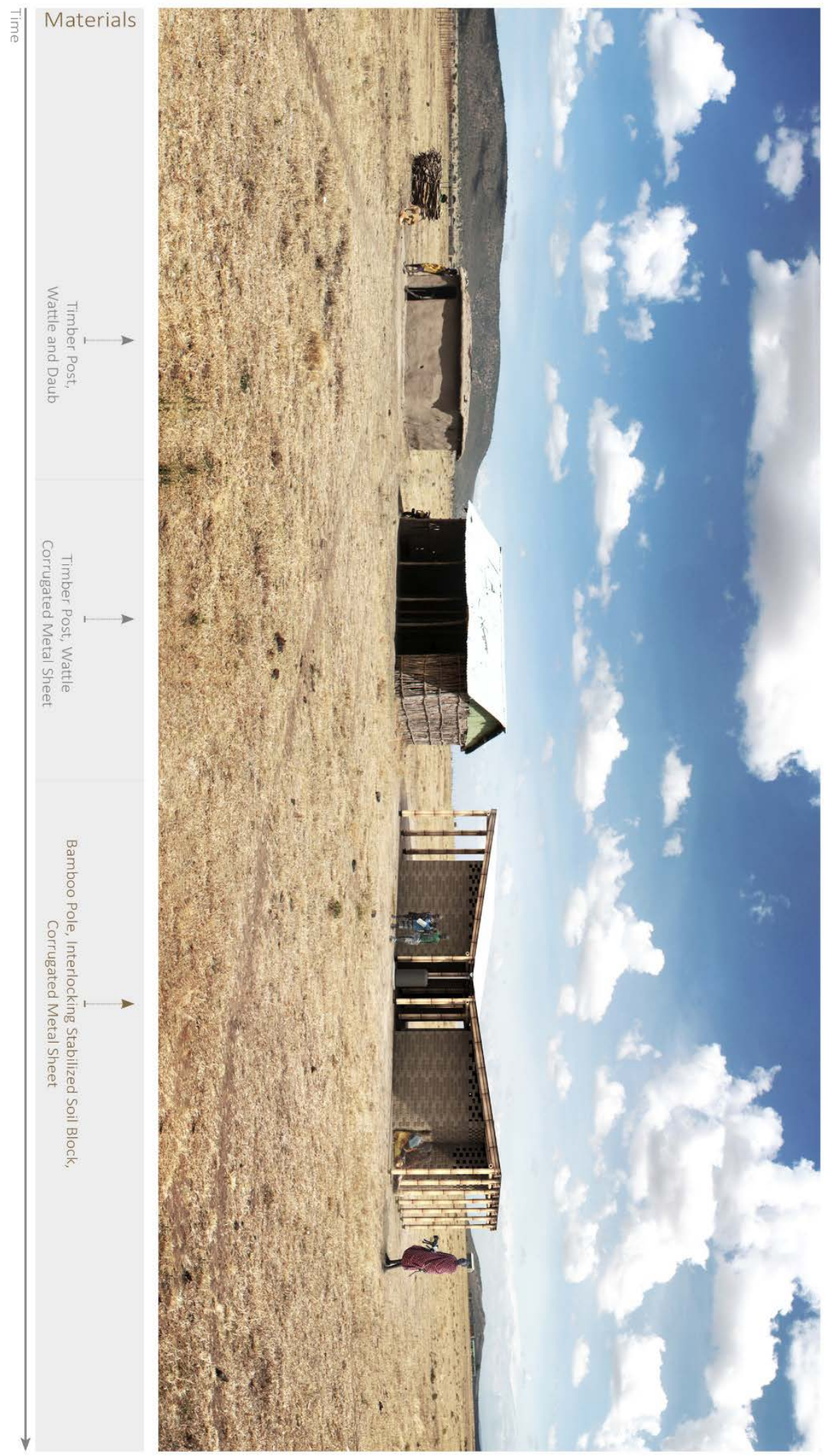




\section{Conclusion}

Participatory construction methods are a valuable series of strategies to be implemented in contemporary vernacular inspired architecture. As proven in the case study analysis and a seen in Francis Kere's Gando Primary school, participatory construction significantly saves costs whilst enhances the sense of ownership over the building process on the part of the community members. Finally, it also enables capacity building, where construction techniques are transferred between skilled artisans and unskilled community members during the building process. The outset of this chapter introduced a diagram of the formal building process, with an existing rift between the role of architects and users. Learning from the examples presented by Kere and others, a new process has been outlined in the following figure, suggesting how users can be included earlier in the process.

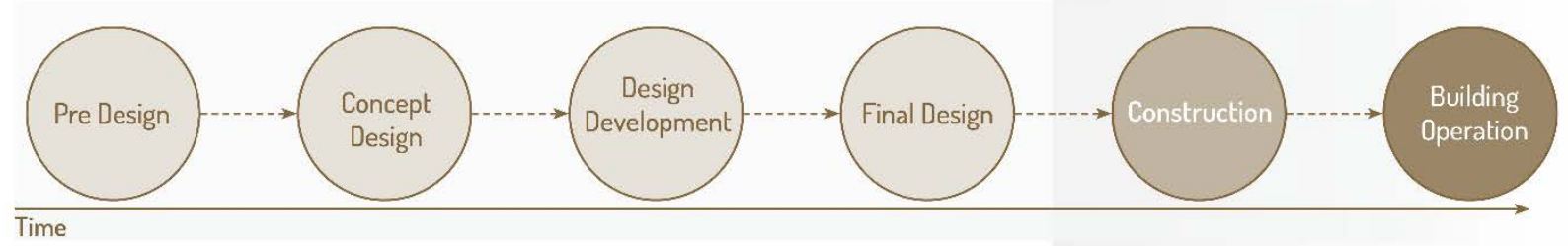

The Trained Architect

Study of Vernacular Building Technologies

Primary Contractor

User Participatory Construction

\subsection{2 - The New Building Process - Image by Author}

As early as the site analysis work that is commonly completed th the outset of an architectural design, research into the existing building technologies and vernacular craft methods can be thoroughly documented so as to uncover design opportunities that invite the agency of unskilled workers in the construction process.

Butterfly house was predicated on these notions, drawing together several materials and tectonic assemblies that will be of use for the final design project of the thesis: The Maasai Cultural Center entitled Netii Apa and will be described in the final chapter: Chapter 5. Butterfly House can serve as a small scale experiment that tests the process presented in the above diagram. At the final stages of this house's design, it awaits a second engagement on-site with local laborers and community members, which was initially done at the outset of the project.

\subsection{Chapter 4 Endnotes}

\footnotetext{
116 Fathy, Architecture for the Poor: An Experiment in Rural Egypt, 10-11.

${ }^{117}$ Francis Varanda, "2004 on Site Review Report," in Primary School: Gando: Burkina Faso (The Aga Khan Award for Architecture, 2004).

118 Community Architects Network, "Bamboo Construction Source Book," (Hunnarshala Foundation, 2013 ) .
} 


\section{Butterfly: Netii Apa: Maasai Cultural Center 5.1 Chapter Introduction}

The outset of this thesis introduced a general polarization between transplanted and vernacular buildings in many countries across Africa, a phenomenon which, as has been described in the thesis introduction, has been shaped by complex historical tensions between tradition and modernity beyond those of the built environment.

Some of the contexts within which this polarization is particularly stark are those of the many indigenous peoples of the continent who still identify with and practice traditional culture. The Zulu of South Africa, the Himba of Namibia, the San of Botswana or the Maasai of Kenya are some examples of indigenous peoples who have retained traditional ways of living. In particular, nomadic tribes such as Kenya's Maasai or Turkana peoples offer particularly interesting contexts within which to examine the architectural relationships between tradition and modernity. As demonstrated by anthropologists, the Maasai, in general, have generally resisted assimilation into mass culture, unlike many of Kenya's other tribes such as the Kikuyu, who in general, did the exact opposite. Many Kikuyu communities readily embraced the colonial conceptions of modernity during Africa's liberation decades, evidenced in part by their almost exclusive tribal representation in early independent Kenyan politics. In general, Maasai peoples might popularly be seen as having been "caught in a time capsule", where ongoing cultural practices that are remarkably ancient are today confronted with technological or political forces that are distinctly contemporary.

This is a notion that is particularly evident in the buildings of many Maasai communities. Ways of building are particularly stark between vernacular Maasai traditions and contemporary architecture. The latter which frequently fits the description of the previously described transplants, right down to the pastiche architectural expressions of Maasai culture, high expenses associated with building construction, and common disregard for passive design techniques. The polarization between vernacular and transplanted building in many Maasai communities might be seen as particularly exaggerated. Few other contexts therefore offer such ideal testing grounds for this thesis. Maasai vernacular buildings have deeply embedded cultural uses of communal space as well as age-old collective building techniques that beg to be explored. Through Chrysalis, these notions are reimagined in the design of a Maasai cultural center for a rural community near the town of Narok.

\subsection{The Maasai Peoples of East Africa}

\subsubsection{An Introduction to Maasai Culture}

"Every people, in order to remain healthy and strong, has to have a grasp of its foundation story. Culture is a chrysalis - it is protective, it takes care of you. That's what cultures are for. You cannot rob a people of language, culture, mother, father, the value of their labor - all of that - without doing vast damage to those people."119

Randall Robinson

African American Lawyer, Activist and Founder of TransAfrica

Maasai are an indigenous peoples of East Africa who reside between the countries of Kenya and Tanzania today. Predominantly in Kenya, the Maasai population countrywide is estimated at about 841,622 people, approximately $2.2 \%$ of Kenya's total population of 38,610,097. ${ }^{120}$ Maasai therefore represent a small minority despite their common representation in popular culture as one of Kenya's most prominent people groups. Maasai might therefore be well known on the international front because of a common tendency to stereotypically portray their 
distinctive culture to brand Kenya, in large part for its tourism industry. Many significant places in Kenya have in fact been named in the Maa language of the Maasai. The country's capital, Nairobi originates from the Maa "enkare nairobi", meaning "place of cool waters"; the town and lake of Naivasha, from the Maa "enaipasha"; meaning "lake" and the town of Nakuru, from the Maa "nakuro" which means dusty place. ${ }^{121}$

Maasai culture is indeed quite unique in its external appearance. Regularly clothed in scarlet red, Maasai have historically been semi-nomadic pastoralists who roamed the entire Kenyan Rift Valley in the mid-19 ${ }^{\text {th }}$ century. Today the image of a Maasai young man, garbed in a red shuka (decorated length cloth that is worn), bearing an olive staff, and protecting a head of cows, is not an uncommon site on the plains of southwestern Kenya (figure 5.2-a).

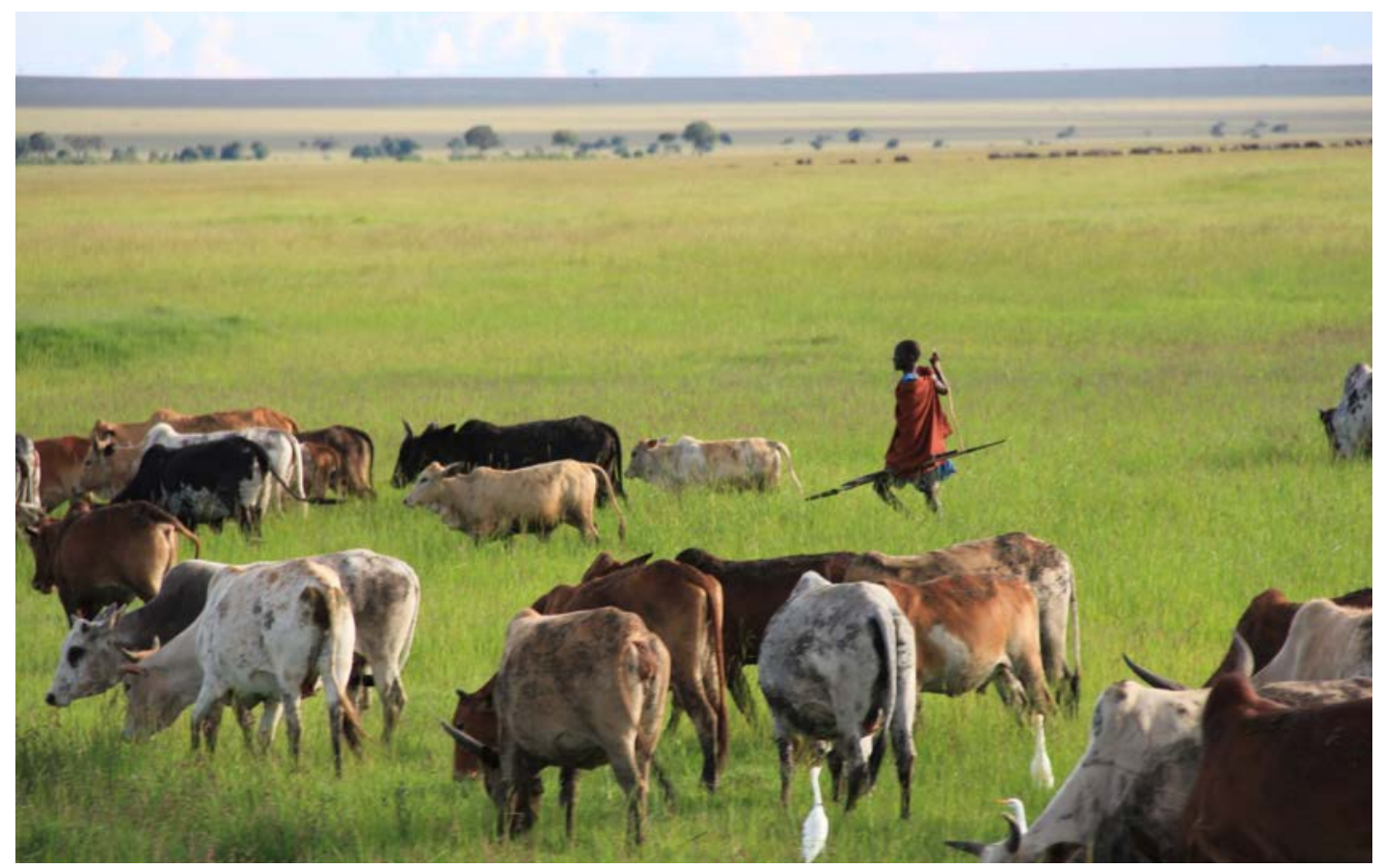

5.1 - Maasai with Cattle - Image retrieved from "http://maasaimedia.com/2014/11/why-all-cattle-are-a-gift-fromgod-to-the-maasai/"

\subsubsection{A Resistance to Acculturation}

The Maasai identity has been extensively studied by anthropologists, many whom have tried to identify a rationale for the Maasai resistance into the mass culture since the colonial era. Anthropologist Valeer Neckebrouck systematically questions this notion in his book Resistant Peoples, the Case of the Pastoral Maasai of East Africa. ${ }^{122}$ His findings illustrate some distinct characteristics of Maasai culture that transcend the introductory knowledge that has presented in this chapter thus far. Most importantly, Neckebrouck's discussion on Maasai culture helps to identify an array of anthropological forces that have contributed to the relatively stark polarization of architectural forms found in Maasai communities. His work is particularly revealing when considering Maasai architecture as a built expression of collective culture.

Neckebrouck evaluates a range of pertinent variables influencing the Maasai resistance to acculturation. Initially, at the outset of his book, Neckebrouck explores the possibility of a nomadic lifestyle being in direct juxtaposition to the territorial organization enacted by British colonial powers. He continues to evaluate the following as being 
reasons to this resistance to acculturation; a lack of new social incentives, an existing material well-being, geographic isolation, highly complex social structures, and cultural conservatism, just to name a few. The conclusion to Neckbrouck's argument is somewhat unexpected. In tandem with some of the previously mentioned variables, Neckbrouck assets that, as many Maasai grow up, they have complex and often difficult processes of socialization that have traditionally existed to best prepare them for the immense challenges of pastoral life. These pastoral life is described as follows:

"The pastoral life demands from those who practice it a virility, an aggressiveness, an endurance and a disposition to confront suffering, dangers and solitude superior to those demanded by the other modes of production in non-Western societies. To guarantee the reproduction of a society of which the way of life is unable to avoid such exigencies, it is indispensable that its members develop exceptionally strong motivations"123

- Valeer Neckebrouck

Priest and Doctor of Theology and Anthropology

His comment brings to mind the biological cornerstone of natural selection; the manner in which organisms might adapt over time to acquire a genetically encoded resilience in response environmental factors, to best enable survival. In the same way, as a culture, Maasai have developed enculturation rituals that build within its peoples an inherent cultural resilience to enable the longevity of their society, namely against the arduous forces of nomadic life. Neckbrouck writes:

"Infliction of pain which must be mastered plays an important part in these rituals. Here are a few examples. At the age of about four, the inferior incisors are torn out with the help of a knife. If they grow back they are again removed. The small boys are encouraged to burn themselves all along their limbs with burning hot coals, competing to see who best withstands this test. A little later they are tattooed on their belly and on the arms by means of a needle and a knife. Holes in the superior cartilage of the year are pierced with a red hot iron and a piece of flesh is cut from the lobes. The holes are subsequently maintain an enlarged with the piece of wood, ivory, or metal which is put there and which is made increasingly bigger. These interventions are known to be very painful. The Maasai male initiation involves a type of circumcision which is very complicated and extremely painful.

All this in initiatory violence is not without purpose. It contributes to preparing them aside for the pastoral life which is difficult and harsh. From morning to evening he is exposed to the inclemencies of the weather, to the blazing sun and to whipping storms, to clouds of dust and to biting winds. His days are long, tiring, and often lonely. He must every moment be prepared to confront wild animals and armed thieves who attack the flock. These threats sometimes present themselves suddenly and presuppose, in a man often relying only on himself, an immediate and almost instinctual perception of danger, the capacity to develop a strategy of defense in a few fractions of a second, and the courage and ability to effectively ward off an attack. Moreover, the ethos inculcated by the socialization make certain that he can distantiate himself from these attacks only at the risk of carrying for the rest of his days the inalienable stigma of cowardice."124

- Valeer Neckebrouck Priest and Doctor of Theology and Anthropology

Highly prized is the virtue of bravery in Maasai culture and conversely, intensely humiliating is even the slightest association with weakness or cowardice. To be Maasai means to be brave and tough against all odds. These are 
character traits which are made achievable through ritualistic training formed over years of cultural tradition. What results, according to Neckbrouck, is an extraordinary sense of ethnocentrism for the Maasai. He argues that it is a strong ethnocentric outlook that largely contributed to the Maasai resistance to acculturation and consequently the continued practice of ancient cultural traditions, sometimes even against the direct efforts of the colonial administration. The bold ethnocentric outlook of the Maasai, in tandem with the several other forces outlined in Neckbrouck's book, comprise the rationale of the Maasai resistance to acculturation and therefore the presence of their distinctive cultural identity today. Naturally, Maasai vernacular ways of building are no exception to this statement. Their buildings also speak of a remarkable tradition despite their short life spans.

\subsubsection{Maasai Vernacular Architecture}

One of the leading scholars on Maasai vernacular architecture is Dr. Robert Rukwaro at the University of Nairobi who based his PhD research on the notion of Maasai architectural evolution. The following information on traditional Maasai buildings has almost entirely been borrowed from his 2006 publication on the subject entitled, Transformation of Maasai Art and Architecture, which was written in collaboration with Sylvester J.M. Maina. ${ }^{125}$ The works of other scholars have been utilized to provide supplementary information to this primary source where necessary. The following information provides the reader with an overview of Maasai vernacular forms.

Maasai buildings are almost always homesteads. Known as enkang' in the Maasai language of Maa, these homesteads are usually conceived as an aggregation of buildings that reflect kinship ties. The following figure is a floor plan of an enkang'. In this plan, three houses encircle a central cattle kraal, known in Maa as boo or olosingo. This arrangement is a built expression of Maasai society's polygamy as well as of their collective living arrangements. Within the boo, several divisions are present to allocate space for various livestock such as cattle, sheep and goats. The boo is made from the branches of the Oleleshwah tree and thorny shrubs called endamejoi. Other young animals reside inside the Maasai houses, commonly adjacent to kitchen quarters.

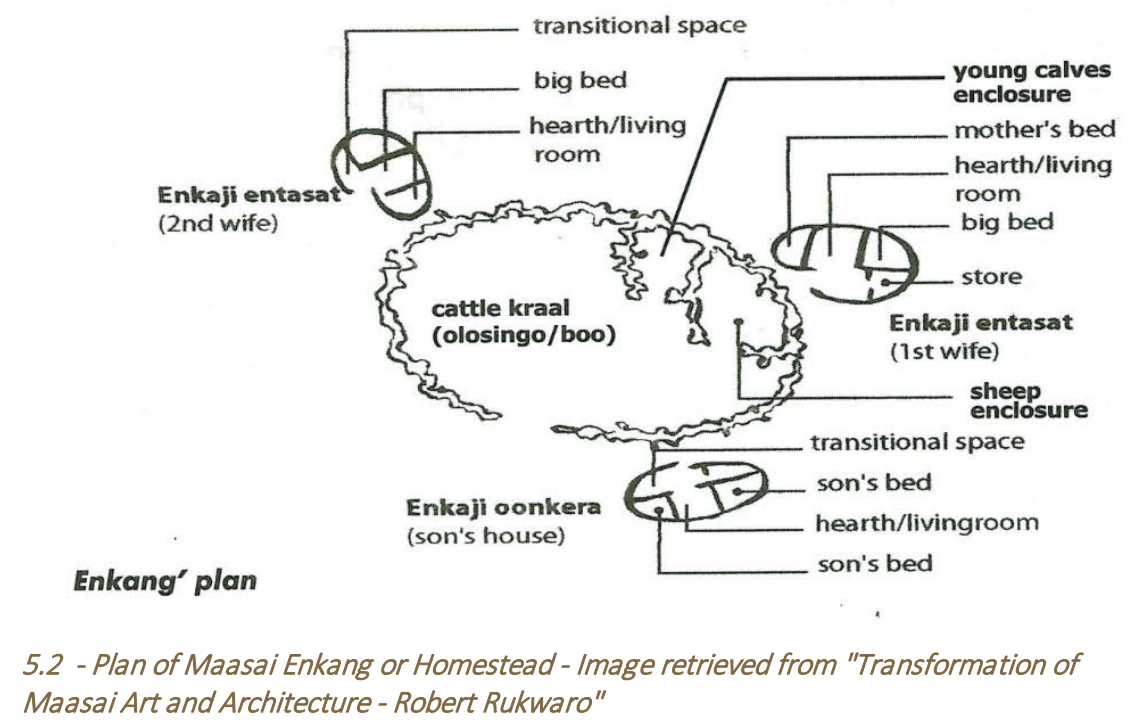

There are a variety of typical configurations of Maasai houses or enkaji. A mother's house is called enkaji entasat, a father house is called enkaji orripie, an elderly boy's house is called enkaji oo nkera and the equivalent for an elderly girl is called enkaji oo esiangiki. Lastly, orng'oboor refers to a more temporary one-roomed structure that functions 
as a kitchen to serve the needs of important ceremonies that take place within the enkang. ${ }^{126}$ The floor plans for these aforementioned structures are as follows. 


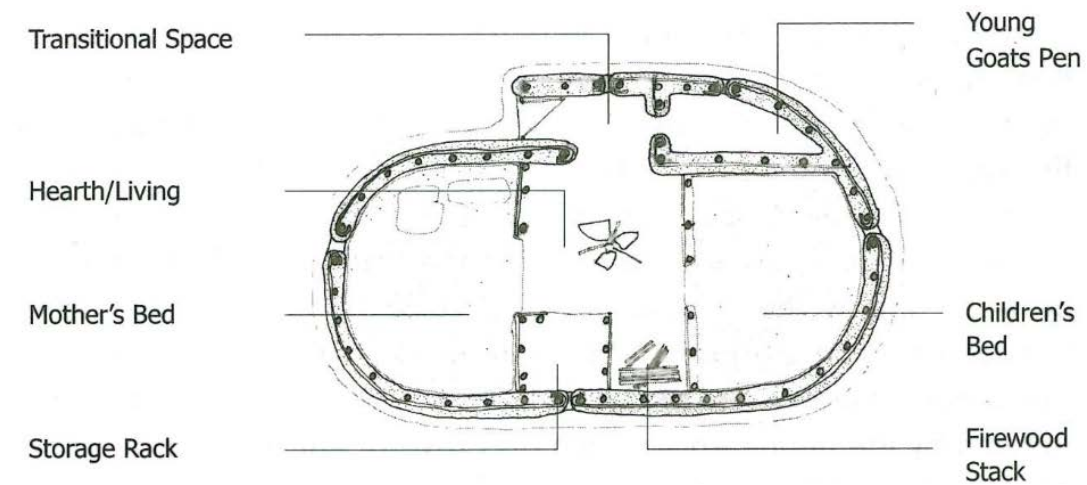

5.3 - Maasai Mothers House - Enkaji Entasat - Image retrieved from "Transformation of Maasai Art and Architecture - Robert Rukwaro"

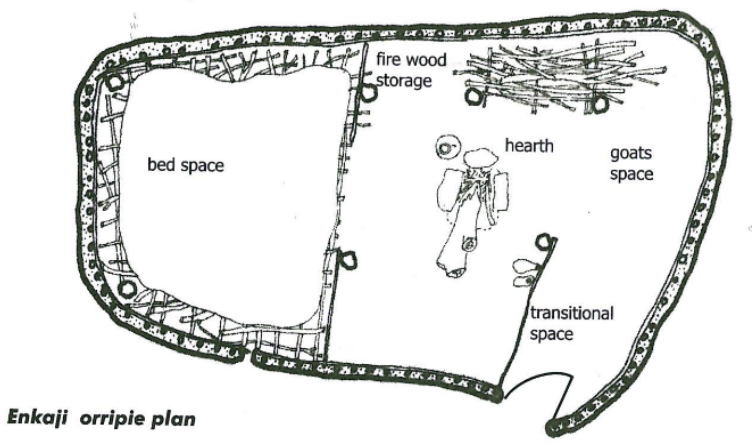

5.4 - Maasai Fathers House - Enkaji Orripie - Image retrieved from "Transformation of Maasai Art and Architecture - Robert Rukwaro"

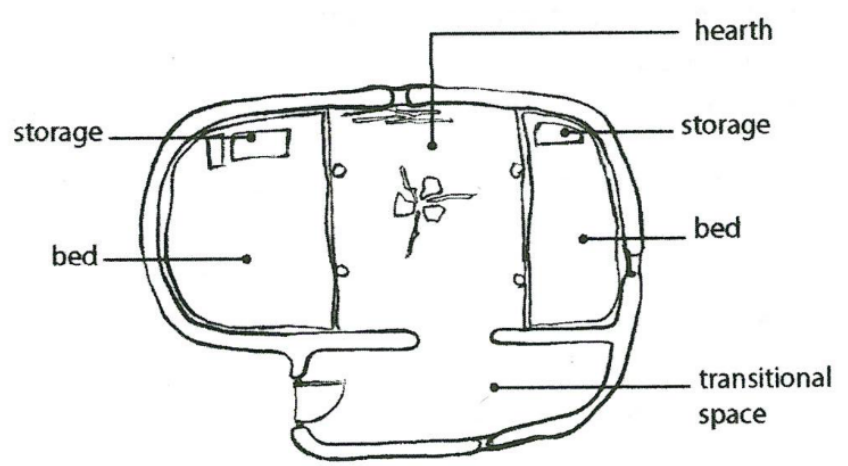

enkaji oo nkera plan or enkaji oo esiangiki plan

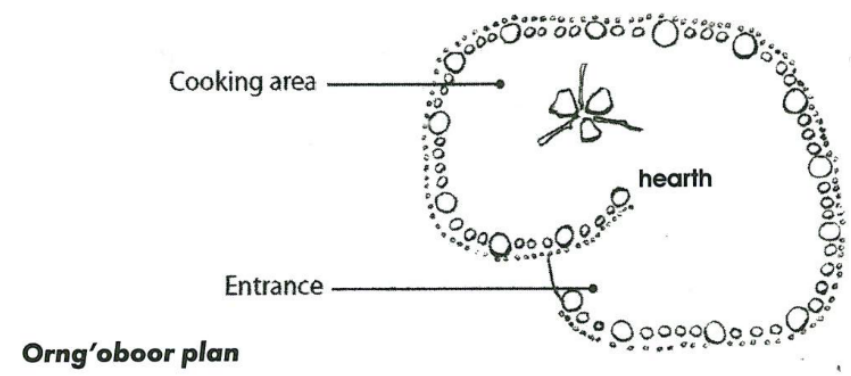

5.5 - Elderly Boy and Girls House - Enkaji oo Nkera and Kitchen structure, Orng'oboor Image retrieved from "Transformation of Maasai Art and Architecture - Robert Rukwaro" 
Traditionally, Maasai structures exhibit a general consistency of construction techniques. Vernacular Maasai buildings typically do not exceed $1800 \mathrm{~mm}$ in height. They utilize timber poles and wattle and daub as primary construction materials. The following image by Dr. Robert Rukwaro shows a detail drawing of how these materials are amassed together in a typical Maasai structure.

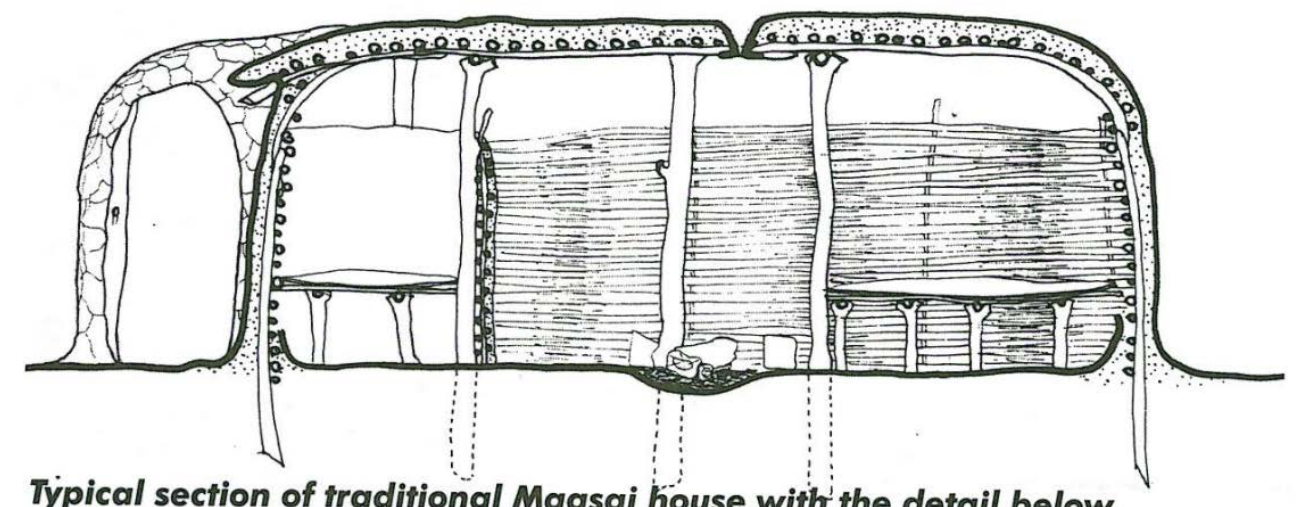

Typical section of traditional Maasai house with the detail below

\section{Wall and roof construction defails of a traditional house without eaves}

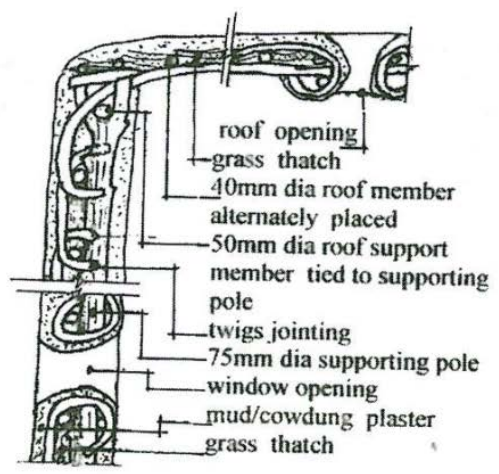

5.6 - Section and Wall Section of Maasai House - Image retrieved from "Transformation of Maasai Art and Architecture - Robert Rukwaro"

This hand-made loaf shaped structure expresses the process of its production. It is not rigid in its geometry and therefore might be seen as imperfect when viewed through the lens of common contemporary Architectural practice today. The walls of the house undulate, and just like nature's unique flora and fauna, and no two Maasai buildings are alike. One might take special notice of the low tech assembly methods illustrated in figure 5.2-f. Materials are fastened without the need for elaborate tools or machinery. As Maasai vernacular architecture is still quite widespread today, an unusual polarization within the Maasai built environment exists, particularly in response to new technological forces and the ways of building that it brings. 


\subsubsection{Staying Maasai?}

"over the centuries the bravery of the Maasai has enabled them to acquire large tracts of land and the highest number of stock per person among tribes of Africa. Now however, things have changed drastically for the worse. Our huge landholdings are shrinking at a frightening rate and our livestock is diminishing as a result of the encroachment on our land by other tribes and the creation of national parks by the governments of Kenya and Tanzania. Without land and cattle, there will be no Maasai. But my people are still holding on and continue to celebrate our culture despite the urgent demands that we change our ways and assimilate to contemporary modes of living. If change must come, as seems inevitable, it must be gradual, not abrupt. We will adapt, we will survive $" 127$

- Tepilit Ole Saitoti

Maasai Author of "The Worlds of a Maasai Warrior"

The Maasai lie at a critical junction between preserving their cultural traditions of the past and conforming to the forces of contemporary urbanization. A rich cultural history of traditions, values and knowledge are on the verge of disintegrating against the pressures of 21st century living. As a result, the future of the Maasai identity is uncertain. The above excerpt from the biography of Tepilit Ole Saitoti expresses a local perspective on contemporary forces of modernisation that are challenging Maasai traditional ways of life. This section of the chapter is entitled "Staying Maasai?", which is from the title of a book by Katherine Homewood, It articulates the challenges facing contemporary Maasai society in the context of community based conservation approaches. ${ }^{128}$ Its title is appropriate for the sentiment expressed by Saitoti. One of the largest forces threatening the Maasai way of life are those regarding land use systems and policy.

Today, increasingly, traditional Maasai lands are subdivided and privatized, and therefore cease to be drawn upon for the strength of Maasai communities. Dr. Michael Thompson of the University College London (UCL) writes the following:

The rangelands around the Maasai Mara National Reserve (MMNR) provide an important example of the ways in which land use and land ownership are changing rapidly in Kenya Maasailand, particularly in areas of higher agricultural and economic potential. Privatization of once-communal rangelands and subsequent subdivision into individually owned plots are far advanced." 129

- Dr. Michael Thompson

Professor of Biological Anthropology and Developmental Economics at the University College London

The challenges of Maasai cultural erosion are evident in the environment. With an age old tradition of communal living, the Maasai today are experiencing new pressures that are shifting their relationship to the land and notably, with one another. Many of the new buildings in the Maasai context are in complete juxtaposition with traditional ways of living. These buildings stick out like sore thumbs, inducing new individualistic ways of living, and advancing cultural erosion. Dr. Rukwaro writes the following:

"The introduction of western ideas with an apparent air of superiority has had a devastating effect on the Maasai conception of being and totality. The lure of modern education, technology and lifestyles of the dominant western culture is almost shattering the Maasai hitherto self sustaining world view. Modern houses built by Maasai no longer have spiritual value. They are only functional 
empty rooms. The Maasai change in the conception of architectural designs is an indication of a general breakdown of African value systems seen almost everywhere across the continent."130

- Dr. Robert Rukwaro

Scholar of Maasai Architecture at the University of Nairobi

While the challenges that the Maasai face are complex and multi-layered, architecture has a significant role to play in both preserving the ethos of the Maasai way of life and ensuring that it is compatible with their new situation in a globalized world. Netii Apa, the Maasai Cultural Center is then presented with a challenge: It must function as a built interstice between the values of the past and the aspirations for the future.

\subsubsection{Caught in a Time Capsule?}

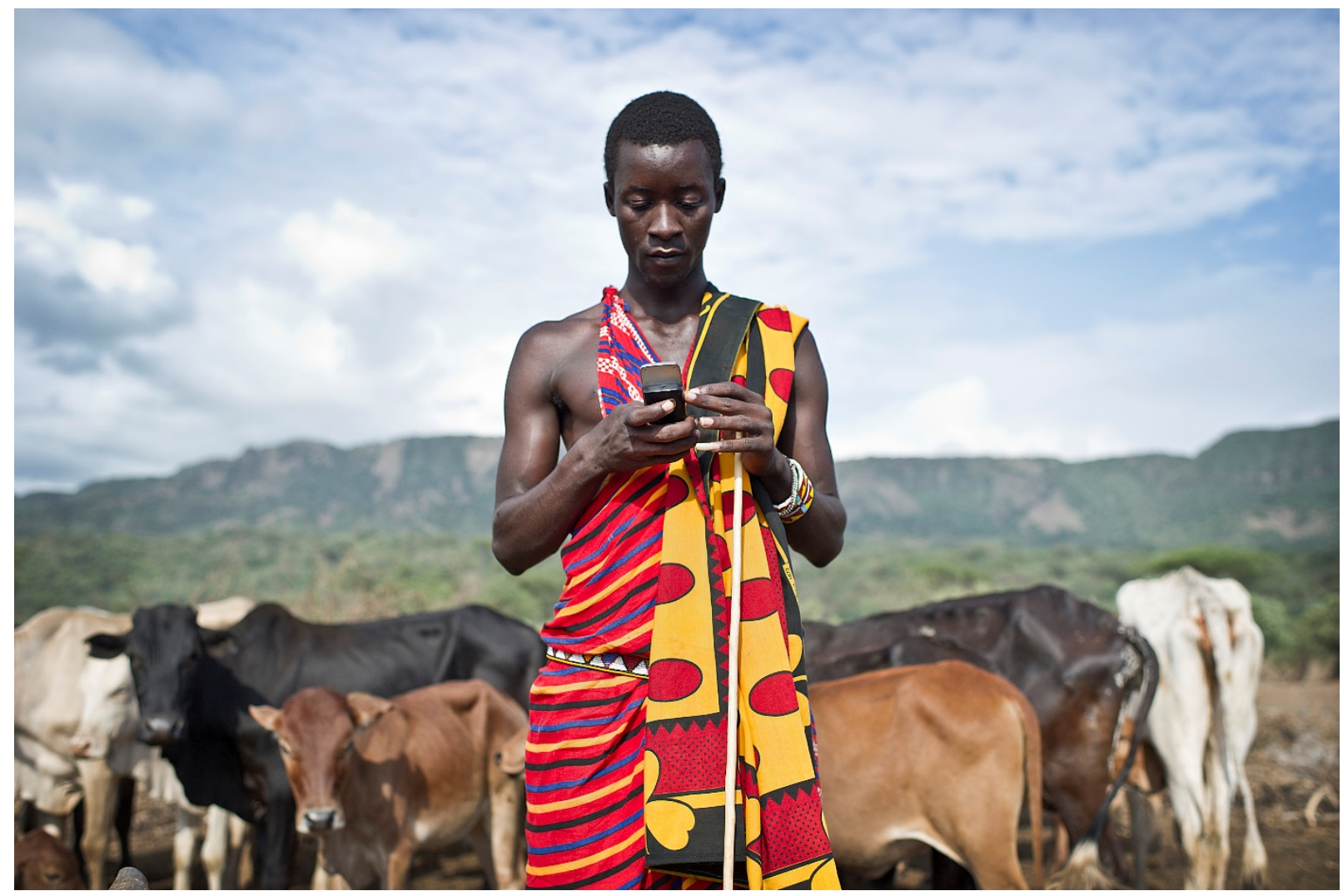

5.7 - A Maasai checks his phone - image retrieved from "http://www.oxfamblogs.org/eastafrica/?p=3615"

The general preservation of Maasai cultural traditions over time as described by Neckbroucke has unfortunately contributed to local stereotypes of their "backwardness", not unlike biases often seen against vernacular architecture in general. Maasai architectural practices are certainly not exempt from this stereotype. Certainly, Maasai traditions when juxtaposed to the mass culture of the adjacent capital of Nairobi, might appear as archaic. The obvious presence of many ancient historical traditions in Maasai culture today result in interesting juxtapositions with forces that are distinctly modern. Pictured above in Figure 5.2-g is a Maasai man checking his phone against a background of cattle. The presence of a cellular phone in the photograph might even be seen as humorous; a hyperbole of the supposed contrast between Maasai traditions and contemporary global mass culture. 
Maasai ways of building exhibit similar juxtapositions between "new" and "old" that might represent in a microcosm, the polarization between transplanted forms and vernacular architecture identified across the continent. Figures 5.2-h and 5.2-i illustrate Maasai women transporting, and installing solar panel on a house respectively.

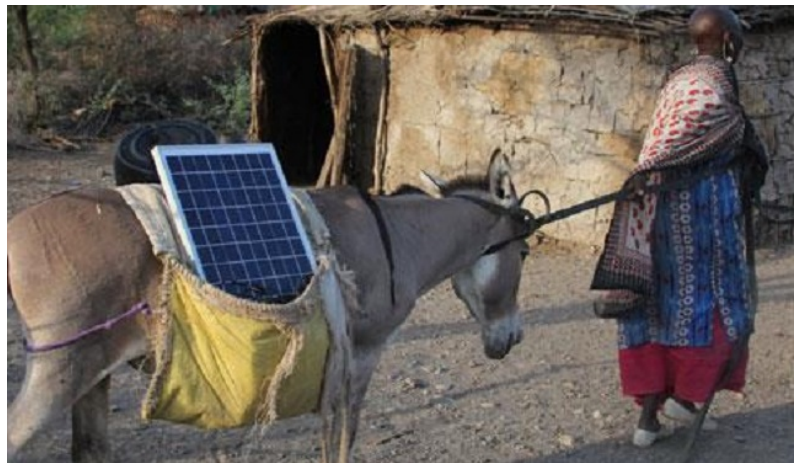

5.8 - Maasai Lady Transports a Solar Pane/ - Image retrieved from "http://www.trueactivist.com/wpcontent/uploads/2015/09/maasai.jpg"

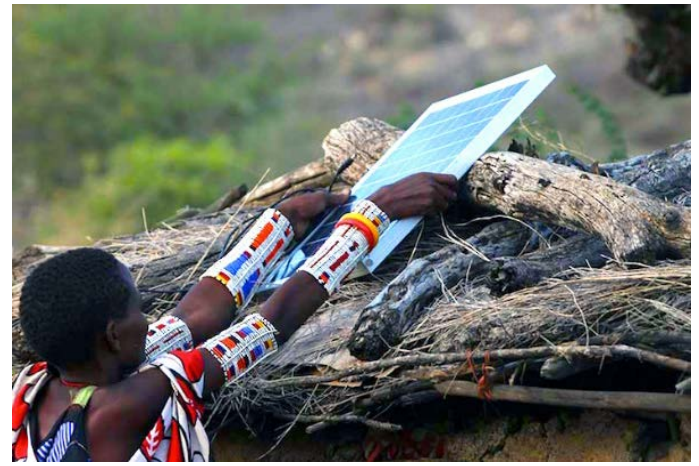

5.9 - Maasai Lady Installs a Solar Panel on her House Image retrieved from "http://assets.inhabitat.com/wpcontent/blogs.dir/1/files/2015/06/Maasai-GreenEnergy-Africa-solar-lead.jpg"

Both these examples represent an attachment to the traditional housing but also a new desire for electricity, which Maasai buildings historically do not have. While this is a small juxtaposition of new and old, the sometimes competing demands between vernacular building and new technologies manifest themselves in larger bizarre juxtapositions that speak to a lack of architectural creativity in mediating between the two. The following is a photograph of a new transplanted house or enkaji that is located with a traditional Maasai homestead near Sekenani gate in Maasai Mara. In this homestead, a single concrete house sits within an aggregation of traditional wattle and daub homes. It sticks out like a sore thumb, completely discarding traditional Maasai ways of building.

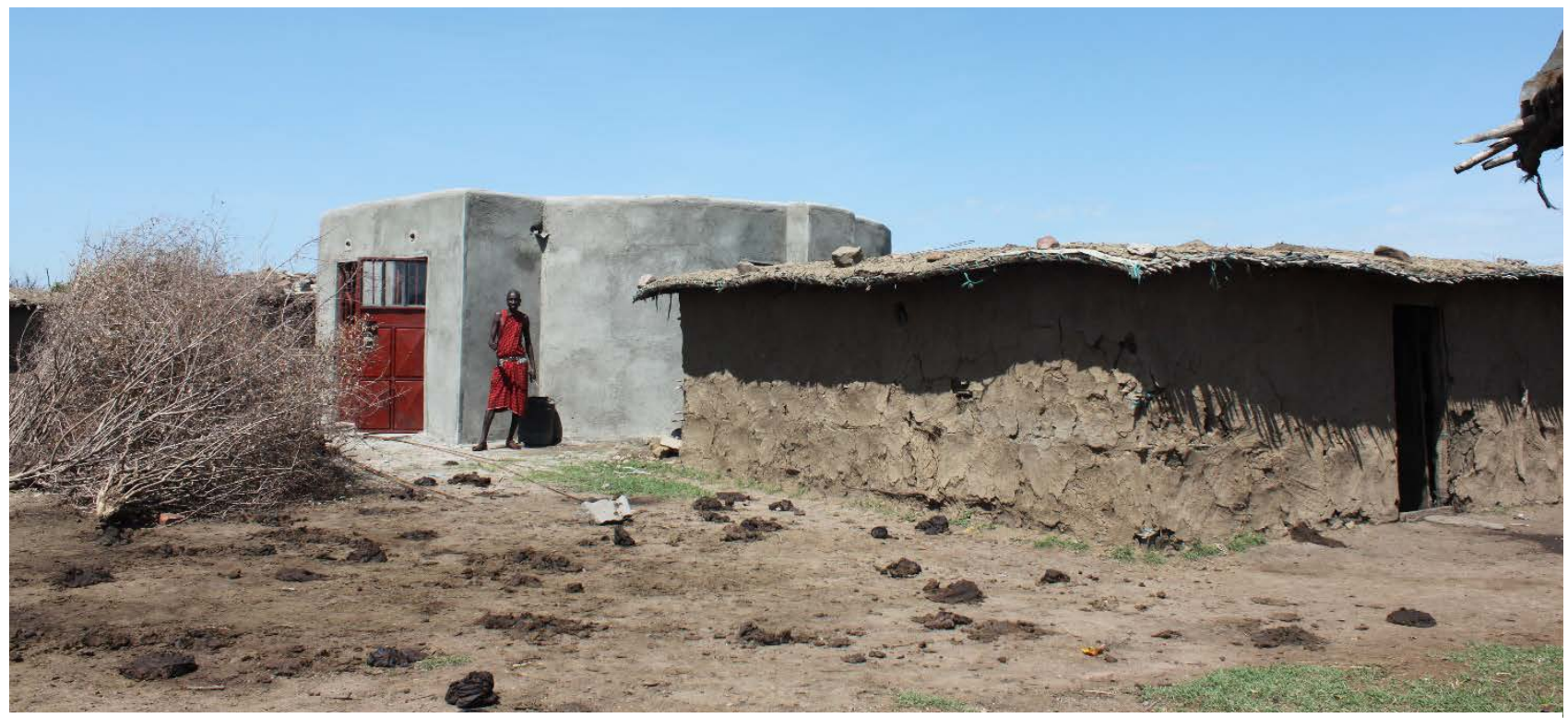

5.10 - Transplanted Enkaji - Photograph by Author 
This image expresses the polarization between transplanted architecture and vernacular building within a single homestead.

Like shortcomings of transplanted architecture described in the introduction, the concrete house poorly factors in the needs of the immediate Maasai community as well as insensitively responds to the forces of local climate. Estimated at a cost of about 1 million KSH or about 9,600 USD, the new concrete house is far beyond the reach of many Maasai in the homestead. Traditional houses which cost about 30,000 KSH or about 300 USD, are significantly cheaper. Built by an American NGO, despite the best of intentions, this house completely disregards the financial status of the community it serves, making it unaffordable to the average Maasai family. This project therefore asserts the need for external dependency for the community. By requiring external supplementary funds, Maasai lose their independence and the agency traditionally associated with the process of building

The new house is also culturally insensitive. Its monolithic form recalls that of the KENSUP plan from the outset of the thesis. Bare, devoid of texture, colour, or even shadow, the house is incongruous with the remainder of the homestead and present demands of Maasai life, evidenced by the fact that it still remains vacant.

These new buildings reflect a shifting cultural norm for the Maasai, one that provokes questions as to what alternative ways of building can be culturally sustainable while representing the community's evolving role in the 21st century.

\subsection{Netii Apa Cultural Center}

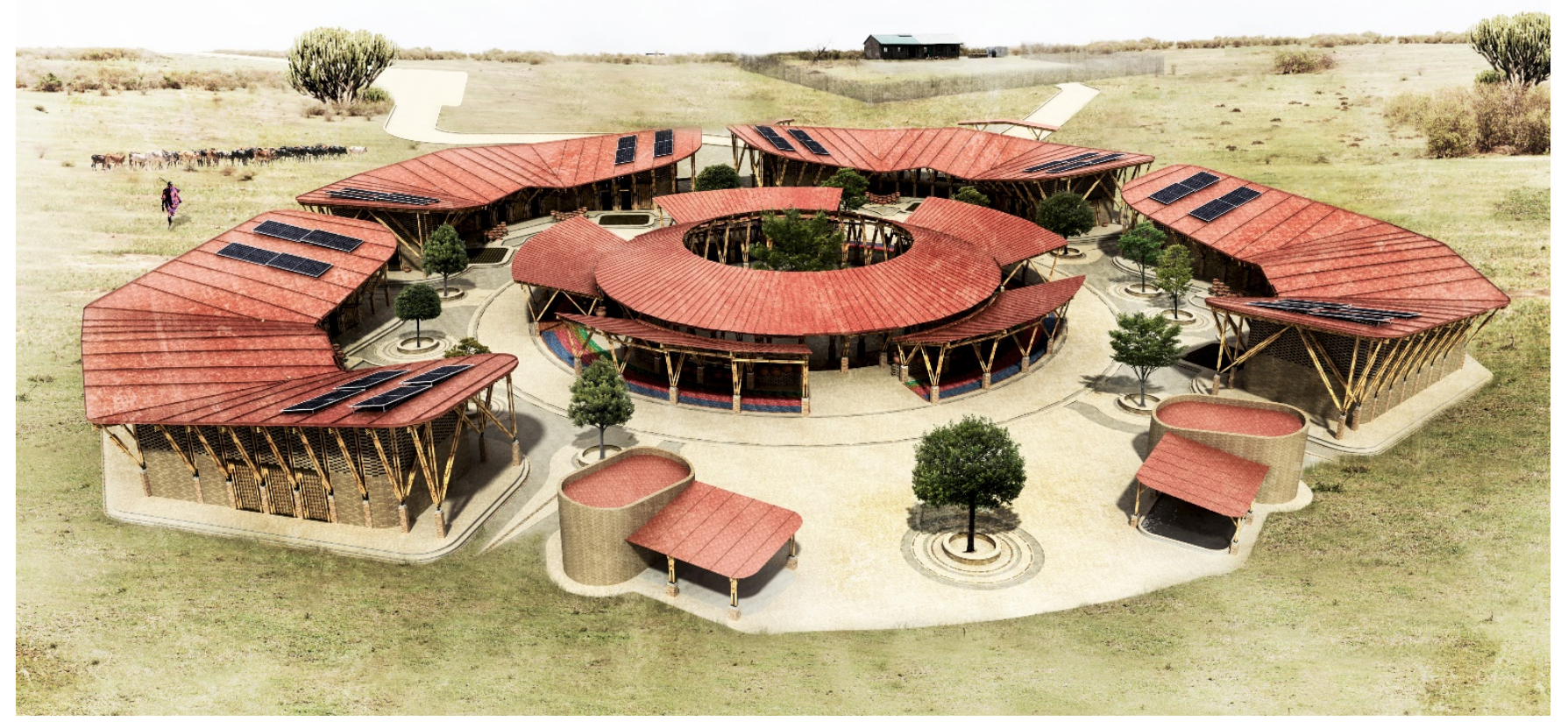

5.11 - Design of Netii Apa: Maasai Mara Cultural Center

"The pursuit of novelty and the disregard of traditional norms and principles bring forth the loss of identity because the tradition is always greater than the individual architect; his true identity lies 
not in his alienation from but in this alliance with tradition. On the other hand, designing within a tradition is not a pretence for repeating the old. It is not a mere act of imitation; for mimicry destroyed the whole significance and meaning of repetition of archetypes. Authentic traditional design is a complex process of careful adaptation and assimilation in an act of gestation. This ritual revitalizes the spiritual identity of the community through the proper active building, and the masterpiece is created by the faith of the artist in his tradition more so than the arrogance of his revolt."131

- Abdel Wahed El Wakil

Egyptian Architect

Section 5.3 introduces the primary architectural investigation of this M.Arch thesis; Netii Apa, the Maasai Cultural Center located in Kenya within a community owned rangeland or "cultural conservancy" Through the two spheres of research that comprise Chrysalis, the cultural center illustrates how Maasai building traditions can inform a project which speaks of an optimistic future for the Maasai community living around the project site.

The site for the cultural center was selected after a research trip to Maasai Mara where I was made aware of a need for community building that was to store and bring to life Maasai culture, primarily by providing a stage to perform cultural stories that have traditionally been passed down from generation to generation by word of mouth. However, as will be described, many other functions have been added to this building, conceived through discussions with the local community and an interdisciplinary team of advisors. The following sections will explore the architecture of this building in great detail, commencing with a discussion of the site, followed by the programmatic distribution of the building, and finally the design itself.

\subsubsection{Netii Apa: The Project Site}

Located about five hours away from the capital city of Nairobi, near the closest town of Narok, Maasai Mara is famous for the nationally owned game reserve where every year, hundreds of tourists flock to see the The Big Five. In addition to the National Reserve, Maasai Mara is also well known for its many conservancies, often privately established to protect the regions species of flora and fauna. 
However as a result of the aforementioned land subdivision policies and the privatisation of what was once communally owned land, a Purko Masai community has recently established the Nashulai Conservancy which is geared toward the protection of wildlife as well as Maasai culture. The collectively owned conservancy is located south of the existing Naboisho conservancy, approximately $3.5 \mathrm{~km}$ from the Sekenani Gate entrance to the Maasai Mara National Reserve and about $23 \mathrm{~km}$ north east of the Tanzanian border.

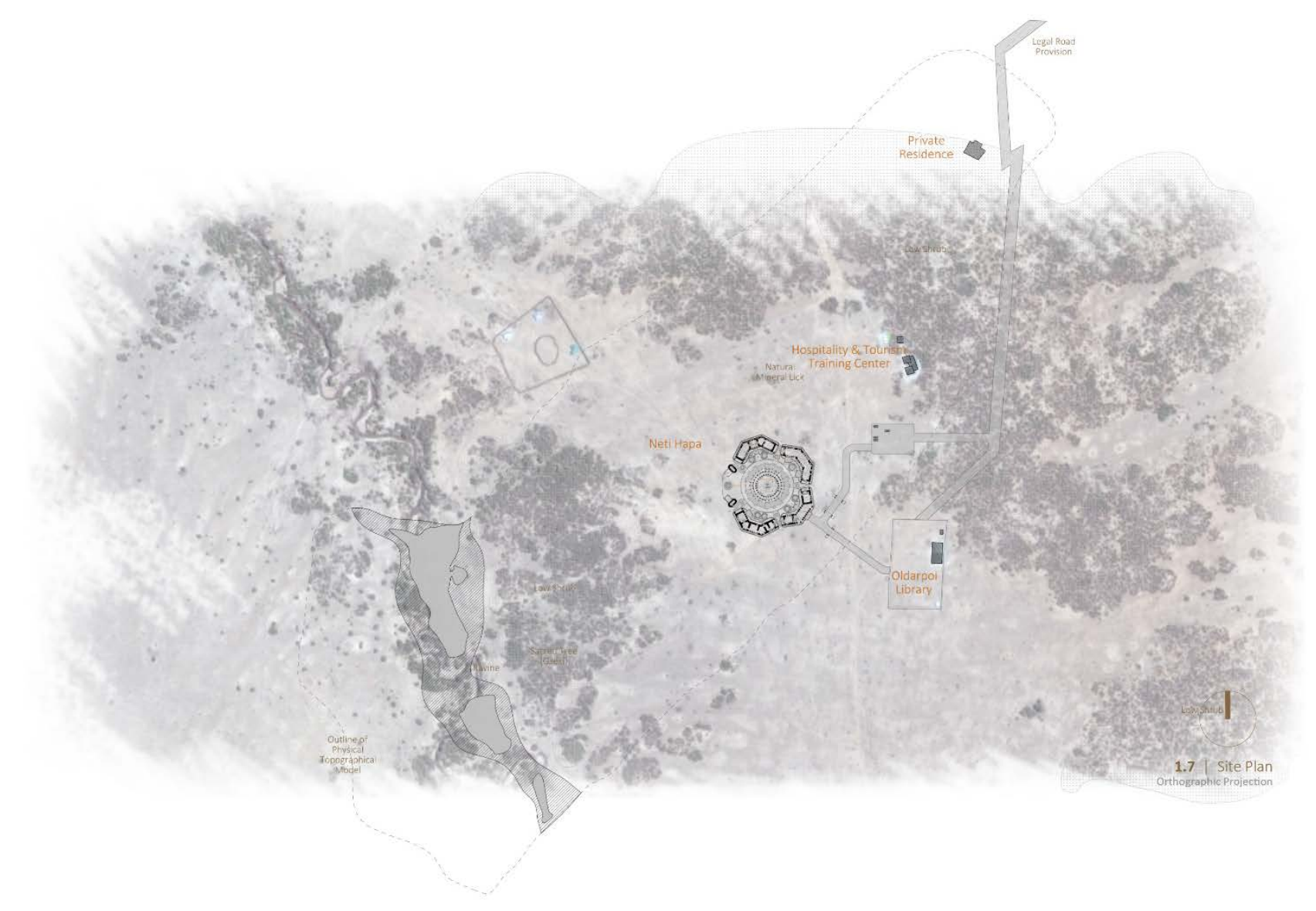

5.12 - Site Plan - Image by Author

The specific site for the cultural center is located at coordinates $-1.49245,35.34266$. The site takes the rough shape of a rectangle. Towards the north east are a few buildings, a culinary school and a library built by the European Ngo Trolltech, as well as a private residence. All of these buildings can be characterised as "transplanted" as illustrated by the image in the preface of this thesis. The site slopes down toward a ravine located on the south-west boundary of the site, shown in the site plan toward the bottom left. 


\subsubsection{Netii Apa: Program}

Netii Apa Maasai Cultural Centre will operate as the headquarters of Nashulai conservancy and houses multiple functions typically seen in other cultural centers. At a theoretical level, this building is to operate as a place of "connection", as defined in a variety of ways. The building is to act as a cultural interface that bridges between the Maasai culture of the local community and many other diverse foreign cultures that visit Maasai Mara through the booming safari tourism industry. The center is to also operate as a connection point between Maasai traditional culture and the future aspirations of the community, taking into account the pressures of contemporary society. It therefore contains programmatic elements of the vernacular buildings (shown in the brown boxes in the diagram) in addition to new uses. The building's programmatic distribution can be broken down as follows.

Programmatic Functions found in the Vernacular Homestead (Enkang)

Communal Living Livestock Habitation Social Interaction Ceremonial Dance Protection Community Governance Craftwork

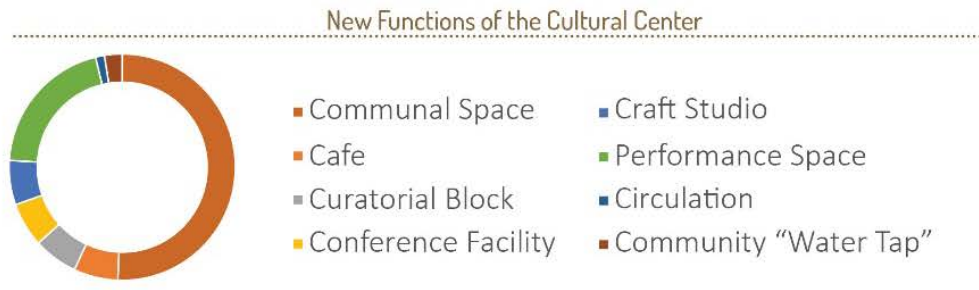

\subsection{3 - Programmatic Distribution - Image by author}

The largest area in the building has been allocated to the boma communal space described in chapter 3 . This space serves as the mortar that binds all the disparate programmatic functions into a whole. Included in this communal space is a large stage space dedicated to the performance of stories, inviting the Maasai oral traditions that have historically meandered across the savannah into a permanent home. In this space Maasai oral stories are reenacted for the community, visiting tourists, and the visiting Maasai diaspora from across the world. The community imagines that this space will be used for weekly community storytelling activities, allowing Maasai elders to share important stories from the past thereby conveying virtues that will hold the community together. Storytelling will be extended for public audiences. These stories will be performed for tourists to immerse them in a cultural experience that can financially support the community. Promote the socio-economic welfare of the community by creating a 21st century tourism experience. The name Netii Apa is derived from this function. A term in the Maa language of the Maasai, Netii Apa means "once upon a time" and connotes one of the cultural centers primary functions as a storytelling center. As will be illustrated, the communal space will also include landscaped grounds that will allow the Maasai community access for social interaction, contemplation and even for the informal sharing of stories at night, the latter which frequently occurs in the Maasai homesteads today.

In addition to this multifunctional communal space, Netii Apa has four primary functions; a curatorial space, a café, a handicraft center and a conference block. A curatorial wing will speak of the past, housing Maasai artefacts that 
speak of traditional ways of life. The building will include a handicraft market, creating opportunities for local artists to advance their commercial enterprise, predominantly undertaken by Maasai women in the community. The Café will serve traditional foods and drinks promoting community health and together with the conference spaces, will generate revenue from the tourism industry. These many functions have been conceived by the community members and I have been fortunate to participate in many discussions to explore the architectural implications of the programmatic considerations.

\subsubsection{Netii Apa: The Design of Maasai Cultural Center}

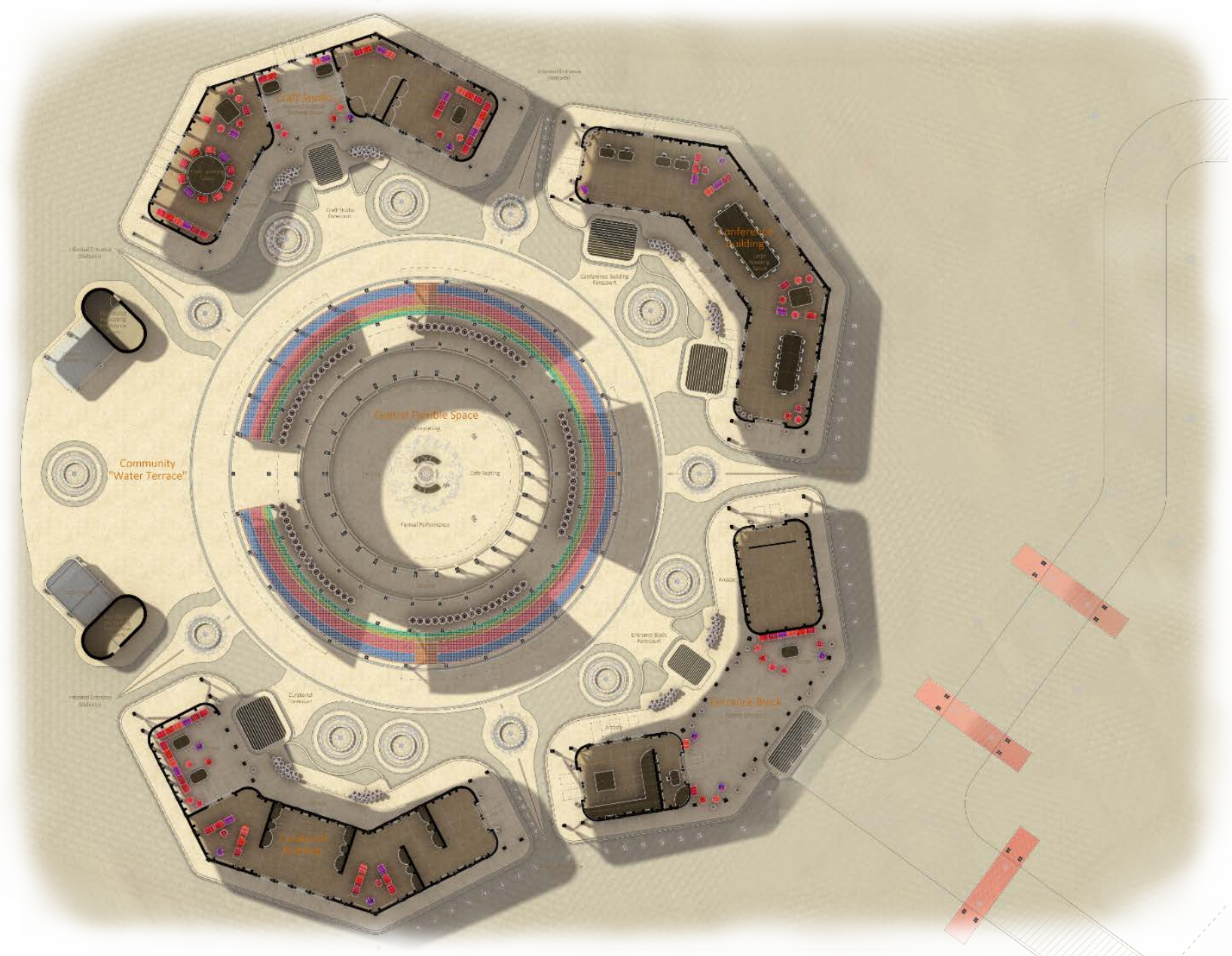


The four primary functions of the center have been individually housed and radially arranged to create a central, polyvalent, compound space shown in orange in the following diagram.

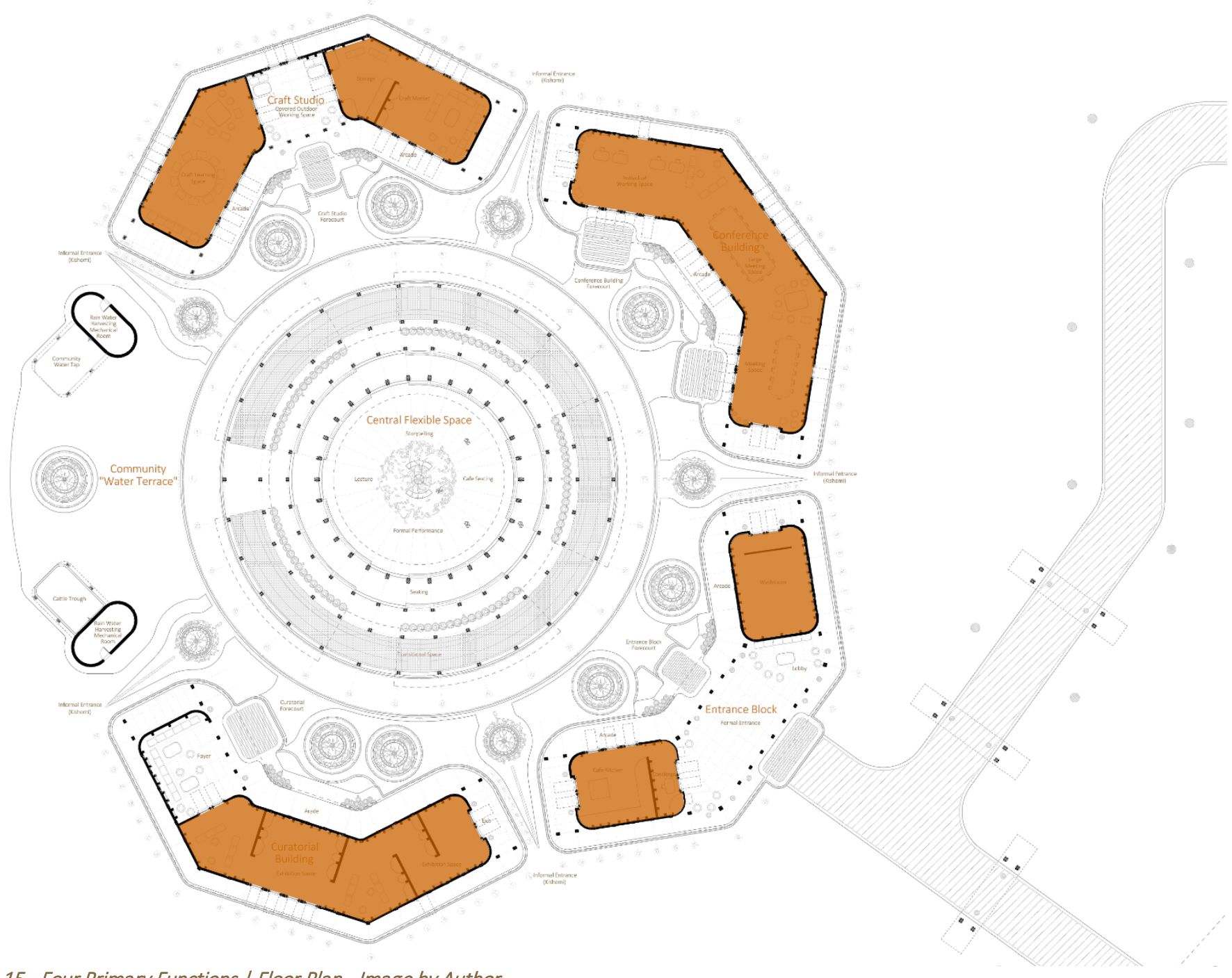

5.15 - Four Primary Functions / Floor Plan - Image by Author

The four primary functions of the cultural center are individually housed and radially arranged around a large open communal space. The four buildings highlighted in orange work together to enclose a spatial oasis, separating it from the rest of the Maasai Mara savannah. 


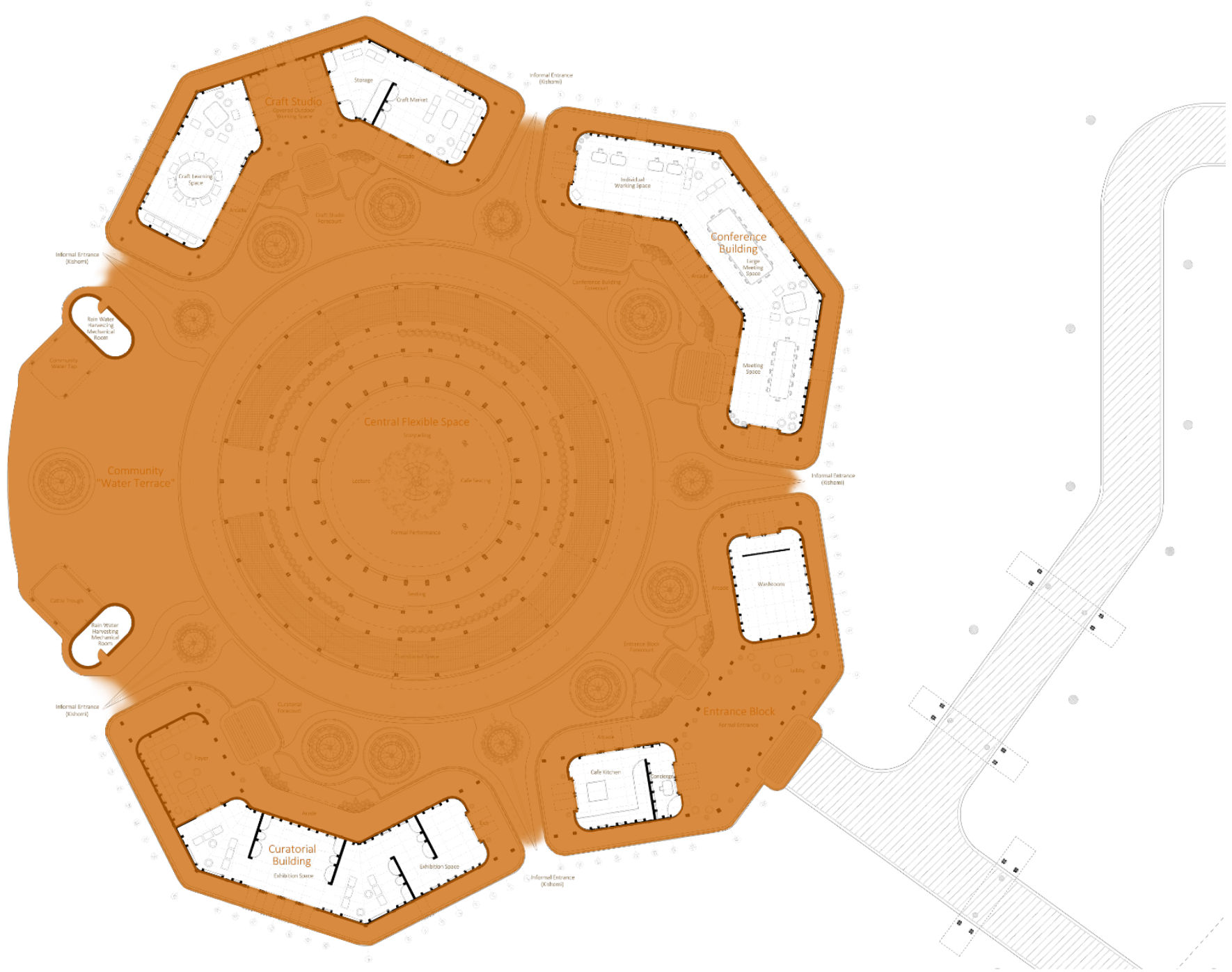

5.16 - Central Boma Communal Space / Floor Plan - Image by Author

As a result, a central, polyvalent communal boma space is created which stiches the perimeter buildings together. 


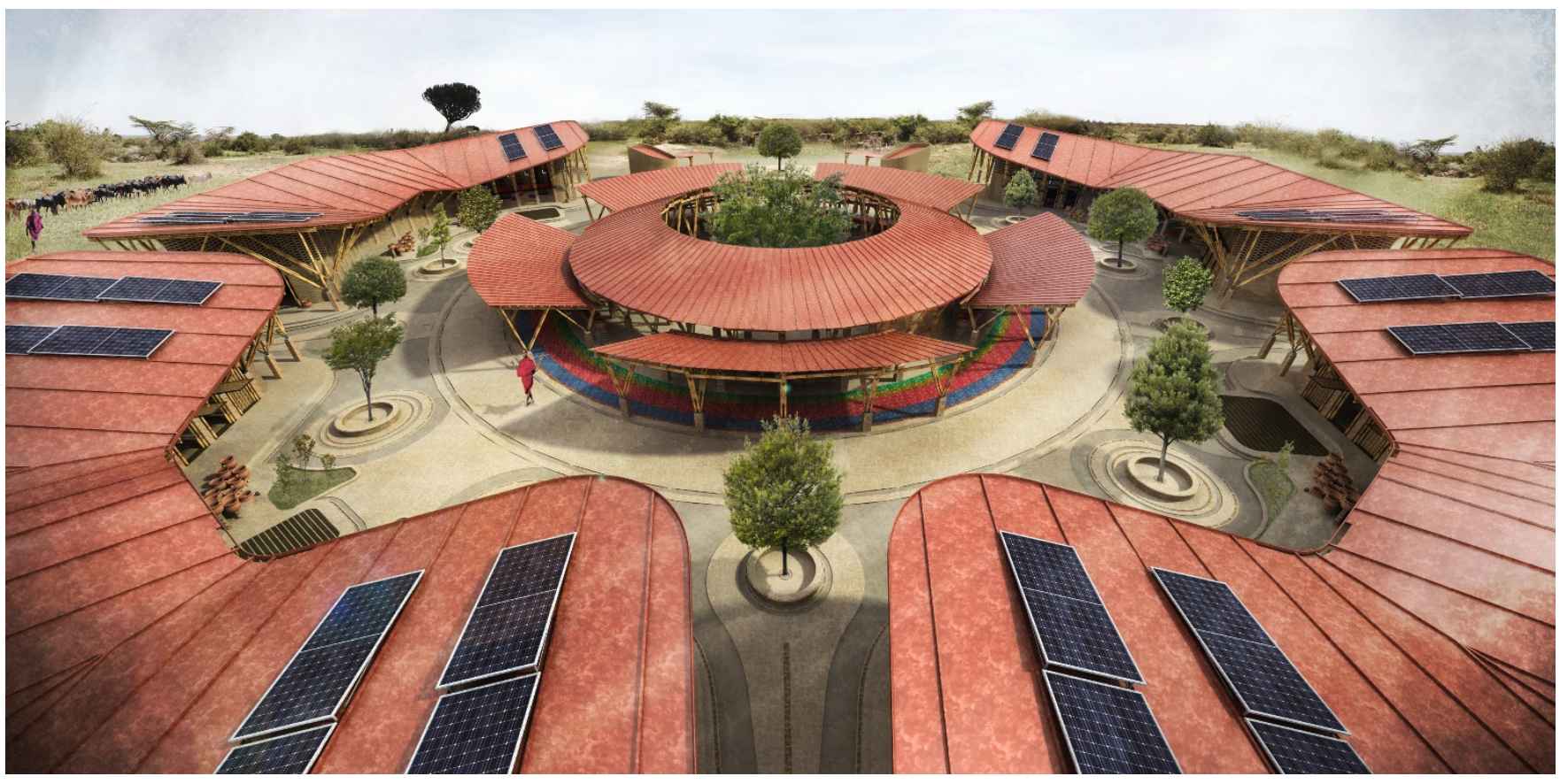

5.17 - Aerial Perspective of the Cultural Center - Image by Author

An aerial perspective of the entire composition is pictured above. As seen in this image, each of the four perimeter buildings takes the form of a wishbone, creating four forecourts between the center and periphery of the plan. 


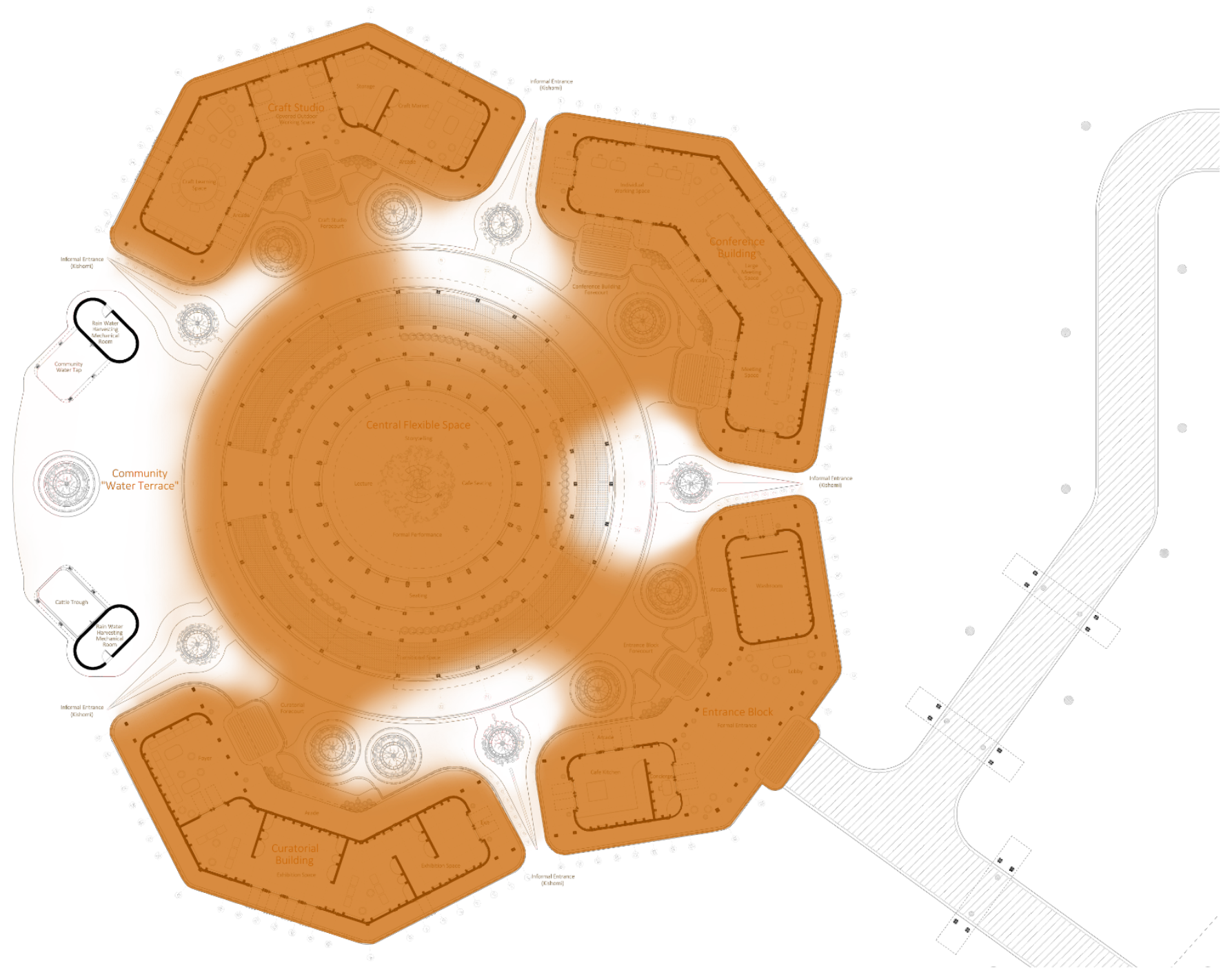

5.18 - Programmatic Blending / Floor Plan - Image by Author

The above diagram shows how the four peripheral functions spill into the center, through these aforementioned forecourts, allowing the compound space to be used in tandem with the periphery buildings. 


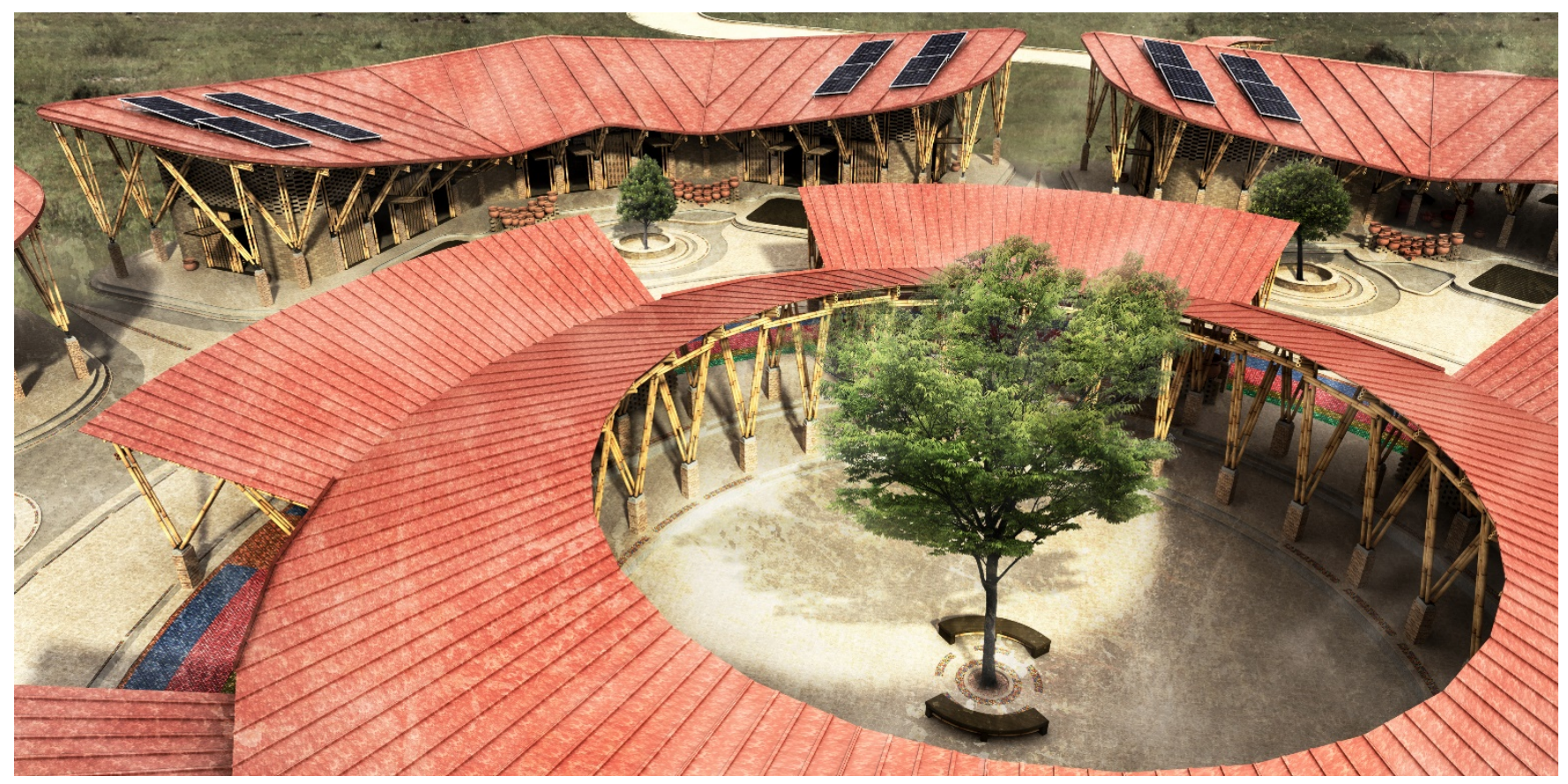

5.19 - Aerial Perspective of Center-Periphery Connection - Image by Author

This notion of spatial blending from center to periphery is illustrated in the above render where split roofs emphasize connectivity between these two general spaces. The image also shows how the forecourts act as spatial buffers between the buildings, each taking on a unique character in response to the programmatic function of its respective adjacent building. 


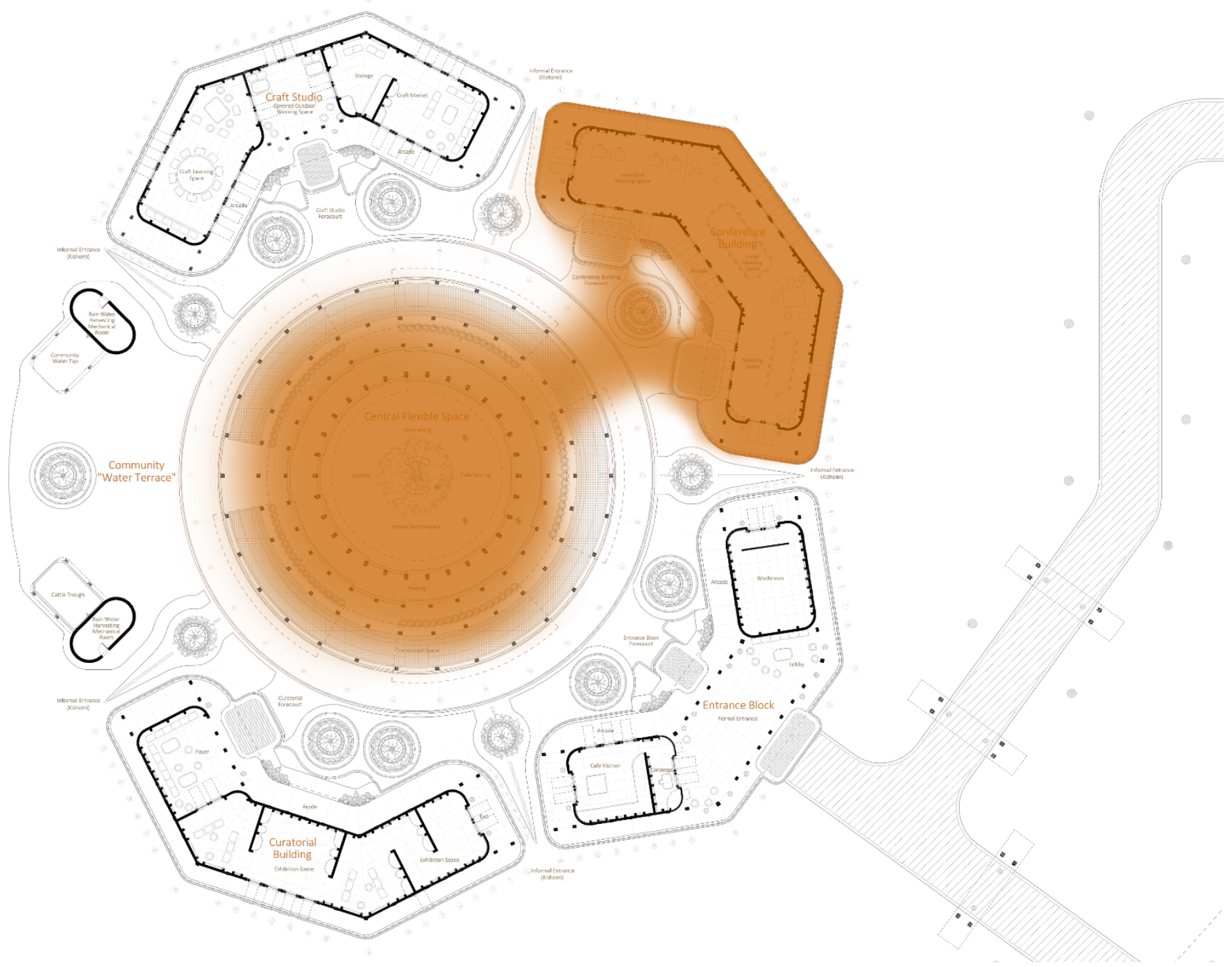

5.20 - Conference Center to Boma Communal Space Connection - Image by Author

For example, the above diagram shows the relationship between the conference building and the central performance space. This is illustrated in the following image 


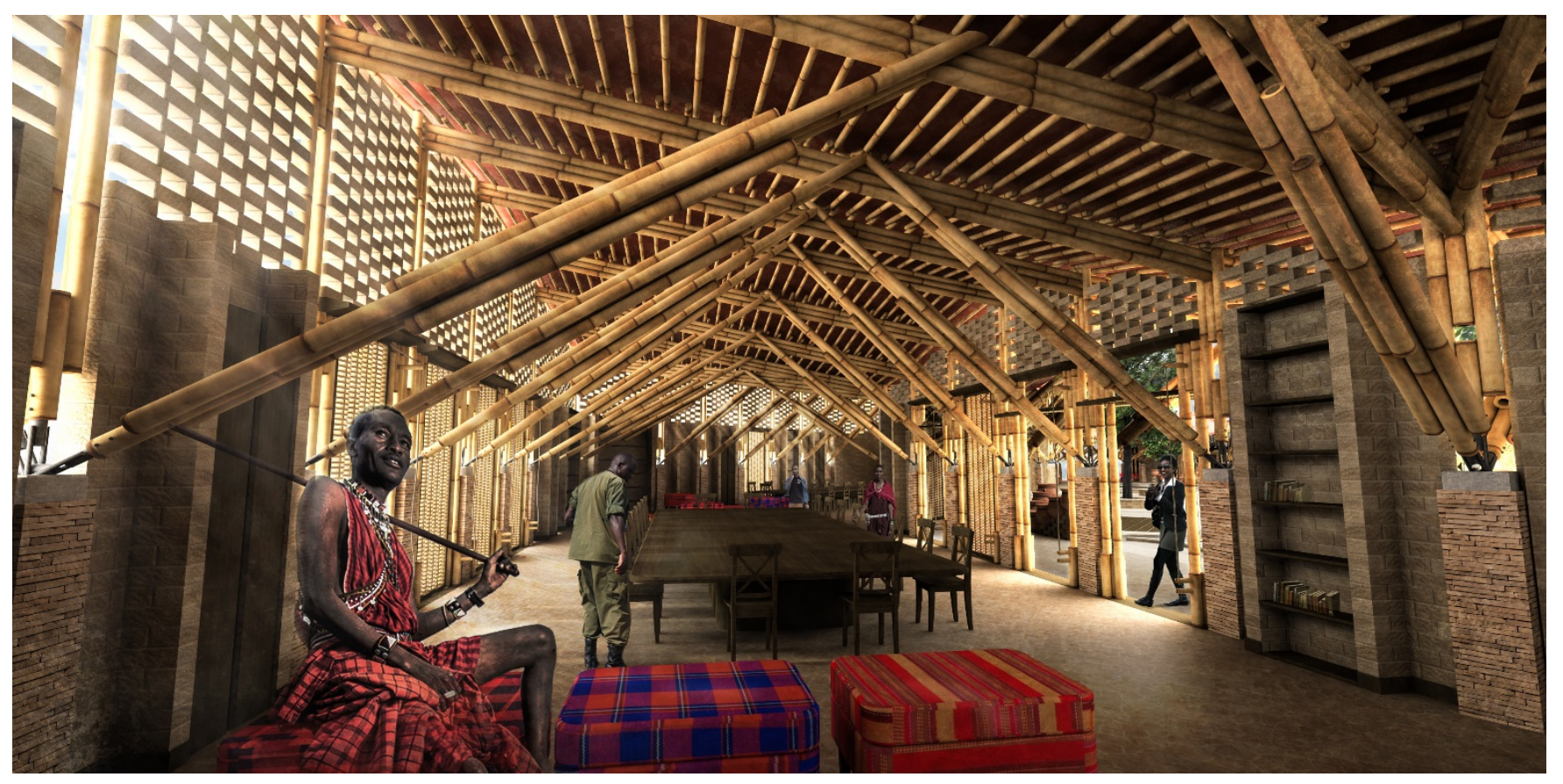

5.21 - Conference Space Perspective - Image by Author

This render above, illustrates in three dimensions the previous diagram. The doors (shown to the right of this image) of this conference block pivot upwards, blurring inside and outside, further emphasizing connectivity to the centre. 


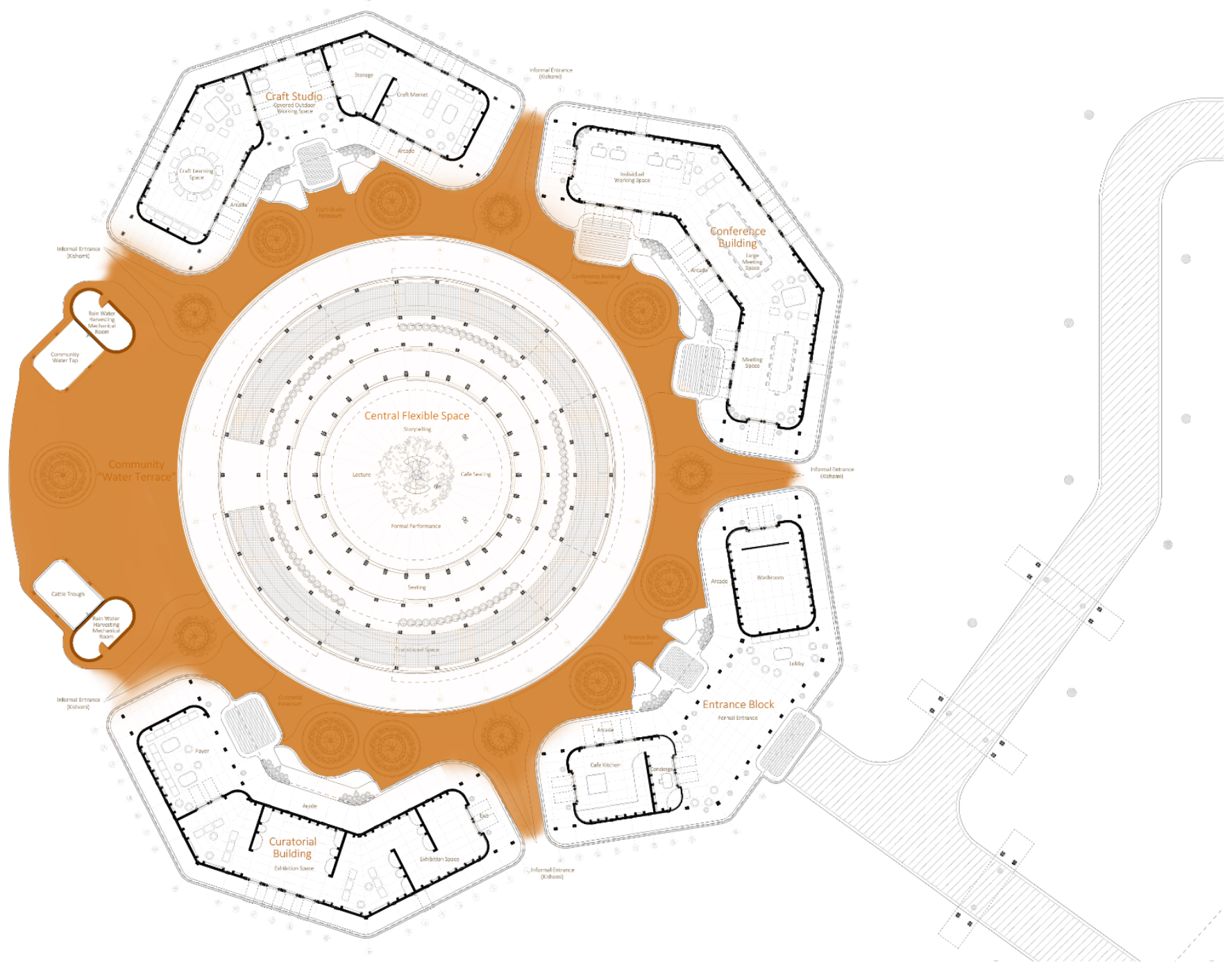

\subsection{2 - Landscaped Communal Space - Image by Author}

The floor plan of the cultural center makes of use of a layering of spaces from center to periphery that suggest different programmatic funtions that overlap in reality. Like a vernacular Maasai home, these boma commual space takes on a high degree of polyvalency. The above diagram shows the first spatial layer, the exterior landscaped boma space. 


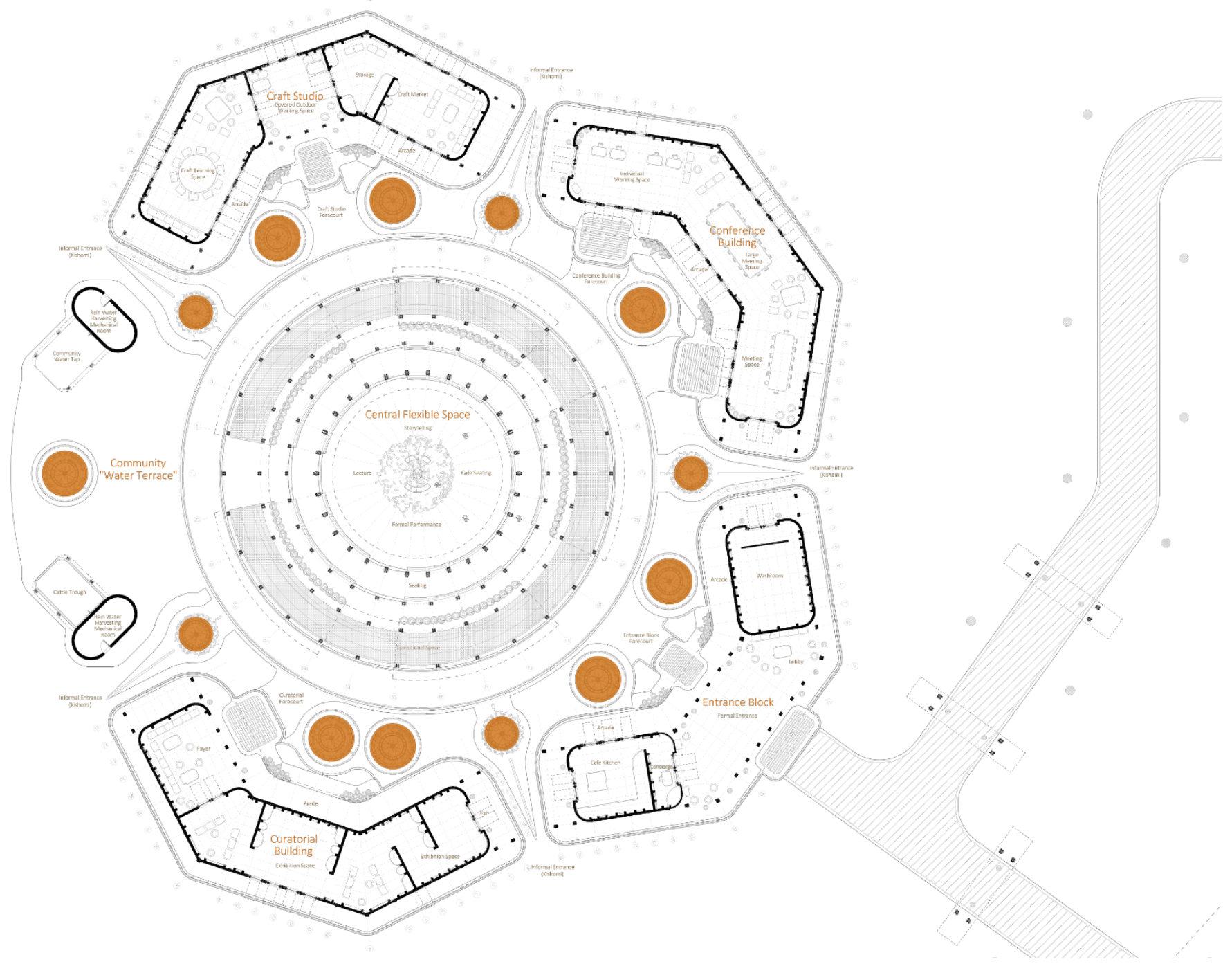

\subsection{3 - Spaces for Informal Social Interaction under Trees}

The above diagram shows spaces for repose under the shade of trees. These have been strategically positioned near the entrances for informal surveillance or "eyes on the boma space". 


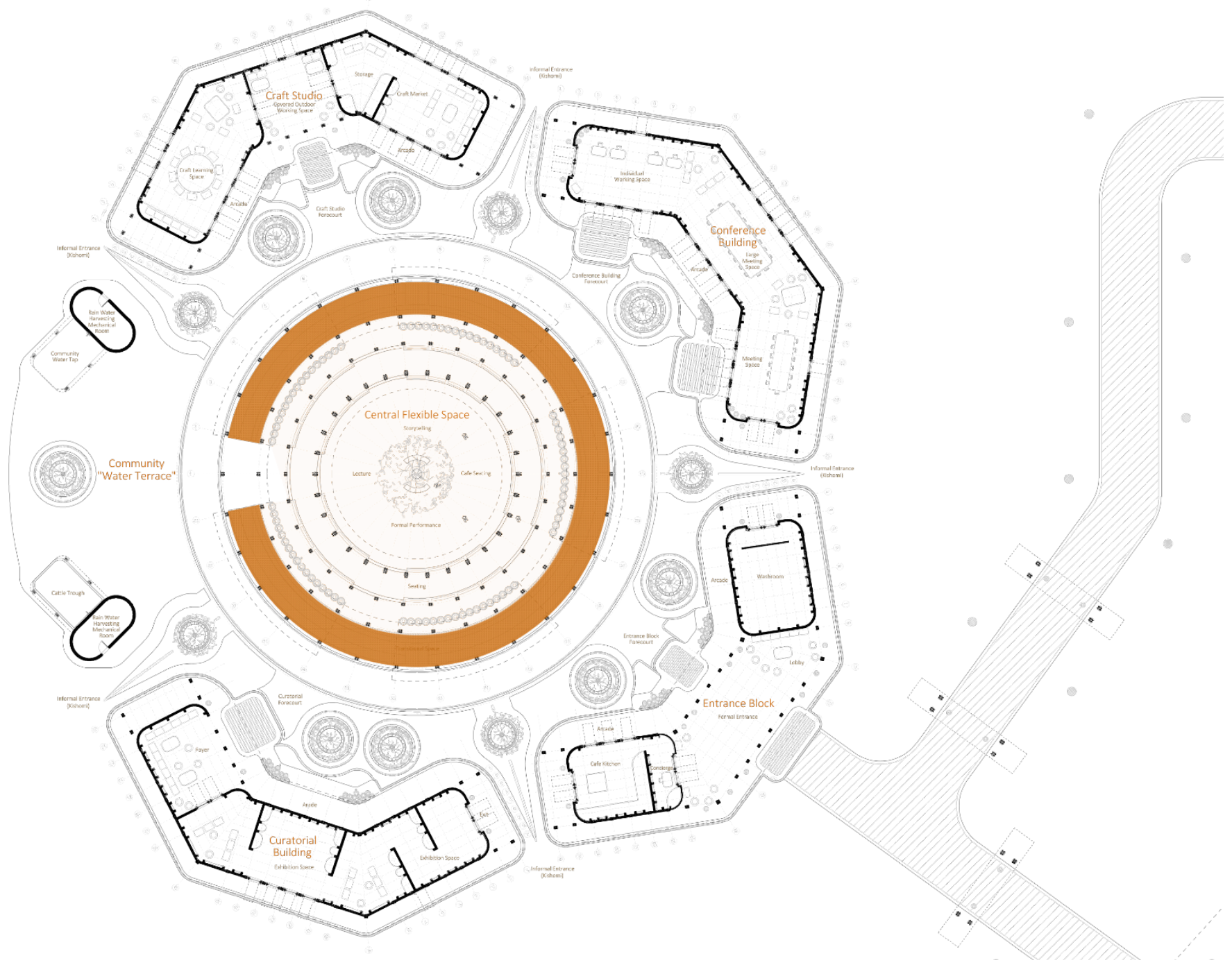

5.24 - The Exhibition Ring - Inspired by a Maasai Wedding Necklace

The Exhibition ring is the next most spatial layer. It is a space which can be used for showcasing various display material for cultural events. Its spatial circularity provokes curiousity by encouranging movemnt about the center. 


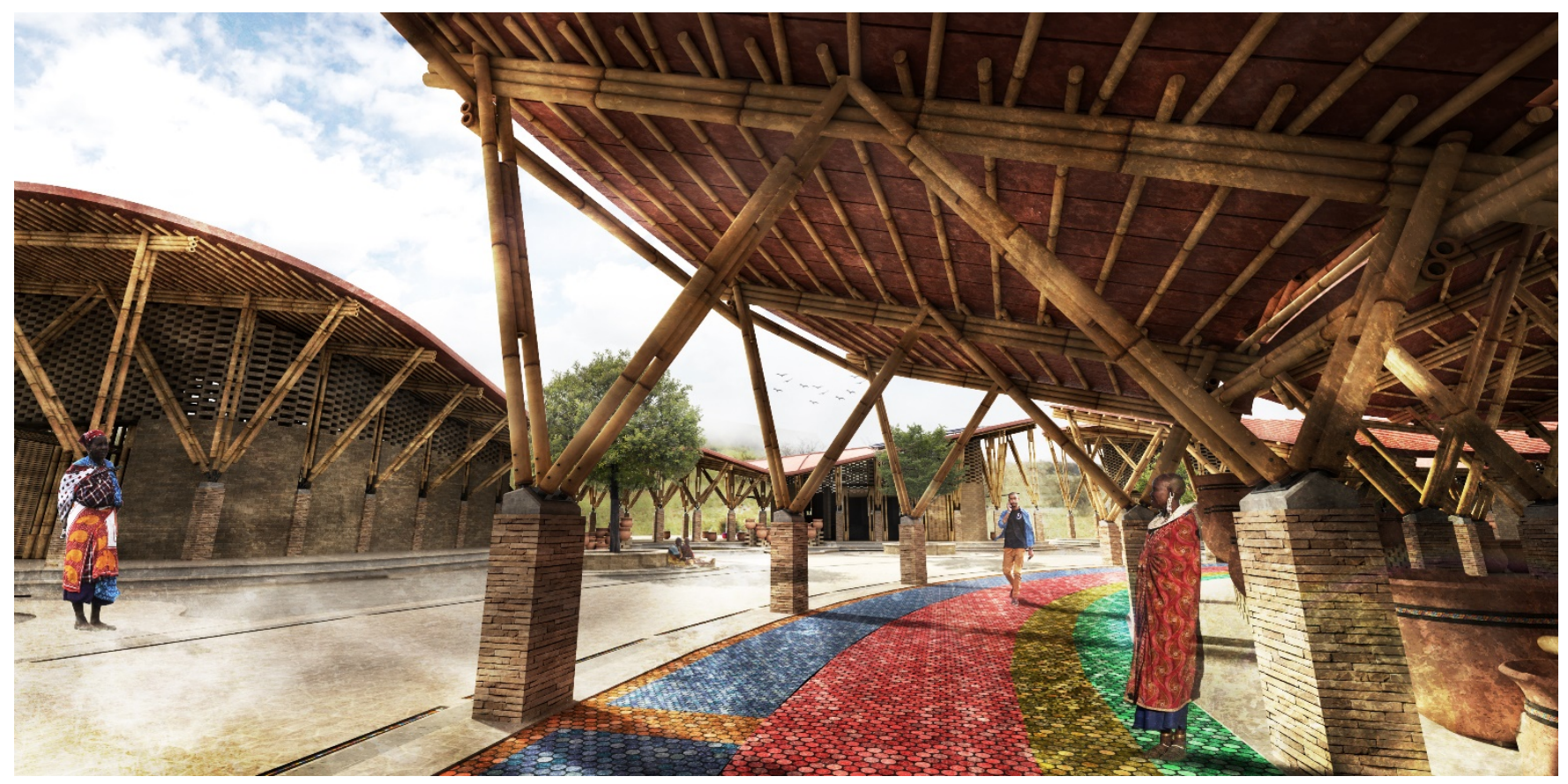

5.25 - Exhibition Ring Perspective - Image by Author

The hardscaping has been inspiried by a Maasai wedding necklace whworn by the woman to the right in the above image. The floor makes use of mosaic tiles to add a brilliant flash of colour to the otherwise more natural material palette of the building. This contrast in colour in not unlike the manner in which the Maasai red shuka stand out on the grey-green savannah during cattle herding. Like a necklace, the hardscaping is comprised of small repeated circular unit; a tile. 

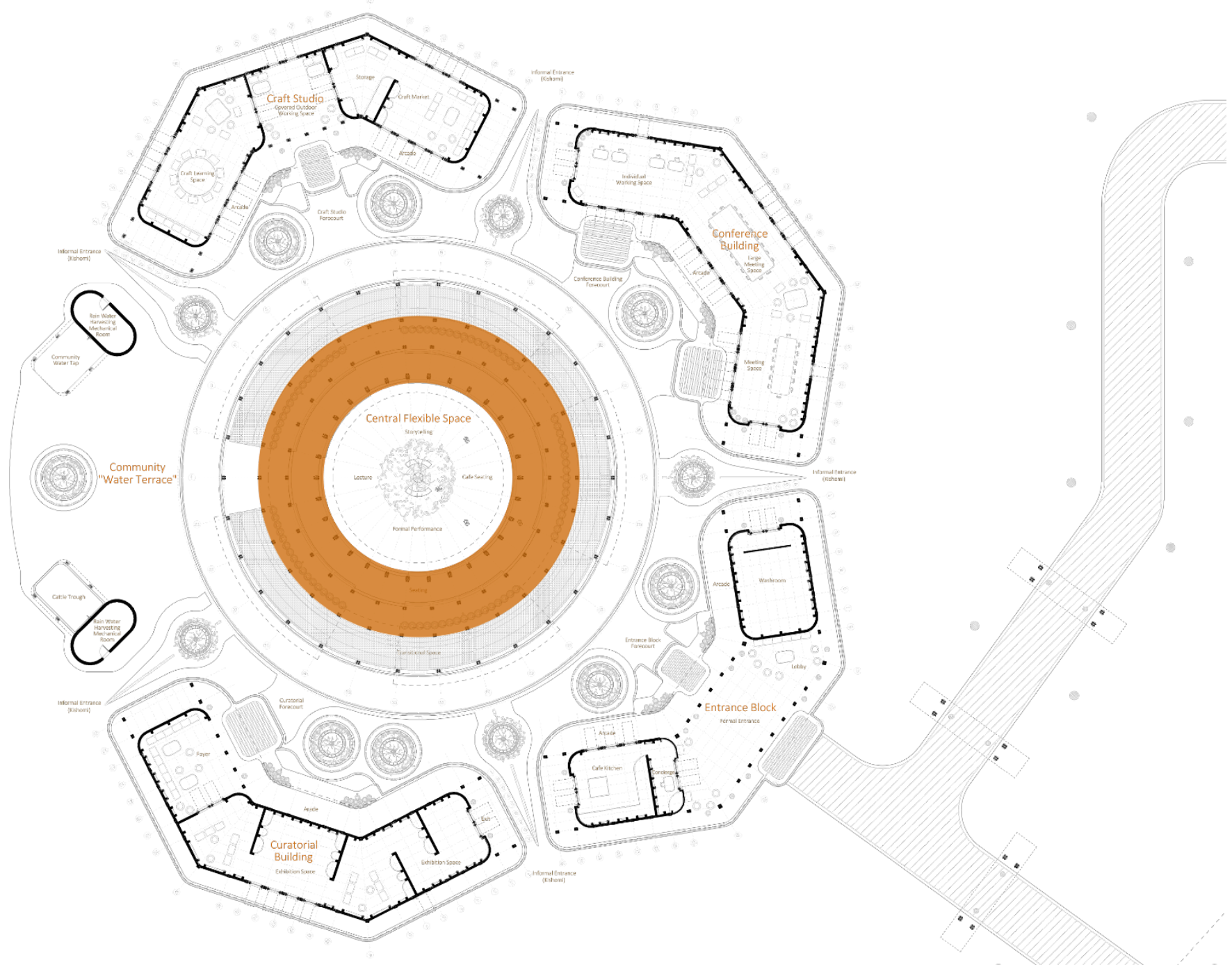

5.26 - Formal Seating for the Performance Space - Image by Author

Under the roof of central performance space are spaces for seating. 


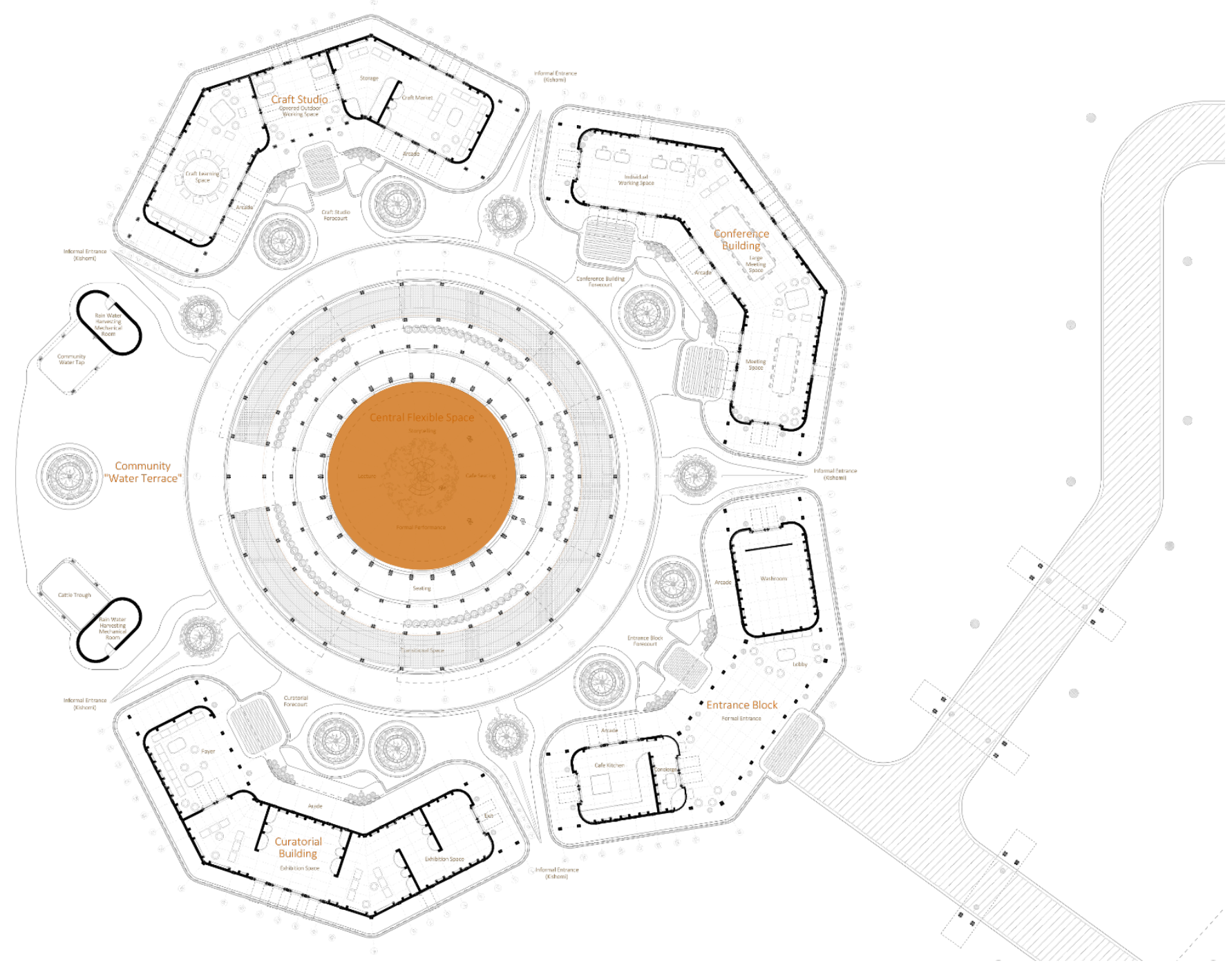

5.27- Performance Space - Image by Author

Lastly the central performance space occuposed the heart of this cultural center and illustrated in the following image. The space supports a large central tree, a reminder of the traditional space for gathering in Maasai culture for the sharing of stories or for community governance meetings called Enkiguena. The species of tree that has been traditionally sought out for these meetings is called the Oldarpoi Tree, known in the West as the Bologna Sausage Tree as it bears elongated kidney-shaped fruit. It is this tree which will be used at the center of the building. 


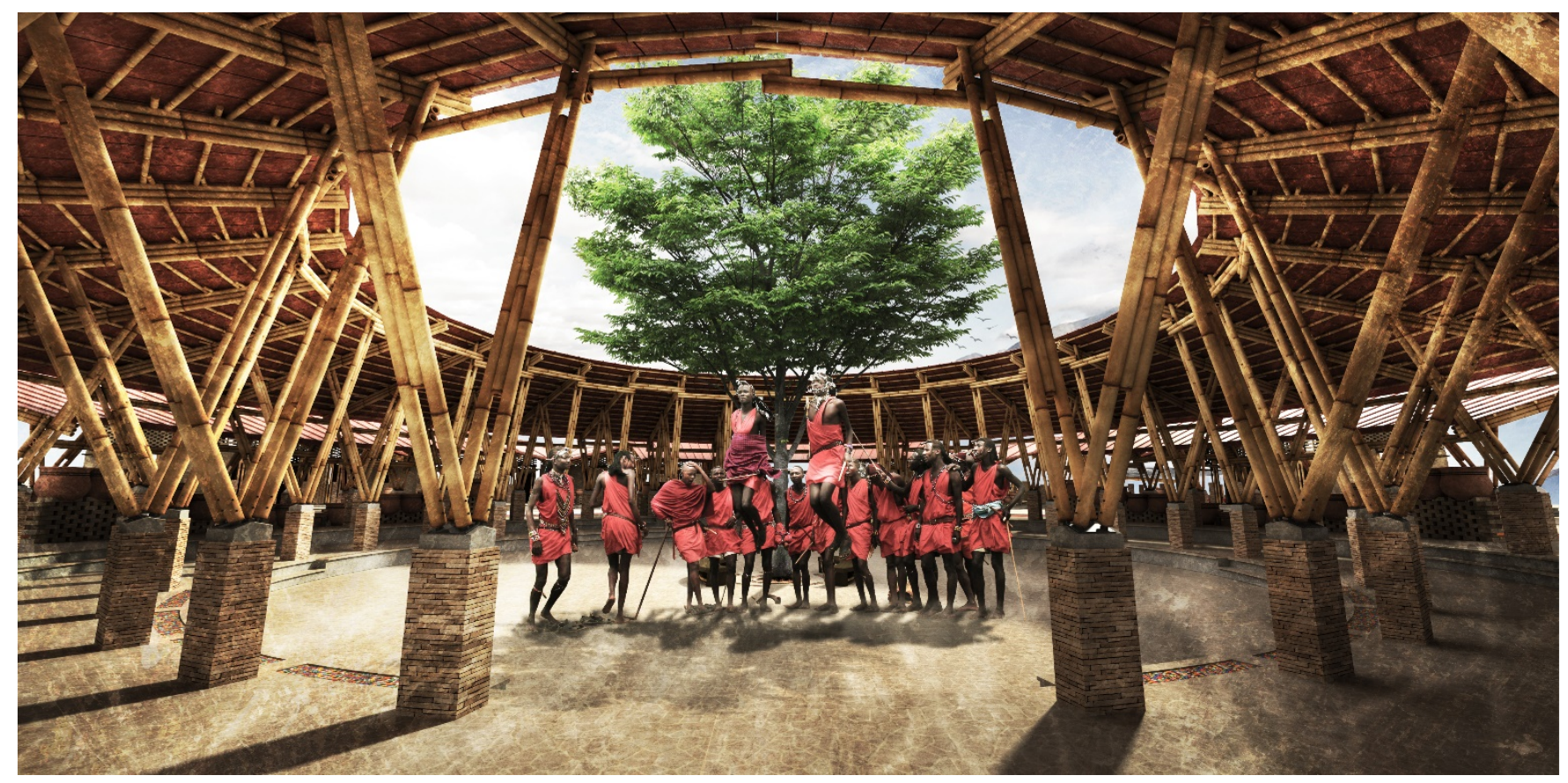

5.28 - Performance Space Perspective - Image by Author

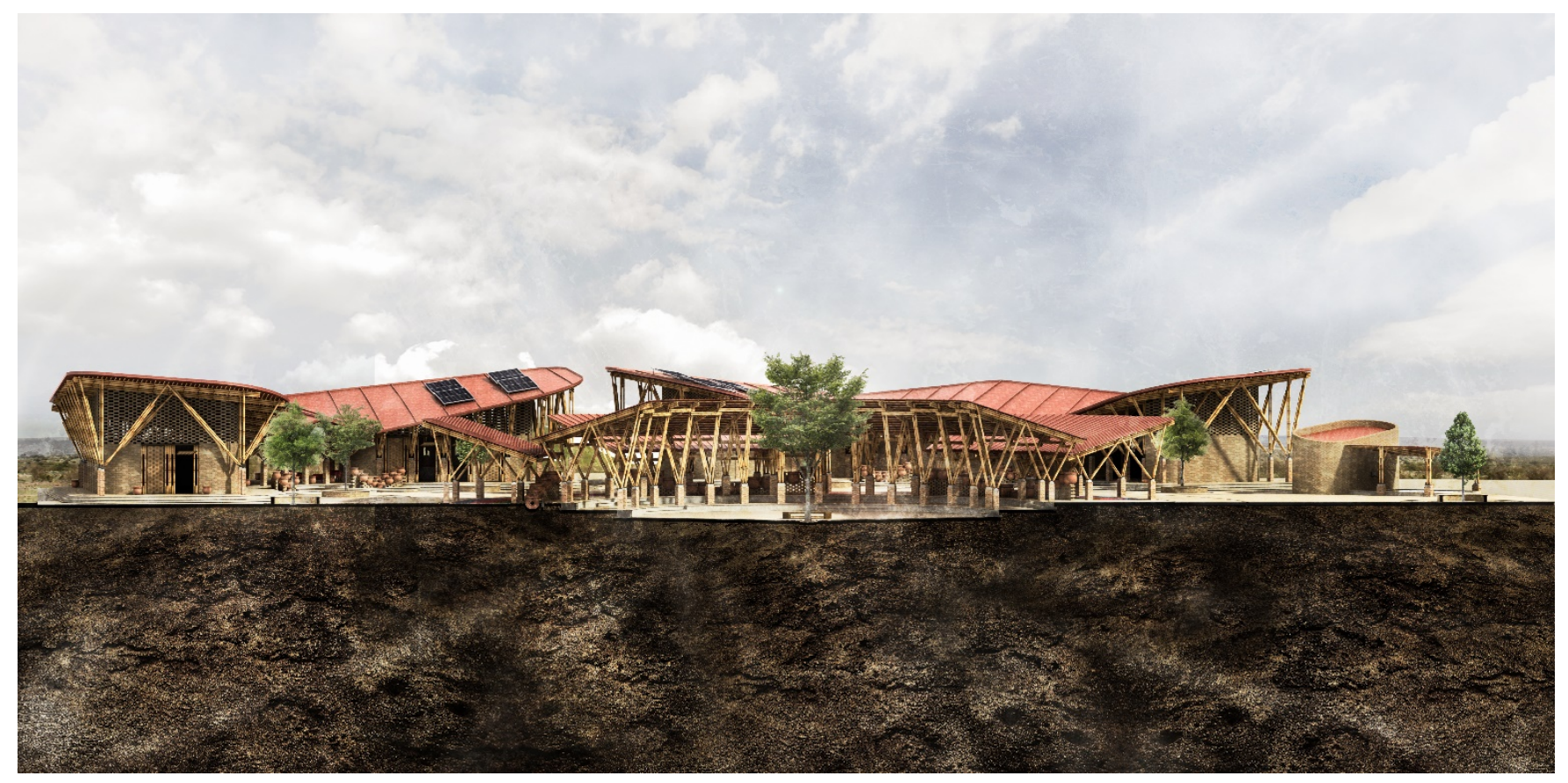

5.29 - Section of the Cultura/ Center 
Unlike the flat ground planes of the vernacular Maasai homesteads, a depression in the section (shown above) further highlights the importance of the central space. A general boundary is created not using a wall but instead a change in ground height.

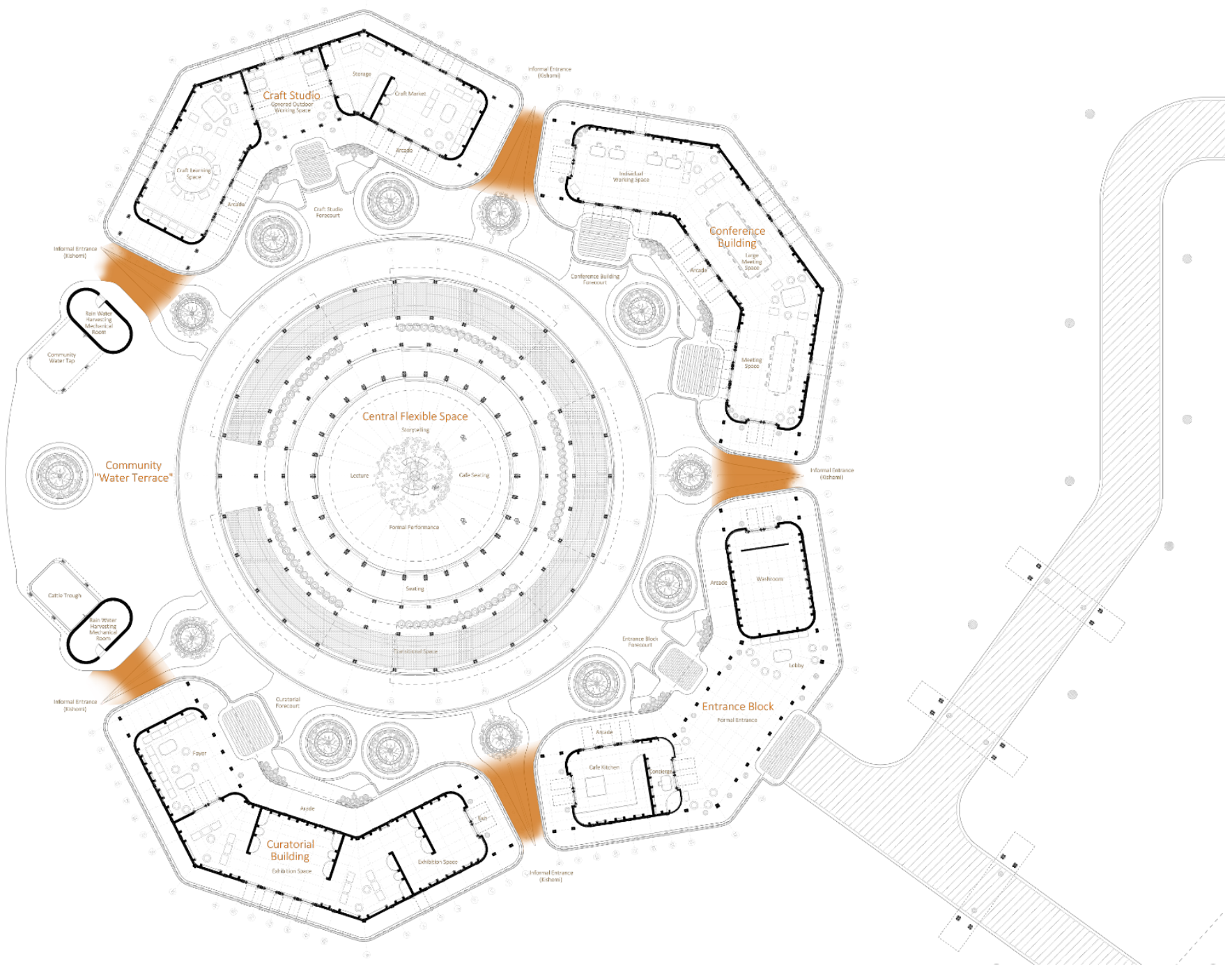

5.30 - Informal Entrances (Kishomi) - Image by Author

The image above highlights informal entrances, traditonally known as Kishomi which allow Maasai arriving from the savannah to access the building in a radial fashion. This is illustrated below. 


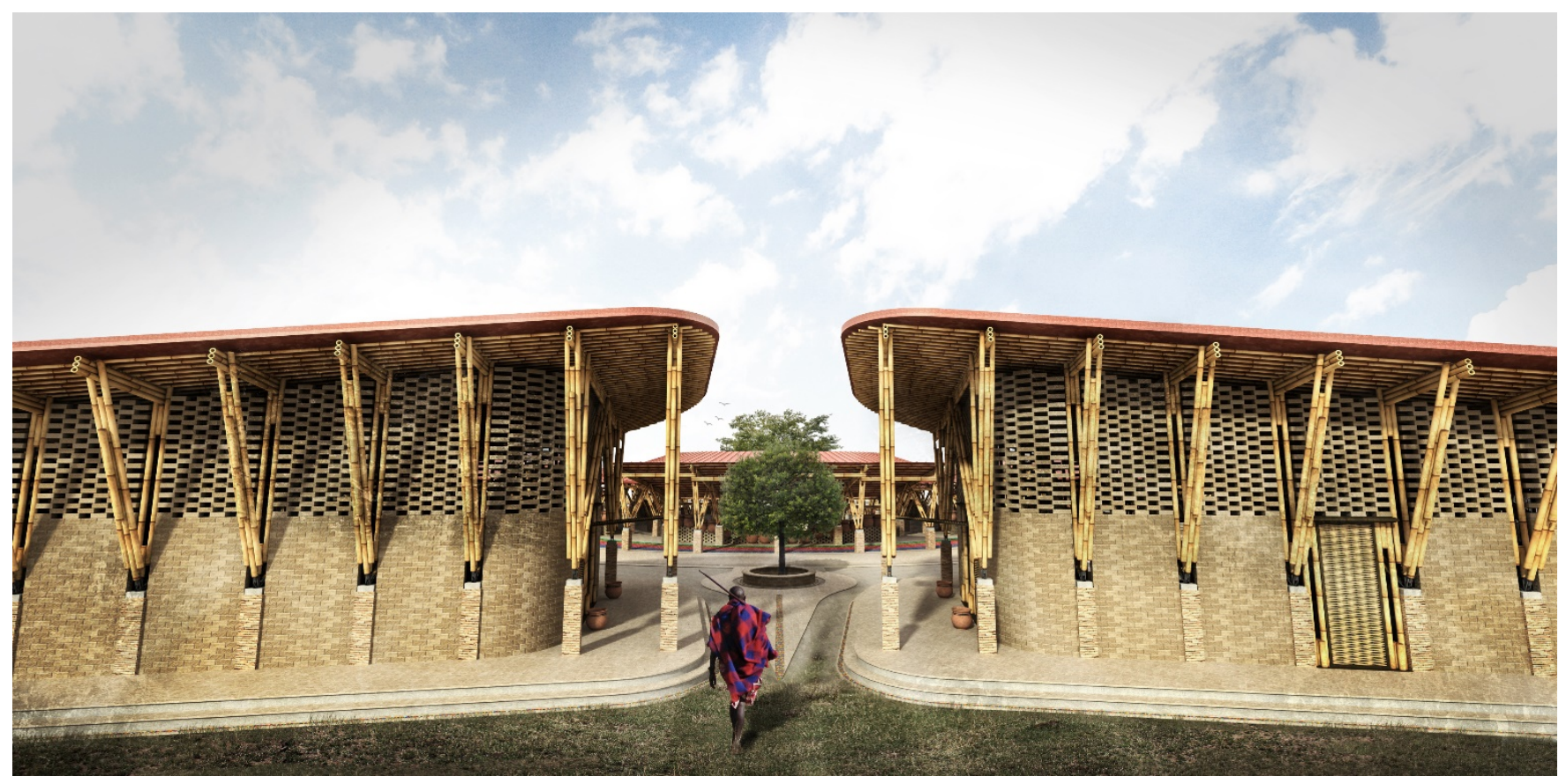

5.31 - Informal Entrance (Kishomi) Perspective - Image by Author

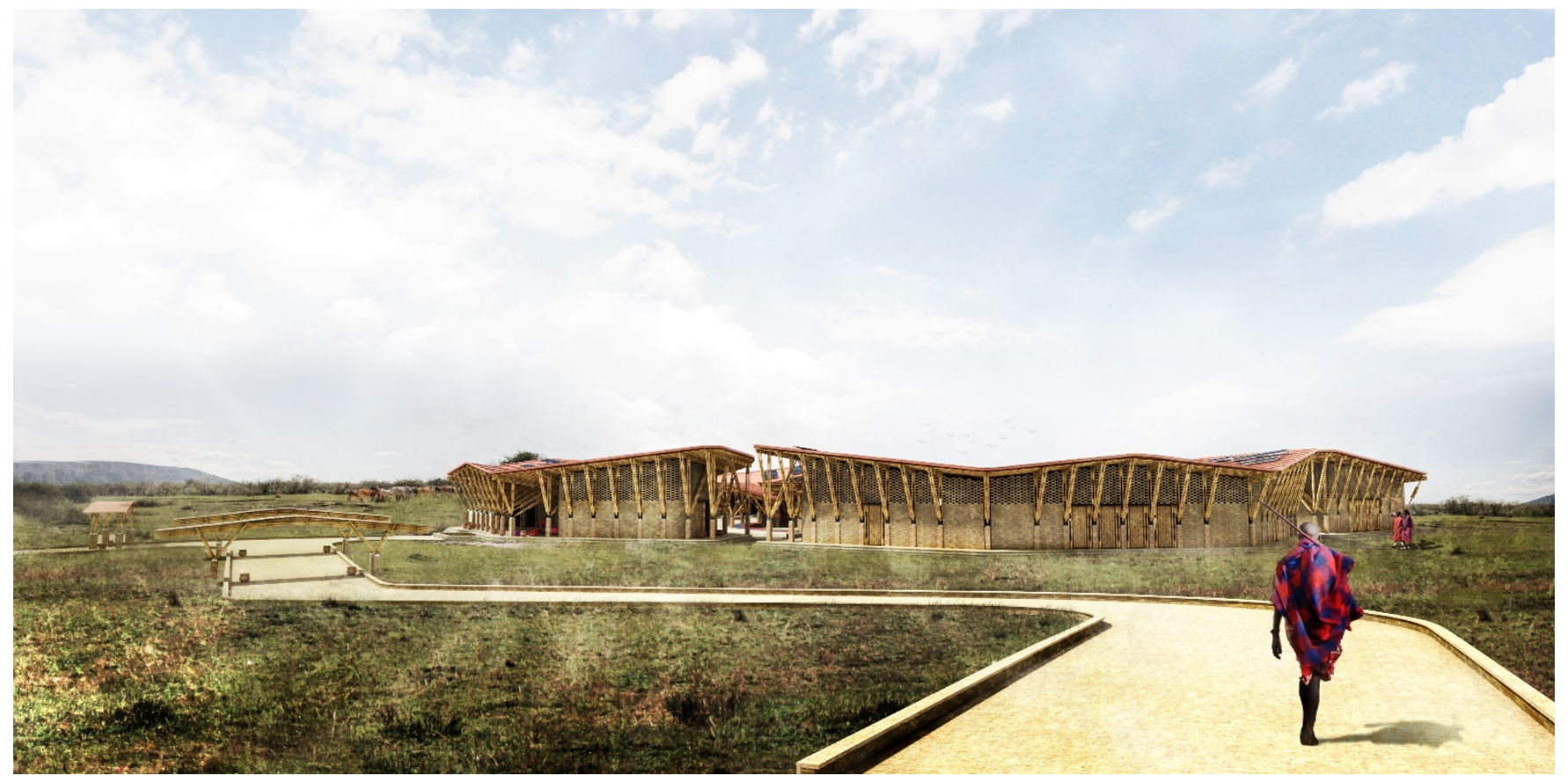

5.32 - Cultural Center Exterior Perspective - Image by Author 


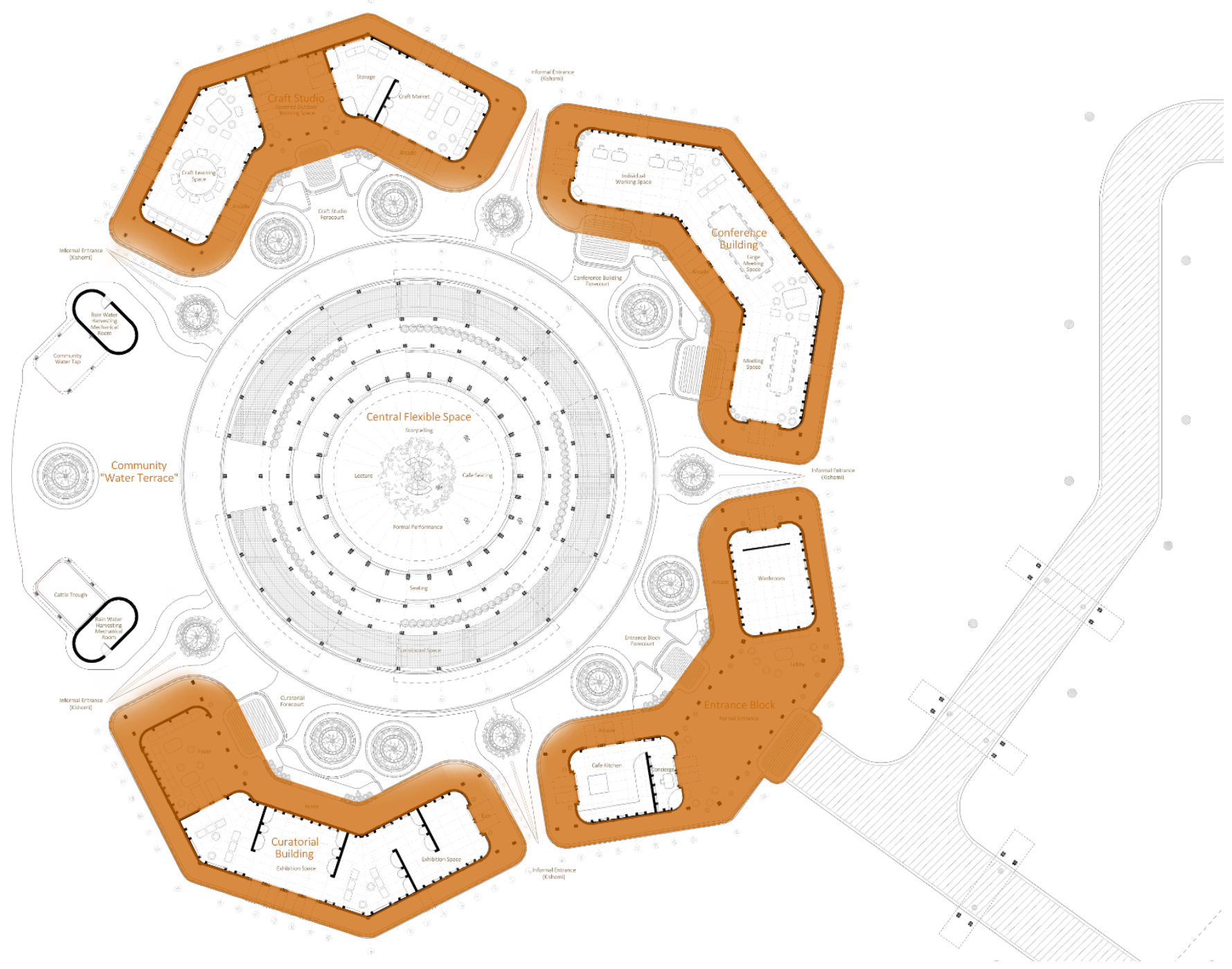

5.33 - Arcade Spaces / Floor Plan - Image by Author

Large roof eaves protect the earth bricks against the elements, created shaded spaces for occupants and create generous spatial buffers between the perimeter buildings and the boma communal space. This is illustrated in the following image. 


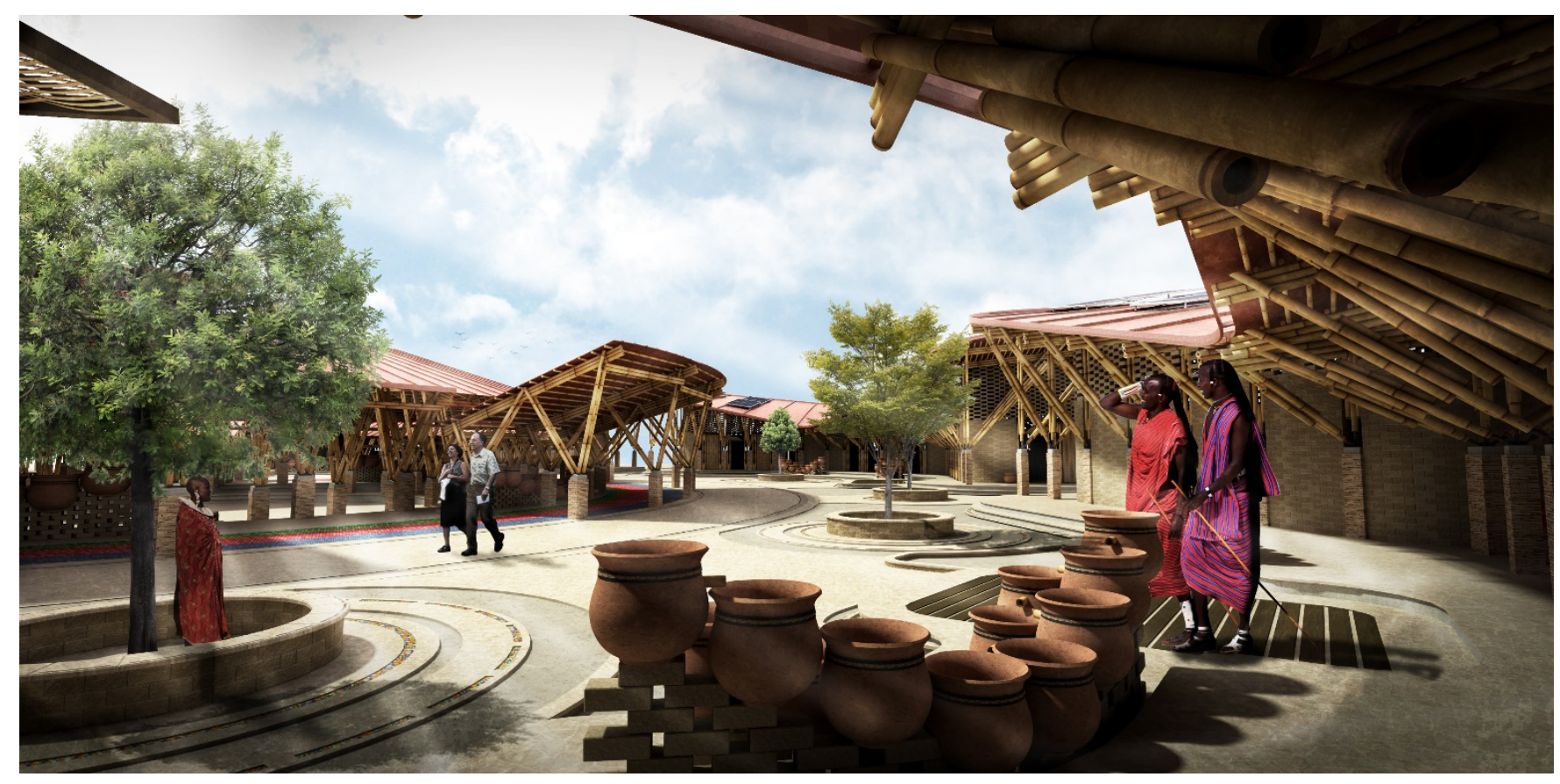

5.34- Arcade Space After Entrance Block Perspective - Image by Author

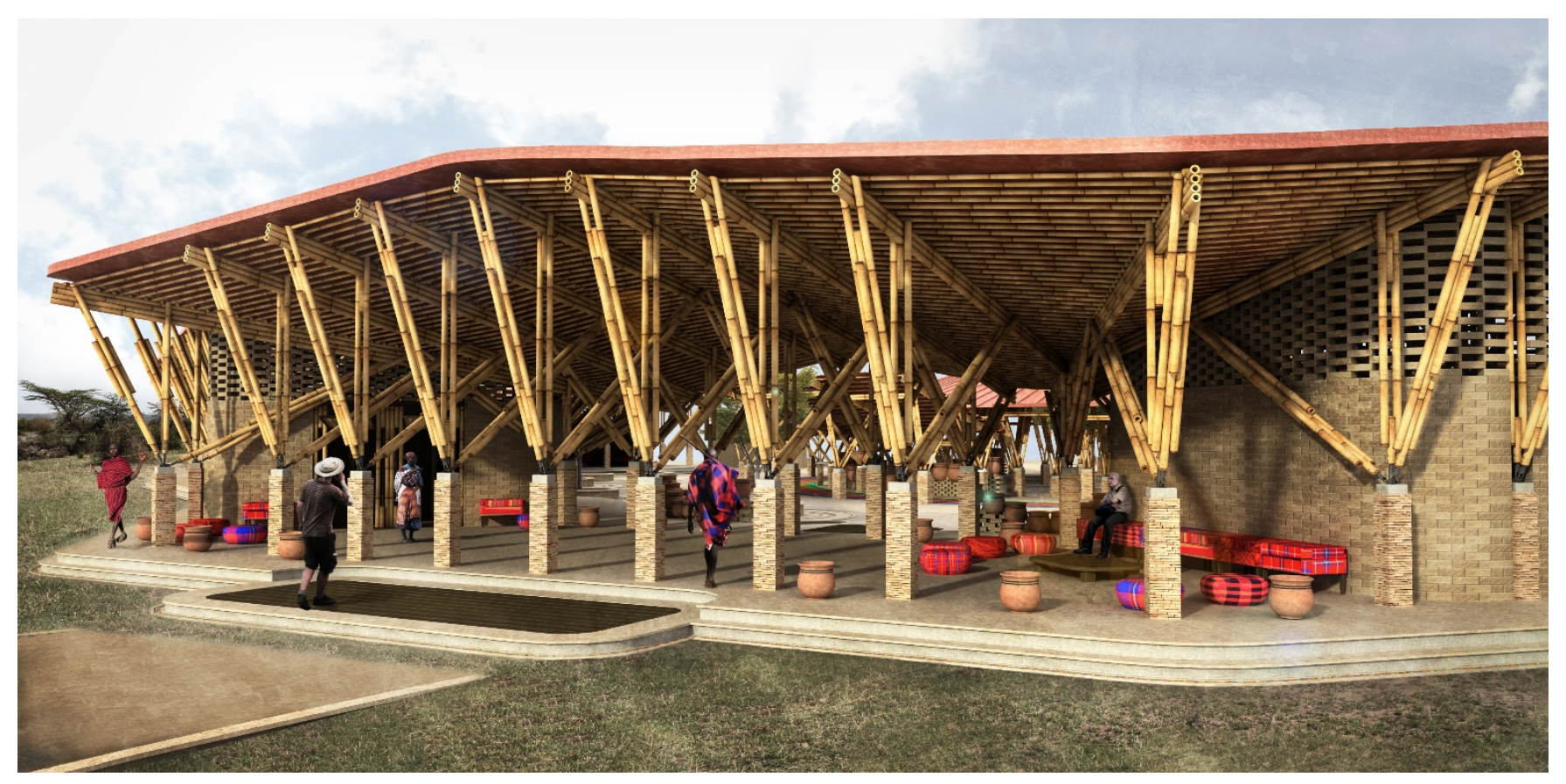

5.35 - Formal Entrance 


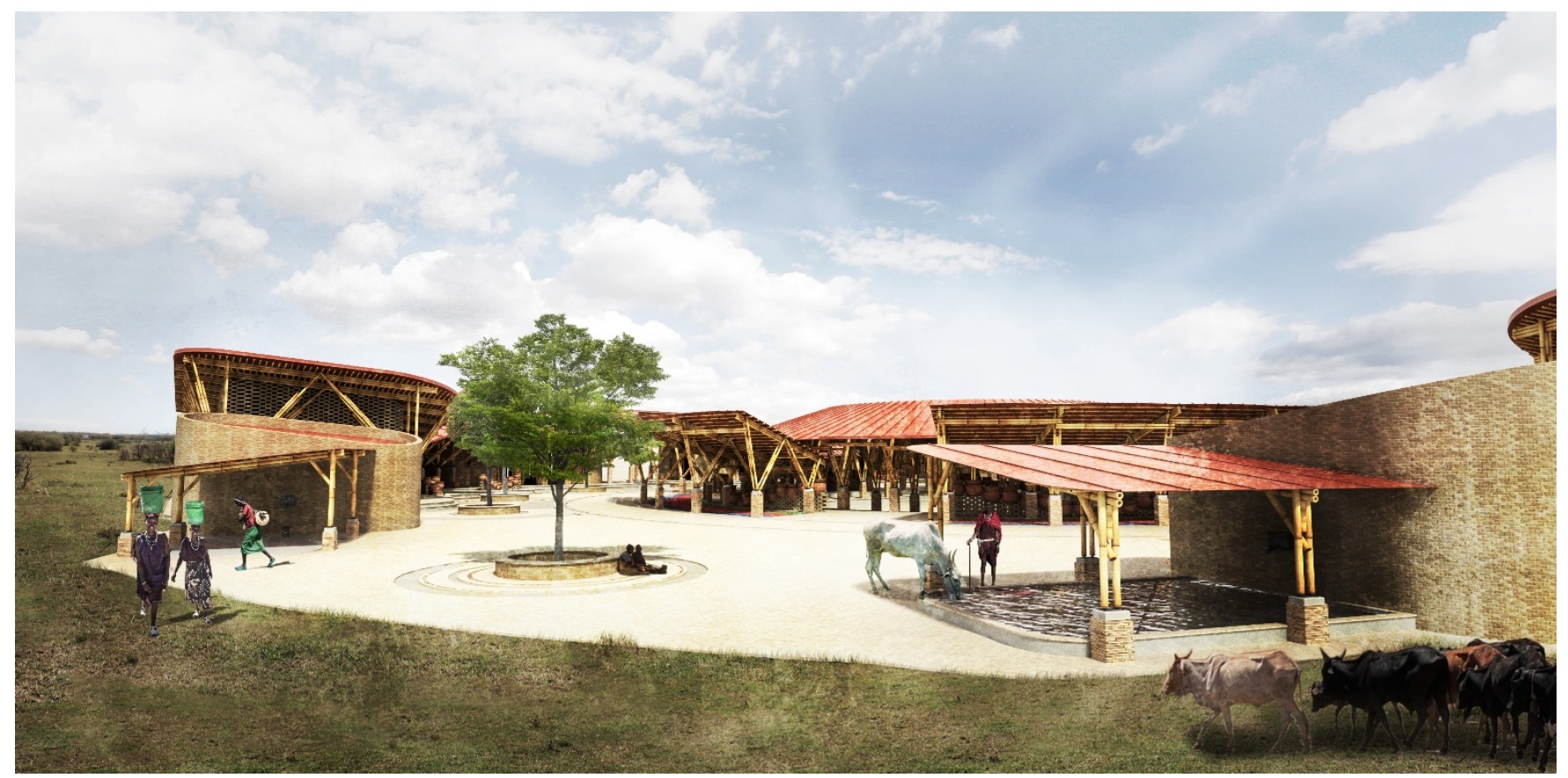

5.36 - Community Water Tap Perspective - Image by Author

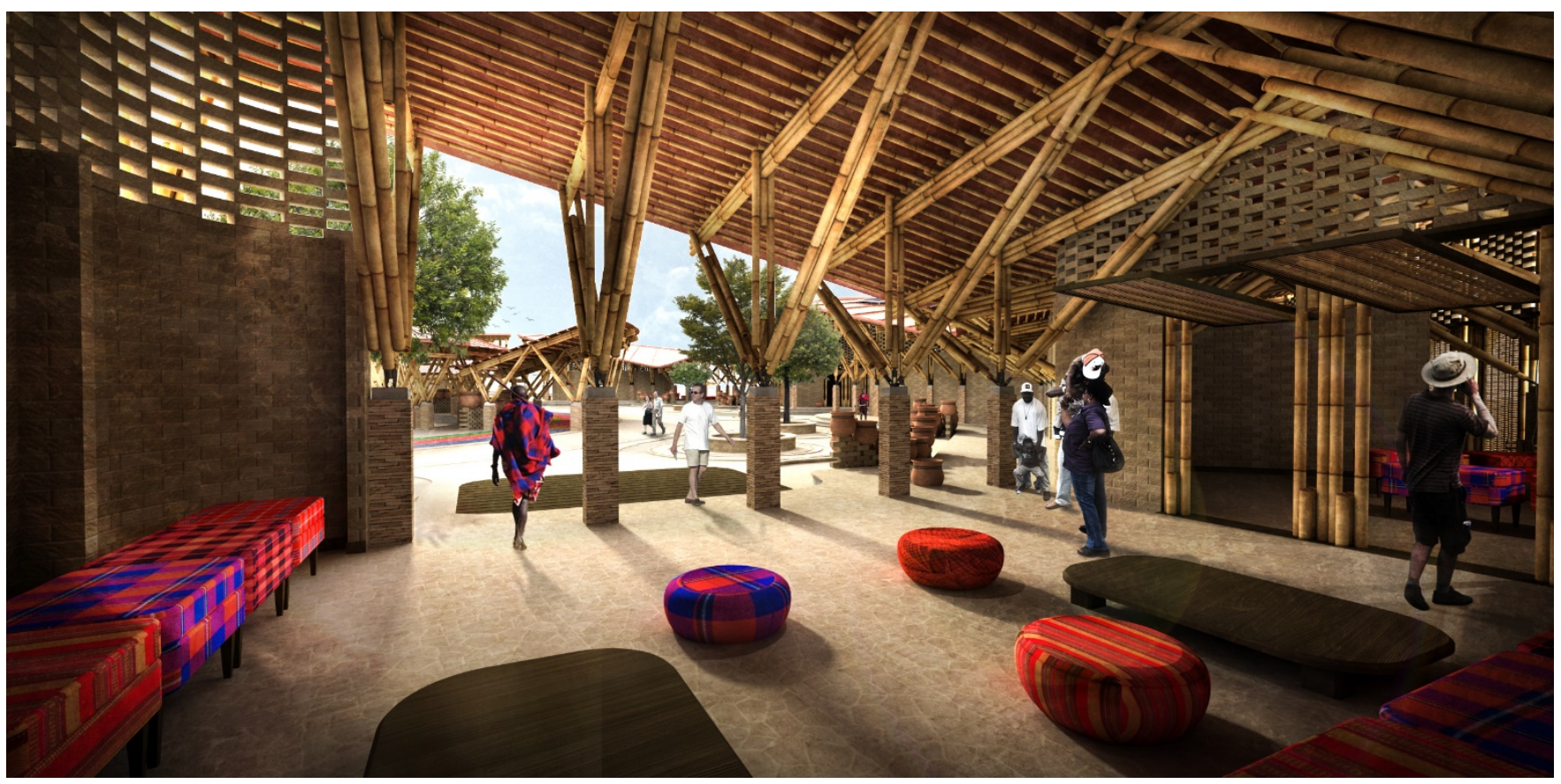

5.37 - Curatorial Forecourt Perspective - Image by Author 


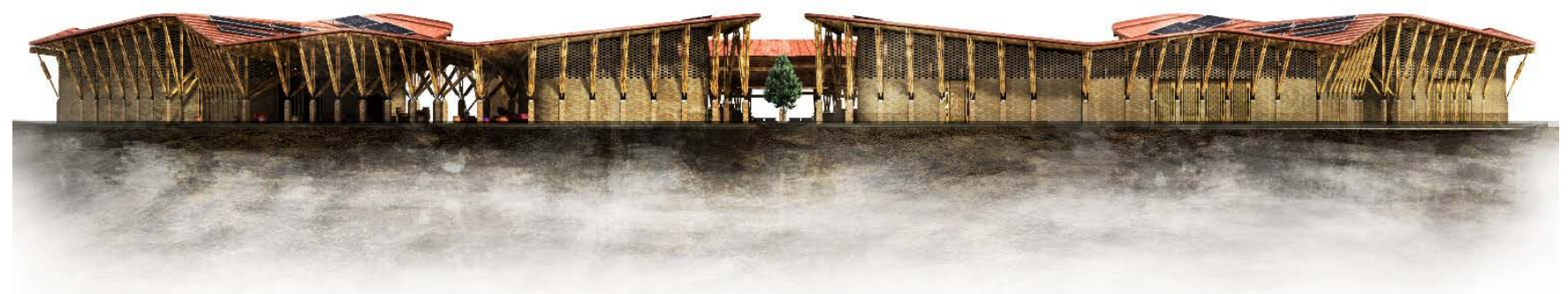

5.38 - East Elevation - Image by Author

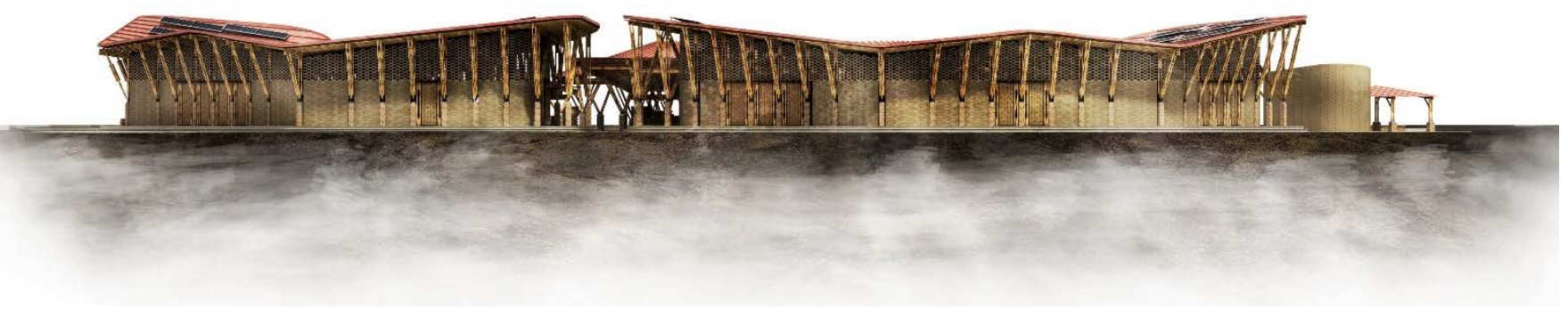

5.39 - North Elevation - Image by Author

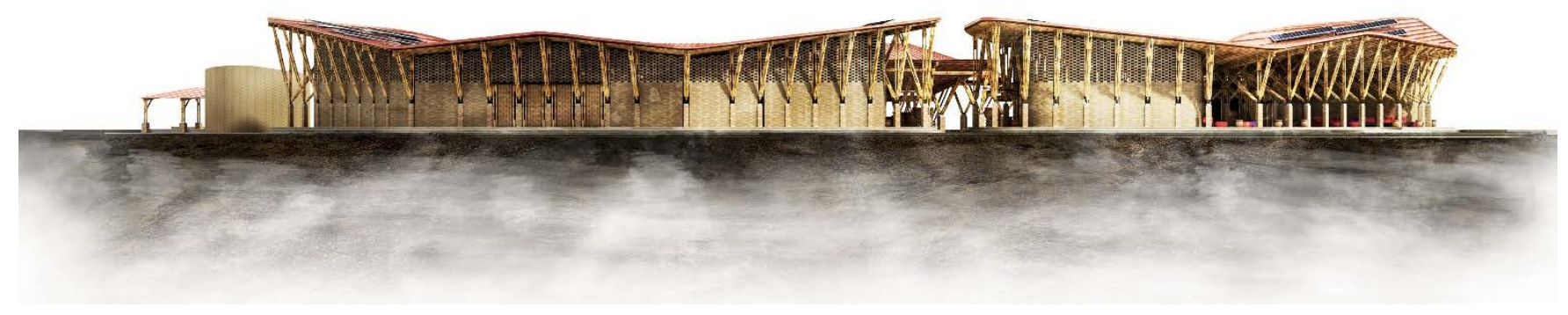

5.40 - South Elevation - Image by Author

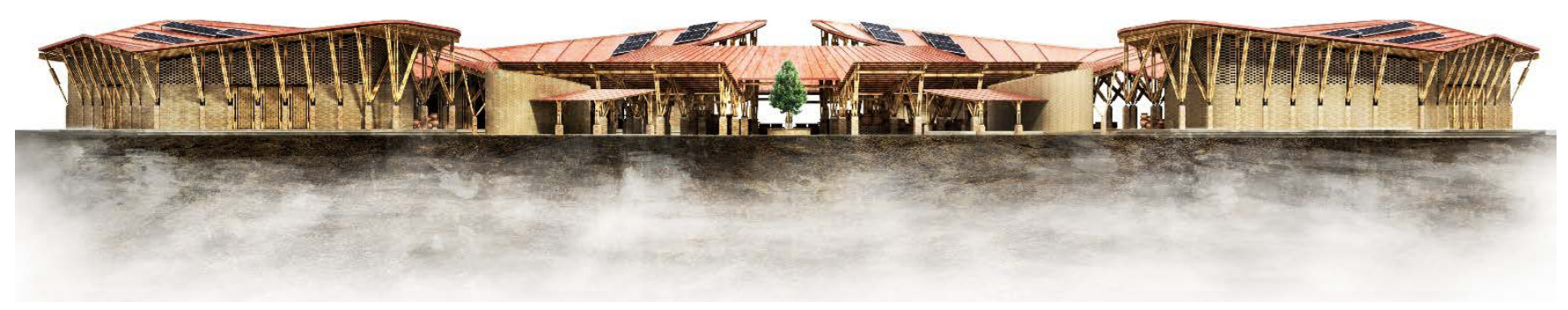

5.41 - South Elevation - Image by Author 


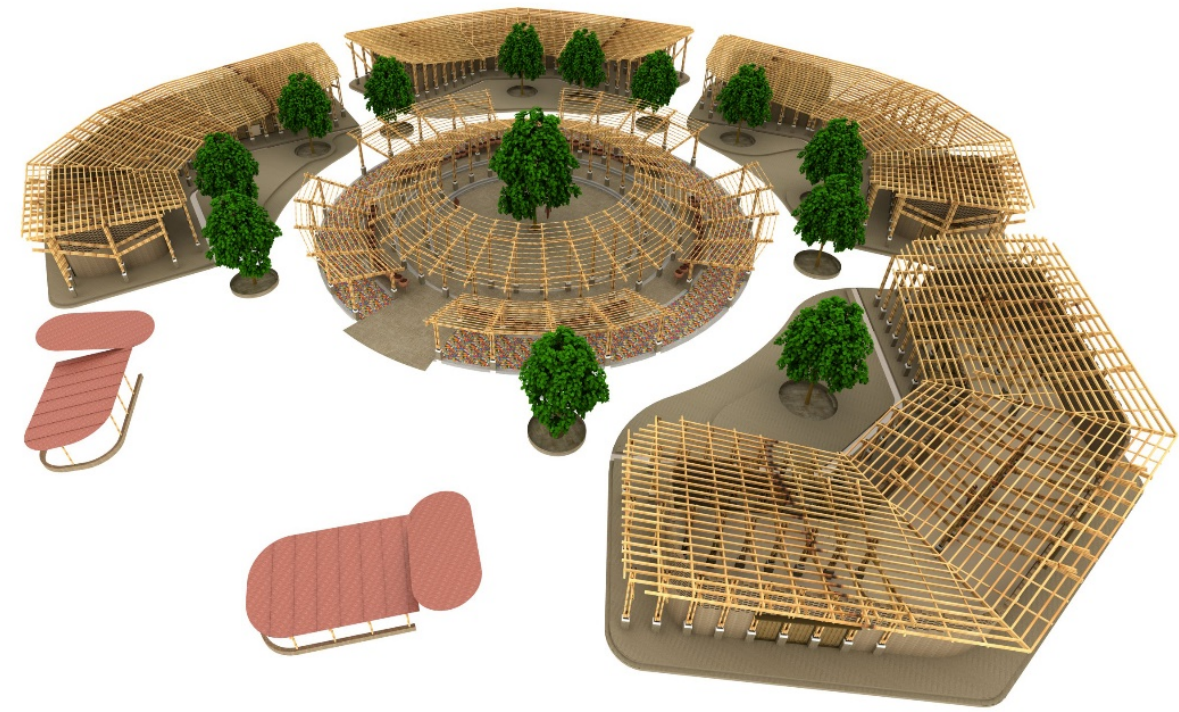

5.42 - Structure

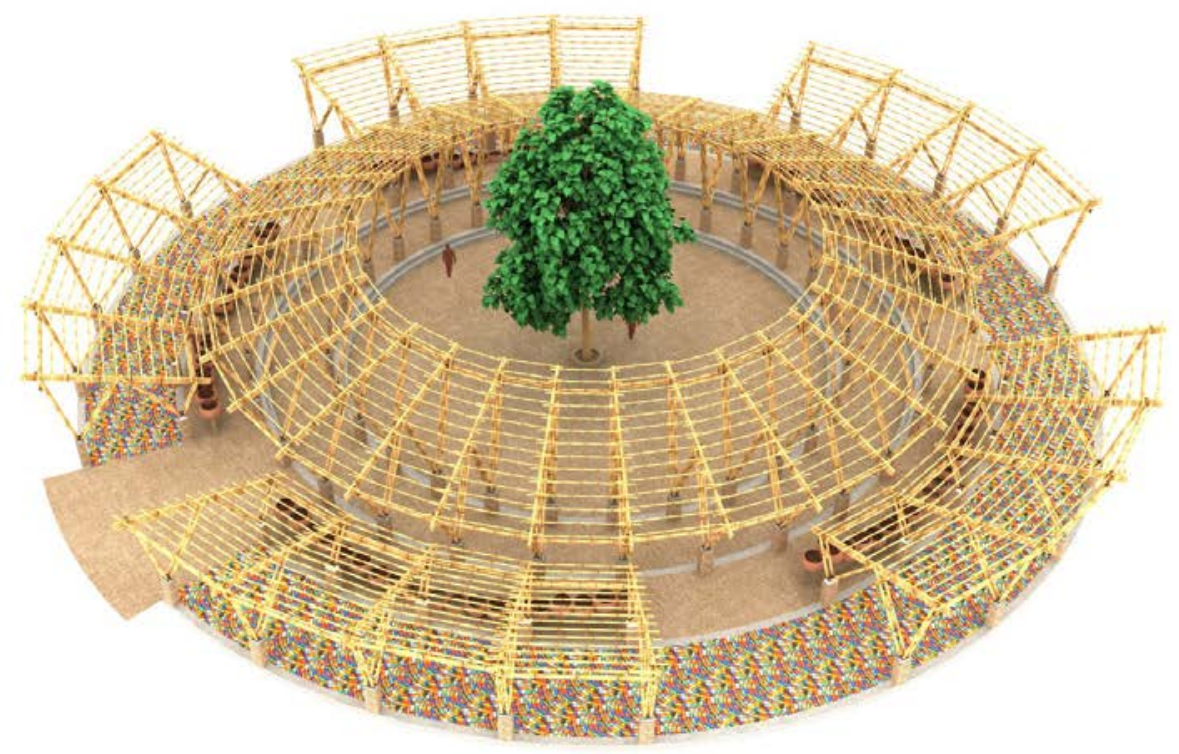

5.43 - Structure of the Performance Space 


\subsubsection{Netii Apa: Design Reflection Summary}

This Maasai cultural center, above all, was provoked by the architecture of the transplanted buildings discussed in the introduction which have begun to widely permeate Maasai Mara. Largely contextually insensitive, these buildings are the antithesis to the rich Maasai building culture, which is a notion recognized first hand in site as well as by scholars such as Dr. Rukwaro.

In response to this situation, this thesis calls for a close exploration of Maasai vernacular architecture, and more theoretically a call for architects to explore pre-colonial building traditions in Africa with an interpretive attitude. As described in this thesis and illustrated through the design of Netii Apa, culturally embedded communal space and participatory design techniques are two primary ways which contemporary African architecture can hope to establish a newfound continuity with the vernacular, in a manner that is particularly relevant for the future. It is through this Chrysalis that Netii Apa: Maasai Cultural Center has been conceived. 


\subsubsection{Chapter 5 Endnotes}

${ }^{119}$ Randall Robinson, interview by Amitabh Pal, 2005.

${ }^{120}$ A more recent census is unavailable. The 2009 census highlights the high cost of about 8.4 billion shillings or about $81,002,964$ USD for a nation-wide census. This is perhaps one of the reasons why the census process has only occurred about five times since Kenya's independence in 1963. "The 2009 Kenya Population and Housing Census," in Population and Household Distribution by Socio-Economic Characteristics (Nairobi: Kenya National Bureau of Statistics (KNBS), 2010), 398.

${ }^{121}$ Michael Mutai, "Origin of the Names of Some Kenyan Localities," Radio Jambo, https://radiojambo.co.ke/origin-of-thenames-of-some-kenyan-localities/.

122 Neckebrouck, Resistant Peoples: The Case of the Pastoral Maasai of East Africa.

123 Ibid., 70.

124 Ibid., 69.

125 Rukwaro and Maina, Transformation of Maasai Art and Architecture.

126 Ibid., 53-64.

127 Tepilit Ole Saitoti, The Worlds of a Masai Warrior: An Autobiography (New York: Random House, 1986), xiv.

${ }^{128}$ Katherine Homewood, Patti Kristjanson, and Pippa Chenevix Trench, Staying Maasai? Livelihoods, Conservation and Development in East African Rangelands, (New York, USA: Springer Science + Business Media LLC, 2009).

129 Ibid., 77.

130 Rukwaro and Maina, Transformation of Maasai Art and Architecture, 148.

${ }^{131}$ El Wakil and Steele, Hassan Fathy, 8. 


\section{Epilogue}

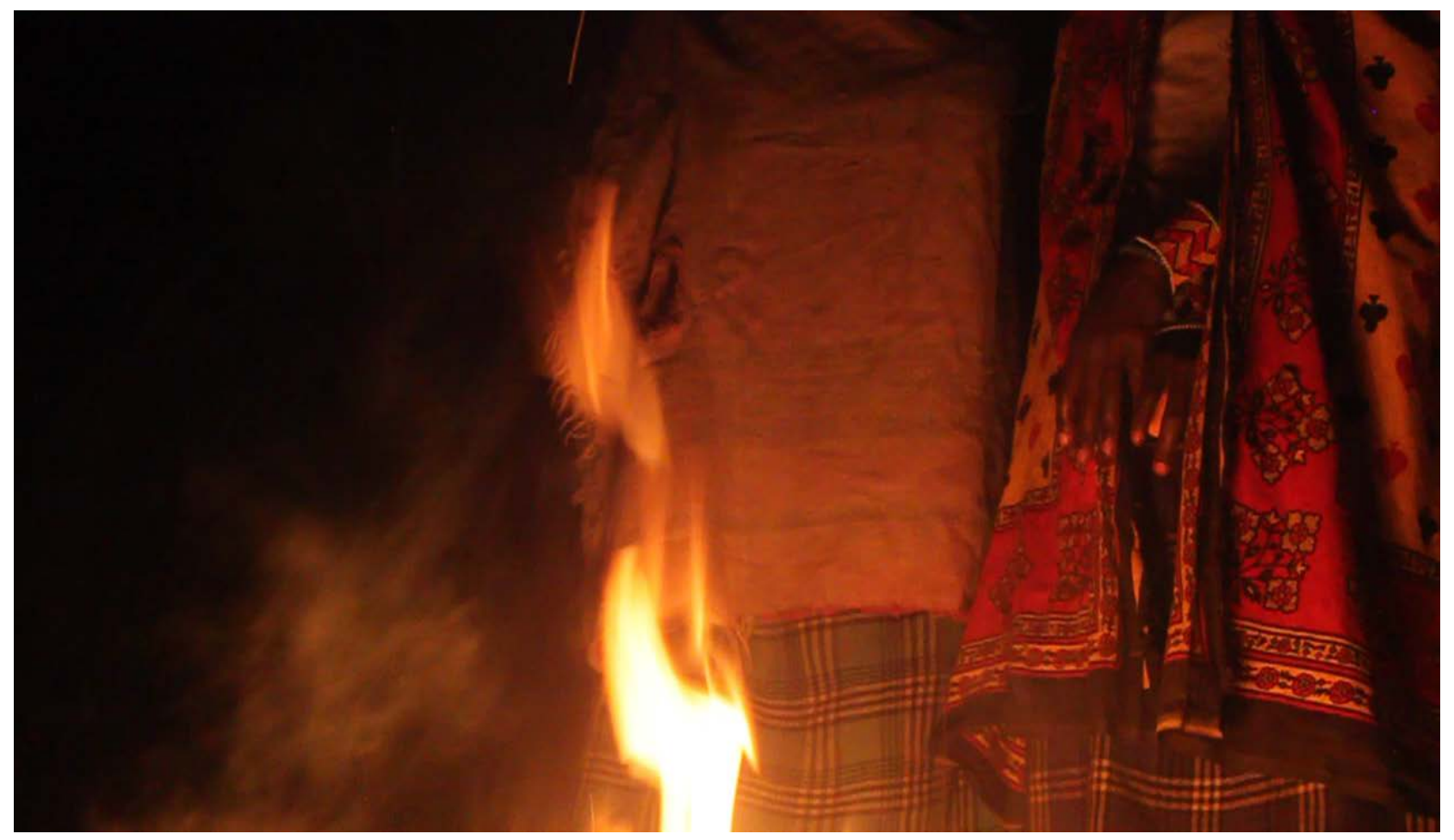

Umberto Eco, the author of How to Write a Thesis, states that "writing a thesis requires a student to organize ideas and data, to work methodically, and to build an "object" that in principle will serve others." 132

Though an architectural thesis frequently yields a building design, most completed architectural theses either serve as a first step in a general thematic trajectory for subsequent years of design practice, or at the very least, offer a set of systematic research and thinking skills to be deployed at the onset of any problem or question, both in design and further research. For obvious reasons, the building design produced by the graduate thesis process rarely comes to fruition as a tangible building. It instead commonly remains in theoretical form through drawings, renders, architectural models and other representational mediums. Despite this, this never seems to hinder the altruistic ambitions present in the work of so many of my colleagues in Ryerson University's M.Arch. program. Just as many architects of the past have sought to better society through their creations, I likewise have enjoyed watching many M.Arch students use their thesis work to tackle the architectural implications of today's critical challenges, such as environmental degradation, social polarization, and the loss of local cultural identities in our increasingly interconnected world - just to name a few. As Masters of Architecture candidates working in our studio, we imagine placing "one brick on top of another", creating each of our unique utopian visions to uplift mankind, or "serve others", using the words of Eco.

It is this precise notion that had has been the most challenging, yet rewarding aspect of my own M.Arch. experience; the ardent desire for this thesis to be of real-world service, beyond the requirements of a graduate thesis. At the outset of this book, I spoke of my experiences with the Maasai community in Kenya, whose buildings 
in general, appear to have been overlooked as a source of inspiration by the formal architectural profession. When traditionally-inspired buildings in this part of the world have been designed by architects, few of them serve as examples of contextually relevant buildings for the Maasai peoples, the majority of them having been created for the booming safari tourism industry nearby. Yet something about the Maasai traditional way of building seems so culturally and environmentally integrated, and most importantly, immensely relevant for the present day. Perhaps it's the manner in which the traditional buildings biodegrade, decomposing into the ground without leaving any waste. Perhaps it was the beautiful sound of traditional building songs sung by women as they weave the wattle together for the walls of their houses. Perhaps it was the imperfect, imprecise quality of the traditional buildings, and the resulting tectonic handprint of community authorship. Provoked by the increasing proliferation of building transplants in Maasai Mara, at the core of this thesis is an incendiary desire to reimagine the dying Maasai building traditions in an architectural language that is appropriate for tomorrow.

However, working on a rural site, which was barely decipherable by Google Maps, presented certain challenges if I was to try realize this goal. While building and land data for project sites in Toronto is readily available online, obtaining basic information such as a topographical drawing for my thesis site took months and required ongoing conversations with professionals and community members on the ground. Moreover, few extensive architectural texts exist on Maasai architecture. I remember searching for Dr. Robert Rukwaro's book on Maasai vernacular buildings ${ }^{133}$ and learning that there was only one copy in the entire country of Canada! It was also particularly difficult to both simultaneously immerse myself in, as well as intellectually investigate, a culture that I was well acquainted with, yet which was very different from my own. Despite these challenges, the opportunity to contribute to the community in Maasai Mara, through a field that I have grown so passionate about, is something that I am immensely grateful for.

However, these challenges were a small cost for the learning experiences and opportunities during the degree. Being in contact with the community and receiving a substantial grant from Norway for building construction have made my thesis experience particularly rewarding, providing a dose of real-world relevance to what could have otherwise been a very intellectually isolating exercise. I was also able to immerse myself in the site in a way I could have only dreamed of at the outset of my thesis process. One of my favorite memories was an evening spent with the Purko Maasai elders of the community who recited traditional songs and performed stories around a smoky campfire. I remember watching the astonished faces of the younger generations as they heard their age-old oral traditions, some of them for the very first time. I was able to witness in this moment, a snapshot of the ebb and flow of Maasai cultural change over time. Experiences such as these allowed me to observe the dialogue between tradition and modernity outside of architecture's immediate realm, undoubtedly contributing to a more holistic understanding of the culture and site which were to inspire the Maasai cultural center. I am also grateful to have had opportunities to share my designs, both with the Purko Maasai community on the ground as well as with the Canadian architectural body after having been recognized by RAIC Moriyama Scholarship in September 2017 and again more extensively at the Design Exchange's Expo for Design and Technology Conference (EDIT) in October 2017. These have been some of the most transformative experiences of my M.Arch and for these I am tremendously grateful.

As I write this epilogue, at the threshold between graduate school and professional practice, I recall the famous story of how architect Moshe Safdie, a then-recent McGill University M.Arch. graduate, was commissioned to build 
Habitat 67 in Montreal, the design project from his own thesis while he was in school. I can only imagine how Safdie must have felt when faced with the daunting task of realizing his twelve-storey housing scheme at such a youthful age. I hope that, with the guidance of friends from the local construction industry, the interdisciplinary team that is forming around the programming of the cultural center, and wisdom of the local community, that I may follow in Safdie's steps.

Should there be an M.Arch candidate at the outset of their own research who happens to be reading this thesis, I may offer a humble word of advice to you - take Eco's statement to heart. Where possible, use the opportunity of the M.Arch. thesis to conceive of a body of research that is not only personally inspiring and practically manageable, but whose outcomes can have the potential to be of real service to humanity in the years after.

Epilogue Endnotes

132 Umberto Eco, Caterina Mongiat Farina, and Geoff Farina, How to Write a Thesis, (Cambridge, Massachusetts London, England: The MIT Press, 2015),

http://myaccess.library.utoronto.ca/login?url=http://ebookcentral.proquest.com/lib/utoronto/detail.action?doclD=33399 48. 6.

${ }^{133}$ Rukwaro and Maina, Transformation of Maasai Art and Architecture. 


\section{Appendix}

Appendix 1 - Case Study Profiles

Appendix 1 includes the case study profile sheets that were created during the case study analysis. Each page showcases a single work of vernacular-inspired contemporary architecture. 
LAAFI Nursery School

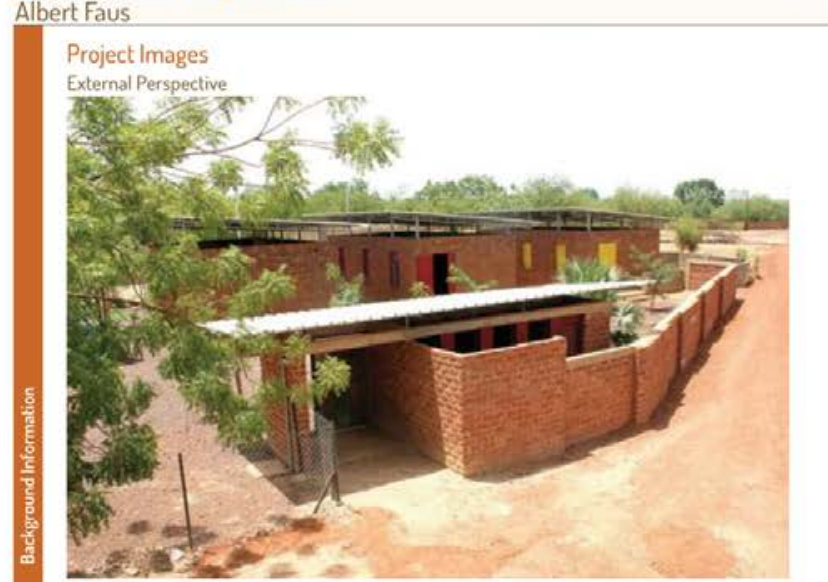

Project Information

Project Date 2014

Program Nursery School

Client

Geographical Context Rural

Size

Budget

Cost per m2 (USD)

Location

Koudougou, Burkina Faso
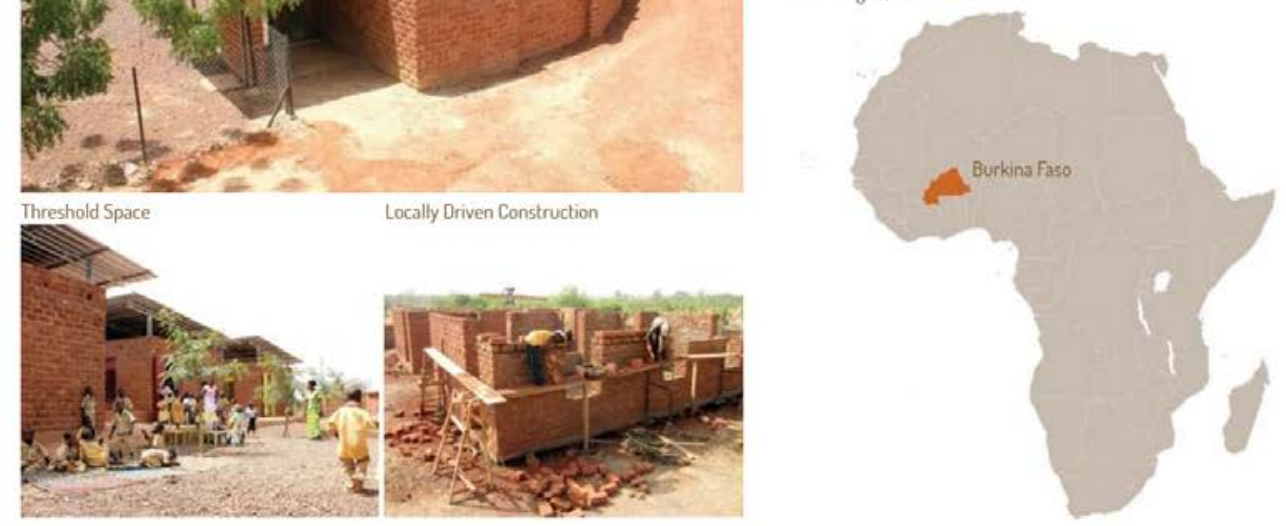

Threshold Space Identification

Threshold Space Categorization Ground Floor Plan

Unifying Roof. Unifying Groundplane
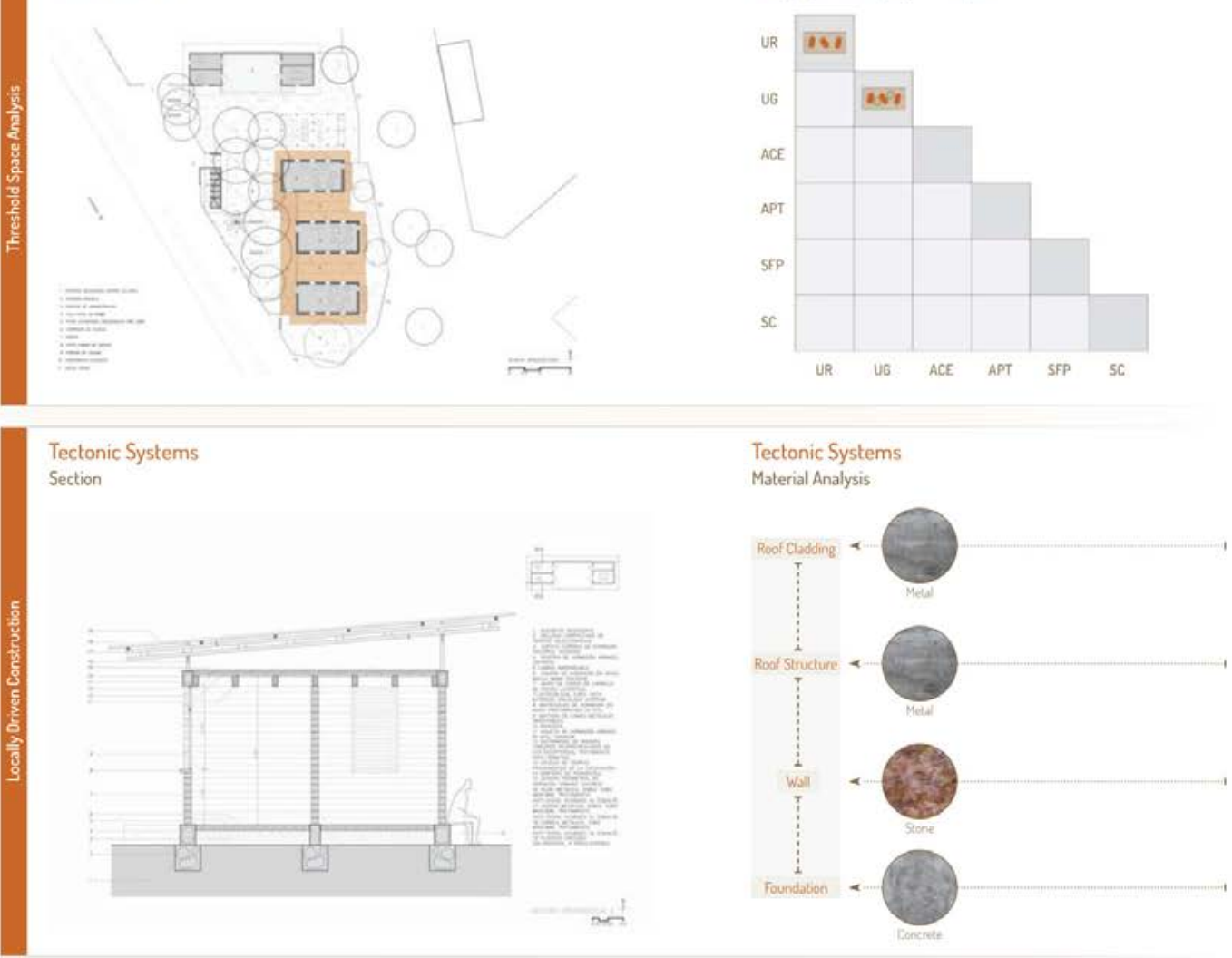
Katiou Library

Albert Faus

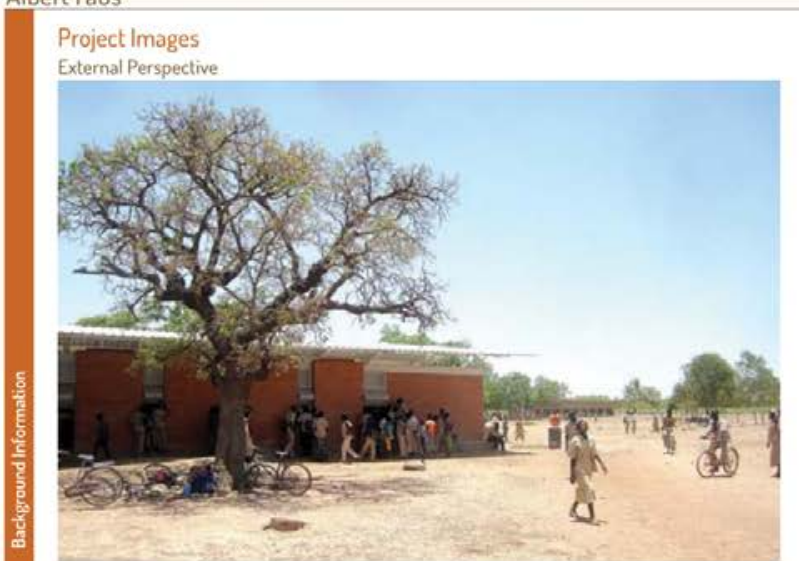

Threshold Space

ocally Driven Construction

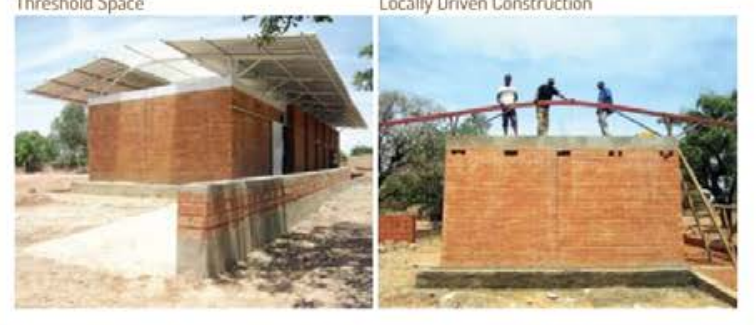

Project Information

Project Date 2014

Program Library

Client Katiou Foundation

Geographical Context Rural

Size $1225 \mathrm{am}$

Budget $\$ 20.647$

Cost per m2 (USD) $\quad \$ 16924$

Location

Komsliga Burkina Faso

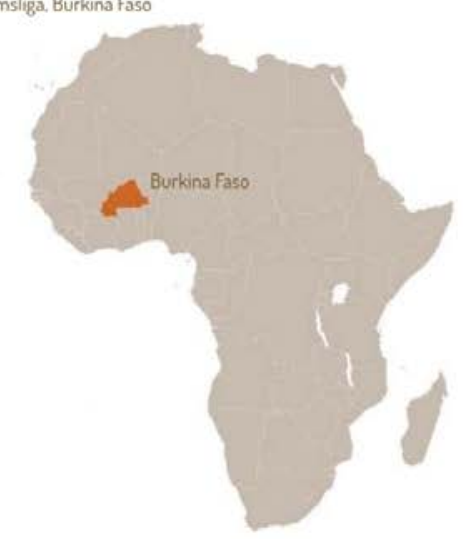

Threshold Space Identification

Threshold Space Categorization

Ground Floor Plan

Additive: Protracted Entrance
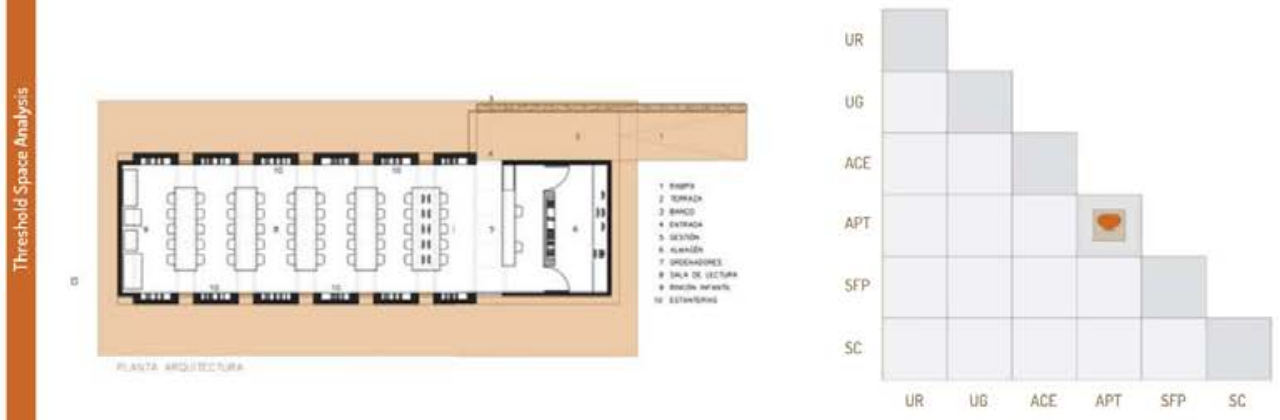

Tectonic Systems

Section

Tectonic Systems

Material Analysis
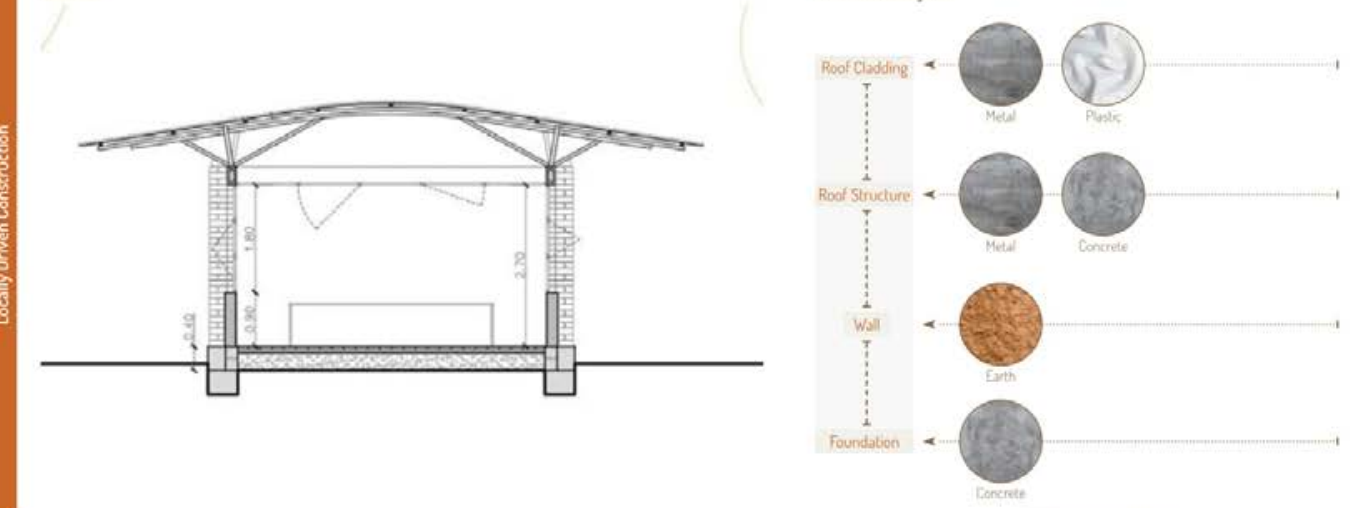
Home Kisito

Albert Faus

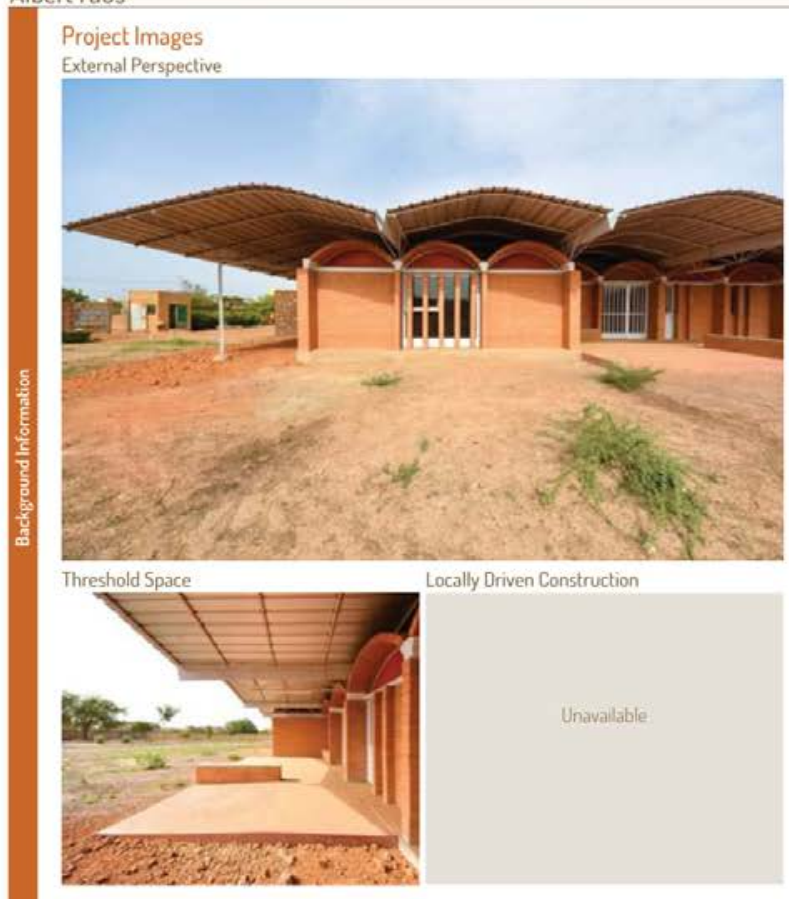
Case Study Code 04

Project Information

Project Date 20is

Program Residential. Childcare

Client Nasaras by Home KusitoArea Association

Geographical Context Rural

Size $23559 \mathrm{~mm}$

Budget $\$ 52.955$

Cost per m2 (USD) $\quad \$ 22534$

Location

Ouagadougou, Burkina Faso

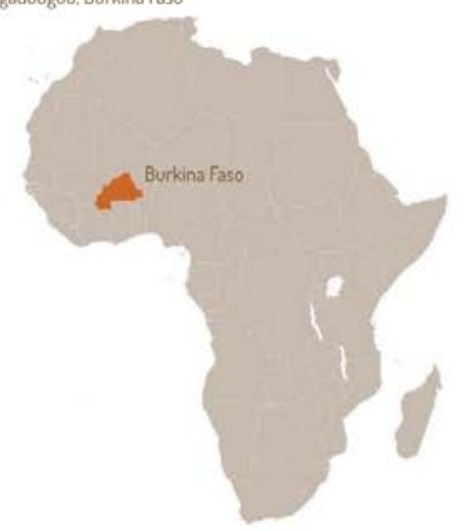

Threshold Space Categorization

Ground Floor Plan

Unifying Roof, Unifying Ground Plane, Additive: Protracted Transition

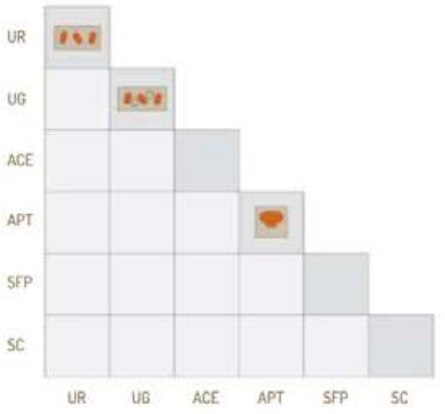

Tectonic Systems

Section

Tectonic Systems

Material Analysis
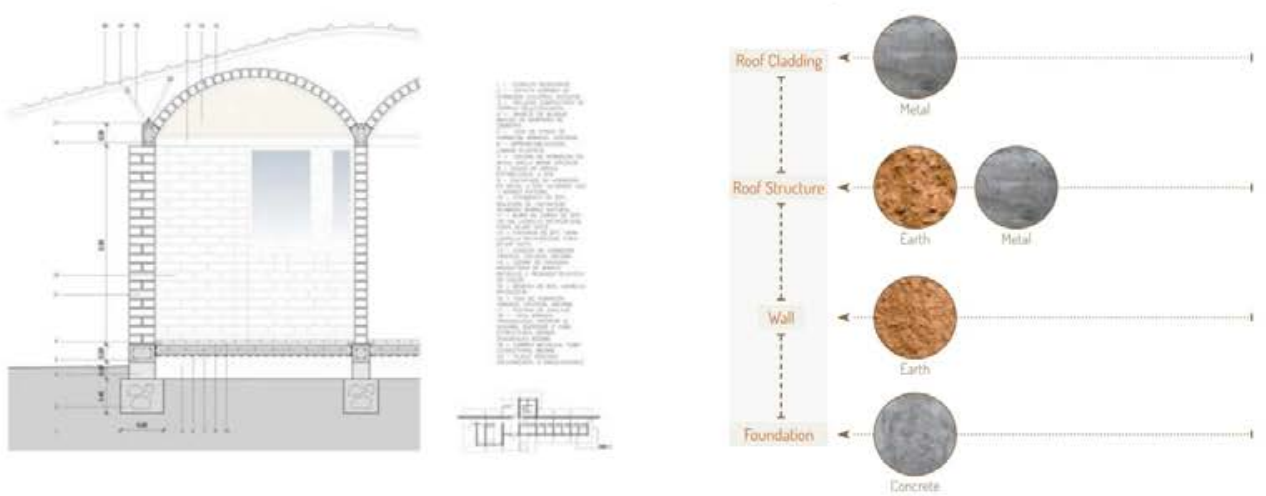
Pre-Primary School

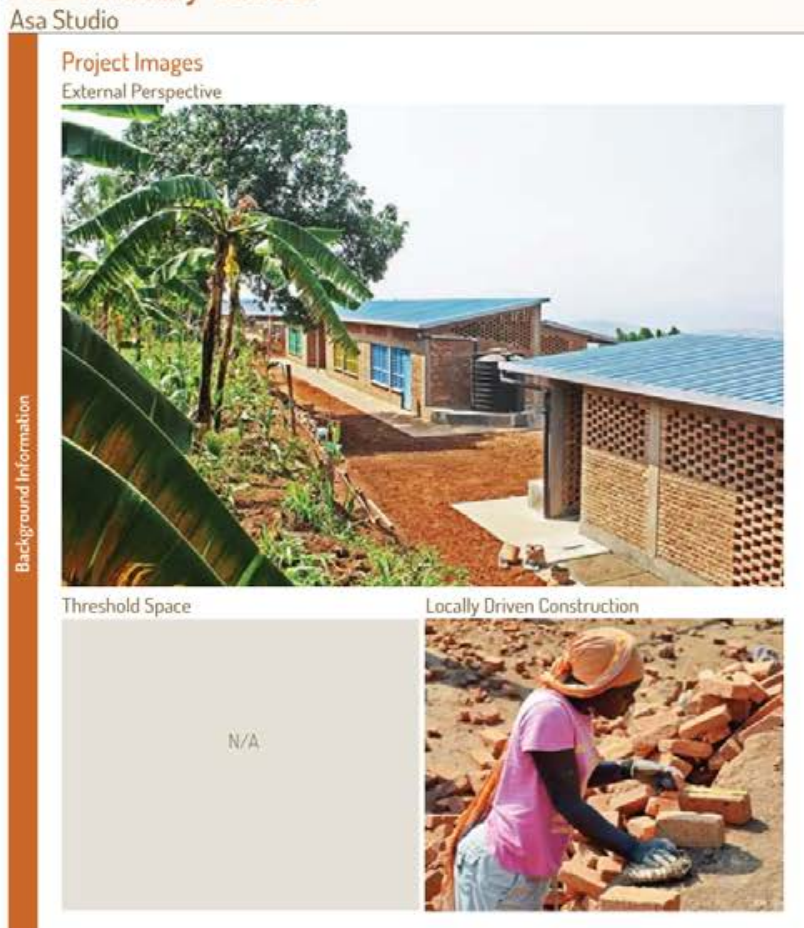

Case Study Code 06

Project Information

Project Date 2013

Program Pre-Primary School

Client

Geographical Context Rural

Size

Budget

Cost per $\mathrm{m} 2$ (USD)

Location

Rwanda

Threshold Space Identification

Ground Floor Plan

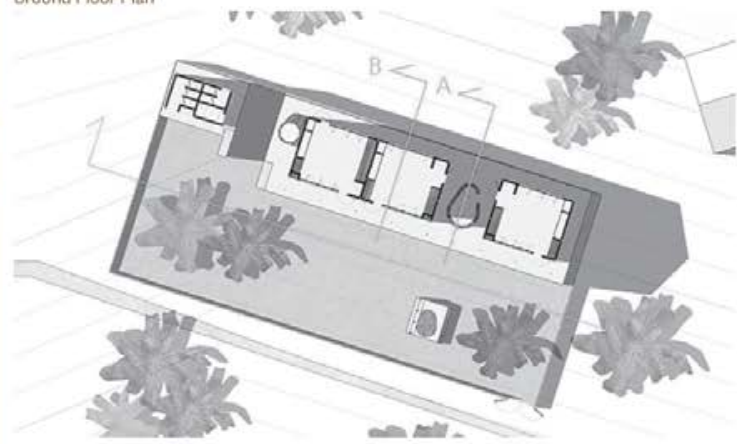

Threshold Space Categorization

N/A

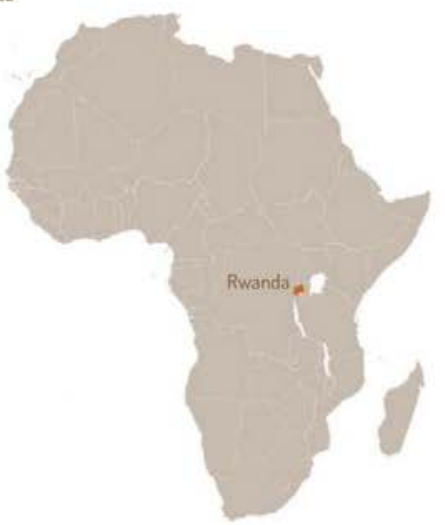

Tectonic Systems

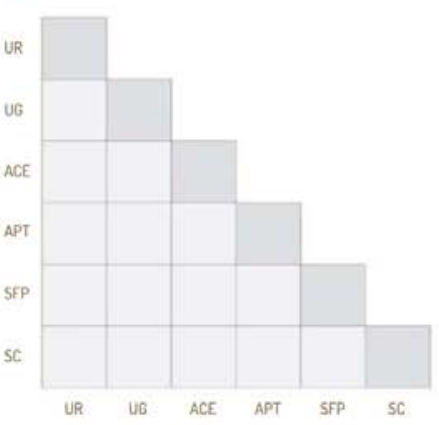

Section

Tectonic Systems

Material Analysis
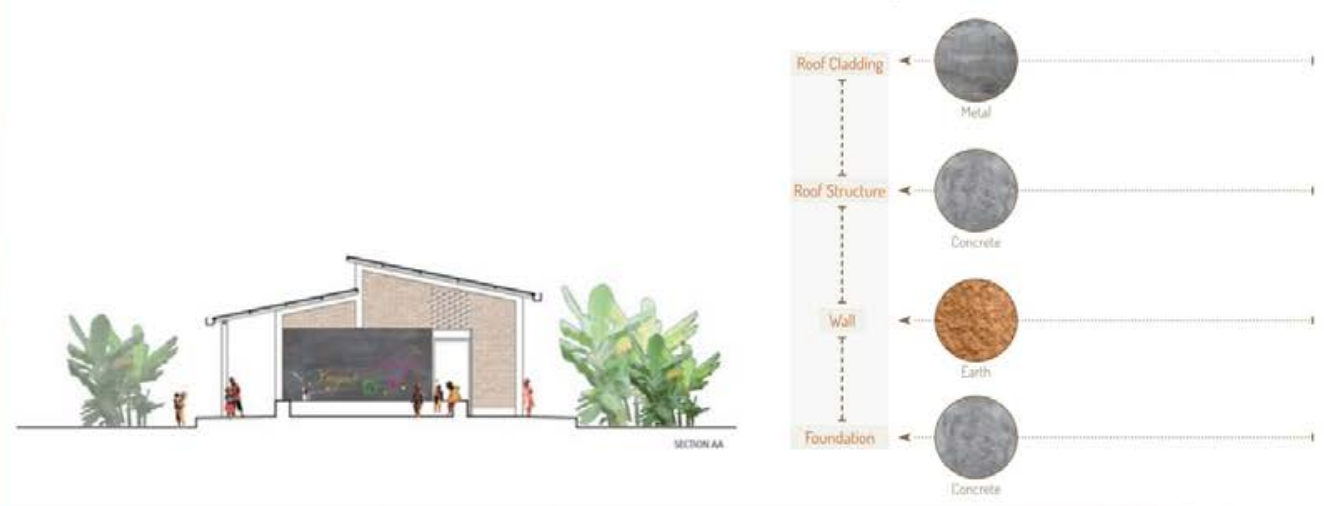
Library of Muyinga

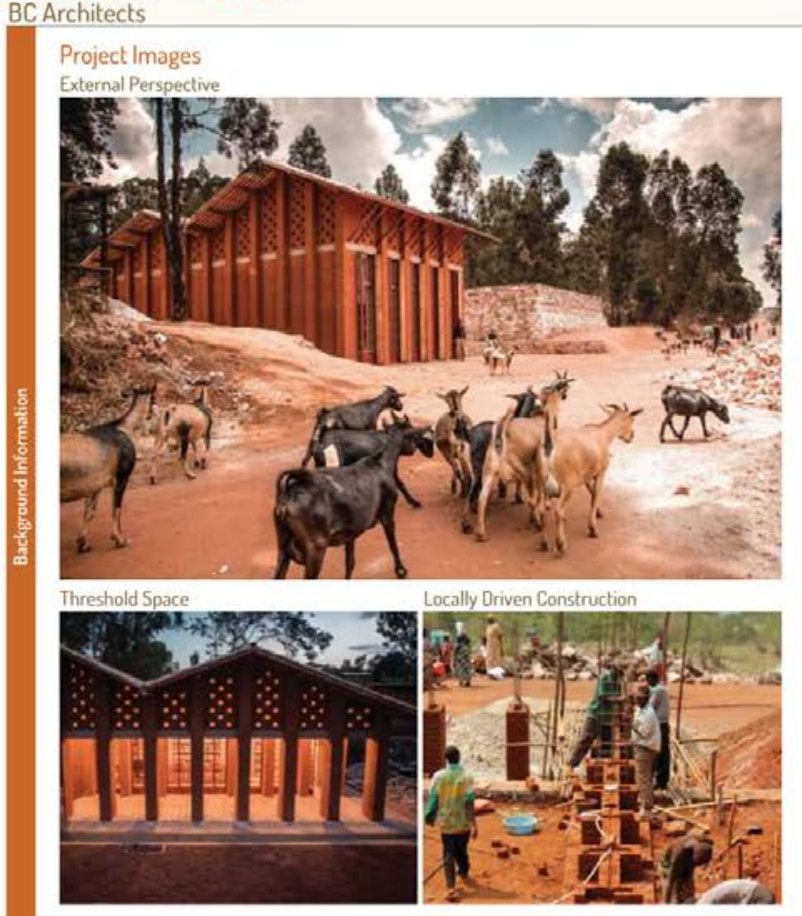

Case Study Code: 07

Project Information

Project Date 2012

Program Library

Client

Geographical Context Rural

Size 1605qm

Budget $\$ 42792$

Cost per m2 (USD) \$305.66

Location

Muyinga, Burundi

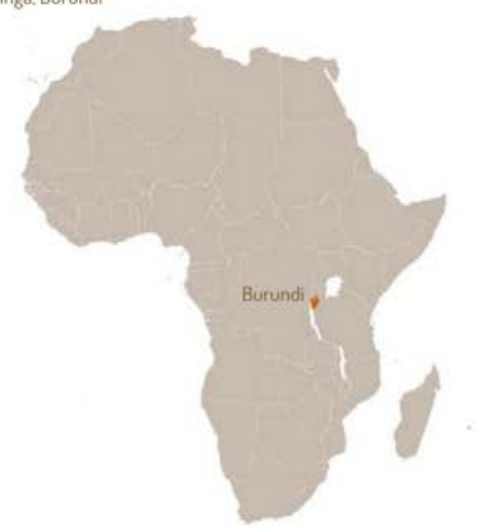

Threshold Space Identification

Ground Floor Plan

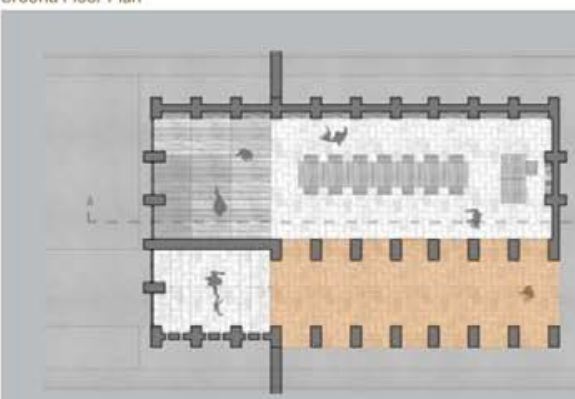

Threshold Space Categorization

Subtractive: Form Perimeter

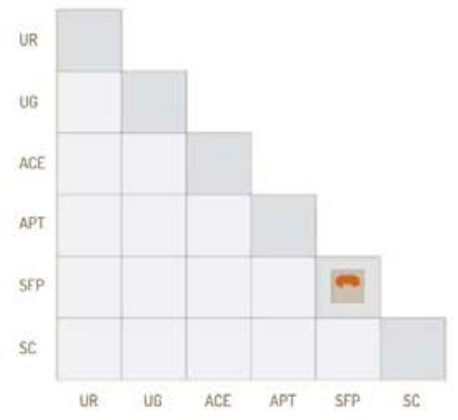

Tectonic Systems

Tectonic Systems

Section

Material Analysis
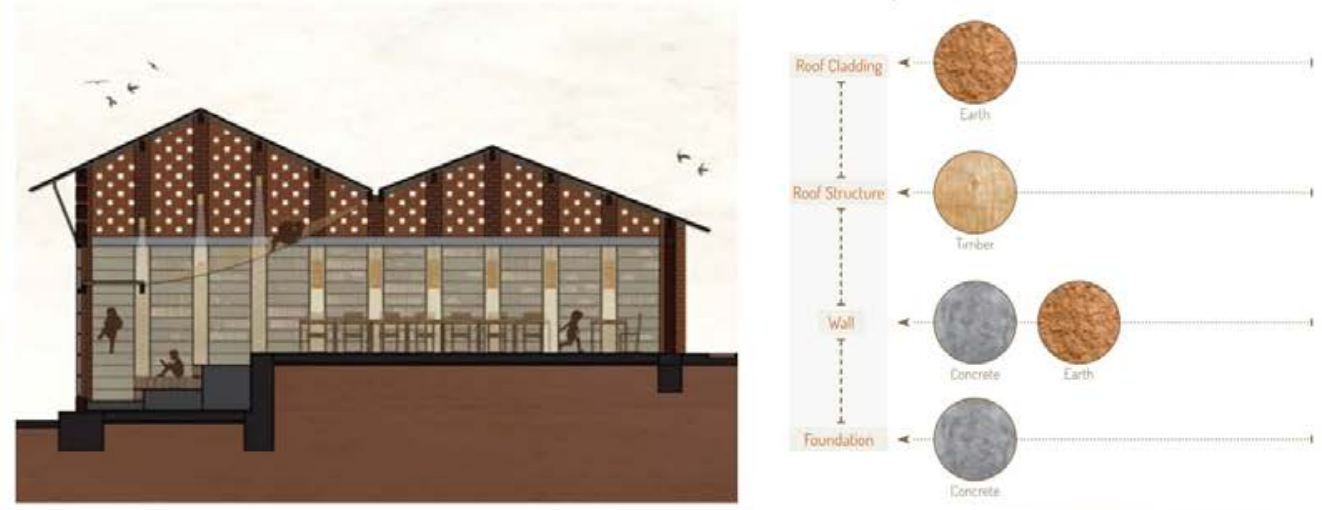
Primary School in Gando

Kéré Architecture

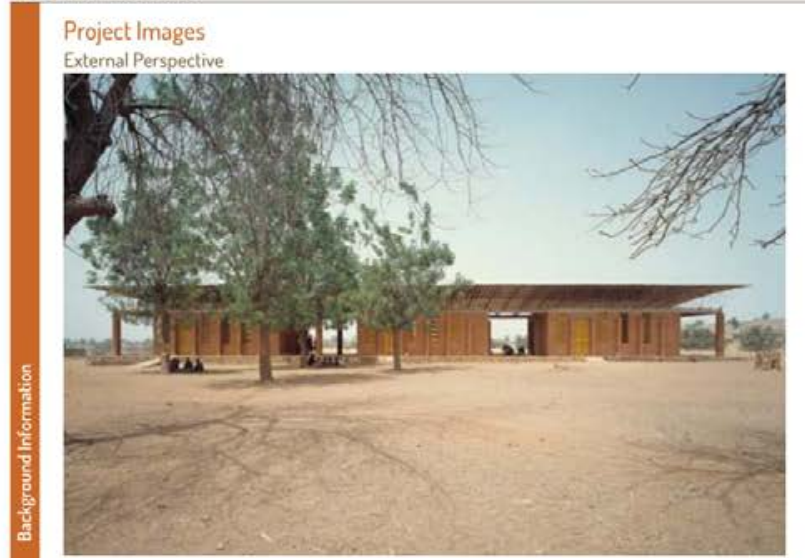

Project Information

Project Date 2001

Program Primary School

Client Schulbausteine fuer Gando / Gando Village

Geographical Context Rural

Size 310 Sam

Budget

Cost per m2 (USD)

Location

Gando, Burkina Faso

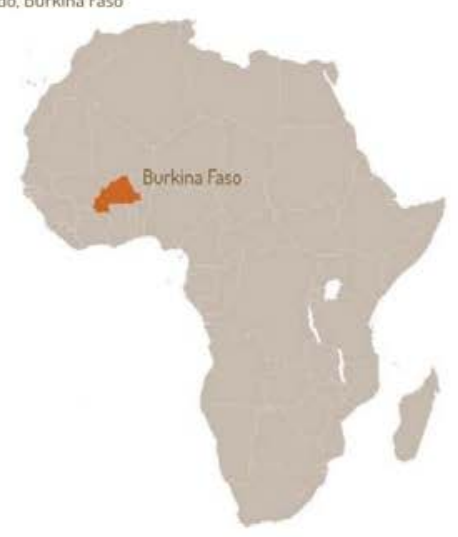

Threshold Space Locally Driven Construction

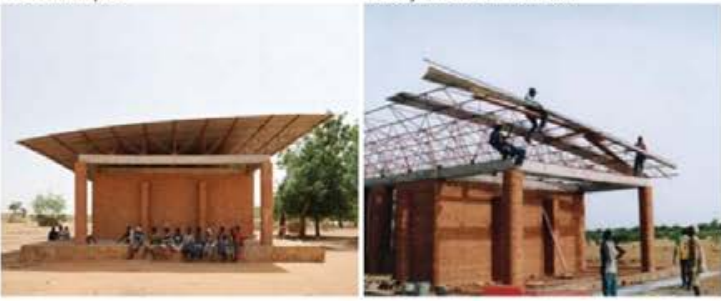

Threshold Space Categorization

Threshold Space Identification

Unifying Roof Unifying Groundplare

Ground Floor Plan

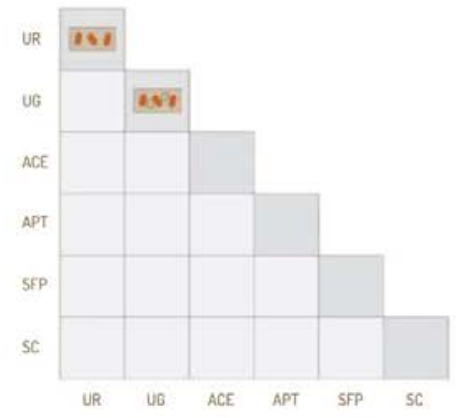

Tectonic Systems

Section

Tectonic Systems

Material Analysis
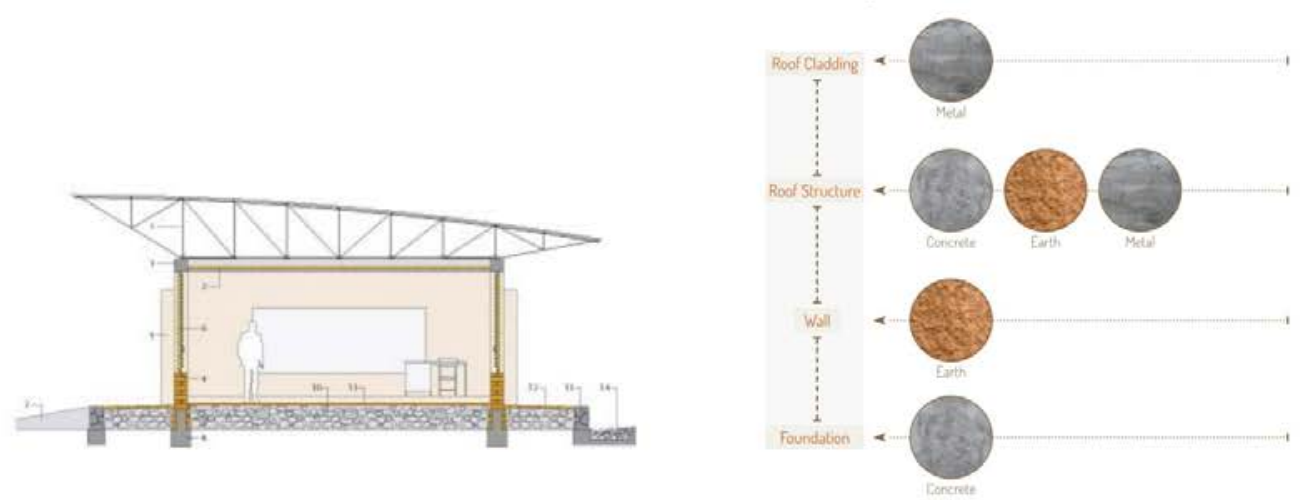
Dano Secondary School

Kéré Architecture

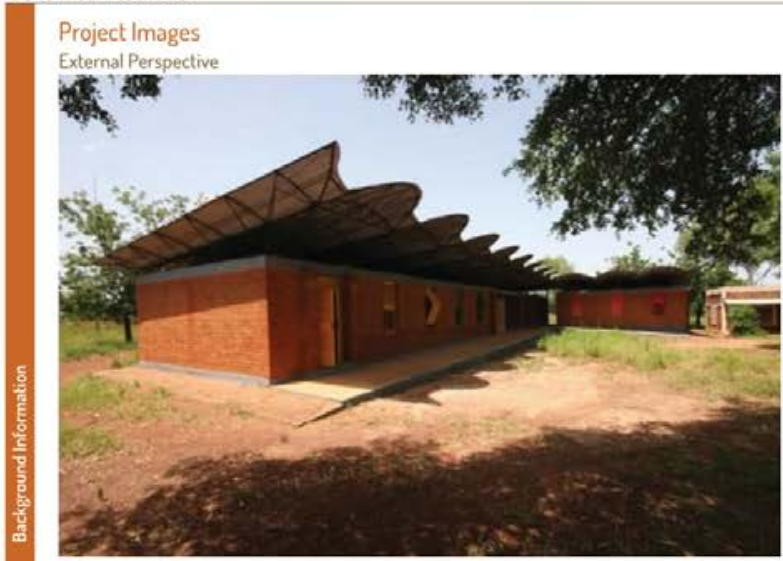

Project Information

Project Date 2007

Program Secondary School

Client Dreyer Foundation Murich

Geographical Context Rural

Size $510 \mathrm{Sqm}$

Budget

Cost per m2 (USD)

Location

Dano, Burkina Faso
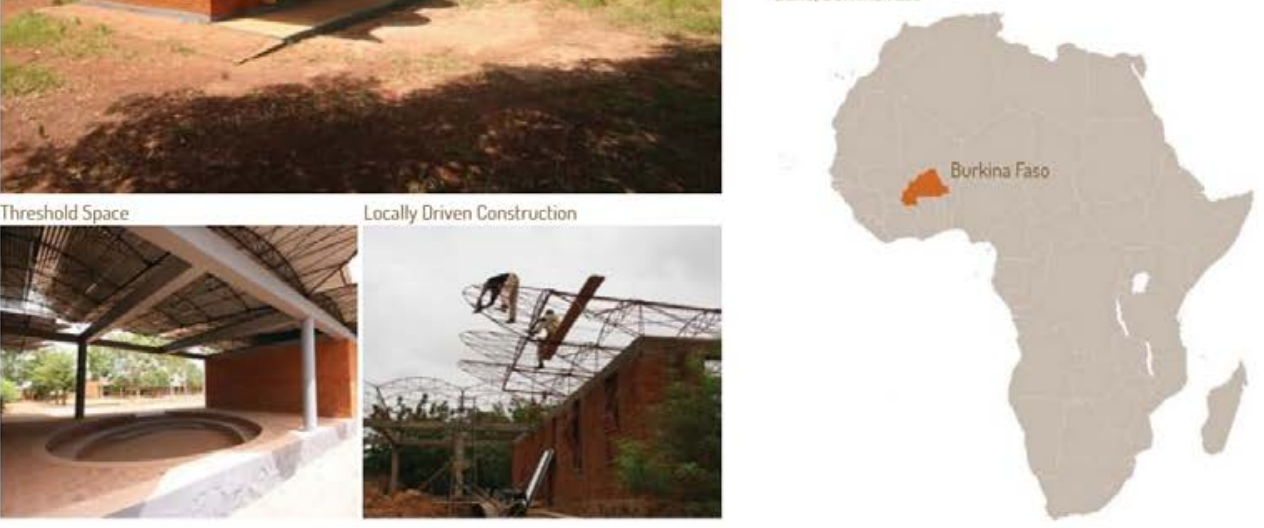

Threshold Space Categorization

Threshold Space Identification

Unifying Roof. Unifying Groundplane, Additive: Creation of Enclosure

Ground Floor Plan
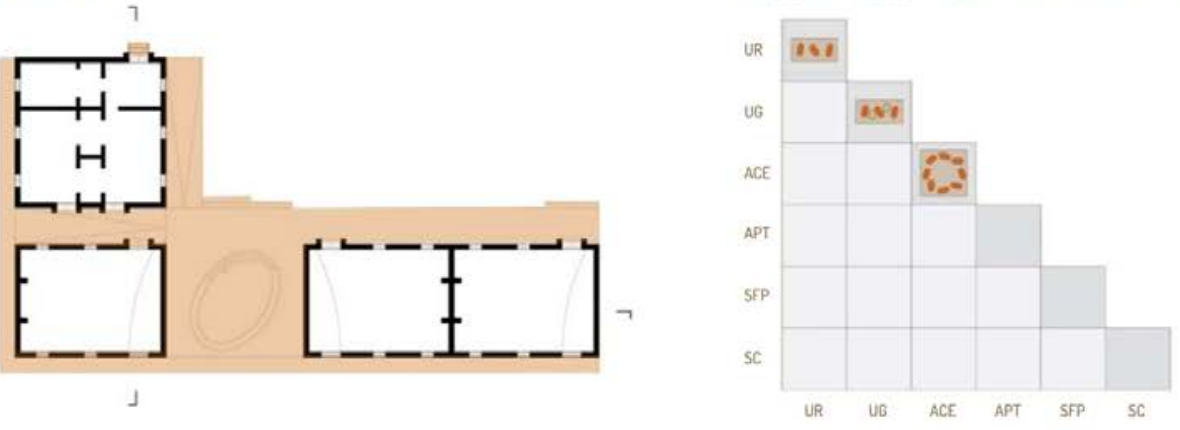

Tectonic Systems

Tectonic Systems

Section

Material Analysis
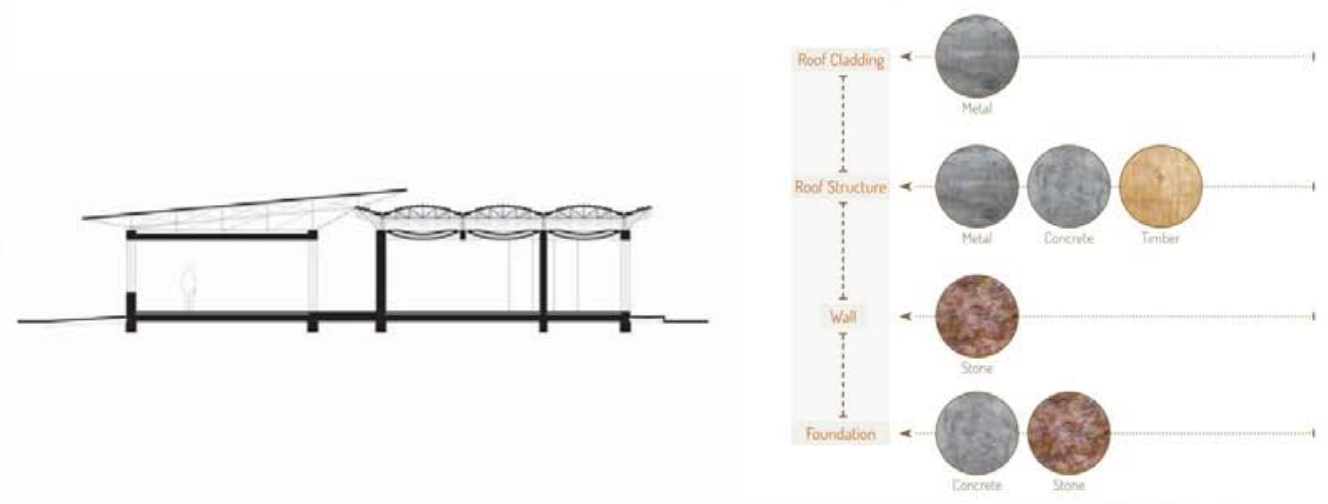
Nursery School - Obama Legacy Campus

Kéré Architecture

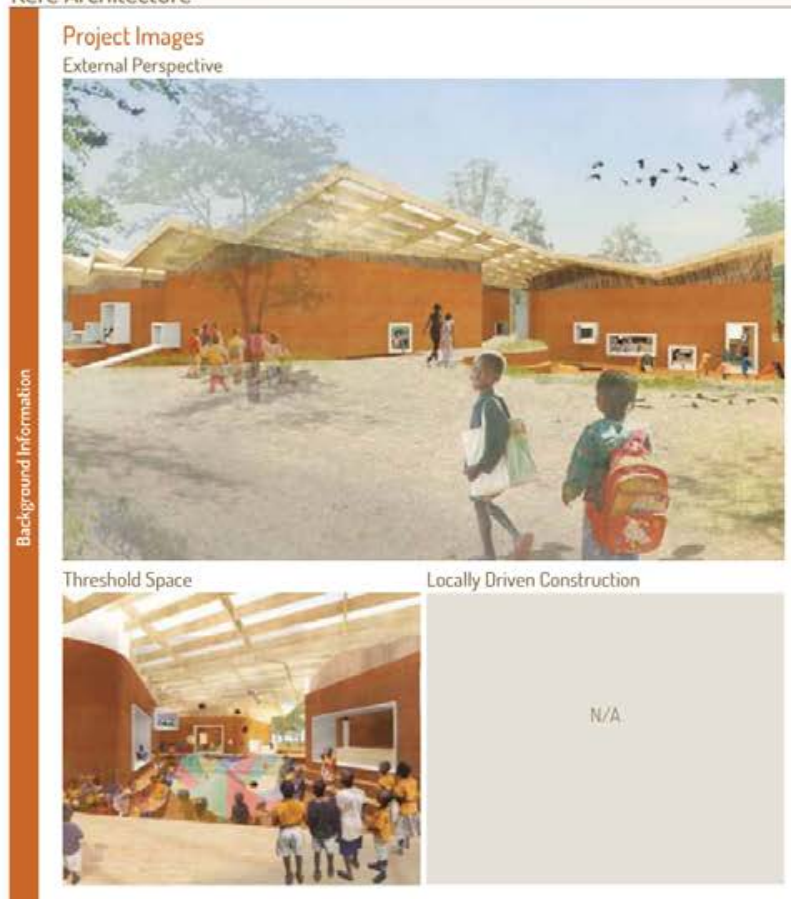

Case Study Code 20

Project Information

Project Date

Program Nursery School

Client Mama Sarah Obama Foundation (MSOF)

Geographical Context Rural

Size 720 Sqm

Budget

Cost per m2 (USD)

\section{Location}

Kogelo, Kenya

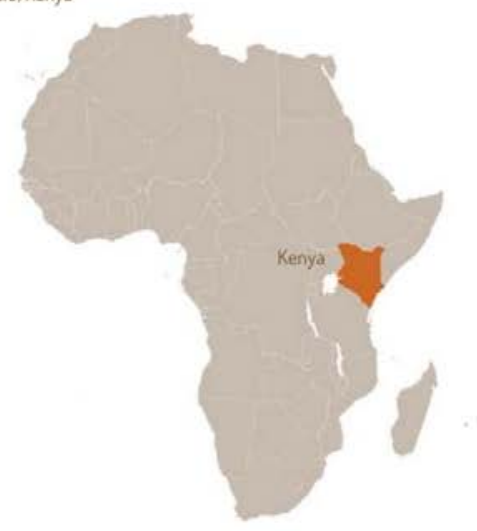

Threshold Space Identification

Threshold Space Categorization

Ground Floor Plan

Unifying Roof. Unifying Groundplane. Additive: Creation of Enclosure
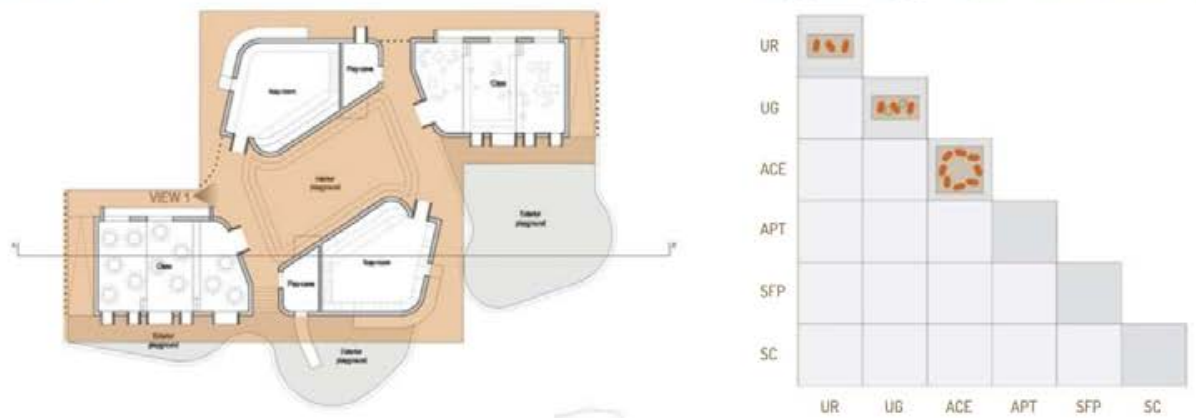

Tectonic Systems

Section

Tectonic Systems

Material Analysis
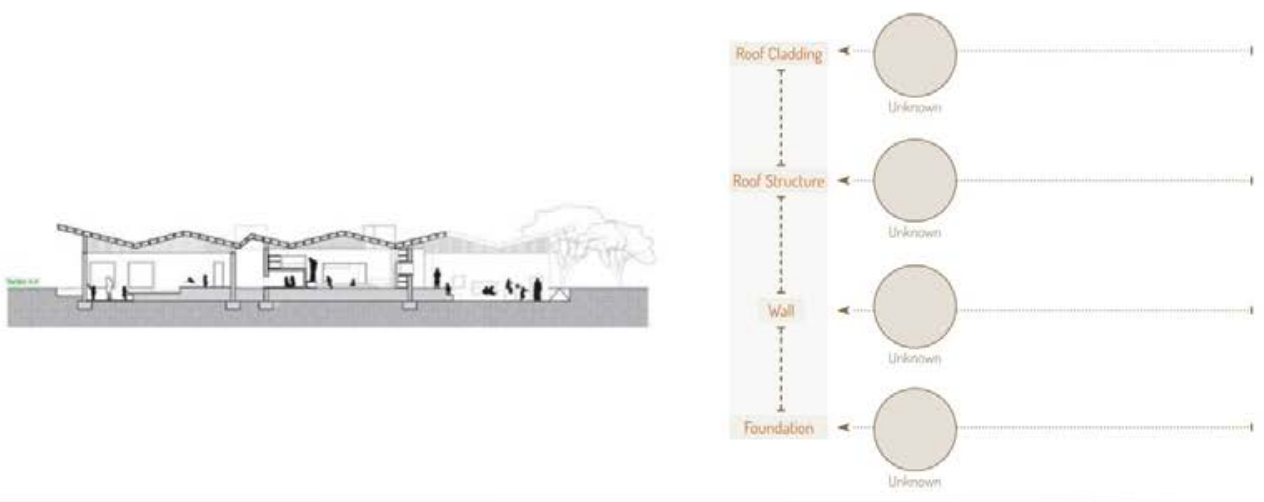
Mizengo Pinda Asali \& Nyuki Sanctuary - Beekeeping \& Education Center Jaklitsch / Gardner Architects

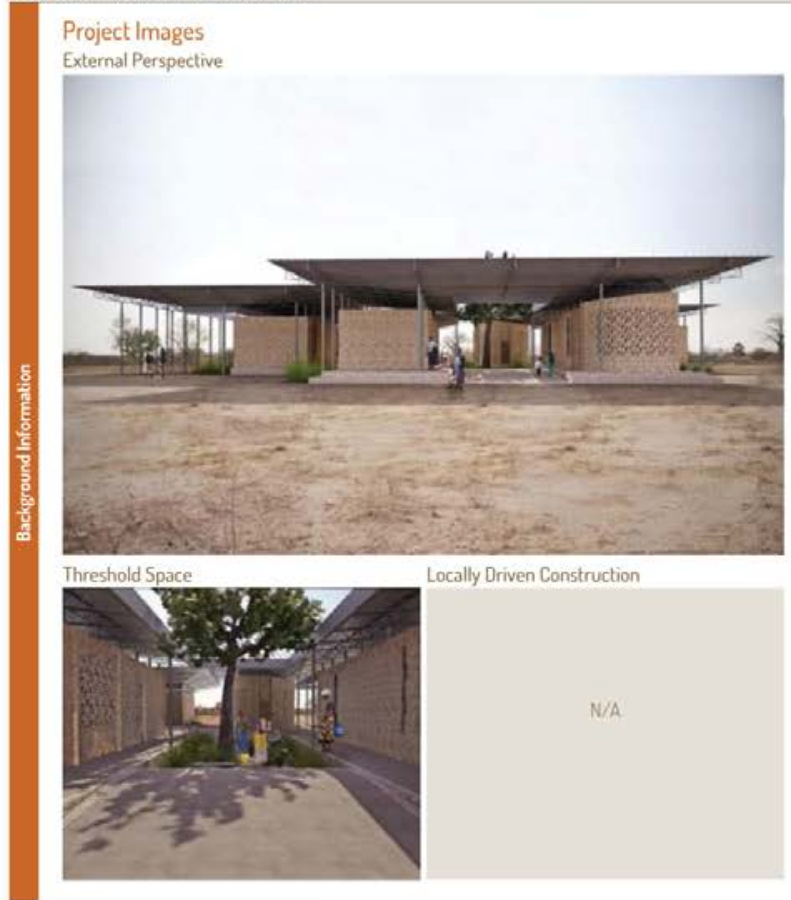
Case Study Code 24

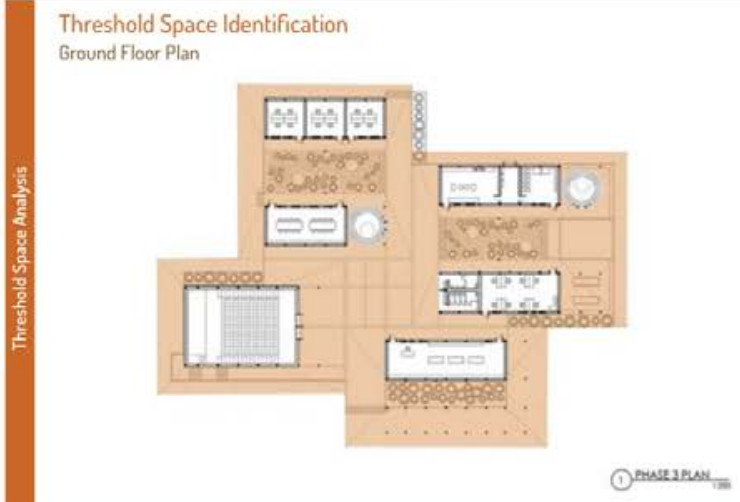

Threshold Space Categorization

Unifying Roof, Unifying Groundplane, Additive: Creation of Enclosure

Tectonic Systems

Section

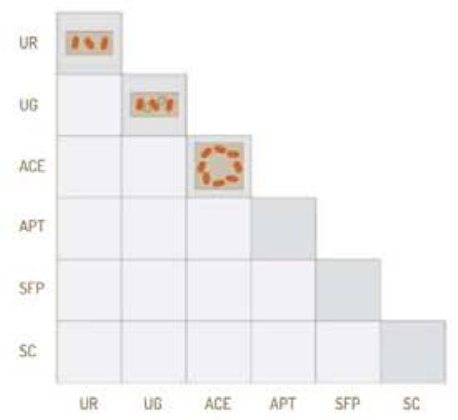

Project Information

Project Date 2015

Program Honey Sanctuary. Education

Client

Geographical Context Rural

Size

Budget

Cost per m2 (USD)

Location

Dodoma, Tanzania

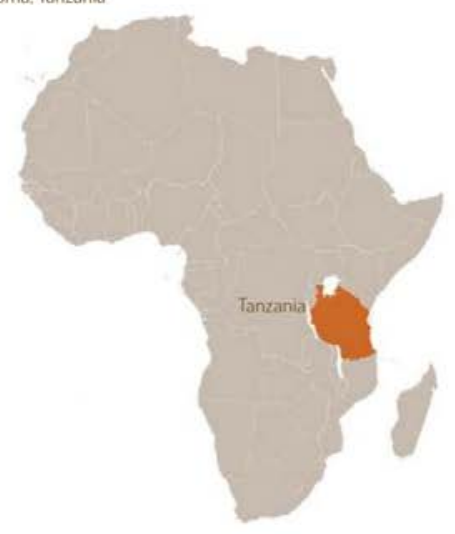

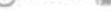

Tectonic Systems

Material Analysis
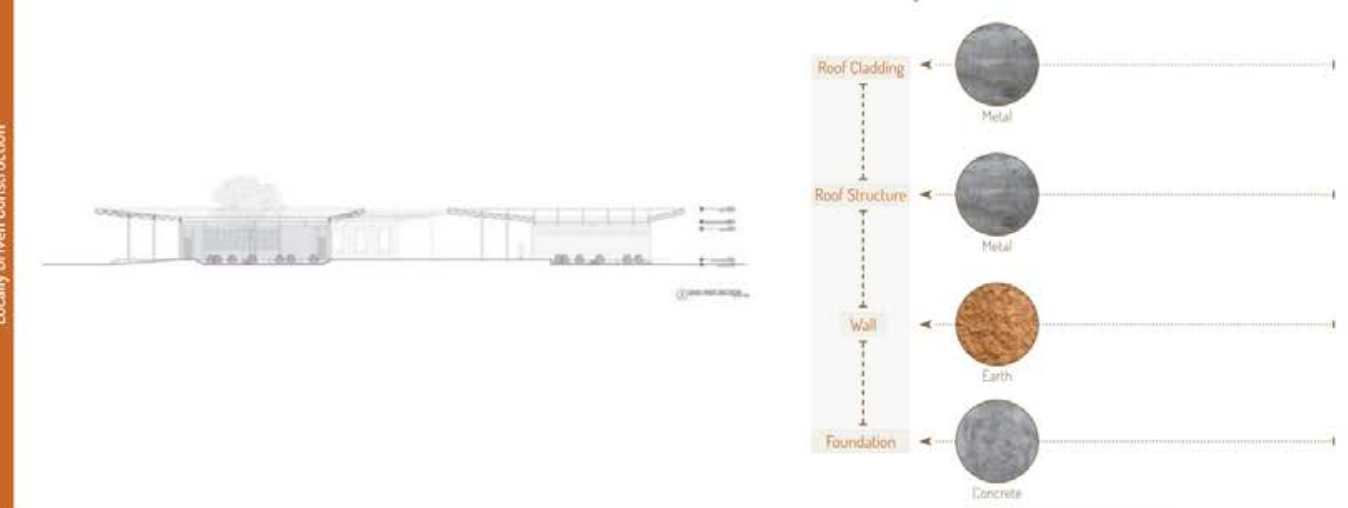
Primary School in Balaguina

Joop van Stigt and Jurriaan van Stigt

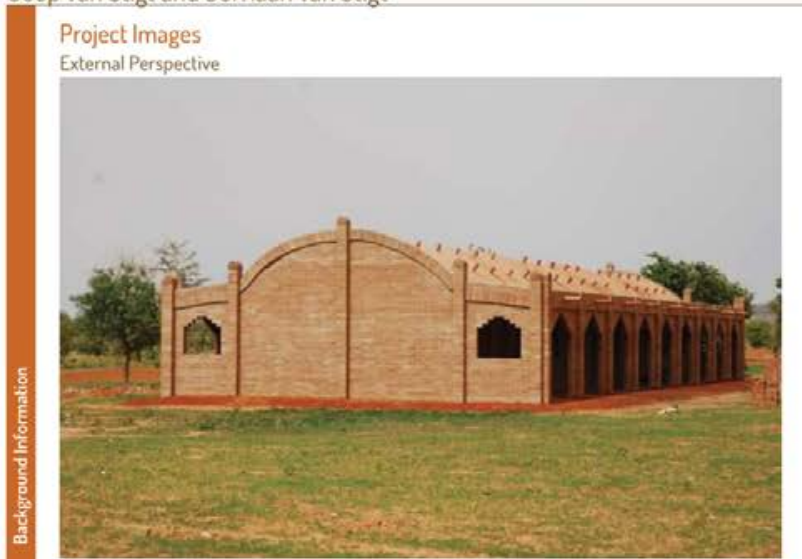

Project Information

Project Date 2012

Program Primary School

Client Foundation Dogan Education

Geographical Context Rural

Size $4205 q \mathrm{~m}$

Budget \$43.862

Cost per m2 (USD) $\quad 5104.43$

Threshold Space

Locally Driven Construction

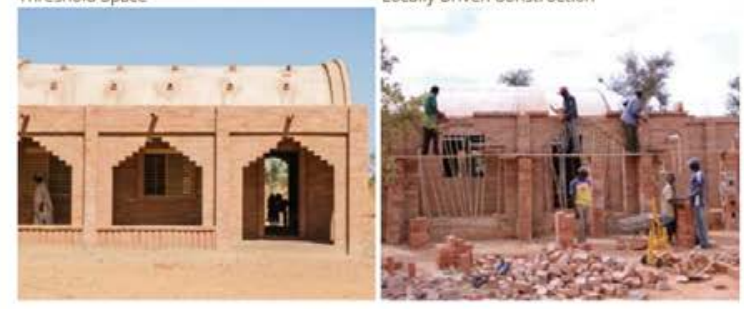

Location

Mopti, Mali

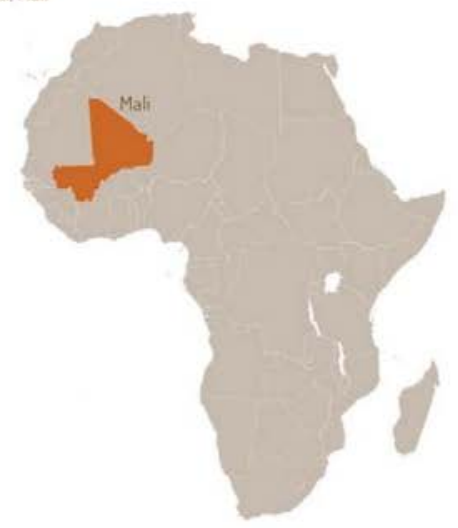

Threshold Space Identification

Ground Floor Plan

Threshold Space Categorization

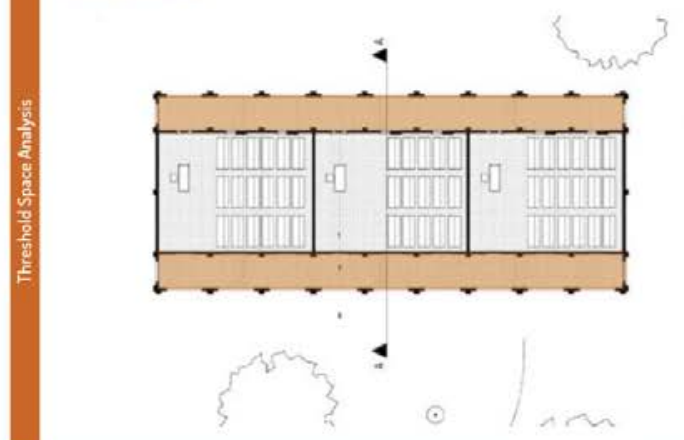

Additive: Protracted Transition Case Study Code 25

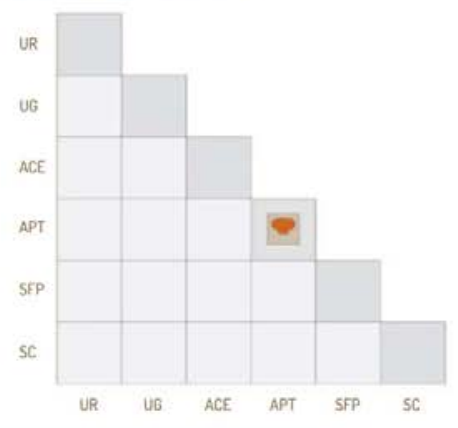

Tectonic Systems

Tectonic Systems

Section

Material Analysis
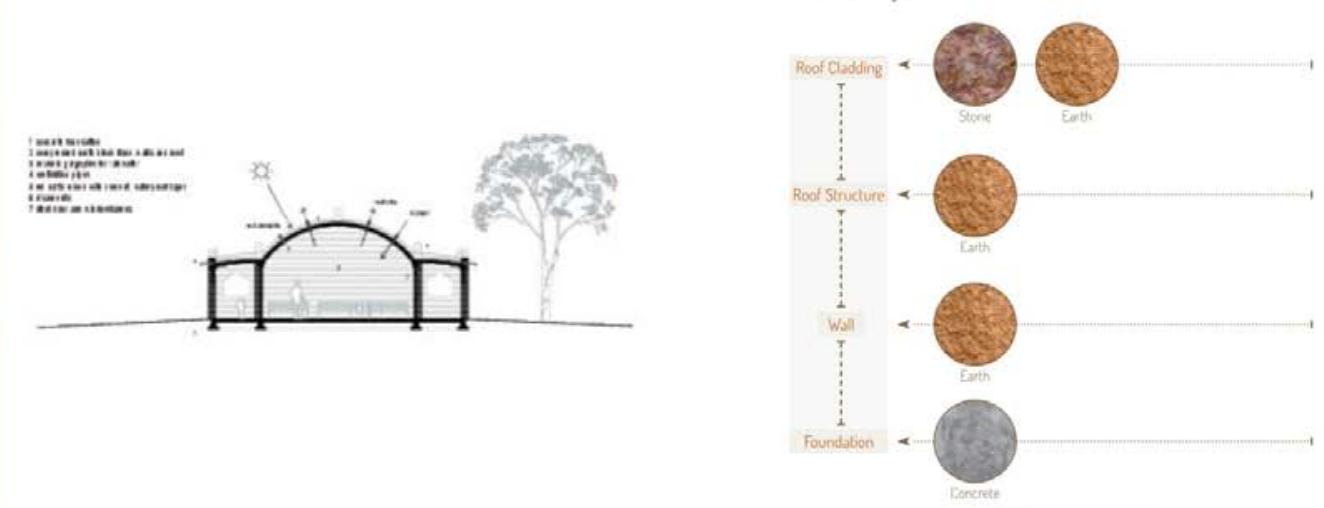
Primary School Tanouan Ibi

LEVS architecten

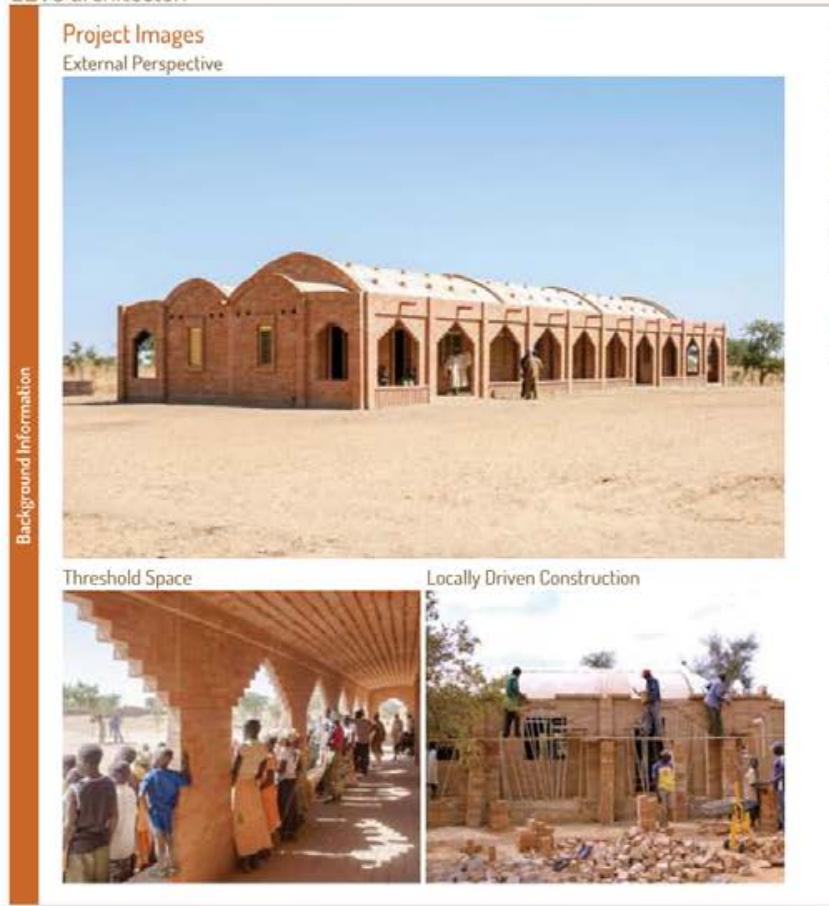

Project Information

Project Date 2013

Program Primary School

Client

Geographical Context Rural

Size $\quad 360$ Sqm

Budget

Cost per m2 (USD)

\section{Location}

Dogon, Mali

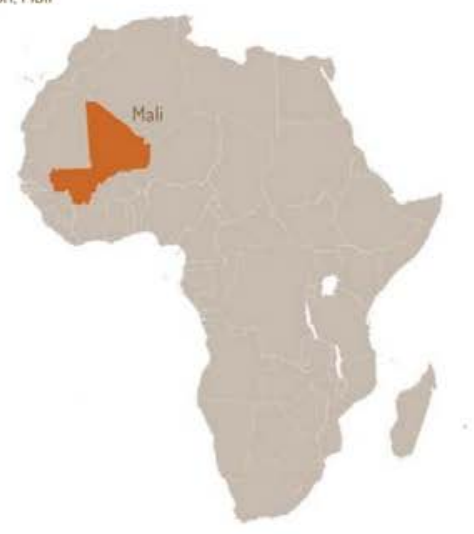

Threshold Space Identification

Threshold Space Categorization

Ground Floor Plan

Unifying Roof, Unifying Groundplane, Additive: Protracted Transition
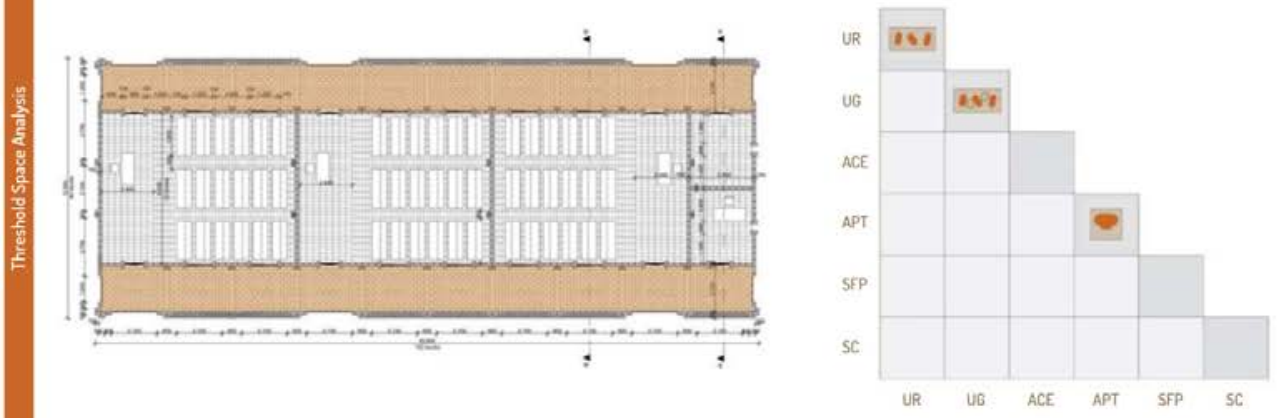

Tectonic Systems

Section

Tectonic Systems

Material Analysis
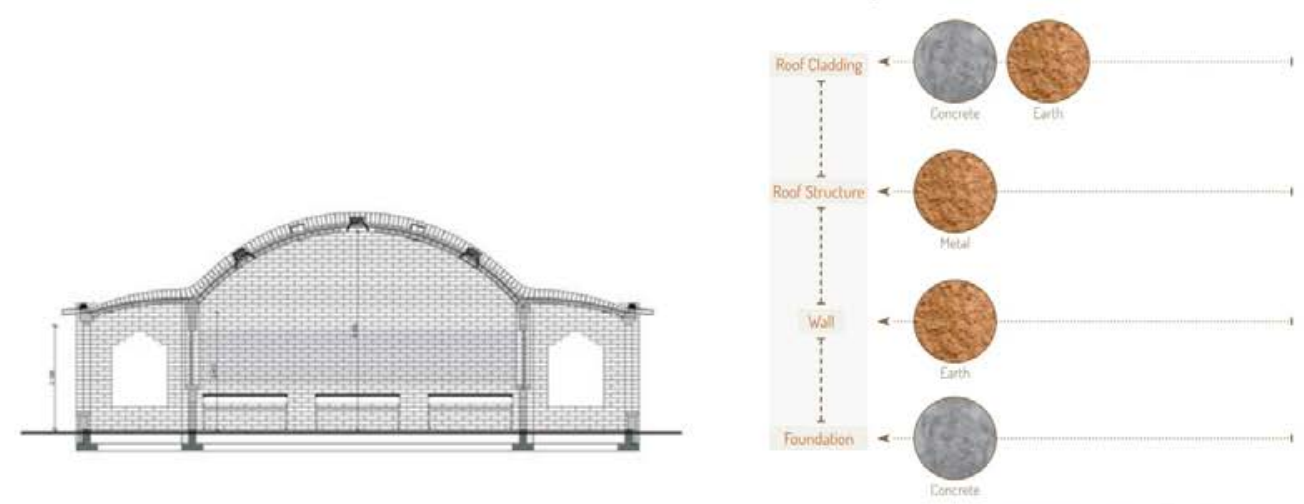
St Jerome's Children's Centre

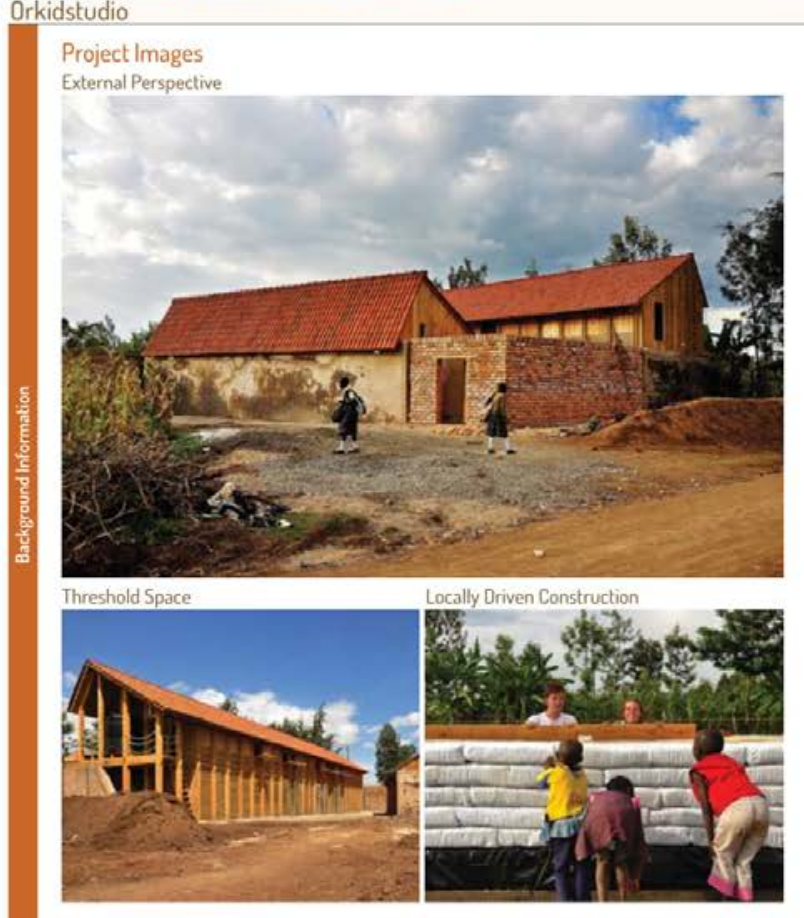

Case Study Code 30

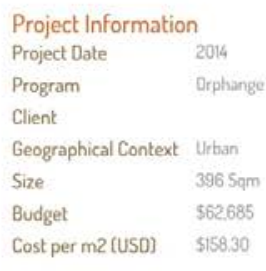

Project Information

Project Date 2014

Program Drphange

Client

Geographical Context Urban

Size $\quad 396 \mathrm{Sqm}$

Budget $\$ 62.685$

Cost per m2 (USD) \$\$58.30

Location

Nakuru, Kenya
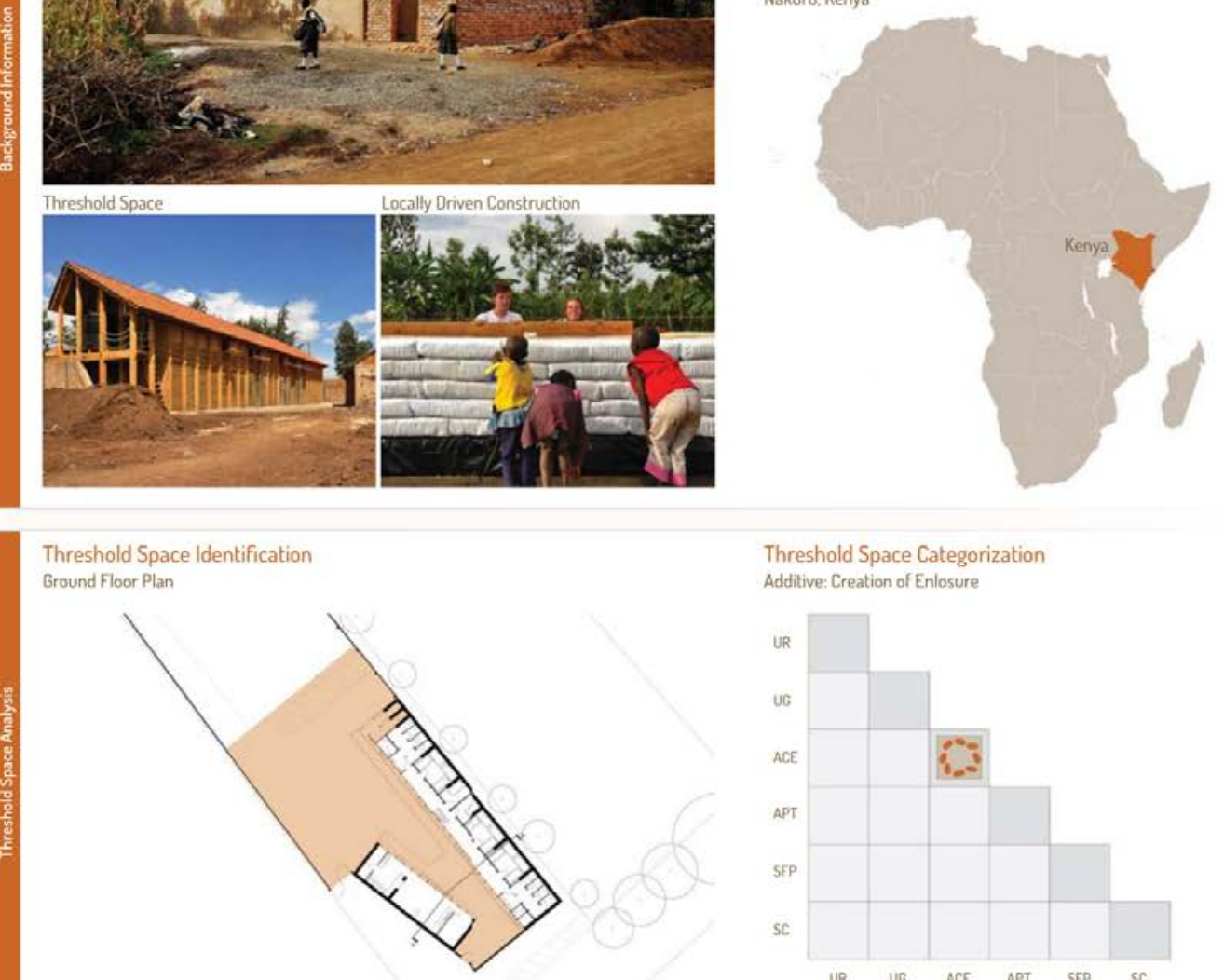

Threshold Space Categorization

Additive; Creation of Enlosure

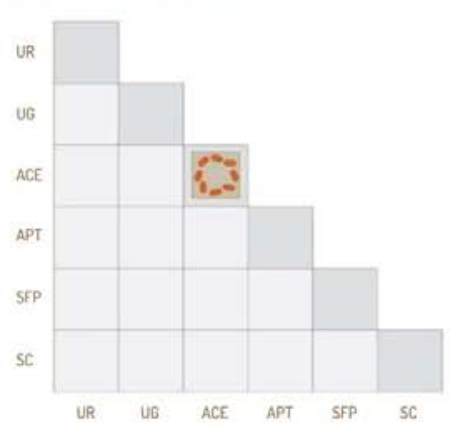

Tectonic Systems

Tectonic Systems

Section

Material Analysis
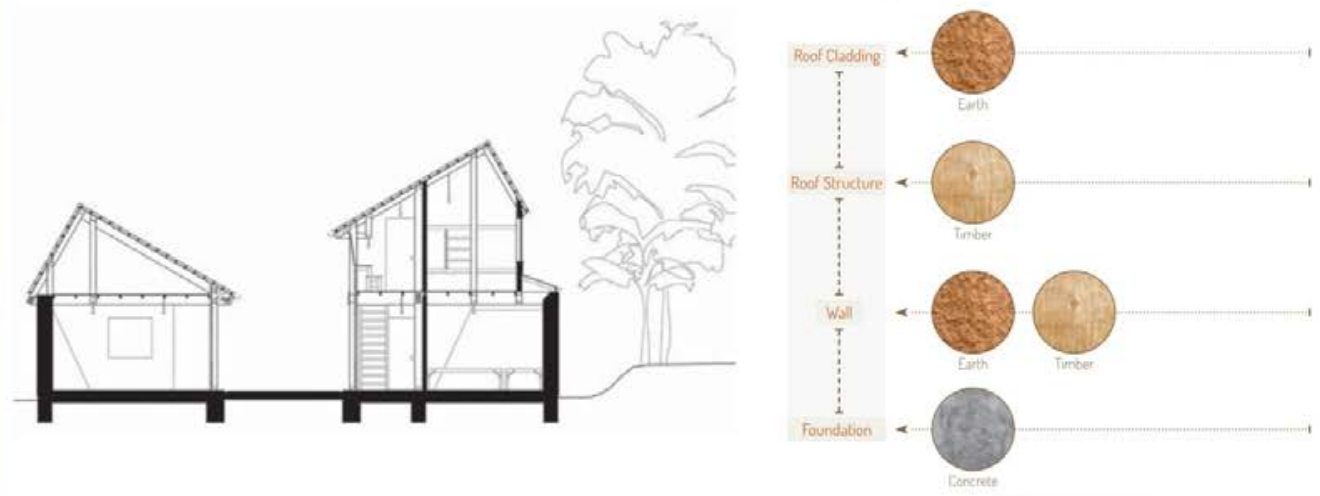
Youth Center In Niafourang

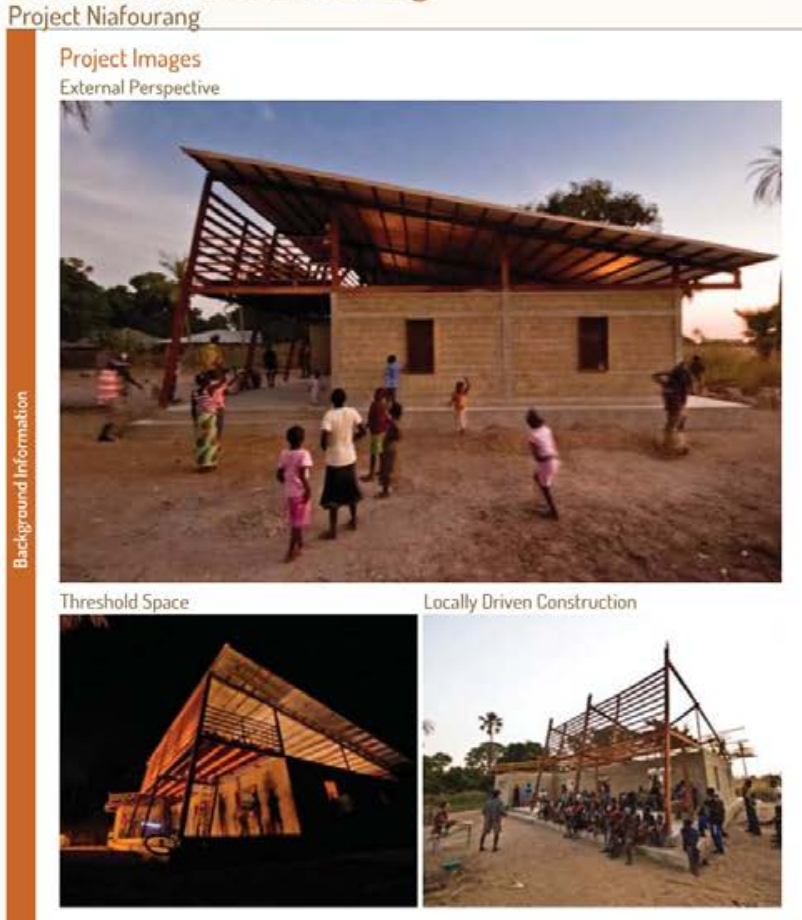
Fase Study code 34

Project Information

Project Date 2011

Propram Youth Centur

Client Friends of Niafourang

Geographical Context Rural

Size $\quad 3005 \mathrm{sm}$

Budget

Cost per m2 (USD)

Location

Niafourang, Senegal

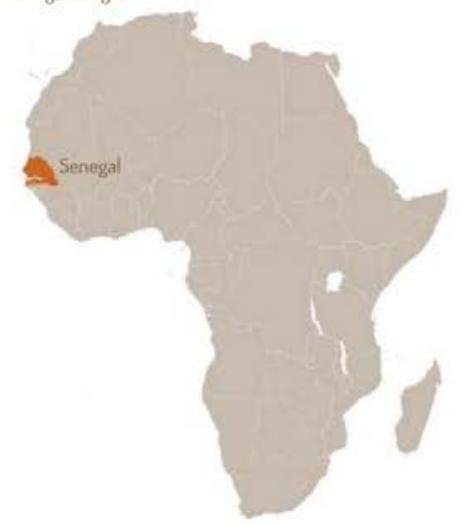

Threshold Space Identification

Threshold Space Categorization

Ground Floor Plan

Unifying Roof, Unifying Groundplane, Subtractive: Form Perimeter
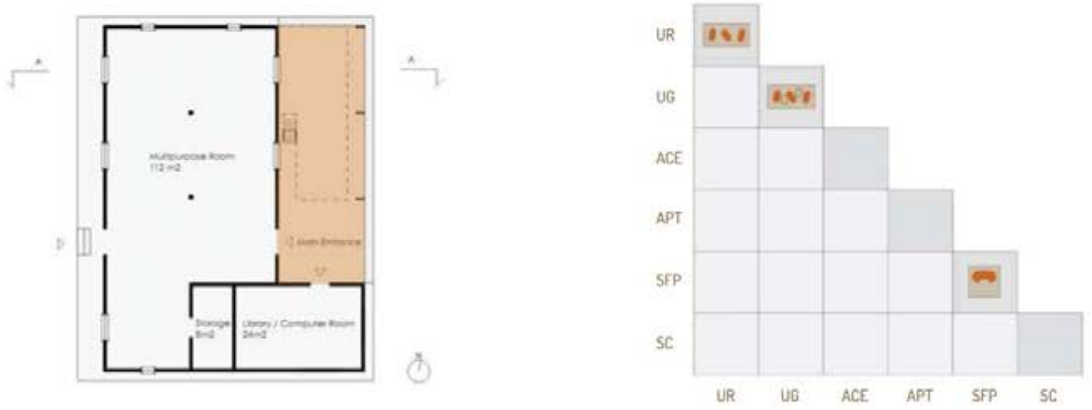

Tectonic Systems

Tectonic Systems

Section

Material Analysis

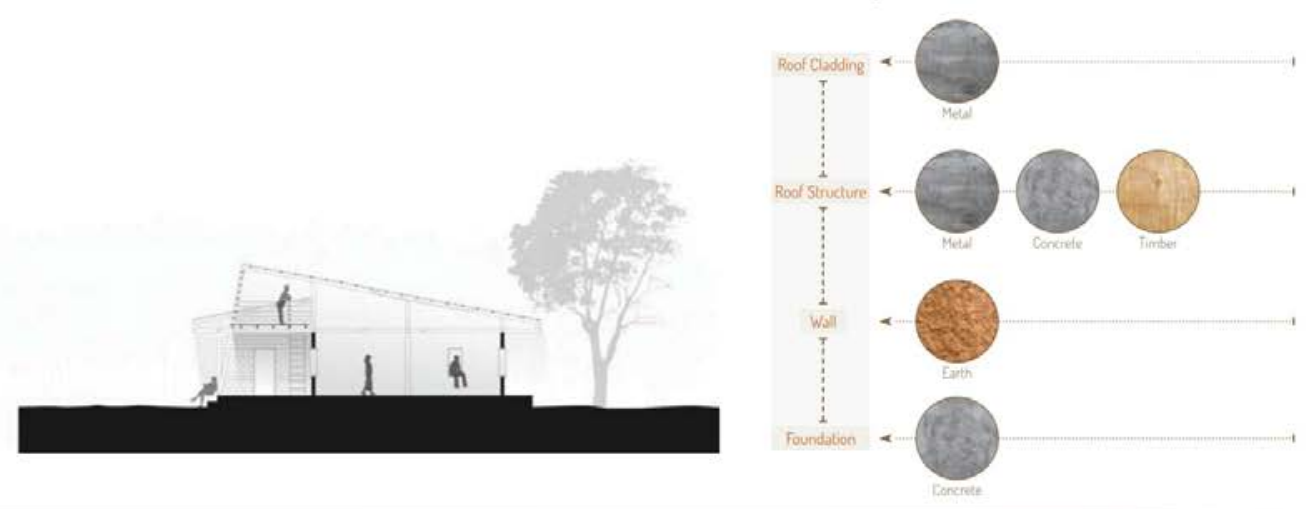


Konokono Vaccination and Educational Clinic

Selgas Cano and MIT Open Studio

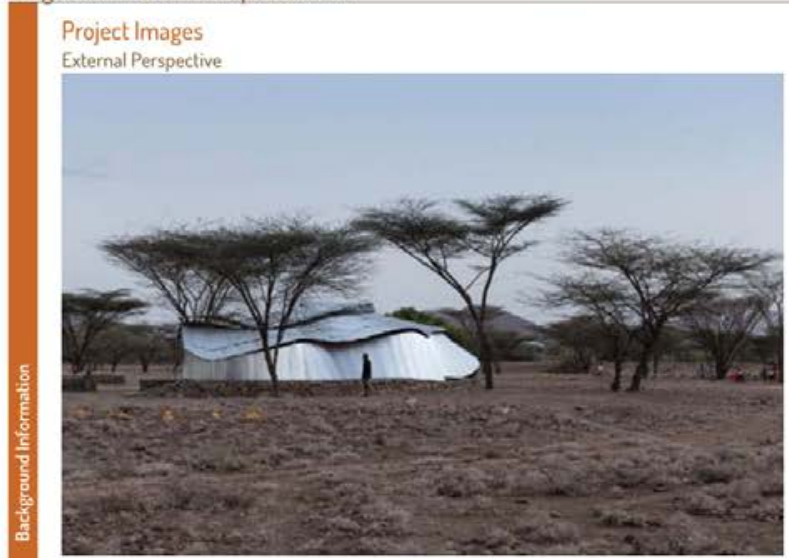

Project Information

Project Date 2014

Program Vaccination and Education Conter

Client

Geographical Context Rural

Size $1495 \mathrm{Sqm}$

Budget $\$ 332,000$

Cost per m2 (USD) \$21477

Location

Turkana, Kenya

Threshold Space

Locally Driven Construction
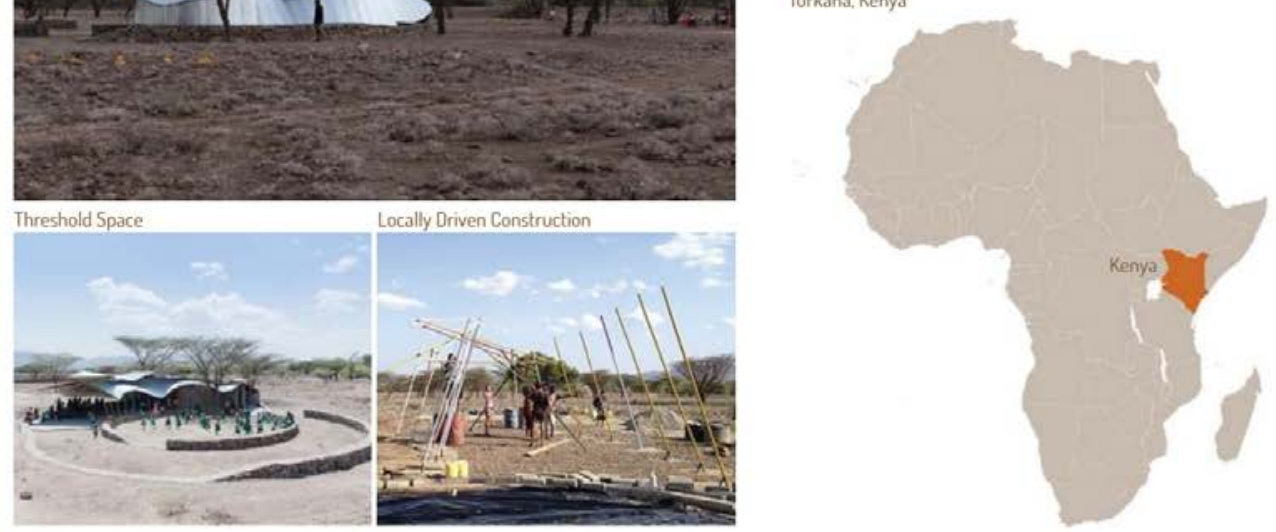

Threshold Space Identification

Threshold Space Categorization

Ground Floor Plan

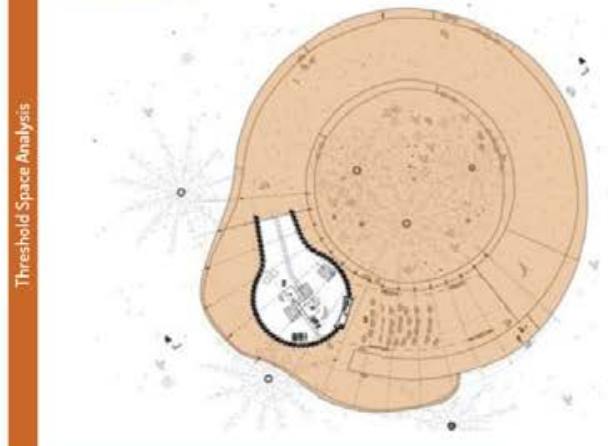

Unifying Roof, Unifying Groundplane, Additive: Protracted Transition

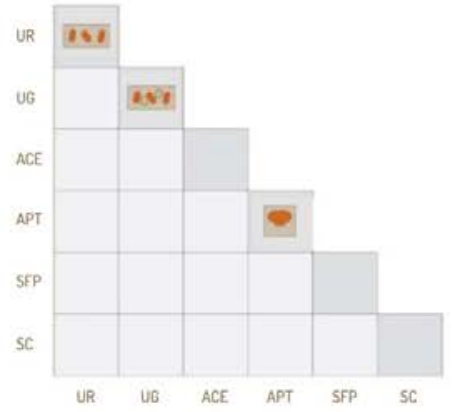

Tectonic Systems

Tectonic Systems

Section

Material Analysis
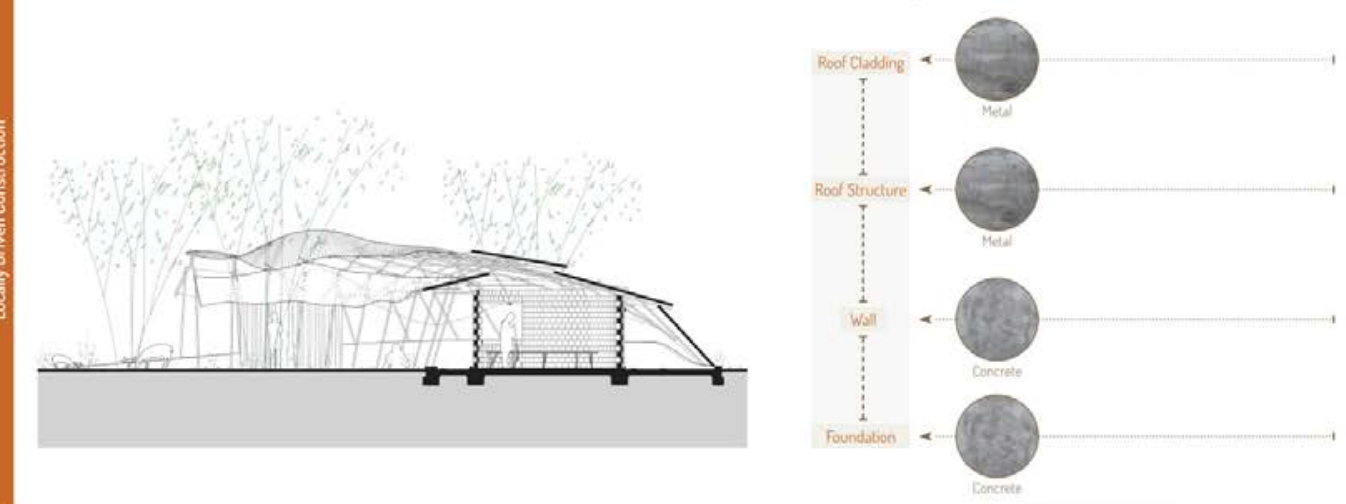
Women's Opportunity Center

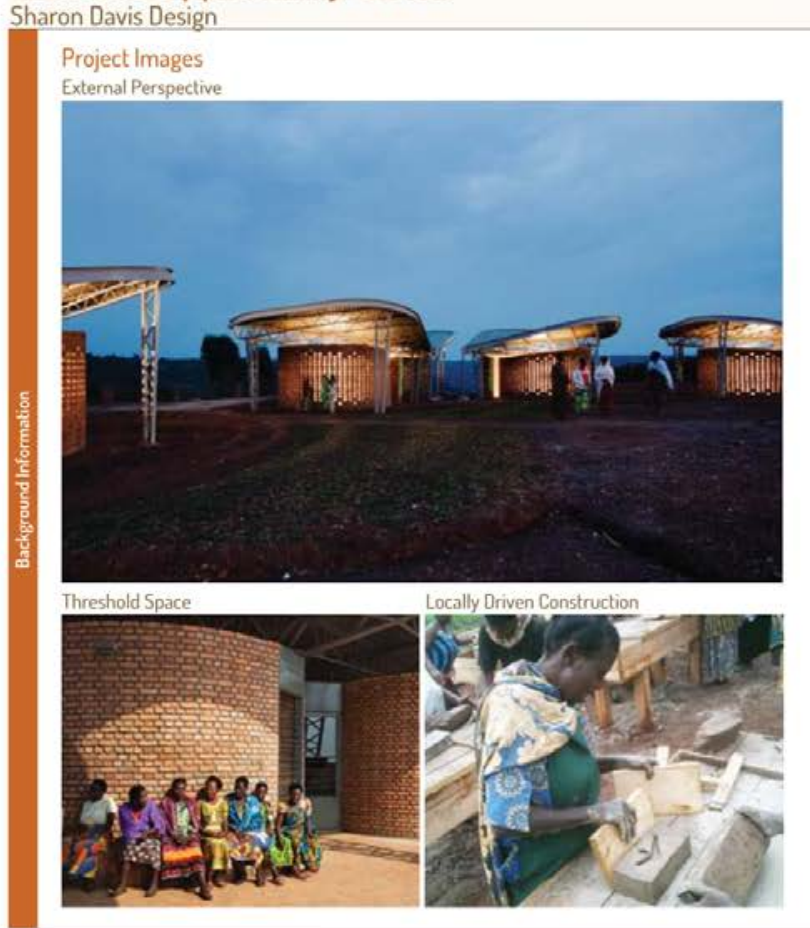

Case Study Code 37

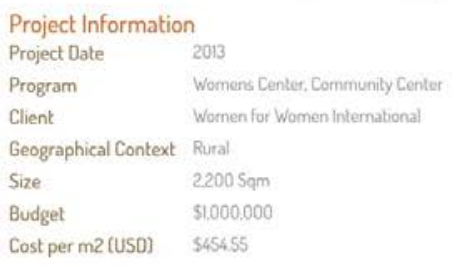

Project Information

Project Date 2013

Program Womens Center, Community Center

Client Wornen for Women international

Geographical Context Rural

Size 2200 Sqm

Budget $\$ \$ 1,000,000$

Cost per m2 (USD) \$45455

\section{Location}

Kayonza, Rwanda

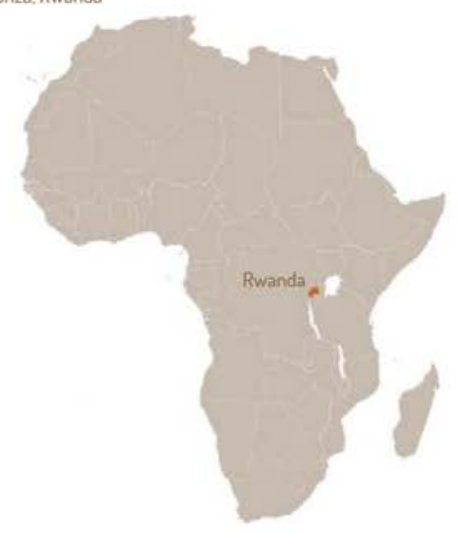

Threshold Space Identification

Threshold Space Categorization

Ground Floor Plan

Unifying Roof. Unifying Groundplane, Additive: Creation of Enclosure
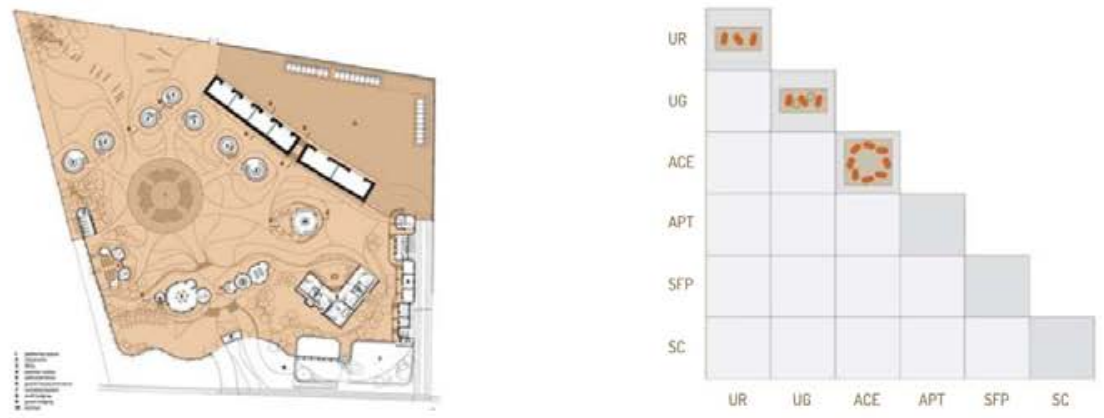

Tectonic Systems

Tectonic Systems

Section

Material Analysis
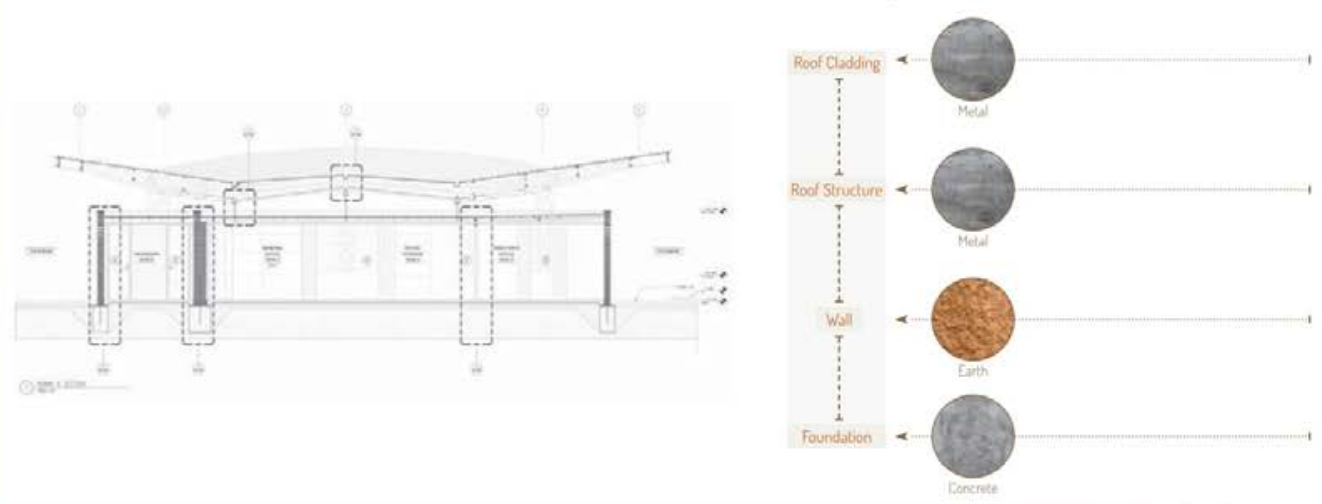
Thread Cultural Center

Toshiko Mori Architects

Case Study Code: 40

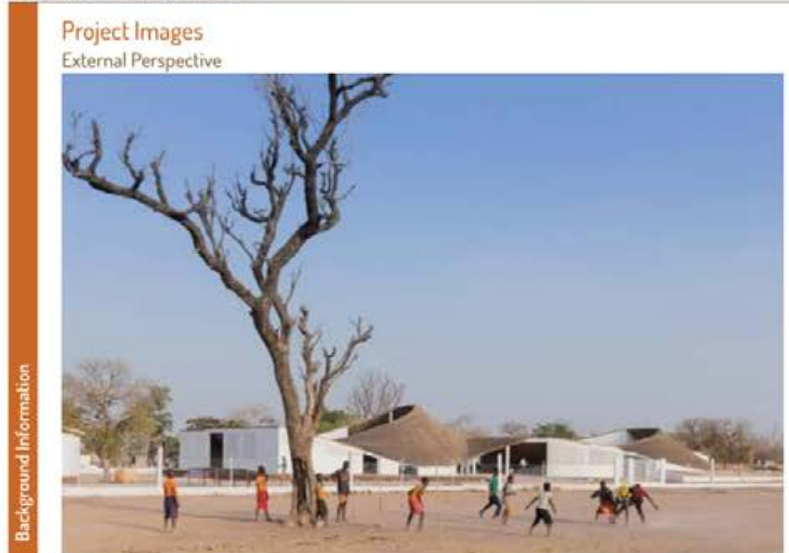

Project Information

Project Date 20is

Program Arts Center. Artists Residency

Client Josef and Anni Albers Foundation

Geographical Context Rural

Size $1.048 \mathrm{Sqm}$

Budget $\$ 146.000$

Cost per m2 (USD) $\quad \$ \$ 39.31$

Location

Sinthian, Senegal
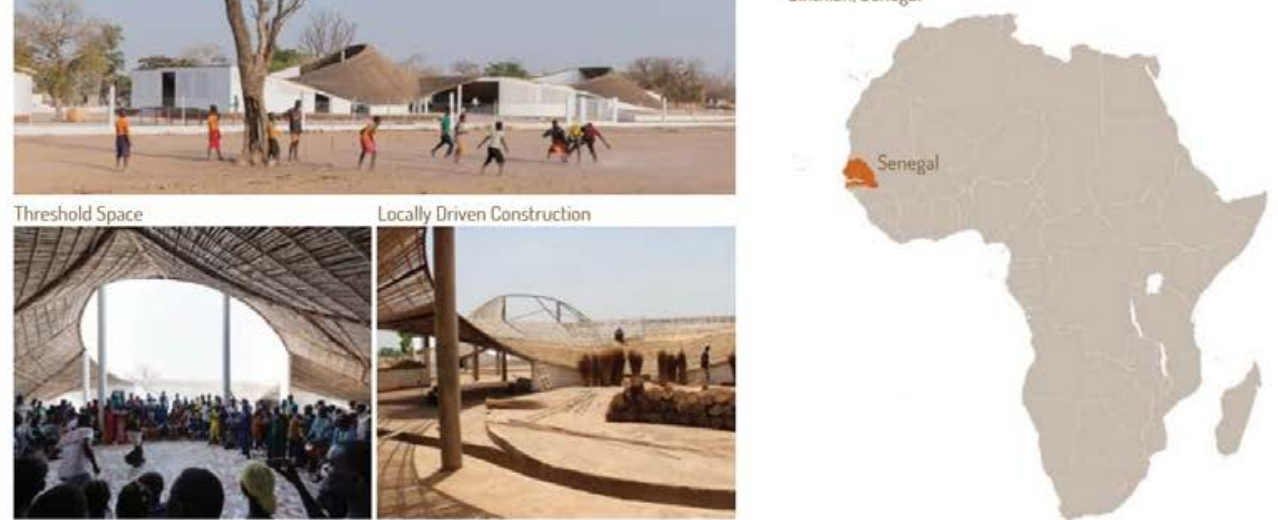

Threshold Space Identification

Ground Floor Plan

Threshold Space Categorization

Subtractive: Form Perimeter, Subtractive: Courtyard
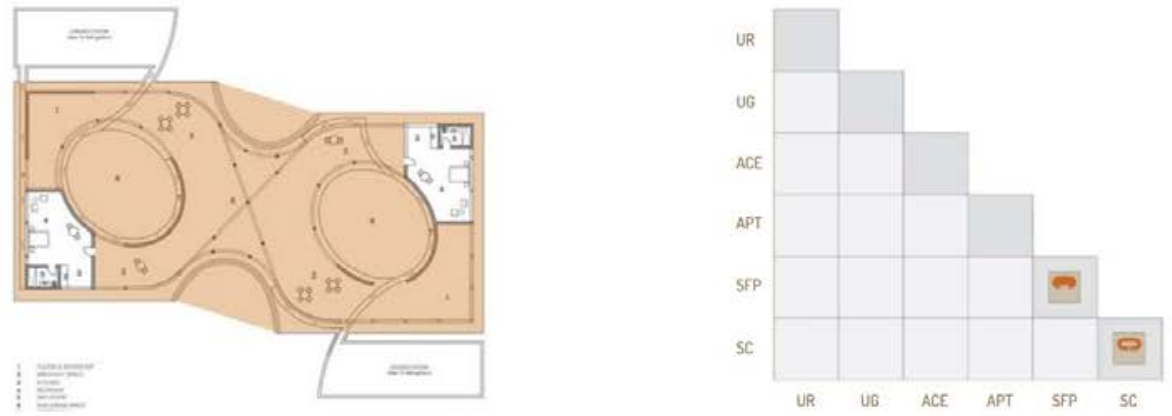

Tectonic Systems

Tectonic Systems

Section

Material Analysis
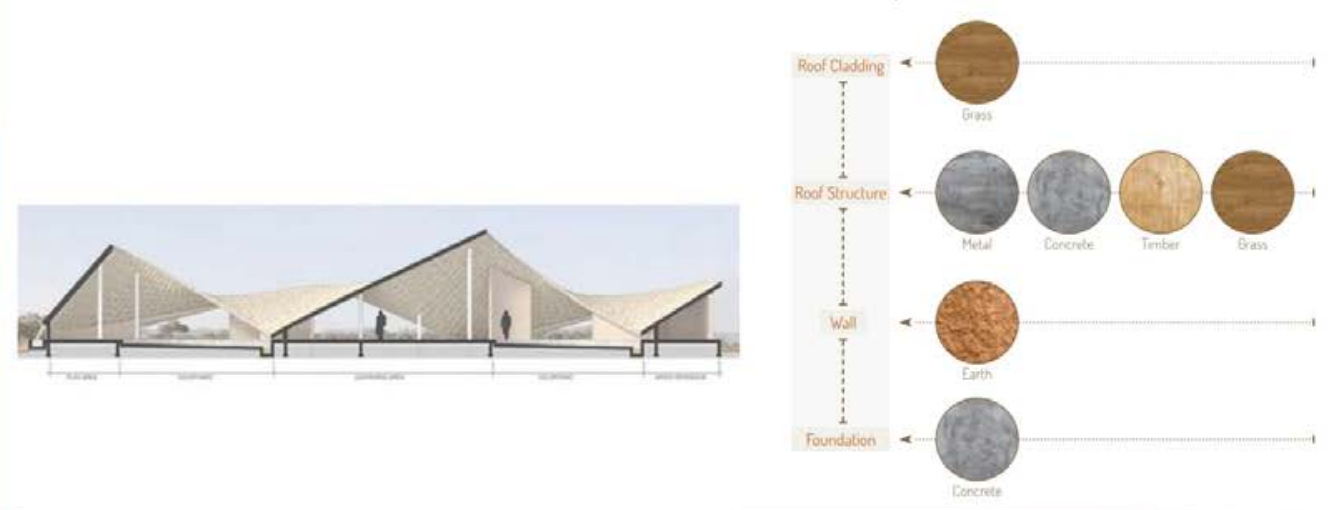


\section{References}

\section{Works Cited}

Achebe, Chinua, and Uche Okeke. Things Fall Apart. London: Heinemann Educational Books Ltd, 1985.

"African Holocaust." African Code, http://www.africanholocaust.net/peopleofafrica.htm.

"Aga Khan Award for Architecture." Aga Khan Development Network (AKDN), http://www.akdn.org/architecture.

"Aga Khan Foundation." Aga Khan Development Network (AKDN), http://www.akdn.org/our-agencies/aga-khanfoundation-0.

Andersen, Kaj Blegvad. African Traditional Architecture: A Study of the Housing and Settlement Patterns of Rural Kenya. Nairobi ; New York: Oxford University Press, 1977.

Anne Isabella Ritchie, Thackeray. Mrs. Dymond. London: Smith, Elder, \& Co., 1885.

Asquith, Lindsay, and Marcel Vellinga. Vernacular Architecture in the Twenty-First Century: Theory, Education and Practice. London; New York: Taylor \& Francis, 2006.

Boettger, Till, and Egon Schirmbeck. Threshold Spaces: Transitions in Architecture: Analysis and Design Tools. Translated by Helen Labies-Volz. Basel; Boston: Birkhäuser, 2014.

Bourdier, Jean-Paul, and T. Minh-Ha Trinh. Vernacular Architecture of West Africa: A World in Dwelling. Abingdon, Oxon England; New York: Routledge, 2011.

Bristol, Katherine G. "The Pruitt-Igoe Myth." Journal of Architectural Education 44, no. 3 (1991): 163-71.

Buccellato, Aimee, and Megan Reineccius. "Exploring Vernacular East African Architecture: Lessons for the Modern World." Paper presented at the Subtropical Cities 2013: Braving A New World: Design Interventions for Changing Climates, Florida, United States of America, 2013.

Curtis, William J. R. Modern Architecture since 1900. 3rd ed. London: Phaidon Press Limited, 1996.

Denyer, Susan, and Peter McClure. African Traditional Architecture: An Historical and Geographical Perspective. New York, USA: Africana Publishing Company, 1978.

Eco, Umberto, Caterina Mongiat Farina, and Geoff Farina. How to Write a Thesis. Cambridge, Massachusetts 
London, England: The MIT Press, 2015.

http://myaccess.library.utoronto.ca/login?url=http://ebookcentral.proquest.com/lib/utoronto/detail.action?docl $\underline{D=3339948}$.

El Wakil, Abdel Wahed, and James Steele. Hassan Fathy. Architectural Monographs. London, New York: Academy Editions, St. Martin's Press, 1988.

Elleh, Nnamdi. African Architecture: Evolution and Transformation. New York: McGraw-Hill, 1997.

Fathy, Hassan. Architecture for the Poor: An Experiment in Rural Egypt. Chicago, USA: University of Chicago Press, 1973.

Fazio, Michael W., Lawrence Wodehouse, and Marian Moffett. A World History of Architecture. $3^{\text {rd }}$ ed. London, United Kingdom: Laurence King Ltd, 2014.

Fischer, Hilke. "130 Years Ago: Carving up Africa in Berlin." Deutsche Welle, http://www.dw.com/en/130-yearsago-carving-up-africa-in-berlin/a-18278894.

Gardi, René. Indigenous African Architecture. New York, Van Nostrand Reinhold, 1974.

Groat, Linda N., and David Wang. Architectural Research Methods. New York: John Wiley \& Sons, Inc., 2002.

Gropius, Walter. Internationale Architektur. Translated by Kenneth W. Kaiser. BauhausbüCher, L. München,: A. Langen, 1925.

Grosfoguel, Ramon. "The Epistemic Decolonial Turn ". Cultural Studies 21, no. 2 (2007): 211-23.

Hargreaves, John D. "Cultural Decolonisation: Unesco and Africa." History Today 36

no. 3 (1986). http://www.historytoday.com/john-d-hargreaves/cultural-decolonisation-unesco-africa.

Harper, Douglas. "Etymonline." http://www.etymonline.com/index.php.

Heath, Kingston Wm. Vernacular Architecture and Regional Design: Cultural Process and Environmental Response. 1st ed. Oxford ; Burlington, Mass.: Architectural Press/Elsevier, 2009.

Hertzberger, Herman. Architecture and Structuralism: The Ordering of Space. Translated by John Kirkpatrick. Polyvalence. nai010 publishers, 2014. 
Herz, Manuel, Ingrid Schröder, Hans Focketyn, Julia Jamrozik, Iwan Baan, and Alexia Webster. African Modernism: The Architecture of Independence: Ghana, Senegal, CôTe D'ivoire, Kenya, Zambia. Zurich, Switzerland: Park Books, 2015.

Higgins, Abby. "Why Residents of Kibera Slum Are Rejecting New Housing Plans - Part 4." edited by The Seattle Globalist: One, 2013.

Homewood, Katherine, Patti Kristjanson, and Pippa Chenevix Trench. Staying Maasai? Livelihoods, Conservation and Development in East African Rangelands. New York, USA: Springer Science + Business Media LLC, 2009.

Iwatani, Yuko, and Evelyne Wanjiku. A Brief Tour of the Buildings of Nairobi. 1st ed. Nairobi, Kenya: Yuko Iwatani, United Nations Office Nairobi (UNON), 2010.

Jackson, lain. "Tropical Modernism: Fry and Drew's African Experiment." Architectural Review (2014). Published electronically July 4. https://www.architectural-review.com/rethink/tropical-modernism-fry-and-drewsafrican-experiment/8665223.article?search=https\%3a\%2f\%2fwww.architecturalreview.com\%2fsearcharticles\%3fqsearch\%3d1\%26keywords\%3dTropical+Modernism\%3a+Fry+and+Drew \%27s+African+Experiment.

Jacobs, Jane. The Death and Life of Great American Cities. Vintage Books ed. New York: Vintage Books, 1992.

"Jalaluddin Rumi." Good Reads, http://www.goodreads.com/quotes/616306-maybe-you-are-searching-amongthe-branches-for-what-only.

Khan, His Highness the Aga. "Aga Khan Award for Architecture Ceremony, Cairo." Aga Khan Foundation.

Kultermann, Udo. New Architecture in Africa. London: Thames and Hudson, 1963.

Lovesey, Oliver. Approaches to Teaching the Works of NgũGĩ Wa Thiong'o. Approaches to Teaching World Literature,. New York: Modern Language Association of America, 2012.

May, John. Handmade Houses \& Other Buildings: The World of Vernacular Architecture. High Holborn, London: Thames \& Hudson, 2010.

Mutai, Michael. "Origin of the Names of Some Kenyan Localities." Radio Jambo, https://radiojambo.co.ke/originof-the-names-of-some-kenyan-localities/.

Naipaul, V. S. A Bend in the River. 1st ed. New York: Knopf Inc., 1979. 
Neckebrouck, Valeer. Resistant Peoples: The Case of the Pastoral Maasai of East Africa. Inculturation. Edited by Arij A. Roest Crollius. Rome: Centre "Cultures and Religions", Pontifical Gregorian University, 1993.

Network, Community Architects. "Bamboo Construction Source Book." Hunnarshala Foundation, 2013

Njeri, Mwangi Mercy. "Transformation of Nairobi Post-Independence Architecture: Climate Responsive Architecture." University of Nairobi, 2002.

Noble, Allen G. Traditional Buildings: A Global Survey of Structural Forms and Cultural Functions. International Library of Human Geography ;. London ; New York: I. B. Tauris, 2007.

--- Vernacular Buildings: A Global Survey. London: I.B.Tauris, 2014.

"'Notopia Is Less a Warning Than a Prophecy of Doom'." The Architectural Review (2016). Published electronically June 2.

Oliver, Paul. Built to Meet Needs: Cultural Issues in Vernacular Architecture. 1st ed. London: Architectural Press, 2006.

- - - Encyclopedia of Vernacular Architecture of the World. New York: Cambridge University Press, 1997.

Patrice Lumumba; the Truth About a Monstrous Crime of the Colonialists. Patrice Lumumba's Will. Moscow: Foreign Languages Publishing House, 1961.

Pelikan, Jaroslav. The Vindication of Tradition. The 1983 Jefferson Lecture in the Humanities. New Haven: Yale University Press, 1984.

"Population and Health Dynamics In Nairobi's Informal Settlements ". In Report of the Nairobi Cross-sectional Slums Survey(NCSS), 212. Nairobi: African Population and Health Research Center (APHRC), 2014.

"Poverty." World Bank, http://www.worldbank.org/en/topic/poverty/overview.

Richardson, Vicky. New Vernacular Architecture. London: Laurence King Publishing, 2001.

Robinson, Randall. "Randall Robinson Interview." By Amitabh Pal (2005).

Rudofsky, Bernard. Architecture without Architects: A Short Introduction to Non-Pedigreed Architecture. USA: Museum of Modern Art: New York, 1964. 
Rukwaro, Robert Wambugu, and Sylvester J. M. Maina. Transformation of Maasai Art and Architecture. Nairobi: ARTS Press, 2006.

Saitoti, Tepilit Ole. The Worlds of a Masai Warrior: An Autobiography. New York: Random House, 1986.

Sposito, Cesare. "Identity, Flexibility and Sustainability for the New Social Housing." Techne : Journal of Technology for Architecture and Environment (2012): 153-59.

Syrjänen, Raakel, and UN-HABITAT KENSUP Team. "Un-Habitat and the Kenya Slum Upgrading Programme: Strategy Document." edited by Tom Osanjo, 72, 2008.

"The 2009 Kenya Population and Housing Census." In Population and Household Distribution by Socio-Economic Characteristics, 438. Nairobi: Kenya National Bureau of Statistics (KNBS), 2010.

"The Pritzker Architecture Prize." The Hyatt Foundation, http://www.pritzkerprize.com/2017/jury-citation.

Thiong'o, Ngũgĩ wa. Decolonising the Mind: The Politics of Language in African Literature. London, Portsmouth, N.H.: J. Currey; Heinemann, 1986. text.

Toronto, City of. "Tall Buildings Design Guidelines." edited by Urban Design, 92. Toronto: City of Toronto, 2013.

Uduko, Ola. "Modernist Architecture and 'the Tropical' in West Africa: The T Ropical Architecture Movement in West Africa, 1948-1970." Habitat International 30 (2006): 396-411.

United Nations Department of Economic and Social Affairs, Population Division. "World Urbanization Prospects: The 2014 Revision." United Nations, 2015.

-_- "World Urbanization Prospects: The 2014 Revision, Highlights." United Nations, 2014.

Varanda, Francis. "2004 on Site Review Report." In Primary School: Gando: Burkina Faso: The Aga Khan Award for Architecture, 2004.

Vellinga, Marcel, Paul Oliver, and Alexander Bridge. "Atlas of Vernacular Architecture of the World." Abingdon, Oxon ; New York: Routledge,, 2007.

Vitruvius, Pollio, and Thomas Gordon Smith. Vitruvius on Architecture. New York: The Monacelli Press, 2003. 


\section{Bibliography}

"130 Years Ago: Carving up Africa in Berlin." Deutsche Welle, 2015.

"About Aecom." http://www.aecom.com/about-aecom/history/.

Achebe, Chinua, and Uche Okeke. Things Fall Apart. London: Heinemann Educational Books Ltd, 1985.

"African Holocaust." African Code, http://www.africanholocaust.net/peopleofafrica.htm.

"Aga Khan Award for Architecture." Aga Khan Development Network (AKDN), http://www.akdn.org/architecture.

"Aga Khan Foundation." Aga Khan Development Network (AKDN), http://www.akdn.org/our-agencies/aga-khanfoundation-0.

Aga-Khan, His Highness the. "Aga Khan Award for Architecture Ceremony, Cairo." Aga Khan Foundation.

Agarwal, Anil. Mud, Mud: The Potential of Earth-Based Materials for Third World Housing. Earthscan Publications. London: International Institute for Environment and Development, 1981.

Andersen, Kaj Blegvad. African Traditional Architecture: A Study of the Housing and Settlement Patterns of Rural Kenya. Nairobi ; New York: Oxford University Press, 1977.

Anne Isabella Ritchie, Thackeray. Mrs. Dymond. London: Smith, Elder, \& Co., 1885.

Asquith, Lindsay, and Marcel Vellinga. Vernacular Architecture in the Twenty-First Century: Theory, Education and Practice. London ; New York: Taylor \& Francis, 2006.

Bekure, Solomon, and International Livestock Centre for Africa. Maasai Herding : An Analysis of the Livestock Production System of Maasai Pastoralists in Eastern Kajiado District, Kenya. Ilca Systems Study. Addis Ababa, Ethiopia: International Livestock Centre for Africa, 1991.

Boettger, Till, and Egon Schirmbeck. Threshold Spaces: Transitions in Architecture: Analysis and Design Tools. Translated by Helen Labies-Volz. Basel; Boston: Birkhäuser, 2014.

Bourdier, Jean-Paul, and T. Minh-Ha Trinh. Vernacular Architecture of West Africa: A World in Dwelling. Abingdon, Oxon England ; New York: Routledge, 2011.

Boyer, Marie-France, and Eric Morin. The French Café. New York: Thames and Hudson, 1994.

Bristol, Katherine G. "The Pruitt-Igoe Myth." Journal of Architectural Education 44, no. 3 (1991): 163-71.

Buccellato, Aimee, and Megan Reineccius. "Exploring Vernacular East African Architecture: Lessons for the Modern World." Paper presented at the Subtropical Cities 2013: Braving A New World: Design Interventions for Changing Climates, Florida, United States of America, 2013. 
Carter, Thomas, and Elizabeth C. Cromley. Invitation to Vernacular Architecture : A Guide to the Study of Ordinary Buildings and Landscapes. Vernacular Architecture Studies. 1st ed. Knoxville: University of Tennessee Press, 2005.

Chicago, University of. "The Chicago manual of Style Online." University of Chicago Press, http://www.chicagomanualofstyle.org/16/contents.html.

Curling, Chris, Mellisa Llewellyn-Davies, Films Incorporated., and Granada Television. Masai Women, Disappearing world. Chicago, IL: Films Incorporated,, 1991. videorecording, 1 videocassette (52 min.) : sd., col. ; $1 / 2$ in.

Curtis, William J. R. Modern Architecture since 1900. 3rd ed. London: Phaidon Press Limited, 1996.

Denyer, Susan, and Peter McClure. African Traditional Architecture: An Historical and Geographical Perspective. New York, USA: Africana Publishing Company, 1978.

Dethier, Jean. Down to Earth: Mud Architecture : An Old Idea, a New Future. London: Thames and Hudson, 1982.

Eco, Umberto, Caterina Mongiat Farina, and Geoff Farina. How to Write a Thesis. Cambridge, Massachusetts London, England: The MIT Press, 2015.

El Wakil, Abdel Wahed, and James Steele. Hassan Fathy. Architectural Monographs. London, New York: Academy Editions, St. Martin's Press, 1988.

Elleh, Nnamdi. African Architecture: Evolution and Transformation. New York: McGraw-Hill, 1997.

Fathy, Hassan. Architecture for the Poor: An Experiment in Rural Egypt. Chicago, USA: University of Chicago Press, 1973.

Fazio, Michael W., Lawrence Wodehouse, and Marian Moffett. A World History of Architecture. $3^{\text {rd }}$ ed. London, United Kingdom: Laurence King Ltd, 2014.

Fischer, Hilke. "130 Years Ago: Carving up Africa in Berlin." Deutsche Welle, http://www.dw.com/en/130-yearsago-carving-up-africa-in-berlin/a-18278894.

Frampton, Kenneth. "The Anti-Aesthetic: Essays on Postmodern Culture." In Towards a Critical Regionalism: Six Points for an Architecture of Resistance, edited by Hal Foster, xvi, 159 p. Port Townsend, Washington, United States of America: Bay Press, 1983.

From Mukogodo to Maasai, Ethnicity and Cultural Change in Kenya. [S.I.]: Westview Press, 2004. http://myaccess.library.utoronto.ca/login?url=http://www.aspresolver.com/aspresolver.asp?ANTH.

Gardi, René. Indigenous African Architecture. New York, Van Nostrand Reinhold, 1974.

Gillmor, Don, and A. J. Diamond. Insight and on Site: The Architecture of Diamond and Schmitt. Vancouver, BC: Douglas \& Mclntyre, 2008. 
Glaeser, Edward L. "Why Has Globalization Led to Bigger Cities?" New York Times (2009). Published electronically May 19 ${ }^{\text {th }}$ 2009. http://economix.blogs.nytimes.com/2009/05/19/why-has-globalization-led-to-biggercities/? $r=0$.

Groat, Linda N., and David Wang. Architectural Research Methods. New York: John Wiley \& Sons, Inc., 2002.

Gropius, Walter. Internationale Architektur. Translated by Kenneth W. Kaiser. BauhausbüCher, L. München,: A. Langen, 1925.

Grosfoguel, Ramon. "The Epistemic Decolonial Turn ". Cultural Studies 21, no. 2 (2007): 211-23.

Hargreaves, John D. "Cultural Decolonisation: Unesco and Africa." History Today 36

no. 3 (1986). http://www.historytoday.com/john-d-hargreaves/cultural-decolonisation-unesco-africa.

Harper, Douglas. "Etymonline." http://www.etymonline.com/index.php.

Heath, Kingston Wm. Vernacular Architecture and Regional Design: Cultural Process and Environmental Response. 1st ed. Oxford ; Burlington, Mass.: Architectural Press/Elsevier, 2009.

Hertzberger, Herman. Architecture and Structuralism: The Ordering of Space. Translated by John Kirkpatrick. Polyvalence. nai010 publishers, 2014.

Herz, Manuel, Ingrid Schröder, Hans Focketyn, Julia Jamrozik, Iwan Baan, and Alexia Webster. African Modernism: The Architecture of Independence: Ghana, Senegal, CôTe D'ivoire, Kenya, Zambia. Zurich, Switzerland: Park Books, 2015.

Higgins, Abby. "Why Residents of Kibera Slum Are Rejecting New Housing Plans - Part 4." edited by The Seattle Globalist: One, 2013.

Hodgson, Dorothy Louise. Being Maasai, Becoming Indigenous : Postcolonial Politics in a Neoliberal World. Bloomington: Indiana University Press, 2011.

Homewood, Katherine, Patti Kristjanson, and Pippa Chenevix Trench. Staying Maasai? Livelihoods, Conservation and Development in East African Rangelands. New York, USA: Springer Science + Business Media LLC, 2009.

Iwatani, Yuko, and Evelyne Wanjiku. A Brief Tour of the Buildings of Nairobi. 1st ed. Nairobi, Kenya: Yuko Iwatani, United Nations Office Nairobi (UNON), 2010.

Jackson, lain. "Tropical Modernism: Fry and Drew's African Experiment." Architectural Review (2014). Published electronically July 4. https://www.architectural-review.com/rethink/tropical-modernism-fry-and-drewsafrican-experiment/8665223.article?search=https\%3a\%2f\%2fwww.architecturalreview.com\%2fsearcharticles\%3fqsearch\%3d1\%26keywords\%3dTropical+Modernism\%3a+Fry+and+Dre w\%27s+African+Experiment.

Jacobs, Jane. The Death and Life of Great American Cities. Vintage Books ed. New York: Vintage Books, 1992. 
"Jalaluddin Rumi." Good Reads, http://www.goodreads.com/quotes/616306-maybe-you-are-searching-amongthe-branches-for-what-only.

"Kenya's Most Famous Building Is "Norwegian"." Norsk rikskringkasting AS, https://www.nrk.no/urix/kenyasmest-kjente-bygg-er- norsk -1.13296603.

Kieran, Christopher. "Good Design Is Good Business." Architectural Record, 2007, 87,102,04.

Kostof, Spiro. A History of Architecture: Settings and Rituals. New York: Oxford University Press, 1985.

Kultermann, Udo. New Architecture in Africa. London: Thames and Hudson, 1963.

Lepik, Andres, and Museum of Modern Art (New York N.Y.). Small Scale, Big Change: New Architectures of Social Engagement. New York: Museum of Modern Art, 2010.

Lovesey, Oliver. Approaches to Teaching the Works of NgũGĩ Wa Thiong'o. Approaches to Teaching World Literature,. New York: Modern Language Association of America, 2012.

May, John. Buildings without Architects : A Global Guide to Everyday Architecture. New York: Rizzoli, 2010.

-- - Handmade Houses \& Other Buildings: The World of Vernacular Architecture. High Holborn, London: Thames \& Hudson, 2010.

McManus, John. "The World Is Running out of Burial Space." BBC News (2015). Published electronically 13 March. http://www.bbc.com/news/uk-31837964.

Meisenheimer, Wolfgang. Choreografie Des Architektonischen Raumes Das Verschwinden Des Raumes in Der Zeit. [in ger] Ad. 1. Aufl. ed. Düsseldorf: Fachhochschule Düsseldorf, 1999.

Minke, Gernot. Building with Earth

Design and Technology of a Sustainable Architecture. Basel ; Boston: Birkhauser-Publishers for Architecture, 2009. http://myaccess.library.utoronto.ca/login?url=http://lib.myilibrary.com?ID=113749.

Mitzlaff, Ulrike von. Maasai Women : Life in a Patriarchal Society : Field Research among the Parakuyo, Tanzania. München [Dar es Salaam]: Trickster Verlag ;Tanzania Publishing House, 1994.

Mutai, Michael. "Origin of the Names of Some Kenyan Localities." Radio Jambo, https://radiojambo.co.ke/originof-the-names-of-some-kenyan-localities/.

Naipaul, V. S. A Bend in the River. 1st ed. New York: Knopf Inc., 1979.

Neckebrouck, Valeer. Resistant Peoples: The Case of the Pastoral Maasai of East Africa. Inculturation. Edited by Arij A. Roest Crollius. Rome: Centre "Cultures and Religions", Pontifical Gregorian University, 1993.

Network, Community Architects. "Bamboo Construction Source Book." Hunnarshala Foundation, 2013 
Njeri, Mwangi Mercy. "Transformation of Nairobi Post-Independence Architecture: Climate Responsive Architecture." University of Nairobi, 2002.

Noble, Allen G. Traditional Buildings: A Global Survey of Structural Forms and Cultural Functions. International Library of Human Geography ;. London; New York: I. B. Tauris, 2007.

---. Vernacular Buildings: A Global Survey. London: I.B.Tauris, 2014.

"'Notopia Is Less a Warning Than a Prophecy of Doom'." The Architectural Review (2016). Published electronically June 2.

Oliver, Paul. Built to Meet Needs: Cultural Issues in Vernacular Architecture. 1st ed. London: Architectural Press, 2006.

-- D. Dwellings : The Vernacular House World Wide. London: Phaidon, 2007.

- - - Encyclopedia of Vernacular Architecture of the World. New York: Cambridge University Press, 1997.

Parkinson, Audrey Stewart. Earth, Mud, and Clay: West African Vernacular Architecture. 1st ed. Mineral Point, Wis.: Preservation Works, 2010.

Patrice Lumumba; the Truth About a Monstrous Crime of the Colonialists. Patrice Lumumba's Will. Moscow: Foreign Languages Publishing House, 1961.

Pelikan, Jaroslav. The Vindication of Tradition. The 1983 Jefferson Lecture in the Humanities. New Haven: Yale University Press, 1984.

"Population and Health Dynamics In Nairobi's Informal Settlements ". In Report of the Nairobi Cross-sectional Slums Survey(NCSS), 212. Nairobi: African Population and Health Research Center (APHRC), 2014.

"Poverty." World Bank, http://www.worldbank.org/en/topic/poverty/overview.

Prussin, Labelle. Architecture in Northern Ghana; a Study of Forms and Functions. Berkeley: University of California Press, 1969.

Prussin, Labelle, and Aga Khan Program for Islamic Architecture. Hatumere : Islamic Design in West Africa. Berkeley: University of California Press, 1986.

Prussin, Labelle, and Adan Amina. African Nomadic Architecture : Space, Place, and Gender. Washington: Smithsonian Institution Press, 1995.

Richards, Larry. "Sight and Sound." Azure, 2006, 110-15.

Richardson, Vicky. New Vernacular Architecture. London: Laurence King Publishing, 2001.

Ricœur, Paul. History and Truth. Evanston Illinois, United States of America: Northwestern University Press, 1965. 
Rigby, Peter. Cattle, Capitalism, and Class : Ilparakuyo Maasai Transformations. Philadelphia: Temple University Press, 1992.

Robinson, Randall. "Randall Robinson Interview." By Amitabh Pal (2005).

Rockwood, David. Bamboo Gridshells. Abingdon, Oxon ; New York, NY: Routledge, 2015.

Rudofsky, Bernard. Architecture without Architects: A Short Introduction to Non-Pedigreed Architecture. USA: Museum of Modern Art: New York, 1964.

Rukwaro, Robert Wambugu, and Sylvester J. M. Maina. Transformation of Maasai Art and Architecture. Nairobi: ARTS Press, 2006.

Saitoti, Tepilit Ole. The Worlds of a Masai Warrior: An Autobiography. New York: Random House, 1986.

Serageldin, Ismail. "The Aga Khan Award for Architecture: Building for Tomorrow." In The Aga Khan Award for Architecture, edited by Azim Nanji. Great Britain: Academy Editions, 1994.

Sinha, Sumita. Architecture for Rapid Change and Scarce Resources. Abingdon, Oxon ; New York, NY: Earthscan from Routledge, 2012.

http://myaccess.library.utoronto.ca/login?url=http://books.scholarsportal.info/viewdoc.html?id=/ebooks /ebooks2/taylorandfrancis/2013-04-

15/1/9780203135181http://myaccess.library.utoronto.ca/login?url=http://www.tandfebooks.com/doi/b ook/10.4324/9780203135181.

Spear, Thomas T., and Richard Waller. Being Maasai : Ethnicity and Identity in East Africa. Eastern African Studies. London: J. Currey, 1993.

Spencer, Paul. The Maasai of Matapato a Study of Rituals of Rebellion. London ; New York: Routledge, 2004. http://myaccess.library.utoronto.ca/login?url=http://lib.myilibrary.com/Open.aspx?id=7546http://myacc ess.library.utoronto.ca/login?url=http://books.scholarsportal.info/viewdoc.html?id=/ebooks/ebooks0/tf/ 2009-12-

01/6/020358340Xhttp://myaccess.library.utoronto.ca/login?url=http://site.ebrary.com/lib/utoronto/Doc ?id=10098704.

-- - Time, Space, and the Unknown

Maasai Configurations of Power and Providence. London ; New York: Routledge, 2003.

http://myaccess.library.utoronto.ca/login?url=http://lib.myilibrary.com/Open.aspx?id=2479http://myacc ess.library.utoronto.ca/login?url=http://books.scholarsportal.info/viewdoc.html?id=/ebooks/ebooks0/tf/ 2009-12-

01/6/0203583523http://myaccess.library.utoronto.ca/login?url=http://books.scholarsportal.info/viewdo c.html?id=/ebooks/ebooks2/taylorandfrancis/2013-03-

13/1/9780203583524http://myaccess.library.utoronto.ca/login?url=http://www.tandfebooks.com/doi/b ook/10.4324/9780203583524http://myaccess.library.utoronto.ca/login?url=http://site.ebrary.com/lib/u toronto/Doc?id=10099859. 
Sposito, Cesare. "Identity, Flexibility and Sustainability for the New Social Housing." Techne : Journal of Technology for Architecture and Environment (2012): 153-59.

"Stairs and Louvres." Canadian Architect 54, no. 5 (2009): 54.

Syrjänen, Raakel, and UN-HABITAT KENSUP Team. "Un-Habitat and the Kenya Slum Upgrading Programme: Strategy Document." edited by Tom Osanjo, 72, 2008.

"The 2009 Kenya Population and Housing Census." In Population and Household Distribution by Socio-Economic Characteristics, 438. Nairobi: Kenya National Bureau of Statistics (KNBS), 2010.

"The Pritzker Architecture Prize." The Hyatt Foundation, http://www.pritzkerprize.com/2017/jury-citation.

Thiong'o, Ngũgĩ wa. Decolonising the Mind: The Politics of Language in African Literature. London, Portsmouth, N.H.: J. Currey; Heinemann, 1986. text.

Toronto, City of. "City Planning | Urban Design | Tall Buildings Design Guidelines." http://www1.toronto.ca/wps/portal/contentonly?vgnextoid=80a70621f3161410VgnVCM10 000071d60f89RCRD.

___. "Tall Buildings Design Guidelines." edited by Urban Design, 92. Toronto: City of Toronto, 2013.

Uduko, Ola. "Modernist Architecture and 'the Tropical' in West Africa: The T Ropical Architecture Movement in West Africa, 1948-1970." Habitat International 30 (2006): 396-411.

UN-Habitat. "State of African Cities 2014, Re-Imagining Sustainable Urban Transitions." Nairobi, Kenya, 2014.

United Nations Department of Economic and Social Affairs, Population Division. "World Population Prospects: The 2015 Revision, Key Findings and Advance Tables." United Nations, 2015.

_-_. "World Urbanization Prospects: The 2014 Revision." United Nations, 2015.

_-_. "World Urbanization Prospects: The 2014 Revision, Highlights." United Nations, 2014.

Van Beek, Gus W., and Ora Van Beek. Glorious Mud! : Ancient and Contemporary Earthen Design and Construction in North Africa, Western Europe, the near East, and Southwest Asia. Washington, D.C.

Lanham, Md.: Smithsonian Institution Scholarly Press ;

Published in cooperation with Rowman \& Littlefield Publishers, 2008.

-- - Glorious Mud! : Ancient and Contemporary Earthen Design and Construction in North Africa, Western Europe, the near East, and Southwest Asia. Washington, D.C.

Lanham, Md.: Smithsonian Institution Scholarly Press; Published in cooperation with Rowman \& Littlefield Publishers, 2008. 
Varanda, Francis. "2004 on Site Review Report." In Primary School: Gando: Burkina Faso: The Aga Khan Award for Architecture, 2004.

Vellinga, Marcel, Paul Oliver, and Alexander Bridge. "Atlas of Vernacular Architecture of the World." Abingdon, Oxon ; New York: Routledge,, 2007.

Villegas, Marcelo, and Eduardo Arango Restrepo. Tropical Bamboo. New York: Rizzoli, 1990.

Virani, Shafique. "Teflon Tents in the Desert: The Hajj Terminal as a Neo-Vemacular Response To Architecture's International Style." The UCLA Journal of Middle Eastern Studies 15 (1999): 1-13.

Vitruvius, Pollio, and Thomas Gordon Smith. Vitruvius on Architecture. New York: The Monacelli Press, 2003. 